\title{
The multidisciplinary team genodermatosis : a simple strategy to solve complex cases
}

Citation for published version (APA):

Vreeburg, M. (2014). The multidisciplinary team genodermatosis : a simple strategy to solve complex cases. [Doctoral Thesis, Maastricht University]. Universitaire Pers Maastricht. https://doi.org/10.26481/dis.20141205mv

Document status and date:

Published: 01/01/2014

DOI:

10.26481/dis.20141205mv

Document Version:

Publisher's PDF, also known as Version of record

\section{Please check the document version of this publication:}

- A submitted manuscript is the version of the article upon submission and before peer-review. There can be important differences between the submitted version and the official published version of record.

People interested in the research are advised to contact the author for the final version of the publication, or visit the DOI to the publisher's website.

- The final author version and the galley proof are versions of the publication after peer review.

- The final published version features the final layout of the paper including the volume, issue and page numbers.

Link to publication

\footnotetext{
General rights rights.

- You may freely distribute the URL identifying the publication in the public portal. please follow below link for the End User Agreement:

www.umlib.nl/taverne-license

Take down policy

If you believe that this document breaches copyright please contact us at:

repository@maastrichtuniversity.nl

providing details and we will investigate your claim.
}

Copyright and moral rights for the publications made accessible in the public portal are retained by the authors and/or other copyright owners and it is a condition of accessing publications that users recognise and abide by the legal requirements associated with these

- Users may download and print one copy of any publication from the public portal for the purpose of private study or research.

- You may not further distribute the material or use it for any profit-making activity or commercial gain

If the publication is distributed under the terms of Article $25 \mathrm{fa}$ of the Dutch Copyright Act, indicated by the "Taverne" license above, 


\section{THE MULTIDISCIPLINARY TEAM GENODERMATOSIS: A SIMPLE STATEGY TO SOLVE COMPLEX CASES}

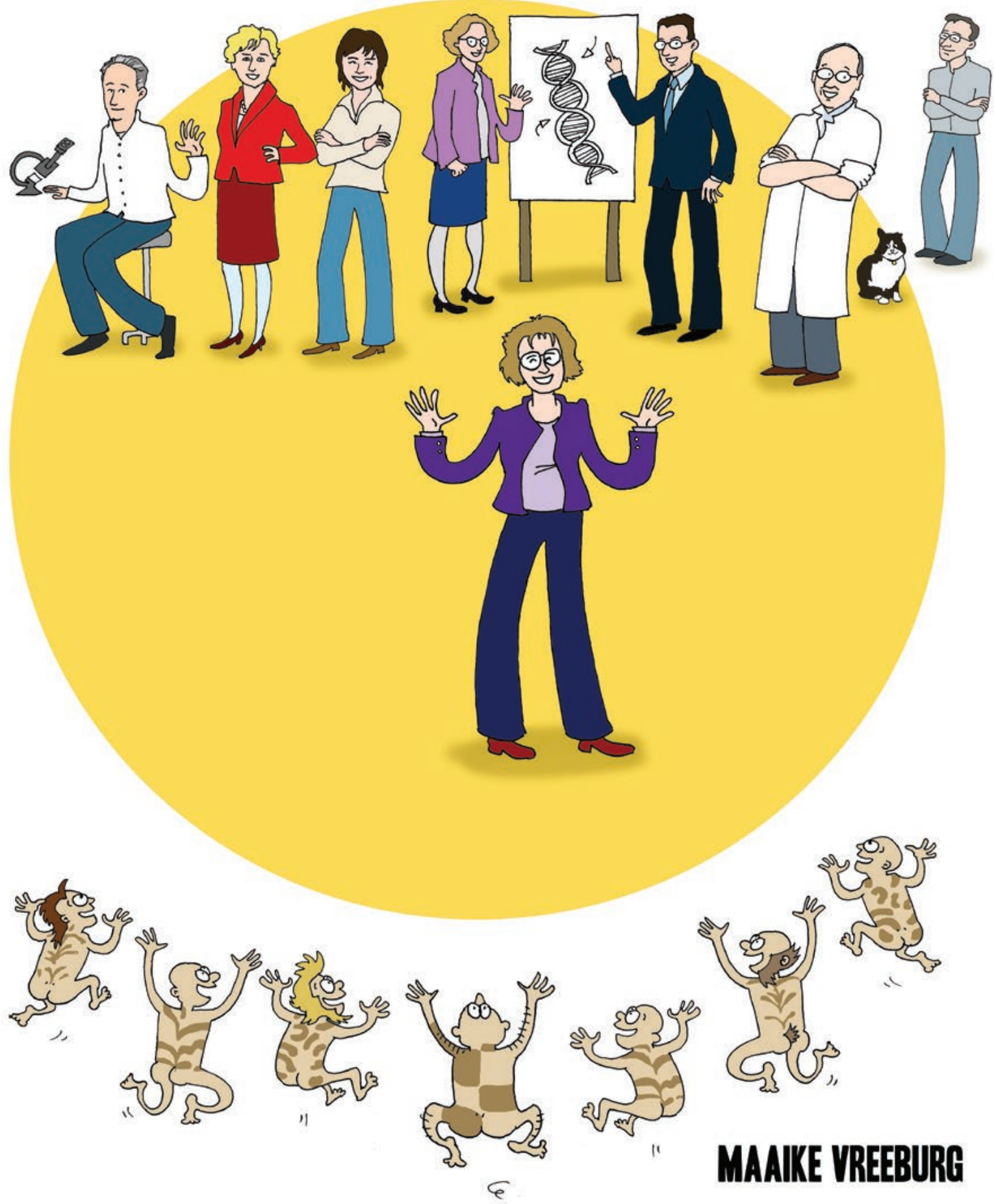


(C) Maaike Vreeburg, 2014

Production: Datawyse | Universitaire Pers Maastricht

ISBN 9789461593832 


\title{
The multidisciplinary team Genodermatosis a simple strategy to solve complex cases
}

\author{
PROEFSCHRIFT
}

ter verkrijging van de graad van doctor aan de Universiteit Maastricht, op gezag van de Rector Magnificus, Prof. dr. L.L.G. Soete volgens het besluit van het College van Decanen, in het openbaar te verdedigen op vrijdag 5 december 2014 om 12.00 uur

door

\section{Maaike Vreeburg}

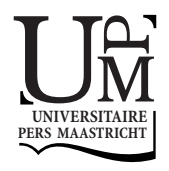




\section{Promotores}

Prof. dr. C.T.R.M. Stumpel

Prof. dr. M.A.M. van Steensel

\section{Copromotor}

Dr. D. Marcus-Soekarman (Hamad General Hospital, Doha, Qatar)

\section{Beoordelingscommissie}

Prof. dr. L.J.I. Zimmermann (voorzitter)

Prof. dr. R.C.M. Hennekam (AMC, Emma Kinderziekenhuis Amsterdam)

Prof. dr. M. Jonkman (UMC Groningen)

Prof. dr. V.V.M. Knoers (UMC Utrecht)

Prof. dr. R.P. Koopmans 


\section{Content}

$\begin{array}{lll}\text { Chapter } 1 \text { General introduction } & 7\end{array}$

Chapter 2 Dermato-oncogenetics 19

Introduction dermato-oncogenetics

Squamous cell carcinoma can be a manifestation of Muir- $\quad 25$

Torre syndrome

Skin abnormalities in individuals with macrocephaly: Cowden 31

disease from a dermatologist's point of view

$\begin{array}{lll}\text { Chapter } 3 \text { X-linked disorders } & 35\end{array}$

Cutaneous clues for diagnosing X-chromosomal disorders $\quad 37$

Focal dermal hypoplasia in a male patient due to mosaicism $\quad 45$

for a novel PORCN single nucleotide deletion

Contiguous gene syndrome due to a maternally inherited 8.41

$\mathrm{Mb}$ distal deletion of chromosome band Xp22.3 in a boy with short stature, ichthyosis, epilepsy, mental retardation, cerebral cortical heterotopias and Dandy-Walker malformation

Novel EBP gene mutations in Conradi-Hünermann-Happle syndrome

\section{Chapter 4 Mosaicism}

Genodermatoses caused by genetic mosaicism

Macrodystrophia lipomatosa

Chapter 5 Miscellaneous conditions

Skin changes in oculo-dento-digital dysplasia are correlated

with C-terminal truncations of connexin 43

Lymphedema-distichiasis syndrome: a distinct type of

primary lymphedema caused by mutations in the FOXC2-gene

Myhre syndrome in a female with not previously described 
$\begin{array}{lll}\text { Chapter } 6 \text { General discussion } & 105\end{array}$

$\begin{array}{lll}\text { Chapter } 7 & \text { Conclusions and future plans } & 121\end{array}$

$\begin{array}{llr}\text { Chapter } 8 & \text { Valorisation } & 127\end{array}$

$\begin{array}{ll}\text { Samenvatting } & 137\end{array}$

$\begin{array}{ll}\text { Summary } & 139\end{array}$

$\begin{array}{ll}\text { Dankwoord } & 141\end{array}$

$\begin{array}{ll}\text { Curriculum vitae } & 145\end{array}$

$\begin{array}{ll}\text { List of publications } & 147\end{array}$ 
CHAPTER 1

General introduction 
Monogenetic disorders are rare conditions compared to other diseases such as diabetes or cancer, which are more common conditions with a multifactorial background. The frequency of monogenetic genodermatoses, which are genetic conditions with major skin involvement, ranges from 1 in 3000 for neurofibromatosis type I (OMIM \#162200), which is one of the more common autosomal dominant disorders, to 1 in 100.000 or even less. Recognizing the correct diagnosis is important as it allows us to offer personalized medicine in individual cases and improve health care for a particular patient. Provision of health care from physicians with a lack of experience of relatively rare conditions results in difficulties with the diagnosis of said conditions.

Coordinated actions of professionals from different backgrounds working in a multidisciplinary setting are supposed to offer a complimentary range of skills, resulting in more efficient healthcare, which benefits both patients and care providers(14).

A multidisciplinary approach in healthcare is now recognised as important by healthcare professionals, patient organisations and health care economics. The general assumption is that a multidisciplinary approach could improve patient care and possibly have a positive cost-benefit ratio. In medical literature, a distinction is made between different types of teams in which various disciplines work together(5):

- Multidisciplinary teams: different professions work together on individually set goals and meet to discuss their progress.

- Interdisciplinary teams: goals are first agreed upon by the team, whose members then coordinate their input to the common treatment plan.

- Transdisciplinary teams: not only goals but also skills are shared by the teammembers.

Data in the medical literature on multidisciplinary diagnostic teams with a clinical geneticist as member are scarce. Reported efforts mainly involve outpatient clinics with a paediatrician and a clinical geneticist as participants. Teams may be disease, diagnostic or treatment specific. Most reports involve teams combining expertise about one (or a group of) disorder(s) or syndromes such as cleft lip/palate, Down syndrome(6) or epidermolysis bullosa(7). Reports providing data on a group of patients with mental retardation showed a diagnostic yield of $50 \%(8,9)$. The authors concluded that one-third of the diagnoses were based on medical history and clinical examination alone. In a further one-third of the cases, clinical observations provided essential clues for technical investigations such as molecular genetics, imaging and/or neurophysiological testing which then established the diagnosis. In the final one-third of the diagnosed patients, diagnosis was solely based on laboratory techniques and/or imaging. Similar studies of diagnostic yield in patients with intellectual disability reported a comparable $30-50 \%$ of identifiable causes $(10,11)$. 
From the laboratory side, the yield of diagnoses will increase due to more recently developed techniques, such as micro-arrays and whole exome or whole genome sequencing (next generation sequencing, NGS), as has happened in the past two decades in particular. Introducing whole exome sequencing lead to an additional diagnostic yield of approximately $10-25 \%$ in patients with intellectual disability in whom extensive investigations had not revealed a diagnosis so far(12). These techniques provide the clinician with a wealth of molecular data, often establishing a genotype before phenotyping has been performed. Modern molecular techniques enable scientists to study even the more common, multifactorial diseases for their genetic components. The problems that are encountered interpreting data from such Genomic Wide Association Studies (GWAS) studies, which often involve several thousands of cases and controls, show that careful phenotyping still remains one of the pillars of medical care and research(13). Stratifying such large study populations into sub-groups defined by a set of clinical parameters might improve the yield of significant associations with certain genetic variants(13) (14). If careful phenotyping is important in improving the interpretation of molecular GWAS data, the same than may be true regarding phenotyping in diagnostic whole exome sequencing.

\section{Aims of the project}

In an effort to increase the number of diagnoses identified in persons with a genodermatological disorder, we initiated a multidisciplinary team with a dermatologist and a clinical geneticist as partners, hypothesizing that synergy might contribute to achieving this goal.

Because stratifying large study populations into clinical subgroups improved the yield of significant associations in molecular studies like $\operatorname{GWAS}(13,14)$, we subdivided the patients attending the interdisciplinary team into subgroups. These subgroups were formed according to clinical parameters clustering the many single, rare disorders. Individuals belonging to the same subgroup share similar clinical characteristics that might require a specific diagnostic approach, treatment and follow up. These similar characteristics could for example be patterns in the family pedigree (inheritance patterns) or the categorization of skin abnormalities or patterns on the skin (according to Blaschko's lines?).

Aims of working together in this interdisciplinary setting were analogous to the "trias academica" of patient care, education and research:

1. To improve patient care by

a) Increasing the number of diagnoses.

b) Providing additional information in treatment, preventive management and genetic counselling for individual patients and their families. 
c) Identifying clinical clues to enable colleagues to recognize patterns and find diagnoses in their own patient population.

2. To improve education

The combined consultation provides opportunities for education of students, residents and colleagues regarding phenotyping and dysmorphology, as well as background and rationale for performing DNA-analysis.

3. To improve knowledge on genodermatoses by research

a) Sharing our experience-based findings in peer-reviewed journals.

b) Reporting new features of known genodermatoses facilitating the diagnostic process.

c) Identifying research questions for further research projects.

The clinical interdisciplinary team was closely linked to the laboratory of experimental dermatology, MUMC, the Netherlands. Because routine molecular diagnosis was not operational for all disorders (yet) in the Netherlands, samples were analysed in a research setting in this laboratory. We expected to confirm additional diagnoses in our research laboratory by offering DNA-analysis that was not part of routine diagnostics in the Netherlands.

\section{Outline of this thesis}

Although a wide variety of disorders was observed, four diagnostic subgroups, each with its own characteristics, emerged in due course: dermato-oncogenetic conditions (Chapter 2), disorders involving the X-chromosome (Chapter 3), mosaicism (Chapter 4) and miscellaneous conditions (Chapter 5)(all reviewed in Chapter 1, Table 1.1). These sub-groups are at the basis of this thesis.

In each chapter we provide information on our experience-based efforts in pattern recognition and determining clinical clues as diagnostic aids. We also describe several new phenotypic features in known genodermatoses.

Whether our aims at the start of this project were eventually reached will be discussed in chapter 6 (general discussion). The data and outcome will be evaluated and incorporated into future plans (Chapter 7).

\section{The outpatient clinic "Genodermatoses" of the Maastricht University Medical Centre (MUMC+)}

In March 2004 we started a multidisciplinary consultation with a clinical geneticist and a dermatologist as joint counsellors, assisted by a genetic nurse. Due to the 
combination of dermatology and genetics, the clinic was given the name of outpatient clinic "Genodermatoses". The outpatient clinic "Genodermatoses" was set up as a model for improving (health)care for patients with diagnostic questions in the combined fields of dermatology and clinical genetics. Our intention was to be a consulting team for other colleagues in this field, especially in complex cases. After a (differential) diagnosis was made and information about the condition and treatment options was provided, the patient returned to the referring specialist/physician. The consultation was designed as a "one-stop shop" for referring specialists, the patients and their families, while their long-term therapy and follow up was conducted by the referring specialist.

\section{Work flow}

Twice a month an outpatient clinic "Genodermatoses" took place in the Maastricht University Medical Centre (MUMC+, Maastricht, the Netherlands). In September of 2008, we established an additional outpatient clinic "Genodermatoses" in the Maxima Medical Centre (MMC, Veldhoven, the Netherlands), and visited this location 4 to 6 times a year. At the first consultation, the medical history of the patient and the family pedigree were recorded. Clinical examination with specific attention for the skin and its appendages was performed. Karyotyping, DNA-analysis, metabolic investigation and/or a skin biopsy (if indicated) were performed afterwards. The decision, regarding which of these analyses would be performed depended on the differential diagnosis. In an earlier phase, cytogenetic techniques involved conventional karyotyping, FISH and/or MLPA. In more recent years (starting in 2007 in a research setting, from 2008 onwards in a diagnostic setting), array-based techniques were used. The dermatologist, if so indicated, prescribed medication or offered other pertinent treatments. Referral to the department of dermatology was arranged if more extensive dermatologic intervention was needed. Patients were counselled and informed on their condition and treatment options, if a diagnosis was made. A follow-up appointment was scheduled to discuss results of genetic laboratory investigations and treatment if necessary. If a hereditary condition was diagnosed, family members were offered genetic counselling in the department of clinical genetics. This process is described in figure 1.1. 


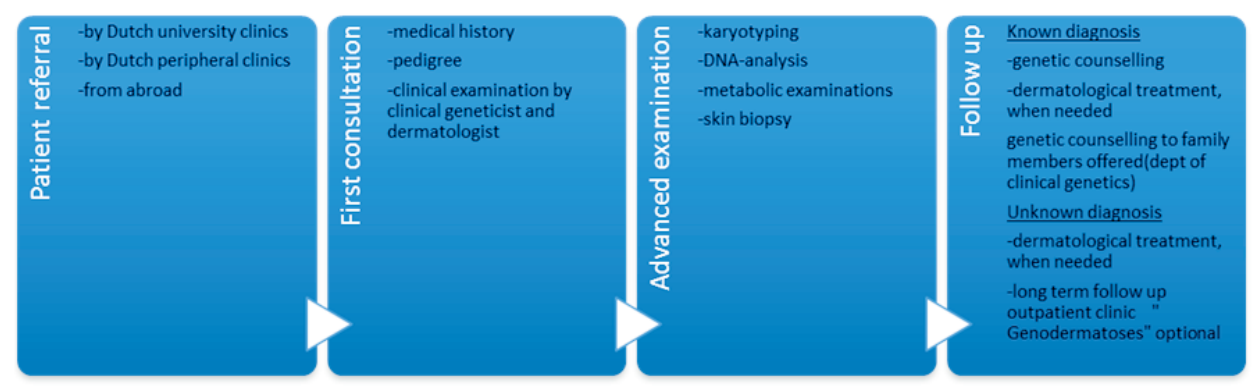

Figure 1.1. Flowchart outpatient clinic "Genodermatoses"

\section{The cohort}

Data described in this thesis are derived from an 8-year time period (March 2004March 2012). During this period 409 patients were seen (Figure 1.2). The first year (2004) consisted of 10 months (March to December) and for the last year covered in this thesis (2012) only January and February were registered.

\section{Number of patients per year}

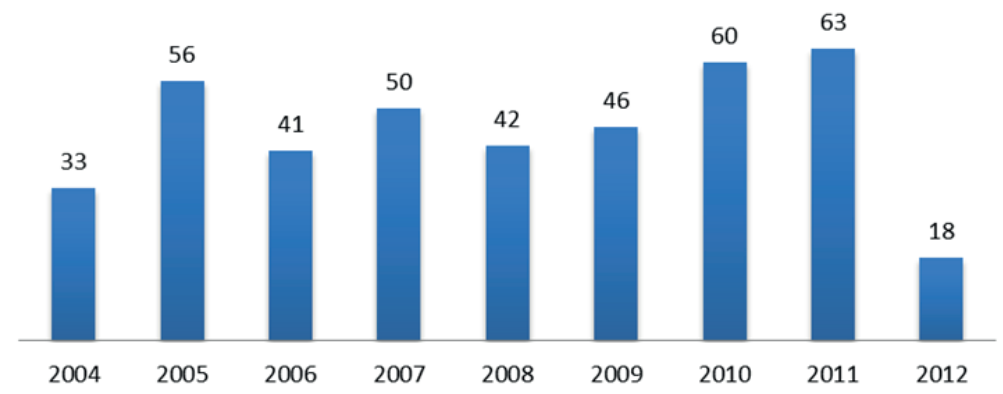

Figure 1.2. Number of patients per year.

$\mathrm{X}$-axis: years, Y-axis: number of patients per year, $\mathrm{n}=409$.

The cohort of 409 patients consisted of 163 males and 246 females. Three subjects were lost to follow-up, leaving 406 individuals with informative data. 196 of the 409 patients were under the age of 18 years when first visiting the outpatient clinic. In due course, four larger subgroups were emerging and these were used for assignment of cases in order to facilitate the diagnostic process (Table 1.1). 


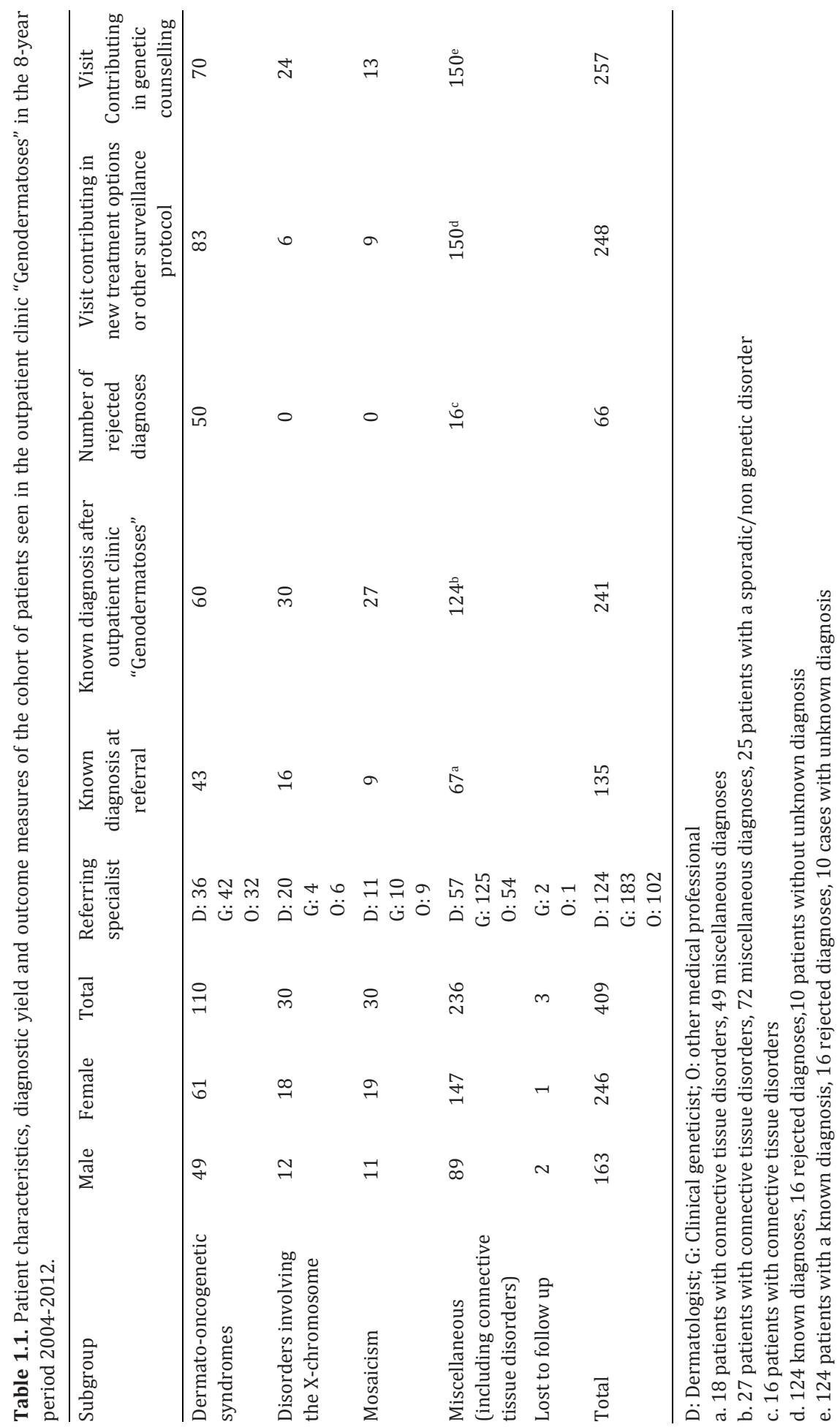




\section{Referrals}

Patients were referred from university and peripheral clinics within the Netherlands or from abroad, most of them by dermatologists, clinical geneticists or other medical specialists (Table 1.1). In fact, dermatologists were the main referring specialists in the X-linked subgroup, while geneticists formed the major group referring in the miscellaneous subgroup. Other medical specialists that referred to us were mainly pediatricians and child neurologists, but also GPs, ophthalmologists, neurologists and oncologists referred patients. Colleagues from the MUMC+ referred 283 patients, mostly from the departments of dermatology and clinical genetics. 126 patients were referred from outside the MUMC+. In the earlier years, the patients that were referred mainly had a diagnostic question. In later years, individuals with more common genodermatoses such as albinism, ichthyosis vulgaris or neurofibromatosis were also seen with questions regarding follow up and therapeutic options.

\section{Diagnoses}

There were several reasons for specialists to refer a patient to the outpatient clinic "Genodermatoses". Many patients were referred to determine whether we agreed with a suggested diagnosis $(n=135 / 409, \sim 33 \%)$. A known diagnosis was defined as a clinical diagnosis, according to the state of the art and/or published criteria. In case a diagnosis had not been established prior to the visit, the interdisciplinary team identified an underlying condition in $26 \%$ of the cases (106/409, Table 1.1). This yield increases to $38,7 \%$ when determining the number of diagnoses made in the group of unknowns (106/274).

The percentage of new diagnoses made by the interdisciplinary team differed between the diagnostic subgroups: from $60 \%$ in the mosaicism $(18 / 30)$ and $46,7 \%$ in the X-linked groups (14/30) to $24 \%$ in the miscellaneous group (57/236), (Chapter 1 , Table 1.1). A clearly lower percentage was observed in the dermato-oncogenetic group $(17 / 110$ or $15,4 \%)$.

\section{Diagnosis depending on subgroup}

Certain conditions were more common in the cohort than others. In the dermatooncogenetic group (chapter 2 of this thesis), 49 of 110 patients (44.5\%) visited the outpatient clinic with questions about the more common neurocutaneous disorders such as Neurofibromatosis and Tuberous Sclerosis Complex. The second important subgroup consisted of 21 patients (19\%) with questions about disorders with an increased risk for renal cell carcinoma, mainly Birt-Hogg-Dubé syndrome (BHD) and hereditary Leiomyomatosis Renal Cell Carcinoma (HLRCC). This high number is 
likely due to the fact that renal cell carcinoma and BHD in particular have become an important research topic in the laboratory of experimental dermatology of the MUMC.

\section{Disorders involving the $X$-chromosome and mosaicism}

30 patients with conditions involving the X-chromosome were seen; incontinentia pigmenti (IP, $\mathrm{n}=10$ ) was the most frequent diagnosis in this group. The characteristics of the patients with disorders involving the X-chromosome are described in detail in the review in chapter 3(15).

30 patients with a form of mosaicism were identified of which 11 had skin pigment mosaicism/linear and whorled hyperpigmentation; this being the most frequent diagnosis. Data on the specific diagnoses made in the mosaicism group can be found in table 4.1 in chapter 4 .

\section{Miscellaneous}

The miscellaneous group consisted of 236 patients with several diagnoses occurring more frequently in various subsets (Chapter 5 ).

a. a subgroup of 68 patients $(68 / 236=28,8 \%)$ were referred with questions about connective tissue disorders, mainly Ehlers Danlos syndrome (EDS) and Benign Joint Hypermobility Syndrome (BJHMS). Within this group a diagnosis was made in 27 cases (EDS hypermobility type $n=12$, BJHMS $n=4$, other connective tissue disorders $n=11$ ). In 16 patients the diagnosis of a connective tissue disorder was rejected, leaving 25 patients for which no definitive diagnosis could be made.

b. a non-genetic disorder was identified in 25 cases $(25 / 236=10,6 \%)$

c. 13 individuals with confirmed Prader-Willi syndrome (confirmed at the molecular level prior to the visit) were part of the cohort because they participated in a research project on skin abnormalities in this syndrome.

d. In 72 other patients $(72 / 236 \sim 30 \%)$ a diagnosis had been known or was identifiable. 42 of these diagnoses could be confirmed at the molecular level (Chapter 5 , table 5.1).

\section{Genetic counselling and treatment}

Patients with a known diagnosis (either made by the referring specialist or by the interdisciplinary team) received information on the condition itself, its inheritance and treatment options (Table 1.1). In 66 cases or $16 \%$ of the cohort a diagnosis could be rejected, and further investigation and/or surveillance protocols became redundant or were adapted (Chapter 1, Table 1.1, Chapter 2, Table 2.1, Chapter 5, page 7). 


\section{Outcome of a visit}

The outcome of a visit was recorded as contributing or positive to care if the visit resulted in a change of treatment or surveillance protocols. Outcome was also positive if referral to another specialist for more appropriate care took place (Table 1.1).

Other examples to score the outcome as positive were providing a different recurrence risk than previously advised, or presymptomatic testing becoming available for family members. Also, if new reproductive options became possible for the patient, this outcome was recorded as positive. 


\section{References}

1. Zadeh N, Getzug T, Grody WW. Diagnosis and management of familial Mediterranean fever: integrating medical genetics in a dedicated interdisciplinary clinic. Genetics in medicine : official journal of the American College of Medical Genetics. 2011 Mar;13(3):263-9. PubMed PMID: 21317656.

2. Tirosh E, Jaffe M. Global developmental delay and mental retardation--a pediatric perspective. Developmental disabilities research reviews. 2011 Nov;17(2):85-92. PubMed PMID: 23362028.

3. Pruthi S, Boughey JC, Brandt KR, Degnim AC, Dy GK, Goetz MP, et al. A multidisciplinary approach to the management of breast cancer, part 2: therapeutic considerations. Mayo Clinic proceedings. 2007 Sep;82(9):1131-40. PubMed PMID: 17803883.

4. Khandelwal KD, van Bokhoven H, Roscioli T, Carels CE, Zhou H. Genomic approaches for studying craniofacial disorders. American journal of medical genetics Part C, Seminars in medical genetics. 2013 Nov;163(4):218-31. PubMed PMID: 24142857.

5. Young CA. Building a care and research team. J Neurol Sci. 1998 Oct;160 Suppl 1:S137-40. PubMed PMID: 9851664. Epub 1998/12/16. eng.

6. Skotko BG, Davidson EJ, Weintraub GS. Contributions of a specialty clinic for children and adolescents with Down syndrome. American journal of medical genetics Part A. 2013 Mar;161A(3):430-7. PubMed PMID: 23401090.

7. Duipmans JC, Jonkman MF. Interdisciplinary management of epidermolysis bullosa in the public setting: the Netherlands as a model of care. Dermatologic clinics. 2010 Apr;28(2):383-6, xiii. PubMed PMID: 20447507.

8. van Karnebeek CD, Jansweijer MC, Leenders AG, Offringa M, Hennekam RC. Diagnostic investigations in individuals with mental retardation: a systematic literature review of their usefulness. European journal of human genetics : EJHG. 2005 Jan;13(1):6-25. PubMed PMID: 15523501.

9. van Karnebeek CD, Scheper FY, Abeling NG, Alders M, Barth PG, Hoovers JM, et al. Etiology of mental retardation in children referred to a tertiary care center: a prospective study. American journal of mental retardation : AJMR. 2005 Jul;110(4):253-67. PubMed PMID: 15941363.

10. Moog U. The outcome of diagnostic studies on the etiology of mental retardation: considerations on the classification of the causes. American journal of medical genetics Part A. 2005 Aug 30;137(2):228-31. PubMed PMID: 16086396.

11. Rauch A, Hoyer J, Guth S, Zweier C, Kraus C, Becker C, et al. Diagnostic yield of various genetic approaches in patients with unexplained developmental delay or mental retardation. American journal of medical genetics Part A. 2006 Oct 1;140(19):2063-74. PubMed PMID: 16917849.

12. Willemsen M, Kleefstra T. Making headway with genetic diagnostics of intellectual disabilities. Clinical genetics. 2013 Jul 29. PubMed PMID: 23895455.

13. Boycott KM, Vanstone MR, Bulman DE, MacKenzie AE. Rare-disease genetics in the era of nextgeneration sequencing: discovery to translation. Nature reviews Genetics. 2013 Oct;14(10):681-91. PubMed PMID: 23999272.

14. Lin DY, Zeng D, Tang ZZ. Quantitative trait analysis in sequencing studies under trait-dependent sampling. Proceedings of the National Academy of Sciences of the United States of America. 2013 Jul 23;110(30):12247-52. PubMed PMID: 23847208. Pubmed Central PMCID: 3725118.

15. Vreeburg M, Sallevelt SC, Stegmann AP, van Geel M, Detisch YJ, Schrander-Stumpel CT, et al. Cutaneous clues for diagnosing X-chromosomal disorders. Clinical genetics. 2014 Apr;85(4):328-35. PubMed PMID: 23578112. 

CHAPTER 2

\section{Dermato-oncogenetics}


CHAPTER 2 
Although cancer is mostly a multifactorial disease, rare monogenetic syndromes have been known to cause a considerable risk for developing cancer in certain families. Well-known, relatively frequent, examples of such monogenetic syndromes are hereditary breast/ovarian cancer and colorectal cancer (Lynch syndrome or polyposis syndromes). Of all breast/ovarian cancers and colorectal cancers, up to 5\%$10 \%$ of tumours is caused by one of these familial cancer syndromes $(1,2)$.

Many of the hereditary cancer predisposition syndromes are due to mutation of tumour suppressor genes, introduced by Knudson in his 2nd hit model(3). A person, carrying a familial mutation (first hit) in one allele in his or her germline is more vulnerable to a second hit in the other allele, which causes loss of heterozygozity (LOH) at the locus. Complete loss of function of a tumour suppressor gene is an important first step in the cascade towards cancer. Thus, a person carrying a germline mutation in a tumour suppressor gene experiences a higher incidence of specific malignancies, which also occur at a relatively young age. In fact, the concept of this theory was illustrated by 2 cases in our cohort(4). In these cases LOH of the Lynch syndrome-genes MSH2 and MLH1 was demonstrated in squamous cell carcinoma cells from patients with Muir-Torre syndrome.

Of the 409 patients seen in the out-patient clinic "Genodermatoses", 110 patients (27\%) had questions regarding dermato-oncogenetic disorders and syndromes (Table 2.1). For the classification of diagnostic subgroups guidelines as proposed by Tsao et al (2000)(5), were followed. Most cases in the dermato-oncogenetic group involved patients and/or their family with questions about conditions presenting with mostly benign cutaneous tumours and an increased risk for developing internal tumours (Table 2.1, $\mathrm{n}=85$ ). As expected, the largest subgroup was diagnosed with neurofibromatosis or tuberous sclerosis, both conditions well known to the clinical geneticist $(\mathrm{n}=49)(6)$. Conditions such as Birt-Hogg-Dubé syndrome (BHD) and Hereditary Leiomyomatosis Renal Cell Carcinoma (HLRCC, familial leiomyomatosis) form a second important subgroup $(\mathrm{n}=21)$ for which evidence based protocols for care have been developed analogous to those in hereditary breast/ovarian and colon cancer $(7,8)$. 
Table 2.1. Dermato-oncogenetic conditions seen in the outpatient clinic "Genodermatoses" .(subdivision after Tsao et al (2000))(5)

\begin{tabular}{|c|c|c|c|}
\hline & Total (female/male) & Confirmed diagnosis & Rejected diagnosis \\
\hline Primary skin malignancies & 20 (F14/M6) & 6 & 14 \\
\hline NBBCS(Gorlin syndrome) & 10 & 2 & 8 \\
\hline $\begin{array}{l}\text { Familial Atypical Moles Malign } \\
\text { Melanoma syndrome }\end{array}$ & 7 & 1 & 6 \\
\hline Xeroderma Pigmentosa & 3 & 3 & - \\
\hline $\begin{array}{l}\text { (Mostly) benign cutaneous } \\
\text { tumours with internal } \\
\text { malignancies }\end{array}$ & 85(F45/M40) & 51 & 34 \\
\hline Neurofibromatosis 1 & 30 & 16 & 14 \\
\hline Segmental NF1 & $6^{1}$ & 6 & - \\
\hline Tuberous Sclerosis & 13 & 5 & 8 \\
\hline $\begin{array}{l}\text { Hereditairy Leiomyomatosis Renal } \\
\text { Cell Carcinoma }\end{array}$ & 5 & 3 & 2 \\
\hline $\begin{array}{l}\text { Muir-Torre syndrome (Lynch } \\
\text { syndrome) }\end{array}$ & 9 & 5 & 4 \\
\hline Cowden syndrome ${ }^{2}$ & 6 & 3 & 3 \\
\hline Birt Hogg Dubé syndrome & 16 & 13 & 3 \\
\hline $\begin{array}{l}\text { Nonneoplastic cutaneous features } \\
\text { or rare cutaneous tumours with } \\
\text { internal malignancies }\end{array}$ & 5(F2/M3) & 3 & 2 \\
\hline Peutz Jeghers Syndrome & 3 & 2 & 1 \\
\hline Fanconi anemia syndrome & 1 & 1 & - \\
\hline Howel Evans syndrome & 1 & - & 1 \\
\hline Total & 110 (F61/M49) & 60 & 50 \\
\hline
\end{tabular}

${ }^{1}$ All clinical diagnoses, NF1 germline gene mutation excluded in 2 patients

${ }^{2}$ van der Velden JJ, Vreeburg M, Smeets EE, Schrander-Stumpel CT, van Steensel MA. Skin abnormalities in individuals with macrocephaly: Cowden disease from a dermatologist's point of view. Int J Dermatol. 2008 Nov;47 Suppl 1:45-8. 


\section{References}

1. Richtlijn Erfelijke darmkanker, (2008) Vereniging Klinische Genetica en Kwaliteitsinstituut voor de Gezondheidszorg CBO. Website: http://www.oncoline.nl.

2. Richtlijn Mammacarcinoom, (2008) Vereniging van Integrale Kankercentra (VIKC). Kwaliteitsinstituut voor de Gezondheidszorg CBO. Website: http://www.oncoline.nl .

3. Knudson AG, Jr. Mutation and cancer: statistical study of retinoblastoma. Proceedings of the National Academy of Sciences of the United States of America. 1971 Apr;68(4):820-3. PubMed PMID: 5279523. Pubmed Central PMCID: 389051.

4. Vreeburg M, Marcus-Soekarman D, van Milligen de Wit AWM, Go IH. Detisch YJHA, van Steensel, MAM. Squamous cell carcinoma can be a manifestation of Muir-Torre syndrome. Submitted for publication 2014.

5. Tsao H. Update on familial cancer syndromes and the skin. Journal of the American Academy of Dermatology. 2000 Jun;42(6):939-69; quiz 70-2. PubMed PMID: 10827397.

6. Kandt RS. Tuberous sclerosis complex and neurofibromatosis type 1: the two most common neurocutaneous diseases. Neurologic clinics. 2003 Nov;21(4):983-1004. PubMed PMID: 14743661.

7. van Spaendonck-Zwarts KY, Badeloe S, Oosting SF, Hovenga S, Semmelink HJ, van Moorselaar RJ, et al. Hereditary leiomyomatosis and renal cell cancer presenting as metastatic kidney cancer at 18 years of age: implications for surveillance. Familial cancer. 2012 Mar;11(1):123-9. PubMed PMID: 22086304. Pubmed Central PMCID: 3297757.

8. Menko FH, van Steensel MA, Giraud S, Friis-Hansen L, Richard S, Ungari S, et al. Birt-Hogg-Dube syndrome: diagnosis and management. The lancet oncology. 2009 Dec;10(12):1199-206. PubMed PMID: 19959076. 
CHAPTER 2 


\section{Squamous cell carcinoma can be a manifestation of Muir-Torre syndrome}

M. Vreeburg, D. Marcus-Soekarman, A.W.M. van Milligen de Wit, I.H. Go, Y.J.H.A Detisch, M.A.M. van Steensel

(submitted) 


\section{To the Editor:}

Muir-Torre syndrome (MTS) is an inherited disorder of DNA mismatch repair, caused by mutations in one of the Lynch syndrome genes (MLH1 gene, MSH2 gene, MSH6 gene or PMS2). Carriers of a mutation in such a mismatch repair gene have an increased lifetime risk of developing intestinal tumours, endometrial carcinoma and skin lesions such as sebaceous gland adenomas or carcinomas. Although kerato-acanthomas are regarded as one of the specific malignant skin lesions in MuirTorre syndrome, it is not clear yet if squamous cell carcinoma is part of the spectrum. We report two cases with supportive evidence that also squamous cell carcinoma is part of the Muir Torre syndrome.

Patient 1 is a 50-year-old healthy male of Dutch descent who visited our outpatientclinic. He asked for presymptomatic DNA-testing, since an MSH2-gene mutation had been identified in his family as the cause of Lynch syndrome. Several family members had had colorectal or endometrial malignancies. The proband already participated in a screening-programme as advised for family members ${ }^{1}$. A colonoscopy had shown several benign polyps at the age of 33 years but had otherwise been normal. At the age of 50 years, he developed a squamous cell carcinoma on his back (figure 1). He reported that he had sunbathed regularly at a younger age.

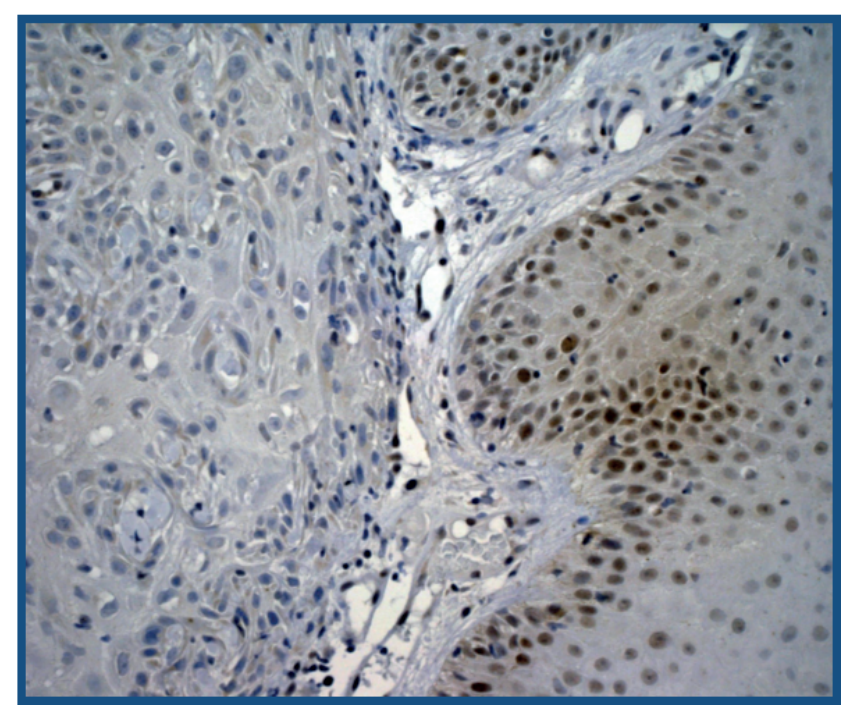

Figure 1. Patient 1: Well differentiated squamous cell carcinoma on the left, no components of sebaceous carcinoma (overview).

Clinical examination of his skin showed areas with sebaceous gland hyperplasia on his forehead and nose. DNA-analysis of peripheral blood leucocytes showed a 
germline mutation (c.IVS1-2A>G) in exon 2 of the $M S H 2$-gene, which was also present in previously analysed, affected family members.

Patient 2 is a 35 -year-old female of Dutch descent. She asked for presymptomatic DNA-testing for the MLH1-gene mutation (c.806C $>$ G) that had caused Lynch syndrome in several family members. A year previously, she had developed squamous cell carcinomas of the scalp and glabella. Both lesions had been radically excised. Surveillance of the colon and uterus had shown no abnormalities. Examination of the skin at the time of consultation revealed no other abnormalities. There was no history of significant sun exposure. DNA-analysis confirmed presence of the familial MLH1 gene mutation.

As Mathiak et $\mathrm{al}^{2}$ have previously shown that immunohistochemistry (IHC) is a reliable method to screen skin tumours for loss of mismatch-repair (MMR)-gene expression, we applied IHC to stored snap-frozen tissue of our patients' squamous cell carcinomas. We used antibodies against MSH2, MLH1, MSH6 and PMS2. We observed that MSH2-expression was absent from the tumour cells of patient 1, while MLH1 was normally expressed (Figure 2). In unaffected skin, MSH2 showed normal expression. In patient 2, MLH1 and PMS2-expression were lost in the tumour, with normal expression of both in the surrounding tissue. A similar case was reported by Nishizawa et $\mathrm{al}^{3}$, who describe a patient with classic MTS in combination with squamous cell carcinoma-like lesions, in which MSH2 expression had been lost.

Squamous cell carcinoma of the skin (cutaneous Squamous Cell Carcinoma, cSCC) is clearly associated with sun exposure, with an incidence reported in 2004 as high as $1 \%$ in Australian males 4 . In the moderate climate of the Netherlands the incidence is much lower, around 25/100.000 (http://www.ikcnet.nl). Mismatch repair proteins such as Msh2 and Mlh1 protect cells from UVB-induced DNA damage ${ }^{5}$. Theoretically, carriers of DNA mismatch repair gene mutations would more readily develop malignancies in sun-exposed skin compared to non-carriers. Liang et $\mathrm{al}^{6}$ support this notion, by demonstrating that $M S H 2$-expression decreased in a dosedependent way in normal skin cells exposed to increasing amounts of sunlight. Interestingly, in cells transforming from precancerous to cancerous lesions, the same decrease was observed. Apparently, sunlight suppresses MSH2's normal protective capacities. Studies in mice lacking Msh2 protein showed that they develop UVB-induced skin tumours at an earlier age and at lower cumulative UVB exposure than isogenic controls7. These data might indicate that CSCC could be part of the MTS phenotype. Surprisingly, very few cases of cSCC associated with MTS have been reported to date ${ }^{3}$. 


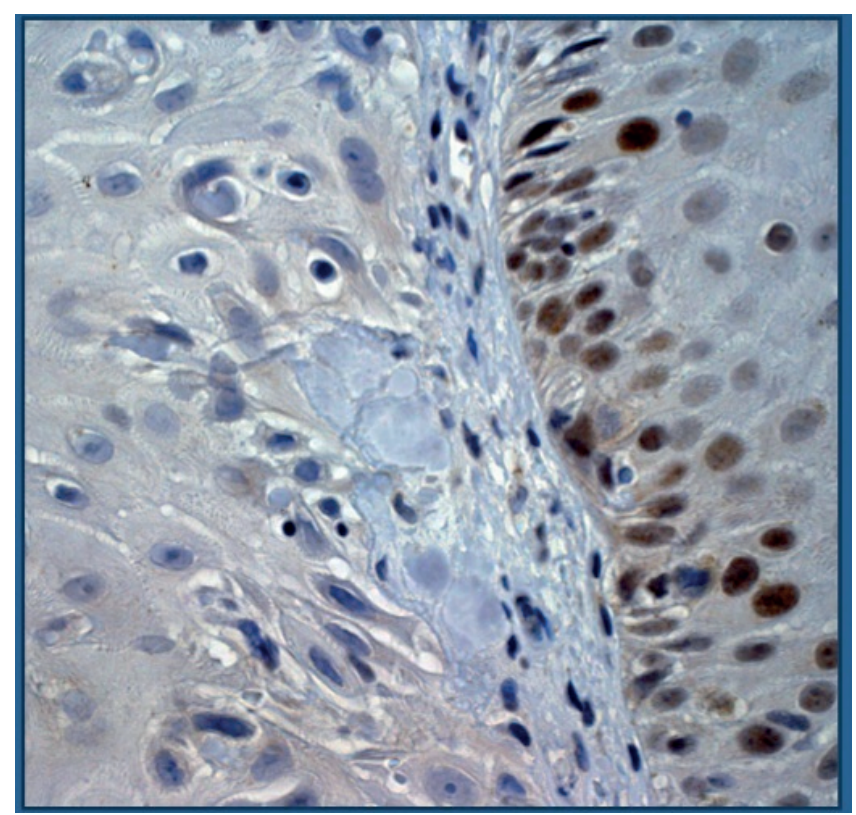

Figure 2 Patient 1. Immunohistochemical staining with an MSH-2 antibody, demonstrating positively stained nuclei of the normal epidermis on the right side and unstained nuclei of the squamous cell carcinoma on the left side, indicating LOH of MSH2 (magnification 400x).

We now describe two patients with MTS and cSCC, In our cases, we found loss of MSH2/MLH1 in the tumour cells, while the adjacent healthy skin still expressing MSH2/MLH1 at normal levels. Therefore, we presume that loss of heterozygosity $(\mathrm{LOH})$ of MSH2 respectively MLH1 has precipitated tumour development in the sun-exposed skin of our cases in concordance with Knudson's theory8.

Based on our observations, we suggest that screening for cSCC should be added to the surveillance for Lynch syndrome. Individuals in a family with Lynch syndrome, who develop squamous cell carcinoma before the age of 50 on parts of the body that have not been excessively exposed to sunlight, might be carriers. In our clinic, we offer newly identified mutation carriers a dermatologic work-up and, depending on the aspect of the skin, yearly follow-up in our interdisciplinary dermatology/clinical genetics team, in addition to the regular colonoscopy and, in females, gynaecological examinations. We also recommend that any carrier of a mutation in a DNA mismatch repair-gene should avoid excessive sun exposure in general.

\section{Acknowledgements}

MvS is supported by GROW School for Oncology and Developmental Biology and the Dutch Cancer Society (KWF), grant UM2009-4352. 


\section{References}

1. Aarnio M, Sankila R, Pukkala E, et al. Cancer risk in mutation carriers of DNA-mismatch-repair genes. Int J Cancer 1999;81:214-8.

2. Mathiak M, Rutten A, Mangold E, et al. Loss of DNA mismatch repair proteins in skin tumors from patients with Muir-Torre syndrome and MSH2 or MLH1 germline mutations: establishment of immunohistochemical analysis as a screening test. Am J Surg Pathol 2002;26:338-43.

3. Nishizawa A, Nakanishi Y, Sasajima Y, Yamazaki N, Yamamoto A. Muir-torre syndrome with intriguing squamous lesions: a case report and review of the literature. Am J Dermatopathol 2006;28:569.

4. Wood GS BM, Gharia M, Gordon E, Larson PO, Snow SN. Nonmelanoma skin cancers: basal cell and squamous cell carcinomas. In: Abeloff MD AJ, Niederhuber JE, Kastan MB, McKenna WG, ed. Clinical Oncology. third ed: Elsevier; 2004:1594-8.

5. Peters AC, Young LC, Maeda T, Tron VA, Andrew SE. Mammalian DNA mismatch repair protects cells from UVB-induced DNA damage by facilitating apoptosis and p53 activation. DNA Repair (Amst) 2003;2:427-35.

6. Liang SB, Furihata M, Takeuchi T, Sonobe H, Ohtsuki Y. Reduced human mismatch repair protein expression in the development of precancerous skin lesions to squamous cell carcinoma. Virchows Arch 2001;439:622-7.

7. Young LC, Thulien KJ, Campbell MR, Tron VA, Andrew SE. DNA mismatch repair proteins promote apoptosis and suppress tumorigenesis in response to UVB irradiation: an in vivo study. Carcinogenesis 2004;25:1821-7.

8. Knudson AG, Jr. Mutation and cancer: statistical study of retinoblastoma. Proc Natl Acad Sci U S A 1971;68:820-3. 
CHAPTER 2 


\title{
Case report
}

\section{Skin abnormalities in individuals with macrocephaly: Cowden disease from a dermatologist's point of view}

\author{
Jaap J. A. J. van der Velden, MD, Maaike Vreeburg, MD, Eric E. J. Smeets, MD, PhD, \\ Constance T. R. M. Schrander-Stumpel, MD, PhD, and Maurice A. M. van Steensel, MD, PhD
}

\author{
From the Departments of Dermatology and \\ Clinical Genetics, Maastricht University \\ Medical Center, the Netherlands \\ Correspondence \\ Jaap J. A. J. van der Velden, MD \\ Department of Dermatology \\ Maastricht University Medical Center \\ P. Debyelaan 25; PO Box 5800 \\ 6202 AZ Maastricht \\ the Netherlands \\ E-mail: jvdrv@sder.azm.nl
}

\begin{abstract}
Cowden disease is a rare autosomal dominant disorder characterized by multiple hamartomas and (malignant) tumors affecting major organs including the breast, thyroid, endometrium, brain, skin and mucosa. Diagnostic criteria as formulated by the International Cowden Consortium serve as a guideline to clinically identify patients in which Cowden disease is suspected.

However, the spectrum of abnormalities associated with PTEN mutations is very broad, such that the term PTEN hamartoma tumor syndrome (PTHS) is often used. The diagnostic criteria for Cowden disease do not always serve to reliably identify patients who fall within the PTHS spectrum. Therefore, it is important that clinicians are aware of features that should raise the suspicion of such a syndrome.

To illustrate this point, we present three patients with clinical features of the PTEN hamartoma tumor syndrome spectrum. These patients have macrocephaly in common. Two of them meet the criteria for Cowden disease; one patient refused mutation analysis, while mutation analysis in the other patient revealed no PTEN mutation. The third patient does not meet the criteria for Cowden disease; however, genetic analysis showed a pathogenic mutation in the PTEN gene. Dermatologists regularly encounter the (muco-)cutaneous abnormalities that can be seen in PTEN hamartoma tumor syndrome. These findings combined with a (family) history of internal malignancy or a macrocephaly should raise the suspicion of PTHS, even in the absence of classical Cowden criteria.
\end{abstract}

\begin{abstract}
Introduction
Cowden disease (CD) (OMIM I 58350) is a rare autosomal dominant disorder characterized by multiple hamartomas and (malignant) tumors affecting major organs, including the breast, thyroid, endometrium, brain, skin, and mucosa. ${ }^{\mathrm{I}} \mathrm{CD}$ has been estimated to affect about one in 200,000 individuals. ${ }^{2,3}$ It is associated with germline mutations in the phosphatase and tensin (PTEN) gene, which are found in about $85 \%$ of all affected probands. ${ }^{4,5}$ Operational diagnostic criteria for Cowden syndrome were initially established in 1995 and were updated in $2000^{6}$ (Table I). We are now learning that the usefulness of the diagnostic criteria, as formulated by the Cowden Consortium, is limited, as CD is part of a spectrum of diseases with strongly variable phenotypes.

CD is part of the PTEN hamartoma tumor syndrome spectrum, which includes Bannayan-Riley-Ruvalcaba syndrome (OMIM I 53480) (characterized by lipomatosis, macrocephaly, vascular malformations, and pigmented macules of the glans penis), Proteus-like syndromes (with significant features of Proteus syndrome, but not meeting the diagnostic criteria), and macrocephaly/autism syndrome (OMIM 605309)..$^{\text {7-12 }}$
\end{abstract}

Thus, PTEN mutations should perhaps be sought for more often in patients fulfilling a subset of the criteria; however, there are patients who have pathognomonic symptoms without any mutation. This observation is suggestive of genetic heterogeneity.

We present three patients with dermatologic features consistent with CD or the PTEN hamartoma tumor syndrome, with and without PTEN mutations, all with obvious macrocephaly.

\section{Case Report}

Case 1

A 45 -year-old man presented to our outpatient clinic with soft, painless, subcutaneous nodules on the trunk and limbs, which had progressively developed during the past year. His medical history revealed palatoschisis at birth and a hypertrophic cardiomyopathy. His brother, a maternal uncle, and his daughter had similar cutaneous lesions. Hypertrophic cardiomyopathy had been diagnosed in his mother and one of her brothers. There was no evidence of thyroid, neurologic, genito-urinary, or intestinal disease in the patient or his family.

On examination, there were multiple lipomas on the trunk and limbs. With an occipitofrontal circumference of $64 \mathrm{~cm}$, the patient was macrocephalic. Examination of the 
face revealed multiple, solid, skin-colored, flat papules, diagnosed as trichilemmomas after histopathologic examination. Apart from a mild lingua plicata, no other mucosal abnormalities were seen. Acral keratoses were not observed. There was a mild gynecomastia.

On the basis of the family history and clinical appearance with one pathognomonic (multiple trichilemmomas), one major (macrocephaly), and one minor (lipomas) criterion, a diagnosis of Cowden disease was made. Our patient refused analysis of the phosphatase and tensin (PTEN) gene. Screening was offered for thyroid and renal malignancy.

\section{Case 2}

A 55-year-old man presented to the neurologist for recurrent headaches and asymmetric perceptive hearing loss, which had developed 2 years earlier. There were no other evident neurologic symptoms. He was referred to our outpatient clinic after cerebral magnetic resonance imaging (MRI) of the brain showed a cerebellar gangliocytoma, or Lhermitte-Duclos disease (Fig. I), and thus a PTEN spectrum disorder was suspected. Apart from hypertension, the medical history was unremarkable. Computed tomography (CT) assessment of the patient's thyroid revealed a multinodular goiter. There was no evidence of genito-urinary or intestinal malignancy in our patient. His father had a goiter, but the family history was otherwise unremarkable.

On clinical examination, there were multiple, solid, skincolored, flat papules on the nose. As the papules were thought

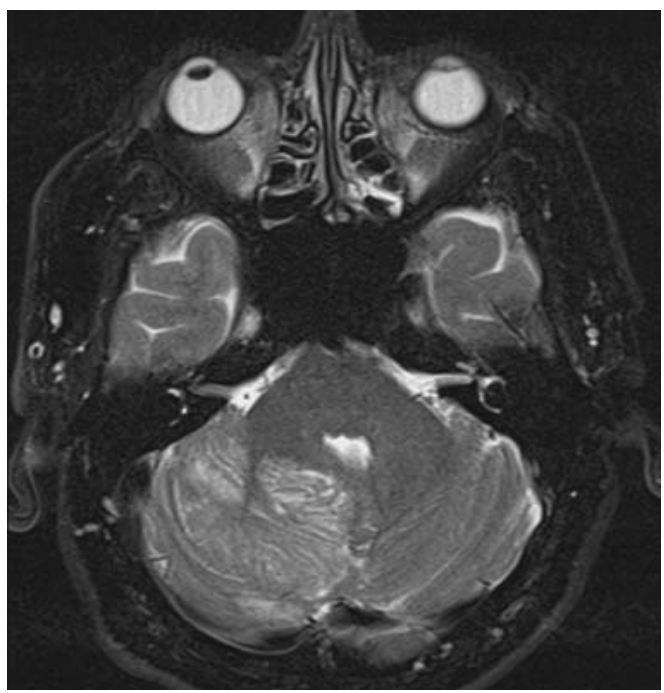

Figure 1 A T2-weighted axial magnetic resonance image shows a gangliocytoma in the right cerebellar hemisphere

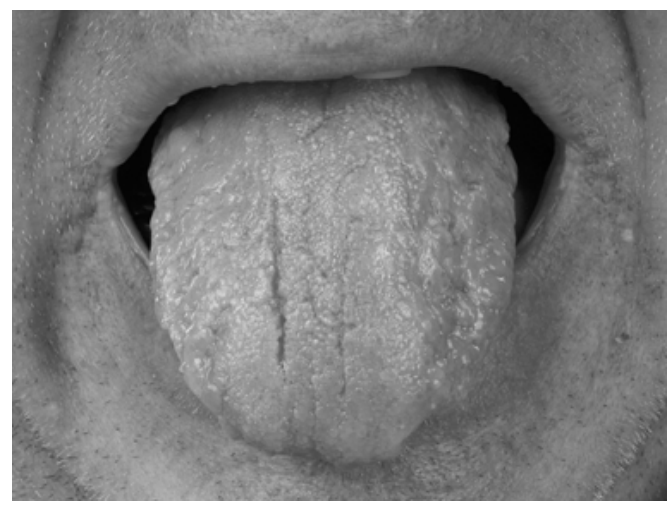

Figure 2 Papillomatosis and fissures of the tongue

to be trichilemmomas, skin biopsy was suggested, which the patient refused. Furthermore, an obvious papillomatosis of the tongue and buccal mucosa was observed (Fig. 2). The occipitofrontal circumference was $62 \mathrm{~cm}$. Acral keratoses were not seen.

Sequencing of the PTEN gene revealed no mutations. Nevertheless, the patient was diagnosed with Cowden disease on the basis of the presence of two pathognomonic criteria (cutaneous facial papules and oral mucosal papillomatosis), two major criteria (macrocephaly and Lhermitte-Duclos disease), and one minor criterion (goiter). The patient agreed to screening for renal cell cancer and thyroid malignancy, and future screening in his children, including screening for breast cancer in his daughters.

\section{Case 3}

A 35-year-old woman presented to our outpatient clinic with joint hypermobility since childhood. Her medical history revealed ovarian cysts, asthma, and obesity. There was no evidence of thyroid, neurologic, genito-urinary, or intestinal disease in the patient or her family. Her sister, mother, and two cousins suffered from joint hypermobility.

On clinical examination, there was macrocephaly with an occipitofrontal circumference of $63 \mathrm{~cm}$. There was mild brachydactyly of the fourth and fifth rays of both hands and feet. Joint hypermobility was assessed using the nine-point Beighton scale, ${ }^{13}$ with a score of less than five. The patient was obese. Skin hyperelasticity was not observed, as assessed by manual stretching of the volar forearm skin. Apart from ichthyosis vulgaris, there were no cutaneous or mucosal abnormalities.

Because of the macrocephaly and ovarian cysts, analysis of the PTEN gene was performed and revealed a heterozygous nonsense mutation in exon 6 of the PTEN gene, 
Table 1 International Cowden Consortium operational criteria for the diagnosis of Cowden syndrome (Version 2000)

\begin{tabular}{lll}
\hline Pathognomonic criteria & Major criteria & Minor criteria \\
\hline Facial trichilemmomas & Breast cancer & Other thyroid lesions \\
Acral keratoses & Thyroid cancer & Mental retardation \\
Papillomatous lesions & Macrocephaly & Hamartomatous intestinal polyps \\
Mucosal lesions & Lhermitte-Duclos disease & Fibrocystic disease of the breast \\
& Endometrial carcinoma & Lipomas \\
& & Fibromas \\
& & Genito-urinary tumors \\
\hline
\end{tabular}

An operational diagnosis of Cowden syndrome is made if an individual meets any one of the following criteria:

I. Pathognomonic mucocutaneous lesions alone, if there are: six or more facial papules, three or more of which must be trichilemmomas, or cutaneous facial papules and oral mucosal papillomatosis, or oral mucosal papillomatosis and acral keratoses, or six or more palmoplantar keratoses.

2. Two major criteria but one must be either macrocephaly or Lhermitte-Duclos disease.

3. One major and three minor criteria.

4. Four minor criteria.

In a family in which one individual meets the diagnostic criteria for Cowden syndrome, other relatives are considered to have a diagnosis of Cowden syndrome if they meet any of the following criteria:

I. A pathognomonic mucocutaneous lesion.

2. Any one major criterion with or without minor criteria.

3. Two minor criteria. designated c. 5 I 8 G >A, p.Arg ${ }_{173}$ His. Her father also had the mutation. As our patient did not meet the criteria for Cowden disease, Bannayan-Riley-Ruvalcaba syndrome, or Proteuslike syndrome, we made a diagnosis of PTEN hamartoma tumor syndrome with a separate joint hypermobility syndrome. Genetic analysis of the PTEN gene will be offered for eligible family members, in addition to screening for thyroid, renal, and breast malignancy.

\section{Discussion}

CD was named after the first patient described in 1963 by Lloyd and Dennis. ${ }^{14}$ Pertinent findings are multiple benign skin and mucosal tumors, breast and thyroid cancer, capillary malformations, verrucous hyperkeratotic skin lesions of the face and limbs, and macrocephaly. ${ }^{15}$ Penetrance is related to age. Progressive macrocephaly, geographic tongue, and mild to moderate mental retardation $(\mathrm{IQ}<75)$ are important signs of Cowden syndrome in young children. Trichilemmomas in the nasolabial folds and palmar and plantar hyperkeratoses usually become evident later in childhood. They are often accompanied by the appearance of subcutaneous lipomas and cutaneous capillary malformations. ${ }^{16}$ Mucocutaneous abnormalities are seen in $99 \%$ of affected individuals. The lifetime risk for the development of breast cancer in Cowden syndrome is estimated to be $25-50 \%$. The risk for thyroid cancer (typically follicular, but occasionally papillary) is approximately $10 \%$, whereas for endometrial carcinoma, although not well established, the risk has been estimated to be $5-10 \%$. $^{\mathrm{I}, 6,15,17,18}$

There are diagnostic criteria for Cowden syndrome, but the strong variability of the phenotypes associated with PTEN mutations causes them to be relatively unreliable. Nevertheless, the presence of mucocutaneous abnormalities and macrocephaly should (clinically) raise the suspicion of PTEN hamartoma tumor syndrome.

Our first patient seems to be a clear-cut case, with one pathognomonic, one major, and one minor criterion. On the basis of these apparent clinical findings, the diagnosis of CD can be made, although our patient refused genetic analysis. As hypertrophic cardiomyopathy has not been described in CD previously, and cardiomyopathy and mucocutaneous lesions do not cosegregate in our patient's family, we believe that it is coincidental.

The second patient is also thought to suffer from CD, as he has pathognomonic symptoms in addition to two major and one minor criterion. Genetic analysis of the PTEN gene, however, showed no mutations. Approximately $85 \%$ of individuals who meet the diagnostic criteria for $\mathrm{CD}^{4,5}$ have a detectable PTEN mutation. Direct sequencing of the promoter region detects mutations that alter the function of the gene in approximately 10\% of individuals with CD who do not have an identifiable mutation in the PTEN coding region. ${ }^{5}$ This may be the case in our patient. 
The detection of mutation c. 5 I $8 \mathrm{G}>\mathrm{A}, \mathrm{p} . \mathrm{Arg}_{\mathrm{I}} 73 \mathrm{His}$ in the PTEN gene in the third patient might seem serendipitous, as she did not meet the criteria for CD and her phenotype was limited to macrocephaly with ovarian cysts. We believe that this patient should be diagnosed with PTEN hamartoma tumor syndrome. The fact that she does not meet the abovementioned criteria serves to illustrate our point that macrocephaly in combination with one or more other symptoms that can be part of PTEN hamartoma tumor syndrome should be considered as an important clue and followed up appropriately. The sequence deviation detected in this patient reflects a novel PTEN germline mutation. Two lines of evidence suggest that $\mathrm{p}$. $\operatorname{Arg}_{173} \mathrm{His}$ is likely to be pathogenic. Firstly, a substitution in the same amino acid residue: p.ArgI 73 Cys has already been reported to cause $C D ;{ }^{19}$ secondly, this mutation has also been reported to occur somatically in different tumors. ${ }^{20}$

In all patients, further genetic analysis and clinical assessment of family members are warranted. With regard to the increased cancer risk, including breast, thyroid, endometrial, and renal cancer, any individual with a PTEN mutation should be entered into an appropriate surveillance program, as stated in the National Comprehensive Cancer Network (NCCN) guidelines. $^{2 \mathrm{I}}$

\section{Conflicts of interest}

The authors have declared no conflicts of interest.

\section{References}

I Starink TM, van der Veen JP, Arwert F, et al. The Cowden syndrome: a clinical and genetic study in $2 \mathrm{I}$ patients. Clin Genet I986; 29: 222-233.

2 Nelen MR, van Staveren CG, Peeters EAJ, et al. Germline mutations in the PTEN/MMACI gene in patients with Cowden disease. Hum Mol Genet 1997; 6: I383-1387.

3 Nelen MR, Kremer H, Konings IBM, et al.Novel PTEN mutations in patients with Cowden disease: absence of clear genotype-phenotype correlations. Eur J Hum Genet I 999; 7: 267-273.

4 Marsh DJ, Coulon V, Lunetta KL, et al. Mutation spectrum and genotype-phenotype analyses in Cowden disease and Bannayan-Zonana syndrome, two hamartoma syndromes with germline PTEN mutation. Hum Mol Genet I998; 7 : 507-5 I5.

5 Zhou XP, Waite KA, Pilarski R, et al. Germline PTEN promoter mutations and deletions in Cowden/Bannayan-Riley-Ruvalcaba syndrome result in aberrant PTEN protein and dysregulation of the phosphoinositol-3-kinase/Akt pathway. Am J Hum Genet 2003b; 73: 404-4II.
6 Eng C. Will the real Cowden syndrome please stand up: revised diagnostic criteria. J Med Genet 2000; 37: 828-830.

7 Marsh DJ, Kum JB, Lunetta KL, et al. PTEN mutation spectrum and genotype-phenotype correlations in Bannayan-Riley-Ruvalcaba syndrome suggest a single entity with Cowden syndrome. Hum Molec Genet I999; 8: I46I-I 472 .

8 Butler MG, Dasouki MJ, Zhou XP, et al. Subset of individuals with autism spectrum disorders and extreme macrocephaly associated with germline PTEN tumour suppressor gene mutations. J Med Genet 2005; 42: 3I 8-32I.

9 Goffin A, Hoefsloot LH, Bosgoed E, et al. PTEN mutation in a family with Cowden syndrome and autism. Am J Med Genet 200I; 105: 52I-524.

Io Biesecker LG, Happle R, Mulliken JB, et al. Proteus syndrome: diagnostic criteria, differential diagnosis and patient evaluation. Am J Med Genet I 999; 84: 389-395

I I Schepis C, Greco D, Siragusa M, et al. Cerebriform plantar hyperplasia: the major cutaneous feature of Proteus syndrome. Int J Dermatol 2008; 47: 374-376.

I 2 Farajzadeh S, Zahedi MJ, Moghaddam SD. A new gastrointestinal finding in Proteus syndrome: report of a case of multiple colonic hemangiomas. Int J Dermatol 2006; 45 : I $35-\mathrm{I} 38$.

I3 Beighton P, de Paepe A, Danks D, et al. International Nosology of Heritable Disorders of Connective Tissue, Berlin, I986. Am J Med Genet I988; 29: 58 I-594.

I4 Lloyd KM, Dennis M. Cowden's disease: A possible new symptom complex with multiple system involvement. Ann Intern Med I963; 58: I36-I 42.

I 5 Brownstein MH, Mehregan AH, Bikowski JB. Trichilemmomas in Cowden's disease. (Letter) JAMA I977; 238: 26.

I6 Hanssen AMN, Fryns JP. Cowden syndrome. J Med Genet I995; 32: II7-II9.

I7 Liaw D, Marsh DJ, Li J, et al. Germline mutations of the PTEN gene in Cowden disease, an inherited breast and thyroid cancer syndrome. Nat Genet I997; 16: 64-67.

I 8 Schrager CA, Schneider D, Gruener AC, et al. Clinical and pathological features of breast disease in Cowden's syndrome: an underrecognized syndrome with an increased risk of breast cancer. Hum Pathol I998; 29: 47-53.

I9 Tan WH, Baris HN, Burrows PE, et al. The spectrum of vascular anomalies in patients with PTEN mutations: implications for diagnosis and management. J Med Genet 2007; 44: 594-602.

20 Bilbao C, Rodriguez G, Ramirez R, et al. The relationship between microsatellite instability and PTEN gene mutations in endometrial cancer. Int J Cancer 2006; I I9: 563-570.

2I National Comprehensive Cancer Network. Guidelines for the detection, prevention and risk of cancer, genetics/familial high risk assessment - Cowden syndrome. http://www.nccn.org/professionals/physician_gls/PDF/ genetics_screening.pdf (Accessed I 2 July 2008). 
CHAPTER 3

\section{Disorders involving the X-chromosome}


CHAPTER 3 


\section{Original Article}

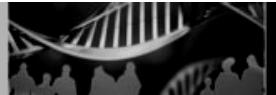

(C) 2013 John Wiley \& Sons A/S. Published by John Wiley \& Sons Ltd CLINICAL GENETICS doi: $10.1111 /$ cge. 12162

\section{Cutaneous clues for diagnosing $\mathrm{X}$-chromosomal disorders}

Vreeburg M, Sallevelt SCEH, Stegmann APA, van Geel M, Detisch YJHA, Schrander-Stumpel CTRM, van Steensel MAM, Marcus-Soekarman D. Cutaneous clues for diagnosing X-chromosomal disorders.

Clin Genet 2013. (C) John Wiley \& Sons A/S. Published by John Wiley \& Sons Ltd, 2013

In a multidisciplinary outpatient clinic for hereditary skin diseases and/or syndromes involving the skin, 7\% (30 of 409) of patients were found to have an abnormality involving the $\mathrm{X}$ chromosome, a mutation in a gene located on the X chromosome or a clinical diagnosis of an X-linked monogenetic condition. The collaboration of a dermatologist and a clinical geneticist proves to be very valuable in recognizing and diagnosing these conditions. By combining their specific expertize in counselling an individual patient, $\mathrm{X}$-linked diagnoses were recognized and could be confirmed by molecular and/or cytogenetic studies in 24 of 30 cases. Mosaicism plays an important role in many X-linked hereditary skin disorders. From our experience, we extracted clinical clues for specialists working in the field of genetics and/or dermatology for considering $\mathrm{X}$-linked disorders involving the skin.

\section{Conflict of interest}

Nothing to report.

\section{Vreeburg ${ }^{a}$, SCEH Sallevelt ${ }^{a}$, APA Stegmann ${ }^{a}, M$ van Geel ${ }^{a, b}$, YJHA Detisch ${ }^{\mathrm{a}}$, CTRM Schrander-Stumpel ${ }^{a, c}$, MAM van Steensel $\left.\right|^{a, b, c}$ and D Marcus-Soekarman ${ }^{a}$}

aDepartment of Clinical Genetics, bepartment of Dermatology, and ${ }^{\circ}$ GROW School for Oncology and Developmental Biology, Maastricht University Medical Center, Maastricht, the Netherlands

Key words: genodermatology mosaicism - multidisciplinary - review - X chromosome

Corresponding author: Maaike Vreeburg, MD, Department of Clinical Genetics, Maastricht University Medical Center (MUMC+), P. Debyelaan 25, 6202 AZ Maastricht, the Netherlands. Tel.: +31433875855;

fax: +31433871720 ; e-mail: m.vreeburg@mumc.nl [PO BOX 5800]

Received 14 January 2013, revised and accepted for publication 5 April 2013
A significant proportion of genetic disorders affects the skin. However, many specific genetic skin disorders (genodermatoses) are rare in the general population. For example, neurofibromatosis type I (OMIM \#162200), one of the more common disorders, has a frequency of 1 in 3000. However, many genodermatoses have a frequency of 1 in 10,000 or even less. As a result, diagnosing such conditions can be challenging because of the lack of familiarity on the part of individual clinicians. In an effort to overcome this problem, we formed a multidisciplinary team, consisting of a dermatologist and a clinical geneticist, who combined their specific expertize in diagnosing and counselling an individual patient. The team saw referred patients with genetic disorders in which the skin was involved, either as a cardinal feature or as a minor part of the phenotype. In the past 8 years, we counselled 409 patients in a multidisciplinary setting. Approximately
$7 \%$ of these patients had a disorder involving the $\mathrm{X}$ chromosome. We perceived clinical clues that might draw the attention of the clinician to X-linked disorders. Here, we report our data regarding $\mathrm{X}$ linked conditions as diagnosed in our multidisciplinary outpatient clinic and compare our experiences with those reported in the literature. On the basis of these data, we provide guidelines for recognizing and formulate recommendations for follow-up of these $\mathrm{X}$ linked genodermatoses.

\section{Methods}

Consecutive patients, referred in the years 2004-2012 by dermatologists, clinical geneticists or other specialists to our genodermatology outpatient clinic, were seen by two specialists (clinical geneticist and dermatologist) assisted by a genetic counsellor, and constituted a 


\section{Vreeburg et al.}

highly selected cohort of 409 genodermatology patients, probably enriched for relatively rare disease. In earlier years, most referrals were of cases with an unknown diagnosis; later, more common genodermatoses such as albinism, ichthyosis vulgaris or neurofibromatosis were also referred, for questions about therapeutic options. The medical history of the patient and the pedigree were recorded. Clinical examination with special attention for the skin and its appendages, followed by karyotyping, DNA analysis, metabolic investigation and/or a skin biopsy (if indicated) were performed depending on the differential diagnosis. In an earlier phase, cytogenetic techniques involved conventional karyotyping, fluorescence in situ hybridization (FISH) and/or multiplex ligation-dependent probe amplification (MLPA) examinations. In recent years, array techniques were used. The dermatologist, if so indicated, prescribed medication. Referral to the department of dermatology was arranged if specific treatment of the skin condition was needed. A follow-up appointment was scheduled to discuss results of laboratory investigations and treatment, and explain topics that had not been clear to the patient at first consultation. If a hereditary condition was diagnosed, family members were offered counselling in the department of clinical genetics.

\section{Results}

In 8 years, the multidisciplinary team counselled 409 patients. For the characteristics of the whole cohort, see Table 1. A known diagnosis was defined as a clinical diagnosis (according to the state of the art and/or published criteria) with or without a confirmation using laboratory techniques; 30 patients showed either a numerical or structural abnormality involving the $\mathrm{X}$ chromosome, a mutation in a gene located on the $\mathrm{X}$ chromosome or a clinical diagnosis of an X-linked monogenetic disorder (Table 2). There were 12 male and 18 female patients. Various subgroups could be discerned, based on the diagnosis:

(1) Aneuploidy accompanied by skin abnormalities $(n=2)$.

(2) Structural abnormalities of the $X$ chromosome with skin involvement $(n=8)$.

(3) Mutations of genes located on the X chromosome or a clinical diagnosis of a monogenetic Xlinked skin disorders $(n=20)$.

Karyotyping revealed an abnormal chromosomal pattern in 10 of 30 cases. In 20 cases, a clinical diagnosis of a monogenetic condition was made that could be confirmed by molecular studies in 14 cases. The most frequent diagnosis in this group was incontinentia pigmenti (IP), with confirmation at the DNA level in seven patients (IP, OMIM \#308310, $n=10$ ). In three patients from two families with the clinical diagnosis of IP, no mutation could be identified in the NEMO gene. Focal dermal hypoplasia (FDH, OMIM \#305600) was diagnosed in a male and was confirmed by DNA analysis (1). Conradi-Hünermann-Happle (CHH) syndrome
(X-linked dominant chondrodysplasia punctata type II, OMIM \#302960) was diagnosed in two female patients and confirmed by a mutation in the EBP (emopamilbinding protein) gene. In two brothers with ichthyosis and corneal dystrophy (OMIM \#308100), no steroidsulphatase STS) deficiency or deletion of the STS region on chromosome $\mathrm{Xp}$ could be identified. We hypothesize that the cause of the ichthyosis and the corneal dystrophy might be a mutation or deletion of the ARSE gene. Further analysis is pending.

In three patients with hypohidrotic ectodermal dysplasia (HED), mutation(s) were found in the EDl gene. In addition, a patient with Lelis syndrome (OMIM $\% 608290$ ) had a mutation in the EDI gene, suggesting that HED and Lelis syndrome are allelic disorders (2).

One patient with features of X-linked chronic granulomatous disease (CGD, OMIM \#306400) has so far declined the offer to analyse the $C Y B B$ gene.

\section{Discussion}

The sex chromosomes (XX and XY) form 1 of 23 of our genetic material. Assuming that genes are evenly distributed both on autosomes and sex chromosomes, approximately 4\% X-linked disorders are to be expected. In the entire cohort of 409 patients, a higher number of patients $(7 \%)$ was diagnosed with $\mathrm{X}$-linked conditions. If a definitive diagnosis was possible, even a higher percentage of X-linked disorders was found (30 of 241: 12\%, Table 1). Whether overrepresentation of X-linked conditions in our cohort is truly present is a difficult question to answer for several reasons.

No other study of a similar cohort was published in the literature so far, so no data on incidence of $\mathrm{X}$-linked genodermatologic conditions in general are available. However, data on a comparable cohort of unselected patients with mental retardation reported by Hunter show an X-linked disorder in approximately $20 \%$ of known diagnoses (3). As in mental retardation, a surplus of X-linked genes involved in genodermatoses might explain the overrepresentation. On the other hand, a selection bias could also be an important factor: patients were referred with (mosaic) skin patterns for further diagnostic evaluation. As many of the Xlinked genodermatoses are recognizable by specific skin patterns, this might also be one of the factors involved in overrepresentation.

Pattern recognition is essential for diagnosing rare, genetic conditions (4). Those that are due to an $\mathrm{X}$ chromosomal defect or mutations in X-linked genes expressed in the skin may show uniquely visible patterns of pigmentation or textural changes (5). X inactivation plays an important role as an underlying genetic mechanism in the expression of such conditions, and might interfere with the expression of the phenotype (6). The patterns of X-linked genodermatoses can be missed by clinical geneticists because of (too) small pedigrees. The dermatologist can have trouble in the pattern recognition because he/she primarily focuses on the skin. 


\section{Cutaneous clues for diagnosing $\mathbf{X}$-chromosomal disorders}

Table 1. Patient characteristics of the cohort of patients seen in the outpatient clinic for Genodermatology in the 8-year period from 2004 to 2012

\begin{tabular}{lccccc}
\hline & Male & Female & $\begin{array}{c}\text { Patients } \leq 18 \\
\text { years of age }\end{array}$ & $\begin{array}{c}\text { Total } \\
\text { a known diagnosis } \\
\text { a knowients with }\end{array}$ \\
\hline Dermato-oncogenetic syndromes & 49 & 61 & 33 & 110 & 60 \\
Disorders involving the X chromosome & 12 & 18 & 13 & 30 & 30 \\
Mosaicism & 11 & 19 & 24 & 30 & 27 \\
Miscellaneous (including connective tissue disorders) & 89 & 147 & 126 & 236 & $124^{\mathrm{a}}$ \\
Lost in follow-up & 2 & 1 & - & 3 & 241 \\
Total & 163 & 246 & 196 & 409 & 241 \\
\hline
\end{tabular}

${ }^{a}$ Twenty-seven patients with connective tissue disorders, 72 miscellaneous diagnoses, and 25 patients with a sporadic/non-genetic disorder.

Table 2. Diagnoses in X-linked genodermatoses

\begin{tabular}{|c|c|c|c|}
\hline & $\begin{array}{l}\text { Number of } \\
\text { patients }\end{array}$ & $\begin{array}{l}\text { Female }(F) \\
\text { /male (M) }\end{array}$ & Gene involved \\
\hline \multicolumn{4}{|l|}{ Numerical abnormalities or aneuploidy } \\
\hline Turner syndrome & 1 & $1 \mathrm{~F}$ & \\
\hline Klinefelter syndrome & 1 & $1 \mathrm{M}$ & \\
\hline \multicolumn{4}{|l|}{$\begin{array}{l}\text { Structural and cytogenetic abnormalities of the } \mathrm{X} \\
\text { chromosome }\end{array}$} \\
\hline $\begin{array}{l}\text { 46,XY.ish del(X)(p22.2pter) (8.41 Mb terminal } \\
\text { Xp-deletion) }\end{array}$ & $1^{\mathrm{a}}$ & $1 \mathrm{M}$ & $\begin{array}{l}\text { Continguous gene syndrome: } \\
\text { STS included }\end{array}$ \\
\hline 46,XY.ish del(X)(p22.31) (STS-,Xpter+) & 1 & $1 \mathrm{M}$ & $\begin{array}{l}\text { Continguous gene syndrome: } \\
\text { STS included }\end{array}$ \\
\hline 46,XX.arr Xp22.2p22.33(0-11,344,746)x1 dn (MLS9) & 1 & $1 \mathrm{~F}$ & \\
\hline $\begin{array}{l}\text { X-linked recessive ichthyosis (XLRI) due to interstitial Xp } \\
\text { deletions of (part of) the STS locus (within Xp22.31) }\end{array}$ & 5 & $2 \mathrm{~F} / 3 \mathrm{M}$ & STS \\
\hline \multicolumn{4}{|l|}{ Monogenic disorders } \\
\hline \multicolumn{4}{|l|}{ Disorders of pigmentation } \\
\hline Incontinentia pigmenti (OMIM \\
#308300) & 10 & $10 \mathrm{~F}$ & NEMO \\
\hline \multicolumn{4}{|l|}{ Disorders of the dermis } \\
\hline Focal dermal hypoplasia (OMIM\\
#305600) & 1 & $1 \mathrm{M}$ & PORCN \\
\hline \multicolumn{4}{|l|}{ Disorders of the epidermis } \\
\hline $\begin{array}{l}\text { Conradi-Hünermann-Happle syndrome } \\
\text { (OMIM \\
#302960) }\end{array}$ & 2 & $2 \mathrm{~F}$ & $E B P$ \\
\hline XLRI with corneal dystrophy & 2 & $2 \mathrm{M}$ & ARSE? (OMIM\\
#302950) \\
\hline \multicolumn{4}{|l|}{ Disorders of the epidermal appendages } \\
\hline Hypohidrotic ectodermal dysplasia (OMIM\#305100) & 3 & $1 \mathrm{~F} / 2 \mathrm{M}$ & ED1 \\
\hline Lelis syndrome (OMIM\%608290) & 1 & $1 \mathrm{M}$ & ED1(?) \\
\hline \multicolumn{4}{|l|}{ Immune deficiency disease } \\
\hline Chronic granulomatous disease (OMIM\#306400) & 1 & $1 F$ & CYBB \\
\hline Total & 30 & $18 \mathrm{~F} / 12 \mathrm{M}$ & \\
\hline
\end{tabular}

EBP, emopamil-binding protein; STS, steroid sulphatase.

avan Steensel et al. (18).

${ }^{\mathrm{b}}$ Microphthalmia with linear skin defects (MLS, OMIM\\#309801).

To illustrate these points, and assist the reader in developing his/her own abilities of pattern recognition, we will discuss the more common disorders that we have seen in our cohort.

Numerical and structural abnormalities of the $X$ chromosome

Klinefelter syndrome $(47, \mathrm{XXY})$ is one of the most frequent aneuploidy syndromes, with an incidence of 1 in 500 (4). It presents with tall stature and reduced fertility in males (4). Specific complications involving the skin are leg ulcers at a young age, which can lead to hyperpigmentation (7). In our cohort, a 13year-old adolescent with Klinefelter syndrome was referred to us because of stucco-keratosis on the thorax. This is a condition characterized by benign, keratotic papules or plaques, usually located on the distal, upper extremities. It is more frequent in males than in females, and mainly occurs at age 40 or over. The reported prevalence is estimated between 7 and $20 \%$ in the general population (8). It has not been reported in 


\section{Vreeburg et al.}

association with Klinefelter syndrome yet. Because Klinefelter's syndrome is one of the most frequent aneuploidies, this might well have been a coincidental finding. However, the unusual location and age of presentation suggest that in our patient, stucco-keratosis could be part of the phenotype. Further reports of similar cases are needed to corroborate this hypothesis.

Another patient visited our multidisciplinary team as an adult because of bilateral lymphedema of the legs. Turner syndrome had been diagnosed by conventional karyotyping $(45, \mathrm{X})$ in childhood (Table 2). Turner syndrome is an aneuploidy syndrome with a frequency of 1 in 2000 (9), characterized by the classical triad of (foetal) hydrops, short stature and infertility (4). Our patient showed various clinical symptoms of Turner syndrome, including a short stature with shortening of the fourth metacarpals and hypertension. Except for the bilateral lymphedema of the limbs, no other dermatologic signs pathognomonic for Turner syndrome were observed. Approximately $80 \%$ of newborns with Turner syndrome have congenital lymphedema, presumably because of disturbed lymphogenesis during embryogenesis. Changes in nail anatomy (small concave finger or toenails with an increased insertion angle) are additional clues for this diagnosis (10). The congenital lymphedema usually resolves spontaneously by the age of 2 years, but may recur unilaterally or bilaterally in later life (11). In general, no treatment is necessary, but if required lymphatic drainage therapy (manually or by machine) and compression bandaging are the methods of choice.

Another characteristic skin finding in Turner syndrome is an increased number of cutaneous melanocytic nevi, which, in the general population, is one of the strongest risk factors for melanoma (12). The incidence of melanoma seems to be reduced in Turner syndrome $(13,14)$, but in our view dermatological follow-up remains indicated in patients with more than 25 melanocytic nevi (15).

\section{Structural abnormalities of the $\mathrm{X}$ chromosome}

The Xp22.3 region is prone to deletions and contains, among others, the STS gene. Mutations in or deletions affecting STS cause recessive X-linked ichthyosis (RXLI, OMIM \#308100) with a prevalence of 1 of 2000-5000 males. Characteristic clinical findings are generalized large, adherent, dark brown scales with involvement of the neck and axillary flexures and usually sparing the palms, soles and flexural areas of elbows and knees (Fig. 1). The confirmation of the diagnosis is based on biochemical and genetic analyses. If DNA analysis does not reveal one of the known deletions or mutations in a male with this dermatologic phenotype, microarray analysis and/or conventional karyotyping should be performed, especially if additional features such as short stature, mental retardation, corneal opacity or cryptorchidism are present $(16,17)$. The latter features may point to larger regions being deleted which escape diagnosis by DNA mutation analysis. In fact, such a diagnosis was found in one of

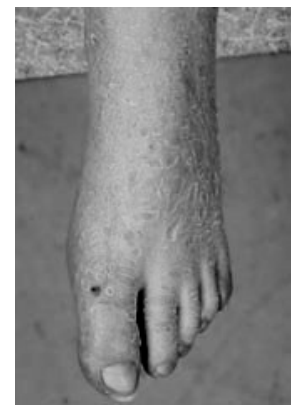

Fig. 1. Characteristic scaling in a patient with recessive $\mathrm{X}$-linked ichthyosis.

our patients, who had been in follow-up for several years with an unknown mental retardation syndrome with abnormal skin (18). This boy had mental retardation and dysmorphic features with RXLI. By MLPA analysis an Xp deletion was found and explained the patient's phenotype completely.

While $\mathrm{X}$ inactivation corrects gene dosage in XX females and males with Klinefelter syndrome, the pseudo-autosomal region on the short arm of the $\mathrm{X}$ chromosome escapes this mechanism (19). Clinical manifestation of RXLI is rare in females, requiring knock-out of the genes on both $\mathrm{X}$ chromosomes (20). Therefore, females with the RXLI phenotype should be offered chromosomal analysis, because loss of heterozygosity may have occurred by means of uniparental disomy or homozygous deletions, as was the case in a female patient with RXLI in our cohort (20).

\section{Monogenetic disorders}

\section{X-linked dominant conditions}

In this cohort of X-linked genodermatoses, females outnumbered males as expected (12 males and 18 females, Table 2). This is owing to the contribution of X-linked dominant conditions with male lethality such as IP and $\mathrm{CHH}$ syndrome (21). The phenotype of X-linked monogenetic disorders is affected by $\mathrm{X}$ inactivation in females, which results in functional mosaicism, and probably makes them easier to diagnose. Skin lesions following the lines of Blaschko are considered to be a reflection of genetic mosaicism $(5,22,23)$ (Fig. 2).

Female carriers of such conditions show mosaic skin lesions following Blaschko's lines, while hemizygous males do not survive pregnancy. In rare cases, males with a phenotype of IP or FDH are life born $(1,24$, $25)$. This can be explained by hypomorphic mutations (26), post-zygotic somatic mosaicism or Klinefelter syndrome (27).

\section{Incontinentia pigmenti}

Cutaneous manifestations of IP (OMIM \#308310) are striking in the infant and are classically subdivided 


\section{Cutaneous clues for diagnosing $\mathbf{X}$-chromosomal disorders}
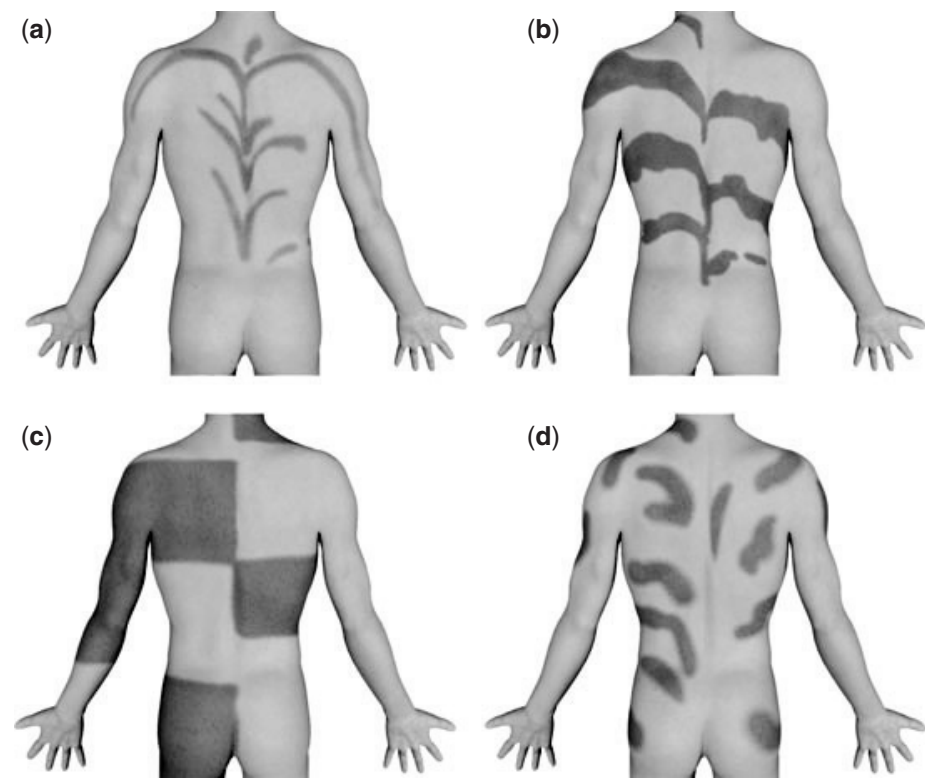

Fig. 2. Patterns of the skin according to Blaschko's lines. (a) Type 1a: linear (many X-linked traits). (b) Type 1b: broad linear (many X-linked traits). (c) Type 2: lateralization or checkerboard pattern (as in congenital hemidysplasia with Ichthyosiform erythroderma and limb defects (CHILD) syndrome, for example). (d) Type 3: phylloid (leaf-like) pattern.

into four stages: vesicular, verrucous, hyperpigmented and atrophic. In due time, the first three phases usually disappear completely, leaving very subtle linear depigmentation following Blaschko's lines, often on the skin of the calves in the adult female (28). It is our experience that in older patients who were not diagnosed before, explicit questioning regarding the aspect of the skin as an infant/young child will give valuable additional information, leading to a diagnosis. Also, specific nail abnormalities such as linear ridging, pitting or nail dystrophy, and male lethality in the pedigree provided diagnostic clues. The gene causing IP, NEMO/IKBKG, is located on Xq28 (29). In three quarters of patients a causative mutation is found, mainly a recurring deletion of exons 4-10 (30). The three patients in whom we could not detect a pathogenic mutation in the NEMO gene did meet the clinical diagnostic criteria for IP (31).

\section{Conradi-Hünermann-Happle syndrome}

$\mathrm{X}$-linked dominant chondrodysplasia punctata type 2 (CHH syndrome, CDPX2; OMIM \#302960) is caused by mutations in the $E B P$ gene coding for $3 \beta$ hydroxysteroid- $\delta 8,7$-isomerase, a central component of cholesterol biosynthesis (32). At birth, patients present with erythroderma and show linear hyperkeratotic skin lesions following Blaschko's lines (Fig. 3a). The erythroderma typically disappears after $24 \mathrm{~h}$. During the first years of life, the ichthyotic lesions develop into linear and whorled atrophic and hypopigmented skin
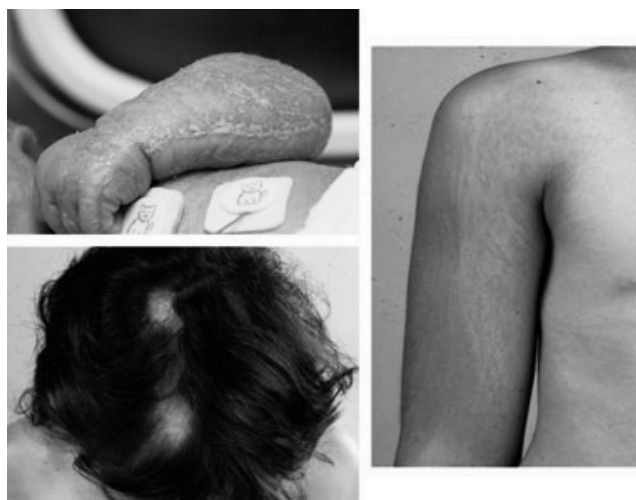

Fig. 3. Skin manifestations in Conradi-Hünermann-Happle syndrome $(34,43)$. (a) Linear hyperkeratosis and generalized erythroderma in the infant (arm). (b) Linear atrophy of the skin (fine linear pattern on the upper arm). (c) Linear alopecia of the scalp.

lesions, and on the scalp into linear alopecia (Fig. 3b,c). Other organs involved may be the eyes (cataracts) and skeleton [rhizomelic limb shortening, short stature, and vertebral anomalies (33)]. Stippling of epiphyses should be sought at a young age, because this sign disappears over time. In adults, the remaining skin manifestations such as linear atrophy or alopecia can be quite subtle and easily missed (34). 


\section{Vreeburg et al.}

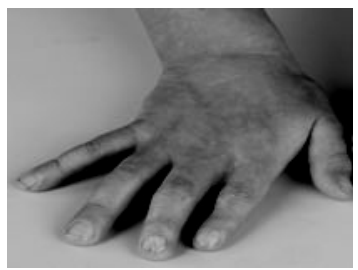

Fig. 4. Hand of a male patient with mosaic focal dermal hypoplasia (1): note the cutaneous 2-3 syndactyly, short index finger and clinodactyly of the middle finger. The nails are dystrophic with linear ridging and notching.

\section{Focal dermal hypoplasia}

FDH or Goltz-Gorlin syndrome (OMIM \#305600) is another $\mathrm{X}$-linked dominant condition involving both ectodermal structures and the skeletal system as in $\mathrm{CHH}$ syndrome. The disorder is caused by mutations and deletions affecting the PORCN gene on Xp11.23.2. PORCN codes for a conserved protein called Porcupine that is an $O$-acyltransferase located in the endoplasmic reticulum. This product plays a role in WNT-protein modification and excretion (35). Clinical features of FDH include atrophy and linear pigmentation of the skin following Blaschko's lines, often with a telangiectatic aspect due to dermal defects with fat herniation. Papillomas of mucous membranes or skin can also occur. Skin defects can be extensive and body wall defects have been reported (36). In our cohort, one male suffered from mosaic FDH. The diagnosis was confirmed by finding a PORCN mutation (1). Digital anomalies, such as syndactyly, polydactyly, camptodactyly and absence of deformities, are common (Fig. 4). Osteopathia striata is an almost constant finding: linear decreases of bone density around the epiphyses, presumably representing Blaschko's lines of the bones (37). Additional diagnostic clues are the small ears with cranial notching and dystrophic nails with linear ridging and notching (Fig. 4).

Although IP, $\mathrm{CHH}$ and FDH all have a distinctive phenotype in young infants and children, a considerable overlap in their clinical features exists, especially in adults. Therefore, these three diagnoses should always be kept in mind in the differential diagnosis of linear hypopigmented skin changes in females.

\section{X-linked recessive conditions}

\section{Ectodermal dysplasia}

HED or anhidrotic ectodermal dysplasia (EDA, OMIM \#305100) is one of the more common types of ectodermal dysplasia. Patients exhibit the classic triad of sparse hair (hypotrichosis), abnormal (cone-shaped) or missing teeth (anodontia or hypodontia) and the inability to sweat (anhidrosis or hypohidrosis), frequently associated with characteristic dysmorphic features $(20,38)$. HED/EDA can be caused by mutations in the EDl gene (X-linked recessive $\mathrm{HED}$ ), the EDARADD gene and the
EDAR gene [autosomal recessive or autosomal dominant HED, OMIM \#224900 and \#129490 (38)]. Patients with EDI/EDAR/EDARADD mutations show a similar phenotype. If they have a classic triad of HED/EDA signs, facial dysmorphism and a family history consistent with an X-linked inheritance, the EDI gene should be first studied, as in our cases (Table 2). If no mutation is found in the EDI gene, the next gene to consider should be the $E D A R$ gene, before analysing the $E D A R A D D$ gene. In the absence of facial dysmorphism, distinct dental anomalies such as microdontia in combination with varying degrees of hyponychia and palmoplantar keratoderma are clues for odonto-onychodermal dysplasia (OMIM \#257980). This recessive disorder is caused by homozygous or compound heterozygous mutations in the WNT10A gene, has a pleiotropic phenotype and seems to occur more frequently than formerly thought (39). Therefore, it is an important differential diagnosis of (X)HED (40).

\section{Ichthyosis}

The ichthyoses are a large and very heterogeneous group of cornification disorders recently categorized in the 2010 Mendelian disorders of cornification (MEDOC) classification (41). Because of the diversity, a multidisciplinary approach to diagnosis and management is highly recommended. This point is proven by the yet unsolved case of two brothers in our cohort with ichthyosis and corneal dystrophy (Table 2). A maternal cousin was also known to have ichthyosis and eye abnormalities but was not available for further examination. First, RXLI (OMIM \#308100) caused by STS deficiency was considered, in which corneal opacities are found in $10-50 \%$ of cases (42). However, metabolic and cytogenetic analyses of the STS locus were normal. As X-linked recessive chondrodysplasia punctata (CDPX1, OMIM \#302950) was considered as differential diagnosis, additional FISH analysis of the ARSE locus in Xp22.3 was performed with normal result. Sequencing of the ARSE gene is being considered. Further investigations, such as cytogenetic array techniques with haplotyping or exome sequencing, may shed light on the aetiology of the ichthyosis in this family in the future.

\section{Conclusion}

In a multidisciplinary outpatient clinic for hereditary skin diseases and/or syndromes involving the skin, $7 \%$ (30 of 409) of patients were found to have an abnormality of the $\mathrm{X}$ chromosome, a mutation in a gene located on the $\mathrm{X}$ chromosome or a clinical diagnosis of an X-linked monogenetic condition. The collaboration of a dermatologist and a clinical geneticist has proven to be fruitful in recognizing and diagnosing these conditions. By combining the specific expertize of both specialists in counselling an individual patient, we are of the opinion that X-linked diagnoses were more readily recognized, and could be confirmed by molecular and/or cytogenetic studies in the majority of cases. 


\section{Cutaneous clues for diagnosing $\mathrm{X}$-chromosomal disorders}

From our experience, we extracted the following clinical clues when to consider an X-linked disorder involving the skin:

(1) If a patient has a mosaic pattern of skin lesions, either by pigmentation, keratinization or hypoplasia/aplasia, following the lines of Blaschko, an Xlinked disorder should be considered. A precise and accurate description of the skin lesions by an experienced dermatologist is of vital importance for diagnosing the correct disorder.

(2) Skin abnormalities in a newborn, such as erythroderma and vesicles or lymphedema, should be documented precisely, by photography whenever possible. Special attention should be paid to distribution according to the lines of Blaschko. Referral to, or consultation of, a dermatologist is warranted.

(3) If a congenital disease such as $\mathrm{CHH}$ or $\mathrm{FDH}$ is considered in the differential diagnosis, skeletal imaging should take place to find additional clues for the diagnosis.

(4) If indication for male lethality is present in the pedigree, an X-linked dominant condition should be considered.

(5) Although DNA analysis is the method of choice nowadays to diagnose many $\mathrm{X}$-linked conditions, (molecular) karyotyping is still warranted in males with features 'outside the spectrum' (developmental delay, dysmorphic features and/or congenital anomalies) or in females with an X-linked condition that usually is not expressed in this gender.

\section{References}

1. Vreeburg M, van Geel M, van den Heuij L, Steijlen P, van Steensel M. Focal dermal hypoplasia in a male patient due to mosaicism for a novel PORCN single nucleotide deletion. J Eur Acad Dermatol Venereol 2010: 25: 592-595.

2. van Steensel MA, van der Hout AH. Lelis syndrome may be a manifestation of hypohidrotic ectodermal dysplasia. Am J Med Genet A 2009: 149A: 1612-1613

3. Hunter AG. Outcome of the routine assessment of patients with mental retardation in a genetics clinic. Am J Med Genet 2000: 90: 60-68

4. Jones KL. Smith's recognizable patterns of human malformation, 6th edn. Elsevier Saunders: Philadelphia; 2006.

5. Happle R. X-chromosome inactivation: role in skin disease expression. Acta Paediatr Suppl 2006: 95: 16-23.

6. Sun BK, Tsao H. X-chromosome inactivation and skin disease. J Invest Dermatol 2008: 128: 2753-2759.

7. Callam MJ, Ruckley CV, Harper DR, Dale JJ. Chronic ulceration of the leg: extent of the problem and provision of care. Br Med J (Clin Res Ed) 1985: 290: 1855-1856.

8. Hafner C, Landthaler M, Mentzel T, Vogt T. FGFR3 and PIK3CA mutations in stucco keratosis and dermatosis papulosa nigra. $\mathrm{Br} \mathrm{J}$ Dermatol 2010: 162: 508-512.

9. Hook EB, Warburton D. The distribution of chromosomal genotypes associated with Turner's syndrome: livebirth prevalence rates and evidence for diminished fetal mortality and severity in genotypes associated with structural $\mathrm{X}$ abnormalities or mosaicism. Hum Genet 1983: 64: 24-27.

10. Kaplowitz PB, Chernausek SD, Horn JA. Fingernail angle in girls with Ullrich-Turner syndrome. Am J Med Genet 1993: 46: 570-573.

11. Sybert VP, McCauley E. Turner's syndrome. N Engl J Med 2004: 351: $1227-1238$
12. Grob JJ, Gouvernet J, Aymar D et al. Count of benign melanocytic nevi as a major indicator of risk for nonfamilial nodular and superficial spreading melanoma. Cancer 1990: 66: 387-395.

13. Becker B, Jospe N, Goldsmith LA. Melanocytic nevi in Turner syndrome. Pediatr Dermatol 1994: 11: 120-124

14. Brazzelli V, Larizza D, Martinetti $M$ et al. Halo nevus, rather than vitiligo, is a typical dermatologic finding of turner's syndrome: clinical, genetic, and immunogenetic study in 72 patients. J Am Acad Dermatol 2004: 51: 354-358.

15. Holly E, Kelly J, Shapall S, Chiu S. Number of melanocytic nevi as a major risk factor for malignant melanoma. J Am Acad Dermatol 1987: 17: 459-468.

16. Ballabio A, Bardoni B, Carrozzo R et al. Contiguous gene syndromes due to deletions in the distal short arm of the human $\mathrm{X}$ chromosome. Proc Natl Acad Sci USA 1989: 86: 10001-10005.

17. Cuevas-Covarrubias SA, Gonzalez-Huerta LM. Analysis of the VCX3A, VCX2 and VCX3B genes shows that VCX3A gene deletion is not sufficient to result in mental retardation in X-linked ichthyosis. Br J Dermatol 2008: 158: 483-486.

18. van Steensel MA, Vreeburg M, Engelen $\mathrm{J}$ et al. Contiguous gene syndrome due to a maternally inherited $8.41 \mathrm{Mb}$ distal deletion of chromosome band $\mathrm{Xp} 22.3$ in a boy with short stature, ichthyosis, epilepsy, mental retardation, cerebral cortical heterotopias and DandyWalker malformation. Am J Med Genet A 2008: 146A: 2944-2949.

19. Hernandez-Martin A, Gonzalez-Sarmiento R, De Unamuno P. X-linked ichthyosis: an update. Br J Dermatol 1999: 141: 617-627.

20. Nagtzaam IF, Stegmann APA, Steijlen PM et al. Clinically manifest Xlinked ichthyosis in a female due to a homozygous interstitial 1.6-Mb deletion of Xp22.31. Br J Dermatol 2012: 166: 905-907.

21. Franco B, Ballabio A. X-inactivation and human disease: X-linked dominant male-lethal disorders. Curr Opin Genet Dev 2006: 16 : 254-259

22. Happle R. Mosaicism in human skin. Understanding the patterns and mechanisms. Arch Dermatol 1993: 129: 1460-1470.

23. Happle R. Dohi Memorial Lecture. New aspects of cutaneous mosaicism. J Dermatol 2002: 29: 681-692.

24. Scheuerle AE. Male cases of incontinentia pigmenti: case report and review. Am J Med Genet 1998: 77: 201-218.

25. Kenwrick S, Woffendin H, Jakins T et al. Survival of male patients with incontinentia pigmenti carrying a lethal mutation can be explained by somatic mosaicism or Klinefelter syndrome. Am J Hum Genet 2001: 69: $1210-1217$

26. Happle R. Hypomorphic alleles within the EBP gene cause a phenotype quite different from Conradi-Hunermann-Happle syndrome. Am J Med Genet 2003: 112A: 279.

27. Traupe H. Functional X-chromosomal mosaicism of the skin: Rudolf Happle and the lines of Alfred Blaschko. Am J Med Genet 1999: 85 324-329.

28. Vreeburg M, van Steensel M. Genodermatoses caused by genetic mosaicism. Eur J Pediatr 2012: 171: 1725-1735.

29. Berlin AL, Paller AS, Chan LS. Incontinentia pigmenti: a review and update on the molecular basis of pathophysiology. J Am Acad Dermatol 2002: 47: 169-187 quiz 88-90.

30. Fusco F, Pescatore A, Bal E et al. Alterations of the IKBKG locus and diseases: an update and a report of 13 novel mutations. Hum Mutat 2008: 29: 595-604

31. Landy SJ, Donnai D. Incontinentia pigmenti (Bloch-Sulzberger syndrome). J Med Genet 1993: 30: 53-59.

32. Derry JM, Gormally E, Means GD et al. Mutations in a delta 8 delta 7 sterol isomerase in the tattered mouse and X-linked dominant chondrodysplasia punctata. jderry@immunex.com. Nat Genet 1999: 22 286-290.

33. Herman GE. Disorders of cholesterol biosynthesis: prototypic metabolic malformation syndromes. Hum Mol Genet 2003: 12 Spec No 1: R75-R88.

34. Steijlen PM, van Geel M, Vreeburg M et al. Novel EBP gene mutations in Conradi-Hunermann-Happle syndrome. Br J Dermatol 2007: 157: $1225-1229$

35. Grzeschik KH, Bornholdt D, Oeffner F et al. Deficiency of PORCN, a regulator of Wnt signaling, is associated with focal dermal hypoplasia. Nat Genet 2007: 39: 833-835.

36. Maas SM, Lombardi MP, van Essen AJ et al. Phenotype and genotype in 17 patients with Goltz-Gorlin syndrome. J Med Genet 2009: 46: 716-720. 


\section{CHAPTER 3}

\section{Vreeburg et al.}

37. Rott HD. Extracutaneous analogies of Blaschko lines. Am J Med Genet 1999: $85: 338-341$.

38. Visinoni A, Lisboa-Costa T, Pagnan N, Chautard-Freire-Maia E. Ectodermal dysplasias: clinical and molecular review. Am J Med Genet 2009: 149A: 1980-2002.

39. Cluzeau C, Hadj-Rabia S, Jambou $M$ et al. Only four genes (EDA1, EDAR, EDARADD, and WNT10A) account for $90 \%$ of hypohidrotic/anhidrotic ectodermal dysplasia cases. Hum Mutat 2011: 32: 70-72.

40. Bohring A, Stamm T, Sapaich C et al. WNT10A mutations are a frequent cause of a broad spectrum of ectodermal dysplasias with sexbiased manifestation pattern in heterozygotes. Am J Hum Genet 2009: 85: $97-105$.
41. Oji V, Tadini G, Akiyama $M$ et al. Revised nomenclature and classification of inherited ichthyoses: results of the First Ichthyosis Consensus Conference in Soreze 2009. J Am Acad Dermatol 2010: 63: 607-641.

42. Fernandes NF, Janniger CK, Schwartz RA. X-linked ichthyosis: an oculocutaneous genodermatosis. J Am Acad Dermatol 2010: 62: $480-485$.

43. Bukkems SF, Ijspeert WJ, Vreenurg M, van Rhijn LW, Schrander JJ, van Steensel MA. Conradi-Hunermann-Happle syndrome. Ned Tijdschr Geneeskd 2012: 156: A4105. 


\title{
SHORT REPORT
}

\section{Focal dermal hypoplasia in a male patient due to mosaicism for a novel PORCN single nucleotide deletion}

\author{
M Vreeburg, ${ }^{\dagger, \S}$ M van Geel, ${ }^{\ddagger, \S}$ LGT van den Heuij, ${ }^{\neq, \S}$ PM Steijlen, ${ }^{\ddagger, \S}$ MAM van Steensel ${ }^{\ddagger, \S, \star}$ \\ Departments of ${ }^{\dagger}$ Clinical Genetics and ${ }^{\ddagger}$ Dermatology, ${ }^{\S}$ GROW School for Oncology and Developmental Biology, Maastricht \\ University Medical Center, Maastricht, the Netherlands \\ ${ }^{\star}$ Correspondence: MAM van Steensel. E-mail: m.van.steensel@mumc.nl
}

\begin{abstract}
Background Focal dermal hypoplasia $(\mathrm{FDH})$ is an X-linked dominant disorder caused by nonsense mutations and deletions in the PORCN gene coding for a transmembrane endoplasmic reticulum protein required for Wingless signalling. Symptoms consist mainly of linear atrophic skin defects, skeletal deformities and, in many cases, mental retardation. Osteopathia striata is a nearly constant feature. Approximately $90 \%$ of patients are women. A few instances of father-to-daughter transmission and a number of sporadic male cases presumably as a result of somatic mosaicism have been recorded.
\end{abstract}

Objectives The aim of this study was to demonstrate the presence of somatic mosaicism for PORCN mutations in a male patient.

Methods We sequenced the PORCN gene in different tissues from a boy with symptoms of FDH.

Results We demonstrate post-zygotic mosaicism for a novel deletion in the PORCN gene.

Conclusions A novel PORCN deletion, present in a post-zygotic mosaic, causes focal dermal hyplasia in a male patient.

Received: 29 April 2010; Accepted 1 June 2010

\section{Keywords}

focal dermal hypoplasia, Goltz, mosaicism, PORCN, WNT

\section{Conflicts of interest}

None declared.

\section{Funding sources}

The Maastricht University Medical Center, the GROW School for Oncology and Developmental Biology and the Dutch Cancer Society grant UM 2009-4352

\begin{abstract}
Introduction
Wingless (Wnt) signalling is emerging as a crucial determinant of vertebrate morphogenesis and growth. Recent research has shown that it is involved in processes ranging from intestinal stem cell maintenance to hair cycle control. ${ }^{1}$ Its role in epithelial development and differentiation is made abundantly clear by the phenotypes associated with defects in the Wnt pathway. One of those is focal dermal hypoplasia (FDH, or Goltz syndrome). This is an $\mathrm{X}$-linked dominant disorder caused by mutations and deletions affecting the PORCN gene on Xp11.23. ${ }^{2}$ PORCN codes for a conserved protein called Porcupine that is an O-acyltransferase located in the endoplasmic reticulum and is required for WNT protein modification and excretion. ${ }^{3}$ It is widely expressed, a.o. in
\end{abstract}

cartilage primordia of long bones and digits, developing teeth and the skin of the developing body wall and limbs.

Clinical features of FDH align with PORCN expression and include atrophy and linear pigmentation of the skin, dermal defects with fat herniation and multiple papillomatosis of mucous membranes or skin. Skin defects can be extensive and body wall defects have been reported. ${ }^{4}$ Digital anomalies are common and can consist a.o. of syndactyly, polydactyly, camptodactyly and absence deformities. Teeth can be absent or malformed. Eye abnormalities and mental retardation have also been reported. Striated bones are probably a nearly constant feature. As an $\mathrm{X}$-linked dominant disorder, FDH is usually lethal in men. There are some reports of affected men and father-to-daughter 
transmission..$^{5-7}$ These observations have been explained by postulating somatic mosaicism that has now been demonstrated in a number of cases. ${ }^{8}$ However, photographic documentation is inconsistent and it is thus difficult to estimate how mosaicism in men affects their phenotype. We report and document a boy with clinical manifestations of FDH caused by post-zygotic mosaicism for a novel deletion in the PORCN gene.

\section{Case report}

The propositus, a 5-year-old boy of Dutch descent, was referred for diagnosis of small stature with atrophic skin lesions. He had been born prematurely at 29 weeks after an otherwise uneventful pregnancy. Birth weight was 1050 grammes. Cerebral ultrasound examination after birth showed an intraventricular cyst on the right side. The neonatal period was complicated by respiratory distress syndrome grade I that was treated with continuous positive airway pressure-ventilation. Psychomotor development afterwards was normal, but growth was significantly retarded. An inguinal hernia was corrected at the age of 3 months. Histopathological examination of the placenta (weight 296 grammes) revealed villi surrounded by trophoblast and peripheral syncytial budding consistent with either accelerated differentiation or a circulatory defect; no other abnormalities were noted.

His parents were not consanguineous. An older brother was not affected. Upon physical examination, height was $98 \mathrm{~cm}(<-2.5$ $\mathrm{SD})$ and weight $12 \mathrm{~kg}(<-2 \mathrm{SD})$. The occipitofrontal circumference was $48 \mathrm{~cm}(-2 \mathrm{SD})$, the inner canthal distance $2.6 \mathrm{~cm}$ (P25) and the interpupillary distance $5 \mathrm{~cm}$ (P50). Gross dysmorphic traits were not evident; however, further examination revealed subtle asymmetries and several minor anomalies including thin lips (Fig. 1). The left eye showed an epicanthus (Fig. 1a). The ears were asymmetric, the helix of the left ear showing cranial notching. The left ear was also slightly cup-shaped. Linear erythematous slightly atrophic skin lesions were visible on the left cheek. Linear alopecia was present on the occipital area (Fig. 1b), following Blaschko's lines. Further atrophic slightly erythematous macules, sometimes containing telangiectasias, following Blaschko's lines, were visible on both flanks (Fig. 1c) and the lateral aspects of both lower legs. Digits 2 and 3 of the right hand showed linear notching and ridging of fingernails, with clinodactyly of digit 3 and cutaneous 2-3 syndactyly (Fig. 1d). Several toenails were similarly dystrophic. The right index finger was shorter than the left one. The (deciduous) teeth were grossly normal.

Skeletal radiography did not demonstrate clear abnormalities. We made a diagnosis of focal dermal hypoplasia as a result of somatic mosaicism and examined the PORCN gene for mutations in three tissues: blood, buccal mucosa and placenta.

\section{Materials and methods}

Informed consent was obtained from the parents according to local ethical guidelines. DNA was isolated from peripheral blood leucocytes using a salting-out procedure. ${ }^{9}$ For DNA isolation from buccal mucosa we used the Oragene 250 DNA from saliva system (DNAgenotek, Kanata, ON, Canada). Placental samples had been obtained after birth and were embedded in paraffin. We isolated DNA from those by preparing thick $(10 \mu \mathrm{m})$ slides. DNA was subsequently isolated from this material by xylene deparaffination and making use of the PureGene DNA isolation tissue kit (Gentra systems, Minneapolis, MN, USA) according to the manufacturer's recommendations.
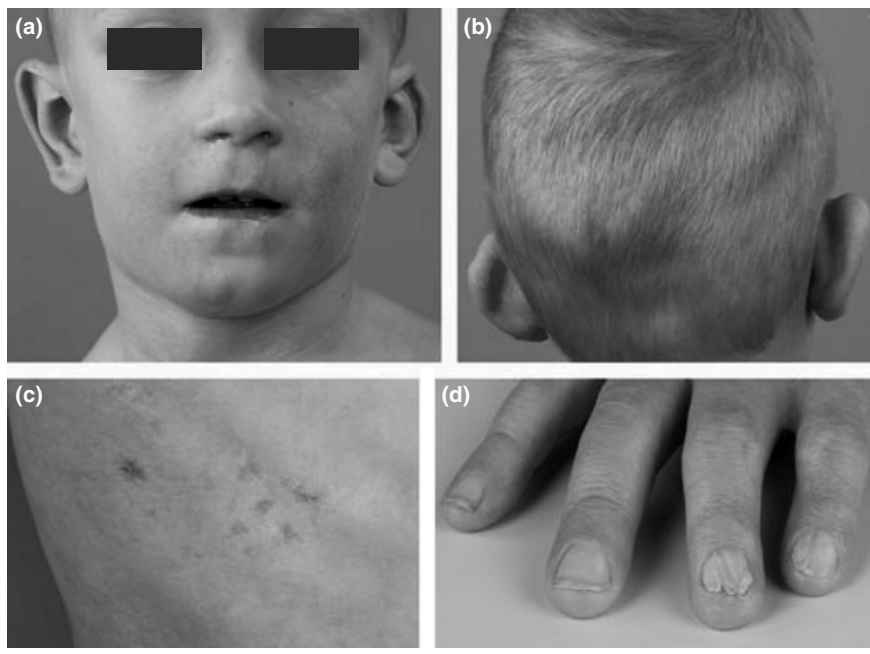

Figure 1 (a) Facial phenotype of the 5 -year-old boy. Note the thin lips, asymmetrical features and the hypoplastic skin lesions following Blaschko's lines; (b) Linear alopecia on the occiput; (c) Atrophic macules with telangectasias on the right flank following Blaschko's lines; (d) Cutaneous 2-3 syndactyly and clinodactyly of the middle finger. The index finger is shortened. Also note nail abnormalities. 
We analysed the PORCN gene by direct sequencing on an $\mathrm{ABI}$ 3730 DNA Analyzer (Applied Biosystems, Foster City, CA, USA). Primer sequences and reaction conditions are available upon request.

\section{Results}

The karyotype was normal, $46 \mathrm{XY}$. We found a single nucleotide deletion c.886delC in exon 9 of the PORCN gene in peripheral blood leucocytes. The putative consequence of this frameshift mutation is incorporation of 17 amino acids in the C-terminus of the porcupine protein (p.R296GfsX18). Trace height is suggestive of mosaicism reflecting an early post-zygotic mutation (Fig. 2a). Analysis of a buccal mucosa sample likewise demonstrated an approximately 50/50 ratio of the normal and mutant alleles (not shown). We did not detect the mutation in placenta samples (fetal side). The mother did not carry the mutation.

\section{Discussion}

We report a boy with mosaic manifestations of focal dermal hypoplasia caused by a novel deletion in the PORCN gene. Chromatograms of DNA obtained from peripheral blood and buccal mucosa were suggestive of post-zygotic somatic mosaicism. The diagnosis was initially suggested by the digital and nail abnormalities, a combination that we suggest should raise the suspicion of a defect in Wingless signalling as nail development depends upon this system. ${ }^{10}$ Examination of the skin revealed linear atrophic macules distributed along type I Blaschko lines. We also found areas of linear alopecia on the scalp. These observations, together with the thin lips and the asymmetries, prompted us to consider focal dermal hypoplasia as a possible diagnosis, which was subsequently confirmed by mutation analysis. The phenotype seems to be relatively mild, taking into account that, by DNA sequencing,

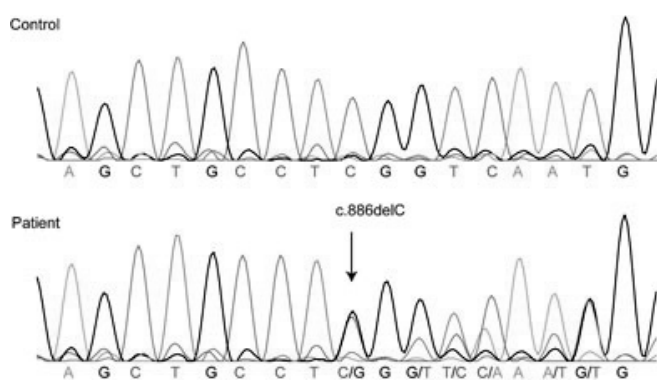

Figure 2 Sequence chromatograms showing wildtype pattern (top panel) and mutation in DNA from mosaic tissue (lower panel). The sequence trace shown is from peripheral blood leucocyte DNA and was identical to buccal mucosa DNA (not shown). a sizable population of mutant cells seems to be present in blood and buccal mucosa. However, the samples that we took may well not be representative of the entire organism and the percentage of mutant cells may differ considerably between tissues. It would be of interest, if possible, to obtain more comprehensive samples in future male patients with FDH. It is also worth noting that it has not yet been proven that the affected areas in X-linked mosaic disorders all consist of mutant cells.

An unusual feature in our case is the prematurity. To the best of our knowledge, this has not yet been reported in the context of focal dermal hypoplasia. Being relatively common in itself, its occurrence in our patient may have been a coincidence. The placental defects may also have been related to the prematurity. However, WNT signalling is involved in invasive trophoblast differentiation. ${ }^{11}$ It is thus possible that placental development may have been affected by the genetic defect. In this case, one might expect to more often find placental abnormalities in FDH, but as far as we know there are no such reports. Systematic examination of placentas from patients might turn up evidence for abnormal placental development. Alternatively, parts of the placenta expressing the mutant PORCN allele might be lost during development, possibly explaining the apparent absence of placental abnormalities in FDH. Our analysis of placental material from the fetal side did not reveal a mutation.

Short stature is a typical and well-known feature of FDH, probably reflecting involvement of Wingless signalling in bone growth and development. ${ }^{12}$ The WNT pathway also has a role in regulating bone mass in response to loading ${ }^{13}$ and our patient's slight build may reflect this role. Bone densitometry might be performed in the future to obtain more insight into the role of $P O R C N$ in determining bone growth and density. It is of interest in this respect to mention X-linked osteopathia striata congenita with cranial sclerosis (OSCS, MIM \#300373). This disorder, which is usually lethal to males, like $\mathrm{FDH}$, is caused by mutations in the WNT repressor WTX. ${ }^{14}$ The osteopathia striata in this disorder resembles that in FDH, but whereas FDH represents the consequences of a decrease in Wingless signalling, OSCS is caused by an increase. Therefore, in OSCS, the stripes probably represent areas of increased density, while in FDH they likely represent decreased bone density.

Clear dental and eye abnormalities in our patient were not present at the time of examination, but as the permanent dentition may yet be abnormal, follow-up by a dentist is warranted. Finally, our diagnosis has implications for future counselling of our patient, as gonadal mosaicism may be present.

\section{Acknowledgements}

This work was supported by the Maastricht University Medical Center, the GROW School for Oncology and Developmental Biology and the Dutch Cancer Society grant UM 2009-4352. 


\section{References}

1 Chien AJ, Conrad WH, Moon RT. A Wnt survival guide: from flies to human disease. J Invest Dermatol 2009; 129: 1614-1627.

2 Grzeschik KH, Bornholdt D, Oeffner F et al. Deficiency of PORCN, a regulator of Wnt signaling, is associated with focal dermal hypoplasia. Nat Genet 2007; 39: 833-835.

3 Hofmann K. A superfamily of membrane-bound O-acyltransferases with implications for wnt signaling. Trends Biochem Sci 2000; 25: 111-112.

4 Maas SM, Lombardi MP, van Essen AJ et al. Phenotype and genotype in 17 patients with Goltz-Gorlin syndrome. J Med Genet 2009; 46: 716-720.

5 Mahe A, Couturier J, Mathe C, Lebras F, Bruet A, Fendler JP. Minimal focal dermal hypoplasia in a man: a case of father-to-daughter transmission. J Am Acad Dermatol 1991; 25: 879-881.

6 Gorski JL. Father-to-daughter transmission of focal dermal hypoplasia associated with nonrandom X-inactivation: support for X-linked inheritance and paternal X chromosome mosaicism. Am J Med Genet 1991; 40: 332-337.

7 Burgdorf WH, Dick GF, Soderberg MD, Goltz RW. Focal dermal hypoplasia in a father and daughter. J Am Acad Dermatol 1981; 4: 273-277.
8 Bornholdt D, Oeffner F, Konig A et al. PORCN mutations in focal dermal hypoplasia: coping with lethality. Hum Mutat 2009; 30: E618-628.

9 Miller SA, Dykes DD, Polesky HF. A simple salting out procedure for extracting DNA from human nucleated cells. Nucleic Acids Res 1988; 16: 1215 .

10 Bergmann C, Senderek J, Anhuf D et al. Mutations in the gene encoding the Wnt-signaling component R-spondin 4 (RSPO4) cause autosomal recessive anonychia. Am J Hum Genet 2006; 79: 1105-1109.

11 Pollheimer J, Loregger T, Sonderegger S et al. Activation of the canonical wingless/T-cell factor signaling pathway promotes invasive differentiation of human trophoblast. Am J Pathol 2006; 168: 1134-1147.

12 Hoeppner LH, Secreto FJ, Westendorf JJ. Wnt signaling as a therapeutic target for bone diseases. Expert Opin Ther Targets 2009; 13: 485-496.

13 Robinson JA, Chatterjee-Kishore M, Yaworsky PJ et al. Wnt/betacatenin signaling is a normal physiological response to mechanical loading in bone. J Biol Chem 2006; 281: 31720-31728.

14 Jenkins ZA, van Kogelenberg M, Morgan T et al. Germline mutations in WTX cause a sclerosing skeletal dysplasia but do not predispose to tumorigenesis. Nat Genet 2009; 41: 95-100. 


\title{
Clinical Report \\ Contiguous Gene Syndrome Due to a Maternally Inherited 8.41 Mb Distal Deletion of Chromosome Band Xp22.3 in a Boy With Short Stature, Ichthyosis, Epilepsy, Mental Retardation, Cerebral Cortical Heterotopias and Dandy-Walker Malformation
}

\author{
M.A.M. van Steensel, ${ }^{1,2 *}$ M. Vreeburg, ${ }^{2,3}$ J. Engelen, ${ }^{2,4}$ S. Ghesquiere, ${ }^{4}$ A.P.A. Stegmann, ${ }^{4}$ \\ J. Herbergs, ${ }^{2,5}$ J. van Lent, ${ }^{4}$ B. Smeets, ${ }^{2,5}$ and J.H. Vles ${ }^{2,6}$ \\ ${ }^{1}$ Department of Dermatology, University Hospital Maastricht, Maastricht, The Netherlands \\ ${ }^{2}$ GROW Research Institute for Oncology and Developmental Biology, Maastricht, The Netherlands \\ ${ }^{3}$ Department of Clinical Genetics, University Hospital Maastricht, Maastricht, The Netherlands \\ ${ }^{4}$ Department of Cytogenetics, University Hospital Maastricht, Maastricht, The Netherlands \\ ${ }^{5}$ Department of Molecular Genetics, University Hospital Maastricht, Maastricht, The Netherlands \\ ${ }^{6}$ Department of Pediatric Neurology, University Hospital Maastricht, Maastricht, The Netherlands
}

Microdeletions of Xp22.3 are associated with contiguous gene syndromes, the extent and nature of which depend on the genes encompassed by the deletion. Common symptoms include ichthyosis, mental retardation and hypogonadism. We report on a boy with short stature, ichthyosis, severe mental retardation, cortical heterotopias and Dandy-Walker malformation. The latter two abnormalities have so far not been reported in terminal Xp deletions. MLPA showed deletion of SHOX and subsequent analysis using FISH and SNP-arrays revealed that the patient had an $8.41 \mathrm{Mb}$ distal deletion of chromosome region Xp22.31 $\rightarrow$ Xpter. This interval contains several genes whose deletion can partly explain our patient's phenotype. His cortical heterotopias and DWM suggest that a gene involved in brain development may be in the deleted interval, but we found no immediately obvious candidates. Interestingly, further analysis of the family revealed that the patient had inherited his deletion from his mother, who has a mos 46,X,del(X)(p22)/45,X/46, XX karyotype. (c) 2008 Wiley-Liss, Inc.

Key words: ichthyosis; chromosome X; Dandy-Walker; mental retardation; deletion; SNP array; cortical heteroropia

How to cite this article: van Steensel MAM, Vreeburg M, Engelen J, Ghesquiere S, Stegmann APA, Herbergs J, van Lent J, Smeets B, Vles JH. 2008. Contiguous gene syndrome due to a maternally inherited $8.41 \mathrm{Mb}$ distal deletion of chromosome band $\mathrm{Xp22.3}$ in a boy with short stature, ichthyosis, epilepsy, mental retardation, cerebral cortical heterotopias and Dandy-Walker malformation. Am J Med Genet Part A 146A:2944-2949.

\section{INTRODUCTION}

Deletions in males involving Xp22 cause contiguous gene syndromes with highly variable symptoms that depend on the genes encompassed by the deletion. Such syndromes offer rare but valuable opportunities to assign genes to human phenotypes or biological processes. A good example is X-linked Kallmann syndrome, characterized by hypogonadotrophic hypogonadism and anosmia. The causative gene was discovered thanks to the identification of two brothers who had inherited a $3.3 \mathrm{~kb}$ deletion of Xp22.3 from their mother. Mapping the breakpoint subsequently allowed for the identification of the
KAL1 gene [Legouis et al., 1991], which was later found to harbor point mutations in several male

\footnotetext{
Grant sponsor: University Hospital Maastricht; Grant sponsor: GROW Research Institute for Oncology and Developmental Biology; Grant sponsor: Netherlands Organization for Scientific Research ZONMW; Grant number: 907-00-202; Grant sponsor: Barrier Therapeutics NV.

*Correspondence to: Dr. M.A.M. van Steensel, M.D., Ph.D., Department of Dermatology, University Hospital Maastricht, PO Box 5800, 6202 AZ Maastricht, Maastricht, The Netherlands.

E-mail: mauricevansteensel@gmail.com

Published online 16 October 2008 in Wiley InterScience (www.interscience.wiley.com)

DOI 10.1002/ajmg.a.32473
} 
patients with Kallmann syndrome and without deletions [Hardelin et al., 1992].

Thus, the identification of patients with Xp22.3 deletions and previously undescribed clinical features may help to identify novel genes involved in human genetic disorders. Here we describe a 21-year-old Dutch male, with a distal deletion of Xp22.3 that we found by SNP-array and Fluorescent in situ hybridization (FISH) analysis to be $8.4 \mathrm{Mb}$ in size, the second largest reported to date [Melichar et al., 2007]. The patient presented with a complex syndrome featuring, among other symptoms, epilepsy, mental retardation, cortical heterotopias and a Dandy-Walker malformation (DWM). To the best of our knowledge, these structural brain abnormalities have not yet been described in patients with deletions of Xp22.3. Interestingly, we found that the deletion was present in the patient's mother, who had a mos 46,X,del(X)(p22.2)/45,X/46,XX karyotype.

\section{CLINICAL REPORT}

The patient, a 21-year-old male, came to our attention because of severe mental retardation, epilepsy and skin abnormalities. He was born to nonconsanguineous parents of Dutch descent after an uneventful pregnancy. An older brother was healthy and family history was unremarkable. The father was healthy; the mother had a history of surgery for bilateral Madelung deformity. Pelvic disproportion necessitated delivery by caesarean. The child was in breech position. Apgar scores were 8 at $1 \mathrm{~min}$ and 9 at $5 \mathrm{~min}$. At birth he weighed 2,950 $\mathrm{g}$ $(-2 \mathrm{SD})$ and had an OFC of $37 \mathrm{~cm}(+2 \mathrm{SD})$. An ultrasound examination prior to birth had shown a DWM. CT scanning after birth confirmed an internal progressive hydrocephalus and a DWM with hypoplasia of the cerebellum.

In the neonatal period, the patient developed a hydrocephalus, which was treated with a ventriculo-peritoneal shunt. Developmental delay soon became apparent. He first started walking at 3 years of age and did not develop speech until he was 6 years old. When he was 1 year old, a right-sided inguinal hernia was corrected and an orchidectomy performed. Routine karyotyping at that time had showed a normal male karyotype 46,XY. Minor dysmorphic features were noted including brachycephaly, hypertelorism with a depressed nasal bridge and a micrognathia, thought to be partly secondary to the hydrocephalus. From age 3 years, the patient developed staring episodes just after awakening, lasting from a few seconds to several minutes, during which he was unresponsive to external stimuli. Valproic acid was tried at the time but discontinued because it had a sedative effect. The complaint was not followed up at the time. At the age of 15 years old, a shunt revision was complicated by a ventriculitis and an abdominal abscess. Both were successfully managed, and the shunt has since functioned without problems. Growth was delayed ( $<3$ rd centile).

When the patient was 19 years old, he again presented with the staring spells. The spells were associated with eye blinking and bilateral clonic arm movements. Neurological examination at the time showed divergent strabismus and generalized hypotonia without weakness and with normal plantar reflexes. Tactile stimuli evoked a withdrawal response. The patient walked with a broad base and everted feet, although ataxia was not apparent. An EEG showed interictal focal spike and wave activity on the left parietal side. An MRI showed extensive occipital cortical heterotopias and hypoplasia of the corpus callosum in addition to the known DWM (Fig. 1A,B). Treatment with oxycarbamazepine resulted in satisfactory seizure control without significant side effects. During a follow-up visit at the age of 21 years old, the parents asked for help with the patient's dry skin and a dermatologist was consulted. Upon examination, generalized scaling was apparent, most pronounced on the abdomen and extremities. Flexures were not affected. The scales where yellow-brown to white and rhomboidal (Fig. 2A,B) over most of the body except for the face, where they were quite small. Hairs, nails and teeth were normal. The face was distinctive, with some frontal bossing, prominent eyebrows and a sunken nasal bridge (Fig. 2C,D). The nasal tip pointed downwards. In addition, we noted thin lips, a short and protruding philtrum and a wide mouth with downturned corners. Facial, axillary and pubic hair was mostly absent. Genital development was delayed. The eyes were normal except for divergent strabismus. In particular, no cataracts were noted. His height was $150 \mathrm{~cm}$, he weighed $40 \mathrm{~kg}$ and had an OFC of $55.5 \mathrm{~cm}$. There were no Madelung deformities or clear mesomelic limb shortening. The patient's skin abnormalities were diagnosed as consistent with $\mathrm{X}$-linked recessive ichthyosis, although perhaps not entirely typical based on the nature of the scaling. Because of the associated abnormalities, we suspected a contiguous gene
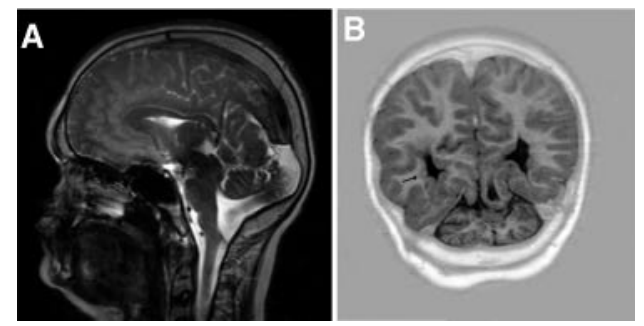

FIG. 1. A: Recent MRI showing Dandy-Walker malformation. B: Extensive (periventricular) cortical heterotopia (arrow). 

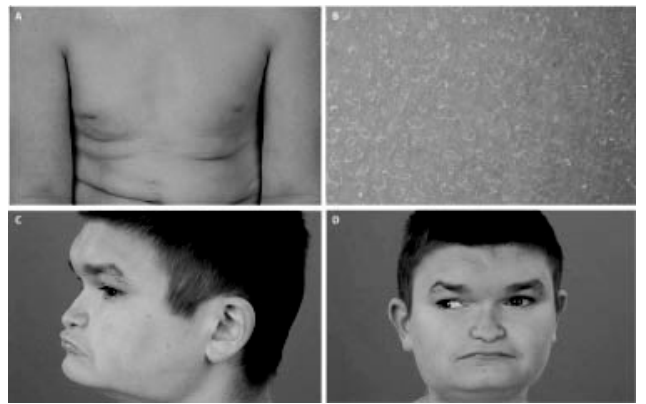

FIG. 2. The patient's phenotype. $\mathbf{A}, \mathbf{B}$ : diffuse off-white to light brown rhomboidal scaling over most of the body. C,D: dysmorphic facies with frontal bossing, flat nasal bridge with downward pointing nose, broad, thin and slightly protruding upper lip. Evident divergent strabismus. [Color figure can be viewed in the online issue, which is available at www.interscience.wiley.com.]

syndrome caused by a deletion in $\mathrm{Xp}$ and initiated appropriate additional investigations.

The parents were also examined and it was noted that the mother, in addition to showing surgical scars resulting from the earlier repair of the Madelung deformity, had a height of $160 \mathrm{~cm}$.

\section{MATERIALS AND METHODS}

\section{Cytogenetics and Molecular Genetics}

Chromosomes were prepared from peripheral blood lymphocyte cultures using the synchronization method of Dutrillaux and Viegas-Pequignot with only minor modifications [Dutrillaux and Viegas-Pequignot, 1981]. Banding was performed by treatment with trypsin followed by Giemsa staining to obtain a GTG-banded pattern. FISH was performed according to Lichter et al. [1988] with the following probes: DXYS129 and 98C2 for chromosome band Xp22.33, 323F16 for chromosome band Xp22.31, 108M6 specific for chromosome band Xp22.2 and the centromeric probe pBamX5. We performed Multiplex Ligation-dependent Probe
Amplification (MLPA) with the primer sets P36b and P70 (specific for the subtelomeric regions of the 22 autosomes and both sex chromosomes) according to the manufacturer's recommendations (MRC Holland, Amsterdam, The Netherlands).

\section{SNP-Array and X-Chromosome Inactivation}

We performed the 250K NspI SNP genotyping array analysis (Affymetrix UK Ltd., High Wycombe, UK) according to the manufacturer's protocol (http:// www.affymetrix.com/auth/support/downloads/ package_inserts/genomewide_snp5_insert.pdf). Briefly, $250 \mathrm{ng}$ of DNA was digested with NspI; adaptors were subsequently ligated, followed by PCR amplification. Next, the PCR product was fragmented, labeled and hybridized to the $250 \mathrm{~K}$ NspI SNP-array. Genotype cells were obtained and analyzed using the Affymetric GTYPE analysis tool embedded in the GeneChip Operating Software (GCOS). For copy number estimation, data were processed using the CNAG_v2.0 tool [Nannya et al., 2005]. The patient's mapping data were analyzed against ten male reference data sets obtained on the same platform using unaffected individuals. $\mathrm{X}$-inactivation was assayed using a standard HUMARA assay as previously described [Allen et al., 1992].

\section{RESULTS}

Metabolic evaluation was performed to rule out multiple sulfatase deficiency. STS activity was zero, but other than that no abnormalities were found. Analysis of 5 GTG-banded metaphases of the patient showed a 46,XY karyotype. However, MLPA showed a decreased peak ratio of the SHOX gene peak (not shown). Subsequent FISH analysis delineated the patients karyotype to 46,XY.ish $\operatorname{del}(\mathrm{X})(\mathrm{p} 22.2)$ (DXYS129-, RP11-98C4-, RP11-323F16-, RP11-108M6+) (see Fig. 3A,B for FISH results).

Based on these results the deletion's size was estimated to be between 7.6 and $9.6 \mathrm{Mb}$. To more
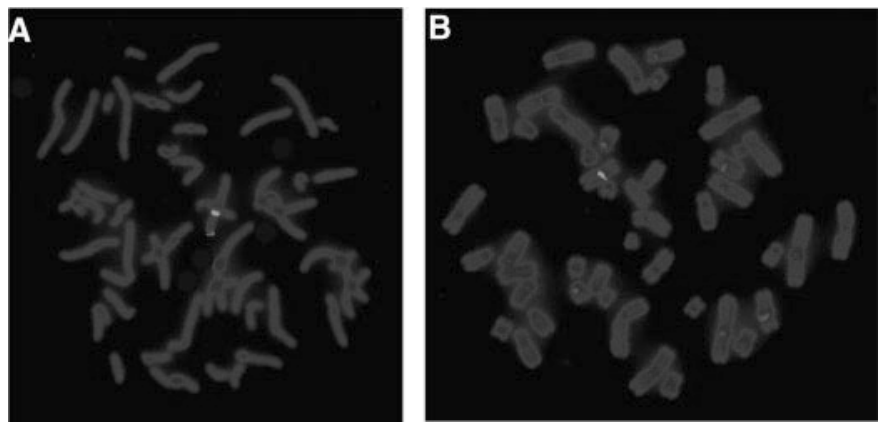

FIG. 3. FISH analysis. A: Two signals obtained with pBamX5 and 108M6. B: Only pBamX5 hydbridizes. [Color figure can be viewed in the online issue, which is available at www.interscience.wiley.com.] 
precisely measure the deletion, SNP-array analysis was performed. The terminal deletion in the short arm of the X-chromosome was called from SNP 4207883 (rs6644970; the most distal Xp SNP present on the array) to SNP 1783429 (rs5934457), corresponding to physical positions 142664 and 8539586 on the NCBI genome Build 36, respectively. The terminal deletion (the pseudo-autosomal region is included in it) therefore totals $8.41 \mathrm{Mb}$ (Fig. 4) with a margin of error of approximately $200 \mathrm{~kb}$. No copy number variants were seen on the other chromosomes.

Analysis of 50 metaphases of peripheral blood lymphocytes of the mother showed loss of one $\mathrm{X}$-chromosome in 18 metaphases. MLPA showed a decreased peak ratio of the SHOX gene peak (not shown). FISH analysis of peripheral blood lymphocytes showed that the mother had an aberrant mosaic 46,XX.ish del (X)(p22.2)(DXYS129-, RP11-98C4-, RP11-323F16-, RP11-108M6+)[32]/45,X[18] karyotype. Additional interphase FISH analysis in buccal smear showed a 46,XX.ish del(X)(p22.2)(DXYS129-, RP11-98C4-, RP11-323F16-, RP11-108M6+)[32]/45, $\mathrm{X}[2] / 46, \mathrm{XX}[25]$ karyotype. Standard karyotyping and FISH analysis in cultured fibroblast cells showed a 46,XX.ish del(X)(p22.2)(DXYS129-, RP11-98C4-, RP11-323F16-, RP11-108M6+)[92]/45,X[7]/46,XX[1] karyotype. The father's karyotype was normal, 46, XY.

\section{DISCUSSION}

We report on a male patient with a distal deletion $\operatorname{del}(\mathrm{X})(\mathrm{p} 22.2)$ that was determined by SNP-array analysis to have a size of $8.41 \mathrm{Mb}$. Intriguingly, the patient inherited the aberrant deletion X-chromosome from his mother, whom we found to have a mosaic 46,X.ish $\operatorname{del}(\mathrm{X})(\mathrm{p} 22.2) /$ 45,X/46, XX karyotype and a subtle concordant phenotype of bilateral Madelung deformity and a height of $160 \mathrm{~cm}$. The presence of a normal female cell line in the mother in several tissues explains both her seemingly normal fertility and why the older brother was unaffected. The mechanism of how this complex mosaic karyotype evolved is unclear and does not readily follow from the pattern of mosaicism. Presumably, two separate genetic events are responsible, with the formation of the deletion $\mathrm{X}$-chromosome as the first event, followed by loss of one X-chromosome in a proportion of cells as the second event. Our patient's deletion is the second largest of Xp22 to ever have been reported. A patient with a $9.6 \mathrm{Mb}$ deletion was described by Melichar et al. [2007]. The authors distinguished six distinct phenotypes in their patient, including ocular albinism resulting from deletion of the OA1 locus. Similarly, our patient has a number of distinct abnormalities that can be explained by his deletion. The ARSE gene, coding for arylsulfatase $\mathrm{E}$ and implicated in $\mathrm{X}$-linked recessive chondrodysplasia punctata (CDPX1, OMIM 302950), was deleted. However, we have seen no cataracts in our patient although some of his facial features, such as the depressed nasal bridge, might be consistent with ARSE deficiency. Epiphyseal stippling was never sought for because at the time when stippling would have been visible a contiguous gene syndrome was not expected. Brachyphalangism and clear mesomelic shortening of the extremities are lacking but seem to be variable in CDPX1 and also in SHOX deficiency. The patient's short stature is well explained by the latter. Madelung deformities are absent. Thus, the sequelae of SHOX deficiency seem to be quite variable, as was previously suggested [Schiller et al., 2000; Ross et al., 2001].

The mental retardation may conceivably be (partly) explained by absence of NLGN4, which codes for neuroligin 4 and has been previously implicated in mental retardation and autism [Jamain et al., 2003]. The ichthyosis, finally, is caused by absence of the STS gene [Bonifas et al., 1987]. Our patient's deletion partly overlaps that of Melichar et al.'s case [2007] but does not extend to the KAL1 gene. Epilepsy has been reported in two brothers

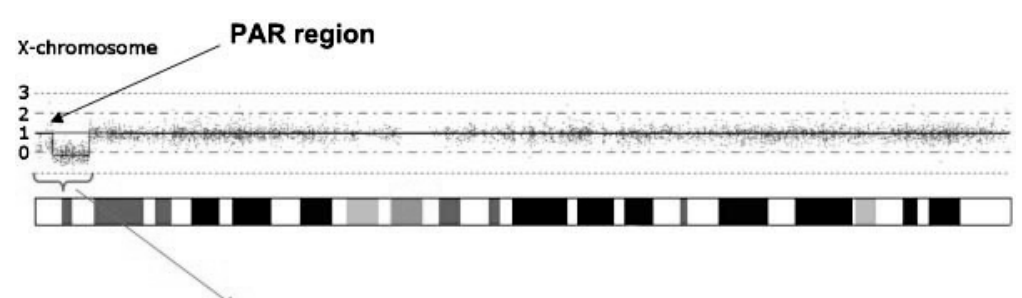

Full terminal deletion incl. PAR

FIG. 4. Copy number analysis in CNAG 2.0. Patient analyzed against 10 unaffected male individuals. HMM parameters of the model were adjusted for the $\mathrm{N}=1$ of the non-autosomal X region. The $\log _{2} \mathrm{AB}$ ratios in the patients X-chromosome compared with sex-matched, unaffected reference individuals are represented as dots in the figure. The straight blue line represents the result of the copy number estimation by the Hidden Markov-model (HMM) in CNAG 2.0 with the parameters adapted to reflect the single copy of the $\mathrm{X}$-chromosome in males. The terminal deletion of the $\mathrm{X}$-chromosome is visible as $\mathrm{n}=0$, while the PAR region of the $\mathrm{Y}$-chromosome adds up to $\mathrm{n}=1$ for the telomere despite the deletion of the homologous $\mathrm{X}$ region. [Color figure can be viewed in the online issue, which is available at www.interscience.wiley.com.] 
with an $\mathrm{Xp} ; \mathrm{Yq}$ translocation that seems to have resulted in a slightly smaller $\mathrm{Xp}$ deletion that removed most of the genes that are absent in our patient [Doherty et al., 2003]. In that report, it is speculated that the epilepsy might be explained by absence of either $N L G N 4$, one of the $V C X$ genes [candidate $M R$ genes, see Fukami et al., 2000], or $A S M T$, coding for a protein involved in melatonin biosynthesis. In view of the awakening spells in our patient, ASMT is a particularly interesting candidate gene because melatonin synthesis is involved in circadian control and melatonin is implicated in the pathogenesis of sleep-related epilepsy [Stewart, 2001]. There are, however, some symptoms that cannot be readily explained from the deletion. To the best of our knowledge, the structural brain abnormalities present in our patient have not been previously described in Xp deletions. It seems logical to assume that one or more genes affecting brain development may be in the region encompassed by the deletion. However, examination of the present physical map of this region (via the UCSC human genome browser, http://genome.ucsc.edu) does not immediately suggest a likely candidate although there are many genes in it whose function in brain development is not yet clear. While the combined absence of NLGN4 and VCX genes might be involved, these genes were also deleted in previously described patients (such as the one described by Melichar et al.) who did not have structural brain defects comparable to our patient. Systematic analysis of the remaining genes without assigned function or associated phenotype turns up no obvious ones that might have a function in the central nervous system and might as such be involved in our patient's brain abnormality. Some ESTs in the area have not yet been assigned to a gene and it is thus possible that there are as yet unidentified genes involved in brain development located in the deleted region. Of note, Melichar et al.'s patient did not have a DWM. However, brain ultrasound examination did show enlarged ventricles but an MRI had not been made. The presence of a DWM can therefore not be ruled out completely and it would thus be of considerable interest to follow up on this particular patient. Enlarged ventricles might represent a "forme fruste" of DWM and thus there might be (a) gene(s) on Xp whose deletion gives rise to posterior fossa malformations. That said, the DWM may have occurred independently. DWM has been reported in association with various chromosomal abnormalities, such as distal deletions of 13q [Alanay et al., 2005], but we found no CNV's on the autosomes that were not present in either parent. We therefore think that it is unlikely that our patient has an independent DWM although we cannot completely rule out the presence of causative microdeletions elsewhere. In conclusion, we report on a patient with an $8.41 \mathrm{Mb}$ distal deletion of Xp. In addition to the symptoms to be expected in such a deletion, our patient has a DWM and extensive cortical heterotopias. Both abnormalities have not been previously described in the context of terminal Xp deletions and might be caused by the deficiency of yet to be identified genes in the deleted region. It would be of considerable interest to examine male patients with DWM for the presence of small deletions in the region we delineate here. SNP-arrays would seem to be the perfect tool for such an undertaking.

\section{ACKNOWLEDGMENTS}

The authors wish to thank the patient and his parents for their cooperation. MvS is supported by the University Hospital Maastricht, the GROW research institute for oncology and developmental biology, the Netherlands Organization for Scientific Research ZONMW grant no. 907-00-202 and Barrier Therapeutics NV.

\section{REFERENCES}

Alanay Y, Aktas D, Utine E, Talim B, Onderoglu L, Caglar M Tuncbilek E. 2005. Is Dandy-Walker malformation associated with "distal $13 q$ deletion syndrome"? Findings in a fetus supporting previous observations. Am J Med Genet Part A 136A: $265-268$

Allen RC, Zoghbi HY, Moseley AB, Rosenblatt HM, Belmont JW. 1992. Methylation of HpaII and HhaI sites near the polymorphic CAG repeat in the human androgen-receptor gene correlates with X chromosome inactivation. Am J Hum Genet 51:1229-1239.

Bonifas JM, Morley BJ, Oakey RE, Kan YW, Epstein EH Jr. 1987. Cloning of a cDNA for steroid sulfatase: Frequent occurrence of gene deletions in patients with recessive $\mathrm{X}$ chromosomelinked ichthyosis. Proc Natl Acad Sci USA 84:9248-9251.

Doherty MJ, Glass IA, Bennett CL, Cotter PD, Watson NF, Mitchell AL, Bird TD, Farrell DF. 2003. An Xp; Yq translocation causing a novel contiguous gene syndrome in brothers with generalized epilepsy, ichthyosis, and attention deficits. Epilepsia 44:1529-1535.

Dutrillaux B, Viegas-Pequignot E. 1981. High resolution R- and G-banding on the same preparation. Hum Genet 57:93-95.

Fukami M, Kirsch S, Schiller S, Richter A, Benes V, Franco B, Muroya K, Rao E, Merker S, Niesler B, Ballabio A, Ansorge W, Ogata T, Rappold GA. 2000. A member of a gene family on $\mathrm{Xp22.3,} \mathrm{VCX-A,} \mathrm{is} \mathrm{deleted} \mathrm{in} \mathrm{patients} \mathrm{with} \mathrm{X-linked} \mathrm{non-}$ specific mental retardation. Am J Hum Genet 67:563-573.

Hardelin J-P, Levilliers J, del Castillo I, Cohen-Salmon M, Legouis R, Blanchard S, Compain S, Bouloux P, Kirk J, Moraine C, Chaussain J-L, Weissenbach J, Petit C. 1992. X chromosomelinked Kallmann syndrome: Stop mutations validate the candidate gene. Proc Natl Acad Sci USA 89: 8190-8194.

Jamain S, Quach H, Betancur C, Rastam M, Colineaux C, Gillberg IC, Soderstrom H, Giros B, Leboyer M, Gillberg C, Bourgeron T. 2003. Mutations of the X-linked genes encoding neuroligins NLGN3 and NLGN4 are associated with autism. Nat Genet $34: 27-29$

Legouis R, Hardelin J-P, Levilliers J, Claverie J-M, Compain S, Wunderle V, Millasseau P, Le Paslier D, Cohen D, Caterina D, Bougueleret L, Delemarre-Van de Waal H, Lutfalla G, Weissenbach J, Petit C. 1991. The candidate gene for the $\mathrm{X}$-linked Kallmann syndrome encodes a protein related to adhesion molecules. Cell 67: 423-435. 


\section{CHAPTER 3}

\section{American Journal of Medical Genetics Part A}

Lichter P, Cremer T, Borden J, Manuelidis L, Ward DC. 1988. Delineation of individual human chromosomes in metaphase and interphase cells by in situ suppression hybridization using recombinant DNA libraries. Hum Genet 80:224-234.

Melichar VO, Guth S, Hellebrand H, Meindl A, von der Hardt K, Kraus C, Trautmann U, Rascher W, Rauch A, Zenker M. 2007. A male infant with a $9.6 \mathrm{Mb}$ terminal Xp deletion including the OA1 locus: Limit of viability of Xp deletions in males. Am J Med Genet Part A 143A:135-141.

Nannya Y, Sanada M, Nakazaki K, Hosoya N, Wang L, Hangaishi A, Kurokawa M, Chiba S, Bailey DK, Kennedy GC, Ogawa S. 2005. A robust algorithm for copy number detection using high-density oligonucleotide single nucleotide polymorphism genotyping arrays. Cancer Res 65:6071-6079.

Ross JL, Scott C Jr, Marttila P, Kowal K, Nass A, Papenhausen P. Abboudi J, Osterman L, Kushner H, Carter P, Ezaki M, Elder F, Wei F, Chen H, Zinn AR. 2001. Phenotypes associated with SHOX deficiency. J Clin Endocrinol Metab 86:5674-5680

Schiller S, Spranger S, Schechinger B, Fukami M, Merker S, Drop SL, Troger J, Knoblauch H, Kunze J, Seidel J, Rappold GA. 2000. Phenotypic variation and genetic heterogeneity in LeriWeill syndrome. Eur J Hum Genet 8:54-62.

Stewart LS. 2001. Endogenous melatonin and epileptogenesis: Facts and hypothesis. Int J Neurosci 107:77-85. 


\title{
Novel EBP gene mutations in Conradi-Hünermann-Happle syndrome
}

\author{
P.M. Steijlen, M. van Geel, M. Vreeburg, ${ }^{\star}$ D. Marcus-Soekarman, ${ }^{\star}$ L.J.M. Spaapen, ${ }^{\star} \dagger$ F.C.M. Castelijns, $\neq$ \\ M. Willemsen§ and M.A.M. van Steensel
}

Departments of Dermatology, *Clinical Genetics and †Clinical Chemistry, University Hospital Maastricht, PO Box 5800, 6202 AZ Maastricht, the Netherlands †Department of Dermatology, Elkerlyck Hospital Helmond, the Netherlands

$\S$ Department of Pediatric Neurology, University Medical Center Nijmegen, the Netherlands

\section{Summary}

\section{Correspondence}

Maurice A.M. van Steensel.

E-mail: mvst@sder.azm.nl

\section{Accepted for publication}

29 July 2007

\section{Key words}

CDPX2, Conradi-Hünermann-Happle, EBP, mosaicism, $\mathrm{X}$-inactivation

Conflicts of interest

None declared.
Background Conradi-Hünermann-Happle syndrome [X-linked dominant chondrodysplasia punctata type 2 (CDPX2); MIM no. 302960] is an X-linked dominant disorder of cholesterol metabolism that causes a wide spectrum of skeletal abnormalities and linear ichthyosiform skin lesions. Mosaicism is probably responsible for the variability of the phenotype.

Objectives To describe new mutations in patients with variable manifestations of the disease.

Methods We studied three patients with CDPX2. We performed mutation analysis of the EBP (formerly known as CDPX2) gene and gas chromatography-mass spectroscopy on serum of two patients.

Results We found two novel ( $3 \mathrm{G} \rightarrow \mathrm{T}$ and 419-422delTTCT) and one known mutation in the EBP gene. We demonstrated the presence of increased levels of dehydrocholesterol and 8(9)-cholestenol in the two patients with new mutations, confirming the diagnosis of CDPX2 and strongly suggesting that the mutations are indeed pathogenic. One patient had a very mild phenotype, presenting with linear alopecia and a mild symmetrical epiphyseal dysplasia. X-inactivation studies in peripheral blood of all patients showed skewing in only the most severely affected patient.

Conclusions The strong phenotypic variability in our patients suggests that there is no clear genotype-phenotype correlation.
X-linked dominant chondrodysplasia punctata type 2 [CDPX2 (Conradi-Hünermann-Happle syndrome); MIM no. 302960] is caused by mutations in the EBP (emopamil-binding protein) gene coding for $3 \beta$-hydroxysteroid- $\Delta^{8}, \Delta^{7}$-isomerase, a central component of cholesterol biosynthesis that catalyses the conversion of 8(9)-cholestenol into lathosterol (5- $\boldsymbol{\alpha}$-cholest-7en-3- $\beta$-ol to 5 - $\alpha$-cholest- 8 -en-3- $\beta$-ol). ${ }^{1}$ Dysfunction of the enzyme leads to increased levels of 8 -dehydrocholesterol and, typically, to the presence of 8(9)-cholestenol in serum. These cholesterol precursors provide an indirect indication of the metabolic defect and can thus be used to confirm functional relevance of any EBP mutation found. ${ }^{2,3}$ Directly after birth, patients can be erythrodermic and show linear hyperkeratotic skin lesions. During the first few weeks of life, these develop into linear and whorled atrophic and hypopigmented skin lesions. Linear alopecia, sectoral cataracts and skeletal abnormalities such as rhizomelic limb shortening, short stature, vertebral anomalies and facial defects are also found. ${ }^{4}$ Stippling of epiphyses can be observed in children suffering from CDPX2 but also in several other disorders including the autosomal dominant, recessive and X-linked recessive forms of chondrodysplasia punctata. Mental retardation has also been reported. As expected, CDPX2 shares characteristics with other disorders associated with defects in the cholesterol synthesis pathways, notably CHILD (congenital hemidysplasia with ichthyosiform erythroderma and limb defects; MIM no. 308050) and Smith-Lemli-Opitz syndromes (MIM no. 270400). Several different mutations have been described in patients with phenotypes that show considerable variation in severity. The variation is not a function of the particular mutation but is thought to result from genetic mosaicism caused by X-inactivation. ${ }^{5-7}$ There has been a report of a single gene mosaicism in an affected boy, ${ }^{8}$ confirming the notion that CDPX2 can only exist in a mosaic state. In conflict with this assertion, a nonmosaic mutation (L18P) was described in a boy with what was called a 'severe atypical phenotype'. ${ }^{9}$ However, this case 
2 Novel EBP gene mutations in Conradi-Hünermann-Happle syndrome, P.M. Steijlen et al.

is doubtful as no stippling of the epiphyses or shortening of tubular bones was seen. The facial phenotype is in our view not typical either, an observation shared by the authors themselves. 8(9)-Cholestenol was increased in the patient and his mother, although not to an extreme degree. Thus, we agree with Happle ${ }^{10}$ that L18P is a hypomorphic allele not associated with CDPX2.

We report three female patients with CDPX2, two of whom have novel mutations in EBP. Their phenotypes range from very mild to quite severe. A clear genotype-phenotype correlation does not seem to be present. X-inactivation patterns did not correlate with disease severity.

\section{Materials and methods}

Informed consent was obtained from the parents in all cases. DNA was isolated from peripheral blood leucocytes as previously described. ${ }^{11}$ The EBP gene has four coding exons that were amplified using the primers and conditions listed in Table 1 . The polymerase chain reaction (PCR) products were subjected to direct sequencing using the PCR primers. Sequences were assembled using the Phred-Phrap-Consed software package. ${ }^{12-14}$ Mutation M1I was screened in 100 healthy controls by NlaIII (New England Biolabs, Frankfurt am Main, Germany) restriction analysis, while mutation 419-422delTTCT was tested on controls by sizing of a fluorescently labelled PCR fragment on a ABI377 DNA sequencer (Applied Biosystems, Foster City, CA, U.S.A.).

For gas chromatography-mass spectrometric (GC-MS) analysis, fresh plasma was obtained and stored at $-80{ }^{\circ} \mathrm{C}$ prior to analysis. Denaturing high-performance liquid chromatography (DHPLC) analysis was performed in patients 2 and 3 as previously described. ${ }^{2}$

$\mathrm{X}$-inactivation studies were performed on peripheral blood leucocytes in all three patients. X-inactivation at the androgen receptor locus (HUMARA) was examined as previously described. ${ }^{15}$

\section{Patients}

Patient 1 is a 6-year-old girl of Dutch descent who presented for evaluation of linear scaling skin lesions and an infected

Table 1 EBP polymerase chain reaction (PCR) and sequence primers

\begin{tabular}{lll}
\hline $\begin{array}{l}\text { Primer } \\
\text { name }\end{array}$ & Sequence $\left(5^{\prime} \rightarrow 3^{\prime}\right)$ & $\begin{array}{l}\text { PCR product } \\
\text { size }(\mathrm{bp})\end{array}$ \\
\hline EBP2Fa & TGGTAAATTCGGTCCATTTACATTTC & 533 \\
EBP2R & GGTAAACATGCAAGCCGATCC & \\
EBP2F & TGCCTATACACACGCAGCCATC & $\begin{array}{c}\text { Sequence } \\
\text { primer }\end{array}$ \\
& & 521 \\
EBP3F & GGAAGCAGACGCATGGGAAG & \\
EBP4R & TGGAAGGGCACCGTTGAGAG & 616 \\
EBP5F & TGATGACTTGGAAAGTGCTTTGG & \\
EBP5R & TCATAGCGCATCTCTGGGGTTAG & \\
\hline & \multicolumn{2}{c}{}
\end{tabular}

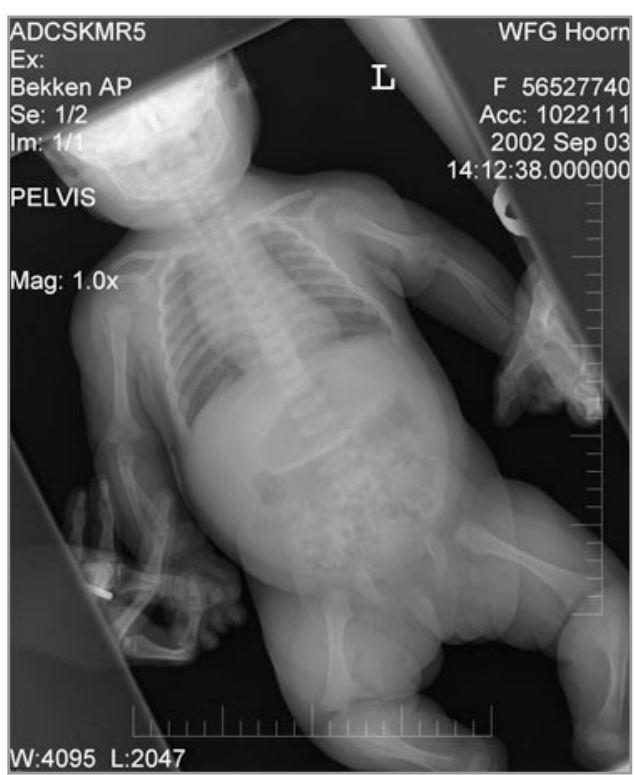

Fig 1. Patient 1 with clear asymmetrical rhizomelic shortening of the extremities.

haemangioma on the upper back. At birth, she had been erythrodermic and an 'ichthyosis' had been diagnosed at the time. In the weeks after birth, the erythroderma disappeared, as did most of the scaling. The haemangioma was not visible at birth but first appeared a few days afterwards, growing rapidly. When we examined her at age 3 months, we saw atrophic hypopigmented linear skin lesions following the lines of Blaschko. Fine white scaling was present in several lesions. The right leg appeared to be slightly shorter than the left and the left upper arm shorter than the right, with the shortening limited to the femur and humerus (rhizomelic). X-ray examination of the skeleton confirmed the clinical impression of rhizomelic shortening (Fig. 1). The haemangioma on the back was ulcerating and infected with Staphylococcus aureus. It was treated with oral amoxicillin, with excellent clinical result. Upon revision several months later, the shortening of the right femur was more pronounced. The haemangioma was no longer ulcerated and had regressed. We diagnosed the patient with CDPX2.

Patient 2, a 12-year-old girl of Iraqi descent, presented to our department for the evaluation of life-long patchy alopecia of the scalp. She was short for her age but had otherwise developed normally. No other family members were affected. The parents denied consanguinity. An older sister was not affected. According to the parents, the patient had been born with normal skin.

Upon examination, we noted subtle atrophic linear skin lesions mostly on the extremities following a type I Blaschko pattern (Fig. 2). On the scalp, a linear hairless lesion was 
Fig 2. Upper arms of patient 2 with subtle hypopigmented streaks following the lines of Blaschko.

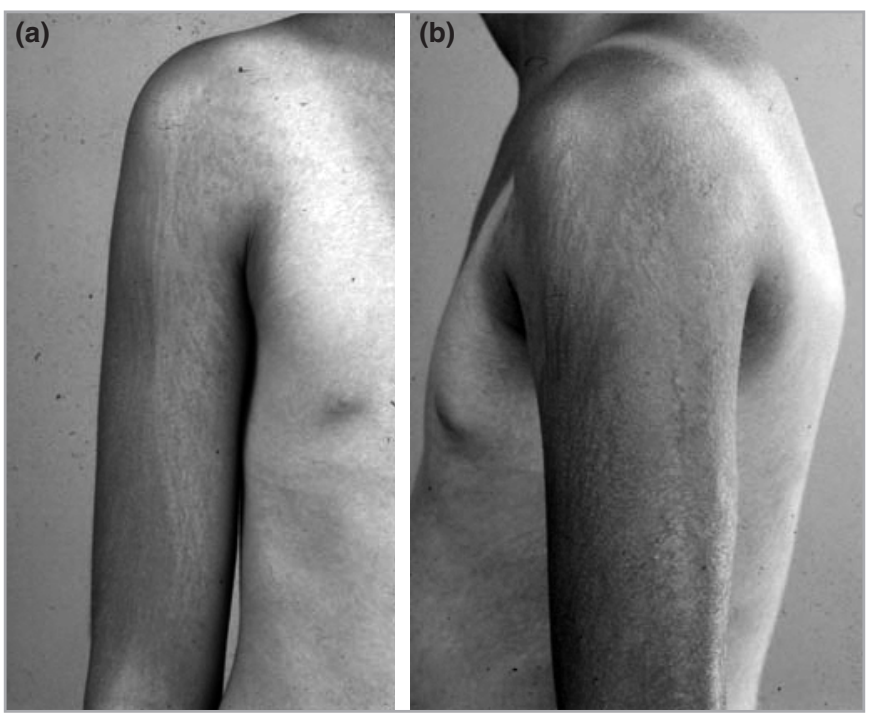

present extending from the vertex to the occiput. There were no overt asymmetries or dysmorphic features. Her height was $150 \mathrm{~cm}$. Mid-parental height was used to predict normal height, as growth curves for Middle Eastern children are not available; it was calculated to be $1.65 \mathrm{~m}$. X-ray examination of both upper legs showed small, slightly deformed, capital epiphyses, an observation which the radiologist deemed consistent with having had 'epiphyseal dysplasia' in the past. Based on the skin abnormalities and the skeletal abnormalities we considered a diagnosis of CDPX2.

Patient 3 was born with erythroderma and linear ichthyosiform skin lesions (Fig. 3). The consultant dermatologist suspected CDPX2 immediately and referred the patient for confirmation of the diagnosis. Upon examination, we saw linear hyperkeratotic, slightly erythematous, skin lesions on the thorax and both arms. The nasal bridge appeared slightly sunken. Other abnormalities were not evident at the time, although clinical revision after 2 months showed that the patient was developing a pronounced scoliosis.

A skeletal survey showed several abnormalities consistent with the diagnosis of CDPX2. In particular, there were thoracic hemivertebrae (Fig. 4) and epiphyseal stippling with asymmetric rhizomelic shortening of the lower extremities. A magnetic resonance image of the brain was performed but did not show clear abnormalities.

\section{Mutation analysis}

In patient 1 , mutation analysis by direct sequencing of the EBP gene showed a $184 \mathrm{C} \rightarrow \mathrm{T}$ mutation in exon 2, leading to a R62W substitution in EBP. This mutation has been previously described. ${ }^{16}$

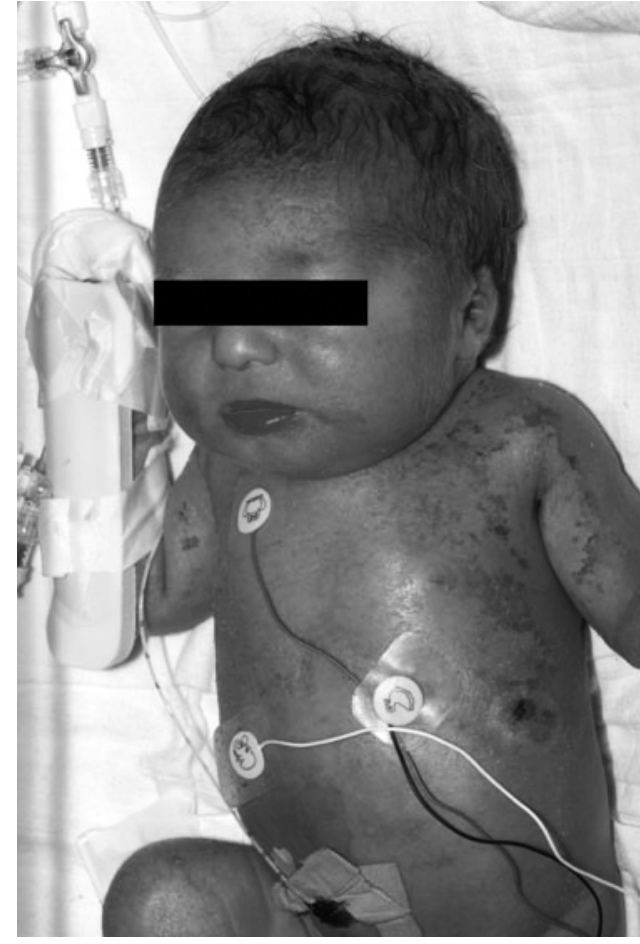

Fig 3. Neonatal presentation of X-linked dominant chondrodysplasia punctata type 2 with erythroderma and linear ichthyosiform skin lesions in patient 3 . 


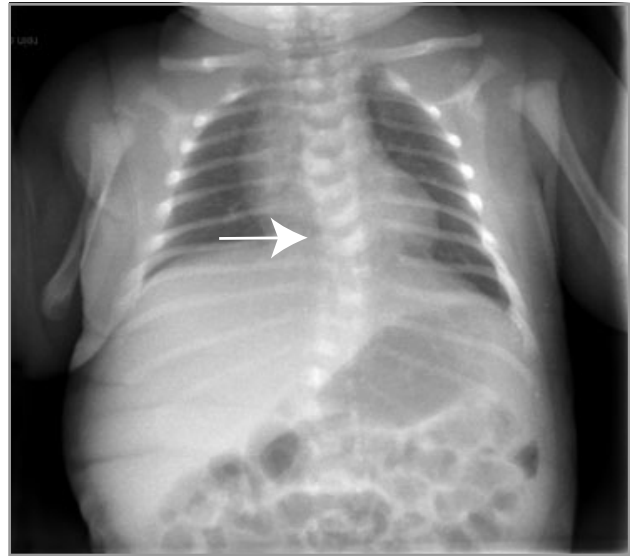

Fig 4. A severe left-convex scoliosis caused by thoracic hemivertebrae in patient 3 (arrow).

Patient 2 had a heterozygous $G$ to $T$ transversion of the third nucleotide of the initiation codon (ATG $\rightarrow$ ATT). Patient 3 was found to have a 4-bp deletion (419-422delTTCT) in the EBP gene, leading to a frameshift and premature stop in the protein (F140fsX166). The latter two mutations have not been described previously. None of the mutations were detected in 100 unrelated healthy controls.

Gas chromatographic examination of fresh plasma was performed in patients 2 and 3, showing increased levels of 8-dehydrocholesterol as well as the presence of 8(9)-cholestenol, thus confirming the functional relevance of the mutations found. X-inactivation studies were performed in all three patients and showed significant skewing only in patient 3 , where more than $90 \%$ use of one allele was demonstrated.

\section{Discussion}

In three patients with widely varying manifestations of CDPX2 we have found two novel and one known mutation in the EBP gene. By GC-MS analysis of plasma sterols ${ }^{2}$ in the two patients with novel mutations, we confirmed the diagnosis. The abnormal sterol levels also strongly suggest functional relevance of the new mutations. The one patient in whom GC-MS was not performed had a classical phenotype with a known mutation and thus, chromatography was not deemed necessary. The surprisingly mild phenotype in the patient with the start codon mutation can in our view best be explained by functional mosaicism. ${ }^{5,7}$ Alternatively, an alternative in-frame initiation codon may explain the mild phenotype. ${ }^{17}$ However, none are available upstream of EBP exon 1 and a putative downstream alternative initiation codon in exon 4 would eliminate more than half of the EBP protein, excluding this explanation for the mild phenotype. If the nature of the mutations were important, abolition of the translation start site should be expected to lead to a severe phenotype. We suggest that this observation can be explained by assuming functional mosaicism. ${ }^{7}$ The other patients, 1 and 3, had more typical manifestations of CDPX2. Surprisingly, but in line with previous findings, ${ }^{18}$ we found no evidence for skewing of X-inactivation in two of our patients (patients 1 and 2). In patient 2, with her mild phenotype, it might be expected that she should show skewed X-inactivation. That we found no evidence for this assumption can be explained in two ways. Either the pattern of X-inactivation strongly varies between tissues, or the extent of mosaicism has no influence on the severity of the phenotype. The latter explanation is untenable in view of previous reports on X-linked dominant disorders. ${ }^{7}$ With regard to the former, although $\mathrm{X}$-inactivation patterns in different tissues are correlated somewhat, they vary strongly. ${ }^{19}$ Therefore, we think that our findings reflect tissue heterogeneity in the pattern of X-inactivation. Confirming this is quite difficult, as affected skin cells tend to disappear over time as a result of secondary selection processes and the sampling of other tissues is for obvious ethical reasons often not possible. Thus, absence of skewing in peripheral blood leucocytes does not equal absence of an $\mathrm{X}$-linked dominant disorder. Its presence is not correlated with the severity of the disease. From a purely clinical point of view, the presentation of patient 2 is most interesting. She came to our attention because of the linear alopecia that was considered as cosmetically unacceptable. The other skin lesions had never been noticed by the parents, not even directly after birth although that may seem unlikely in retrospect. However, the skin lesions that we found were quite subtle and could easily be overlooked. Hence, it seems appropriate to suggest that the presence of linear alopecia should alert clinicians to the possibility that it is caused by an X-linked dominant ectodermal dysplasia. In the presence of atrophic skin lesions, the diagnoses to be entertained are CDPX2, incontinentia pigmenti, focal dermal hypoplasia and MIDAS/MLS (microphthalmia, dermal aplasia and sclerocornea/microphthalmia and linear skin defects). ${ }^{7}$ A careful history and physical examination will usually allow a distinction, but chromatography and mutation analysis are required for a definitive diagnosis.

\section{Acknowledgments}

M. van S. is supported by grants from Barrier Therapeutics NV, the University Hospital Maastricht and the Netherlands Organization for Scientific Research (ZONMW grant 907-00-202).

\section{References}

1 Derry JM, Gormally E, Means GD et al. Mutations in a delta 8-delta 7 sterol isomerase in the tattered mouse and X-linked dominant chondrodysplasia punctata. Nat Genet 1999; 22:286-90.

2 Has C, Seedorf U, Kannenberg F et al. Gas chromatography-mass spectrometry and molecular genetic studies in families with the Conradi-Hunermann-Happle syndrome. J Invest Dermatol 2002; 118:851-8.

3 DiPreta EA, Smith KJ, Skelton H. Cholesterol metabolism defect associated with Conradi-Hunerman-Happle syndrome. Int J Dermatol $2000 ; 39: 846-50$. 
DISORDERS INVOLVING THE X-CHROMOSOME

Novel EBP gene mutations in Conradi-Hünermann-Happle syndrome, P.M. Steijlen et al. $\mathbf{5}$

4 Herman GE. Disorders of cholesterol biosynthesis: prototypic metabolic malformation syndromes. Hum Mol Genet 2003; 12(Spec No 1): R75-88.

5 Feldmeyer L, Mevorah B, Grzeschik $\mathrm{KH}$ et al. Clinical variation in $\mathrm{X}$-linked dominant chondrodysplasia punctata (X-linked dominant ichthyosis). Br J Dermatol 2006; 154:766-9.

6 Happle R, Matthiass HH, Macher E. Sex-linked chondrodysplasia punctata? Clin Genet 1977; 11:73-6.

7 Happle R. X-chromosome inactivation: role in skin disease expression. Acta Paediatr Suppl 2006; 95:16-23.

8 Aughton DJ, Kelley RI, Metzenberg A et al. X-linked dominant chondrodysplasia punctata (CDPX2) caused by single gene mosaicism in a male. Am J Med Genet 2003; 116:255-60.

9 Milunsky JM, Maher TA, Metzenberg AB. Molecular, biochemical, and phenotypic analysis of a hemizygous male with a severe atypical phenotype for X-linked dominant Conradi-Hunermann-Happle syndrome and a mutation in EBP. Am J Med Genet A 2003; 116:24954.

10 Happle R. Hypomorphic alleles within the EBP gene cause a phenotype quite different from Conradi-Hunermann-Happle syndrome. [Comment, Letter.] Am J Med Genet A 2003; 122:279-80.

11 Miller SA, Dykes DD, Polesky HF. A simple salting out procedure for extracting DNA from human nucleated cells. Nucleic Acids Res 1988; 16:1215.
12 Gordon D, Abajian C, Green P. Consed: a graphical tool for sequence finishing. Genome Res 1998; 8:195-202.

13 Ewing B, Green P. Base-calling of automated sequencer traces using phred. II. Error probabilities. Genome Res 1998; 8:186-94.

14 Ewing B, Hillier L, Wendl MC et al. Base-calling of automated sequencer traces using phred. I. Accuracy assessment. Genome Res 1998; 8:175-85.

15 Allen RC, Zoghbi HY, Moseley AB et al. Methylation of HpaII and HhaI sites near the polymorphic CAG repeat in the human androgen-receptor gene correlates with $\mathrm{X}$ chromosome inactivation. Am J Hum Genet 1992; 51:1229-39.

16 Herman GE, Kelley RI, Pureza V et al. Characterization of mutations in 22 females with X-linked dominant chondrodysplasia punctata (Happle syndrome). Genet Med 2002; 4:434-8.

17 Puel A, Reichenbach J, Bustamante J et al. The NEMO mutation creating the most-upstream premature stop codon is hypomorphic because of a reinitiation of translation. Am J Hum Genet 2006; 78:691-701

18 Ikegawa S, Ohashi H, Ogata T et al. Novel and recurrent EBP mutations in X-linked dominant chondrodysplasia punctata. Am J Med Genet 2000; 94:300-5.

19 Sharp A, Robinson D, Jacobs P. Age- and tissue-specific variation of X chromosome inactivation ratios in normal women. Hum Genet 2000; 107:343-9. 

CHAPTER 4

\section{Mosaicism}


CHAPTER 4 
Genetic mosaicism is defined as the existence of at least two genetically distinct cell populations within one individual. Mosaic presence of monogenic or chromosomal disorders is visible on the body surface due to expression in patterns like Blaschko's lines (Figure 4.1). Recognizing such patterns enables one to make a diagnosis "à vue". The review for paediatricians in this chapter discusses several forms of mosaicism and its origin(1).
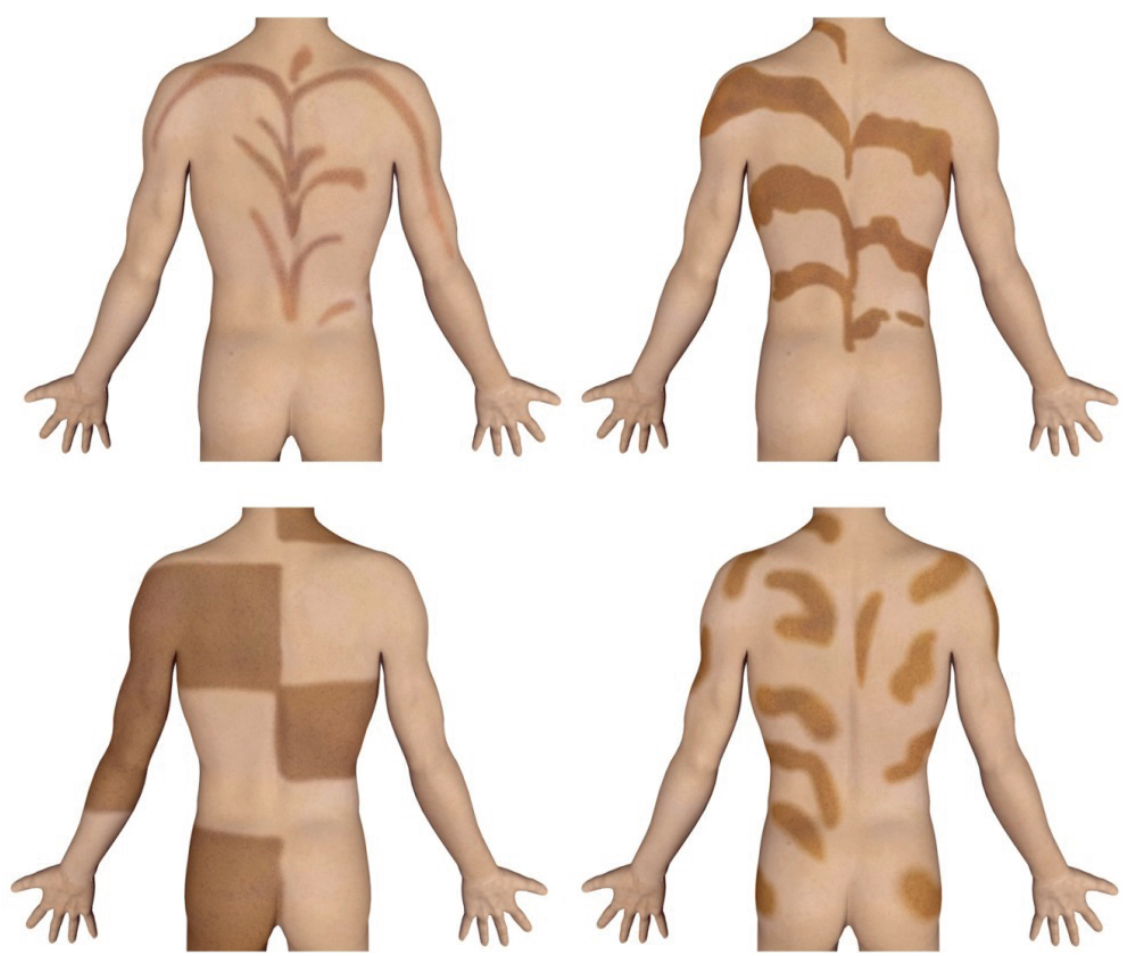

Figure 4.1. Patterns of mosaicism in the skin according to Blaschko's lines.

Type 1a : linear

Type $1 \mathrm{~b}$ : broad linear

Type 2 : lateralization or checkerboard pattern

Type 3: phylloid (leaf-like) pattern

In the cohort of 409 patients, 30 patients with cutaneous manifestations of a mosaic disorder were present. X-linked conditions are excluded and form a separate subgroup as described in chapter 3. A known diagnosis was defined as a clinical diagnosis (according to the state of the art and/or published criteria) with or without a confirmation using laboratory techniques (DNA-, metabolic or cytogenetic analysis). 27 patients fulfilled this criterium; their characteristics are shown in table 4.1. 3 patients were suspected to have a disorder involving mosaicism, but no definite diagnosis has been made yet. 
Table 4.1. Characteristics of 27 patients with a known patterns of mosaicism.

\begin{tabular}{lcc}
\hline & Male : Female & Total \\
\hline Skin pigment mosaicism/linear and whorled hyperpigmentation & 11 \\
Vascular malformations and deregulated growth ${ }^{\mathrm{a}}$ & $2 \mathrm{M}: 9 \mathrm{~F}$ & 4 \\
Twin spotting & $0 \mathrm{M}: 4 \mathrm{~F}$ & 2 \\
Known mosaicisms & $1 \mathrm{M}: 1 \mathrm{~F}$ & 10 \\
- epidermal nevus & & \\
- macrodystrophia lipomatosa & $2 \mathrm{M}: 2 \mathrm{~F}$ \\
- OculoAuriculoVertebralSpectrum (Goldenhar spectrum) & $0 \mathrm{M}: 1 \mathrm{~F}$ \\
- Hyperkeratotic epidermal nevus (mosaic KID syndrome) & $0 \mathrm{M}: 1 \mathrm{~F}$ \\
- Linear sebaceous nevus syndrome & $1 \mathrm{M}: 0 \mathrm{~F}$ \\
Total & $3 \mathrm{M}: 0 \mathrm{~F}$ & \\
\hline
\end{tabular}

a As classified by Oduber et al, 2011(2)

b1 case of Becker nevus syndrome included

In 3 patients ( 1 girl and 2 boys) no fitting diagnosis could be made. The girl and one of the boys had skin manifestations following Blaschko's lines and asymmetric involvement of the skeleton, including polydactyly and short stature. The other boy was thought to have a mosaic disorder because of a situs inversus with an unilateral pre-axial polydactyly of one hand and a non-Blaschkoid pattern of alopecia of the scalp. The case report about macrodystrophia lipomatosa(3) serves to illustrate mosaicism as found in our cohort.

\section{References}

1. Vreeburg M, van Steensel MA. Genodermatoses caused by genetic mosaicism. European journal of pediatrics. 2012 Dec;171(12):1725-35. PubMed PMID: 23114847.

2. Oduber CE, van der Horst CM, Sillevis Smitt JH, Smeulders MJ, Mendiratta V, Harper JI, et al. A proposal for classification of entities combining vascular malformations and deregulated growth. European journal of medical genetics. 2011 May-Jun;54(3):262-71. PubMed PMID: 21356335.

3. Verstraeten VL, Vreeburg M,Dremmen, MH, Stadler AA, Sobczak, C, de Die-Smulders CEM, van Steensel MA. Macrodystrophia lipomatosa. Nederlands Tijdschrift voor Dermatologie en Venerologie. 2012;22(6):124-8. 


\title{
Genodermatoses caused by genetic mosaicism
}

\author{
M. Vreeburg • M. A. M. van Steensel
}

Received: 28 August 2012 /Accepted: 2 October 2012

(C) Springer-Verlag Berlin Heidelberg 2012

\begin{abstract}
Genetic mosaicism is defined as the existence of at least two genetically distinct cell populations within one individual. Mosaic presentation of genetic disorders is common and is often particularly obvious in the skin, because there it will generate recognizable patterns. Recognizing those can frequently assist in establishing a diagnosis. In this review, we discuss the mechanisms that give rise to genetic mosaicism. We describe its most frequent cutaneous manifestations that are relevant to paediatric practice. While most mosaic genetic diseases are rare, it is important to recognize them so that patients and parents may receive appropriate genetic counselling. Moreover, recent developments are now resulting in novel, targeted treatments for such disorders that promise to considerably improve patients' lives.
\end{abstract}

Keywords Genetic mosaicism · X-linked · Lethal gene · Blaschko line

\section{Somatic mosaicism}

The Online Mendelian Inheritance in Man database (http:// www.ncbi.nlm.nih.gov/omim) lists about 1,200 genetic

\footnotetext{
M. Vreeburg · M. A. M. van Steensel

Department of Clinical Genetics, GROW School for Oncology and Developmental Biology, Maastricht University Medical Center, Maastricht, The Netherlands

M. A. M. van Steensel

Department of Dermatology, GROW School for Oncology and Developmental Biology, Maastricht University Medical Center, Maastricht, The Netherlands

M. A. M. van Steensel $(\bowtie)$

Departments of Dermatology and Clinical Genetics, Maastricht

University Medical Center,

Maastricht, The Netherlands

e-mail: mauricevansteensel@gmail.com
}

diseases with cutaneous manifestations or genodermatoses. This number is still increasing. The majority of genodermatoses are monogenic, i.e., caused by mutations in the germ line of a single gene. However, a significant minority is the result not of germ line mutations, but of a somatic mutation that was acquired during embryonic development. In this scenario, a single cell in the developing organism acquires a genetic change. This mutation will then affect the cell's progeny, but not the rest of the embryo. Thus, a genetic mosaic is defined as the presence of two or more genetically distinct clonal cell populations within one individual [37]. It must be distinguished from chimaerism, which is the merger of two genetically distinct individuals into a single organism [92]. Mosaicism acquired during embryogenesis will give rise to recognizable malformation patterns, which are the subjects of the present review.

The mutational events causing genetic mosaicism include point mutations, deletions, or insertions affecting a single gene, chromosomal abnormalities including numerical aberrations, deletions, recombinations and other rearrangements, and gene silencing. The activity of retrotransposons, which are mobile genetic elements, has also been proposed as a cause of cutaneous somatic mosaicism [38]. This mechanism has been shown to be active in the human brain [3], but evidence of it happening in the skin has yet to be provided.

A phenomenon well known from plant and fruit fly genetics, mosaicism in humans was ignored until the late 1980s, when the German dermatologist Rudolf Happle realized that the concept could be applied to hitherto poorly understood congenital and/or inherited disorders that affected only parts of the skin and other organs, the cutaneous lesions following curious linear or rectangular patterns (Fig. 1). These had already been presented by the Viennese dermatologist Alfred Blaschko in 1901 at the 7th Congress of the German Dermatologic Society in Breslau [6]. In the 1920s, the dermatologist Hermann Werner Siemens again 
reported their occurrence in young females [26, 80]. Unfortunately, the scientific community did not notice these reports, until Happle rediscovered them. The lines are now named after Alfred Blaschko to honour his early observations. We do not know for certain what they represent; the most plausible explanation is that they reflect migration paths that keratinocytes follow during embryonic development.

Blaschko himself confused his lines with dermatomes. This still happens and can result in misdiagnosis. Further confusion can arise from the fact that skin disorders, which manifest according to mosaic patterns, are often said to have a "segmental" distribution. However, a segment can also be an anatomic unit, which does not equate a Blaschko line and does not necessarily coincide with a developmental unit [14].

Mosaic disorders from their nature can have extremely variable clinical presentations. If the causative genetic event occurs early in embryogenesis, when an affected cell can be expected to have many offspring, the resulting phenotype will be more severe than when a mutation occurs late in embryogenesis, in a cell that will give rise only to a small skin patch. Diagnosis can therefore be quite challenging and it is often helpful, when dealing with suspected mosaic phenotypes, to consult specialised centres with multidisciplinary teams.

\section{Somatic mosaicism and the lethal gene theory}

Disorders exist that manifest only in mosaic form. Happle suggested that this is a consequence of them being caused by genetic defects that would be lethal if the entire organism were affected [30]. A classic example is the Proteus syndrome, which is caused by activating mutations of the AKT1 protein [64]. These cause mTOR activation and thence deregulated growth of affected body parts [10]. Affected people survive because the $A K T 1$ mutations are present in a mosaic - if all body cells were affected the result would be lethality. The same applies to McCune-Albright syndrome, where activating GNAS mutations are found exclusively in affected tissues [89]. Other overgrowth disorders such as Klippel-Trenaunay syndrome [74] likely also fall within this category.

\section{Functional mosaicism}

In females, one of the two $\mathrm{X}$ chromosomes is inactivated early in embryogenesis. This process is also known as Lyonization. Inactivation is essentially random. Thus, if one $\mathrm{X}$ chromosome carries a gene with a dominant mutation, random $\mathrm{X}$-inactivation will cause the genetic defect to become manifest in a mosaic pattern. In
Fig. 1 Patterns in Blaschko lines. Type 1: a linear lines, b broad linear lines. Type 2: lateralization or checkerboard pattern. Type 3: phylloid pattern

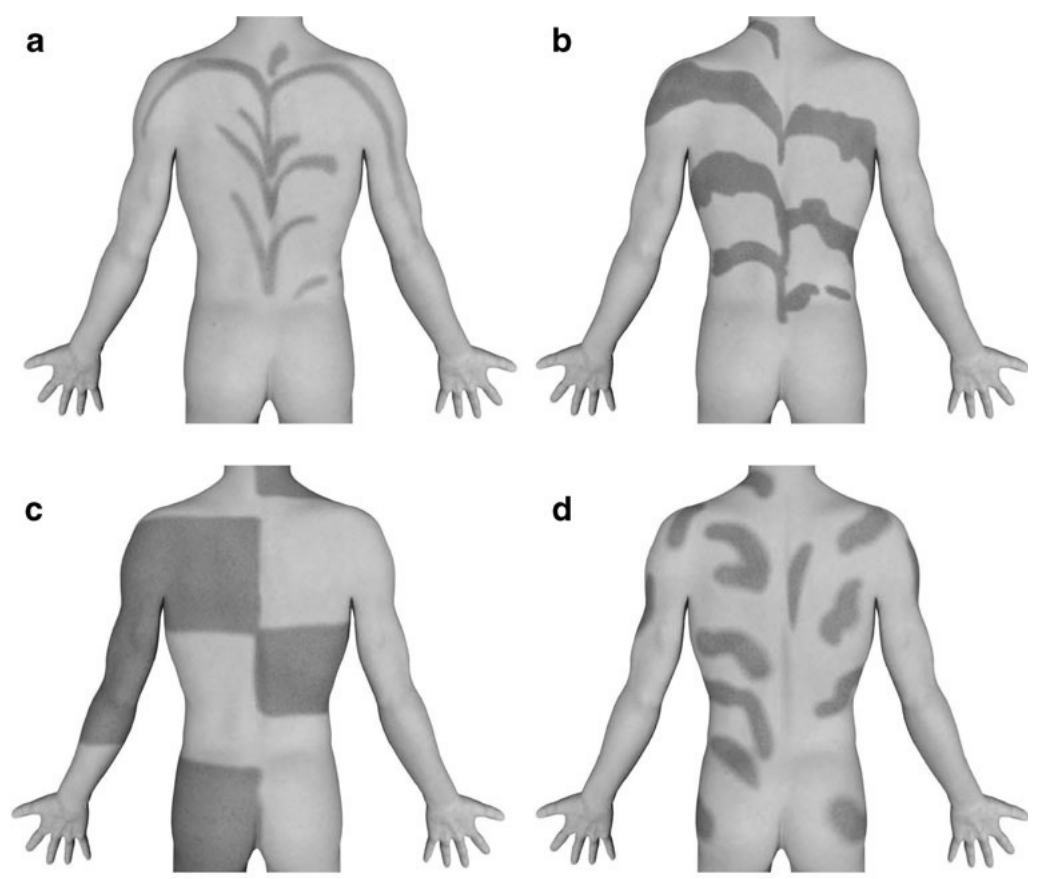


females carrying an inherited X-linked dominant trait, this pattern follows Blaschko lines, similar to somatic mosaics due to post-zygotic mutations [41] [29]. In both cases, the Blaschko lines likely reflect the embryonic migration patterns of affected cells. Mosaic expression of X-linked dominant disorders is referred to as functional mosaicism, because it results from a genetic modification rather than from a mutation. X-linked dominant inherited disorders typically are lethal to males, with exceptions due to chromosome abnormalities [23], somatic mosaicism [88], or hypomorphic alleles [70]. Xlinked recessive diseases will generally not manifest in females; if they do, with very rare exceptions the symptoms will also be restricted to Blaschko lines. For example, female carriers of X-linked recessive hypohidrotic ectodermal dysplasia can present with linear hypotrichosis or selective anodontia [52].

\section{Twin spotting}

Sometimes, a single event affecting one cell can leave its daughters with two distinct genetic defects. Mitotic recombination can cause hitherto hidden gene defects to become manifest due to loss of heterozygosity [35], as illustrated in Fig. 2. If this sequence of events affects a single gene locus, the result is an allelic twin spot, in which two adjacent areas of the body show opposite defects [32]. For example, a capillary malformation lying next to a so-called anemic nevus [33] (Fig. 3). If different loci are involved, a non-allelic twin spot ensues, in which case two neighbouring areas show different mosaic phenotypes. Classic examples include phakomatosis pigmentovascularis (type 3B [63] shown in Fig. 4) and phakomatosis pigmentokeratotica [7].

Twin spotting is well known from Drosophila genetics [84], where it is used in mutagenesis screens. The phenomenon is certainly not uncommon in humans but is frequently overlooked because most physicians are not aware of its existence.

\section{Mosaic disorders}

In spite of the many gaps remaining in our knowledge, mosaicism has been proven exhaustively. It is real and relevant, and clinicians should be aware of its manifestations. We will now discuss the most frequently occurring mosaic disorders that are relevant to paediatric practice. From our own experience, X-linked dominant diseases are the most frequently seen. Clinically relevant twin spotting is exceedingly rare and will not be further discussed.

\section{X-linked dominant}

This important category of disorders will, due to Xinactivation, manifest mainly in females, almost invariably (with notable exceptions) in type 1 Blaschko patterns. Although $\mathrm{X}$-inactivation is in principle random, in X-linked dominant disorders it can diverge from this randomness. In this case, one $\mathrm{X}$ chromosome is preferentially inactivated, and this is called skewing [69]. Quite possibly, it is due to clonal deletion of cells in which the $\mathrm{X}$ chromosome bearing the mutant gene is active. Therefore, if one is considering one of the diagnoses below, or indeed any X-linked dominant trait, skewing can be sought because its presence can support the clinical suspicion.

\section{Incontinentia pigmenti}

Incontinentia pigmenti (IP, MIM\#308300) is the most common X-linked dominant mosaic disorder (Fig. 5), with male lethality. Exceptions include hypomorphic alleles [1], numerical sex chromosome abnormalities [53], and somatic mosaicism [77]. The cutaneous manifestations almost invariably follow the same pattern: linear blistering followed by healing with verrucous crusts that develop into hyperpigmented, reticular to linear streaks [4]. In our experience, careful history taking will often reveal if a child has had these typical skin changes. It should, however, be borne in mind that the blistering and verrucous stages can exceptionally take place in utero. In affected skin, hair follicles and sweat glands are absent. In the blistering stage, confusion with herpes simplex is possible and regularly results in children being isolated and treated with antiviral medication. Consulting a dermatologist before doing so can prevent unnecessary interventions. Typically, lesions resolve completely in the first years of life. In adult females, they will remain as subtle white lines that are best visible on the calves. Linear nail dystrophy can also be present. A less well-known complication in adults is the subungual keratoacanthoma, a painful benign tumor resembling a wart. It responds well to treatment with oral retinoids [67]. Surgery should be avoided if possible because of the high recurrence risk.

IP derives its name from the pigmentary incontinence that is seen upon histopathological examination of a biopsy from affected skin. Apoptotic keratinocytes release pigment granules, which end up in the dermis, to be phagocytosed by histiocytes (melanophages). A pronounced eosinophilic infiltrate is also present. IP is caused by inactivating mutations of NEMO (NF-kB essential modulator/IkappaB kinase gamma) [82]. This protein is required for NFkB activation downstream of ectodysplasin signalling, which is required for placode development in embryogenesis [73]. Ectodysplasin deficiency causes X-linked hypohidrotic ectodermal dysplasia [54], hence IP should be considered as an ectodermal dysplasia that 
Fig. 2 Mitotic recombination causes twin spotting. a A twin spot consisting of two adjacent clonal cell populations manifesting a genetic property, in this case colour. b A mother cell carries two genetic determinants or defects (in this case, yellow and orange) that in the heterozygous state do not manifest. Mitotic recombination causes the traits to become homozygous upon distribution of the duplicated chromosomes over the daughter cells a

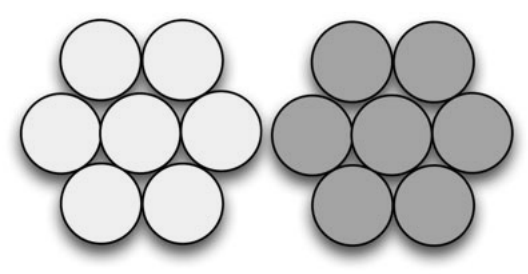

b
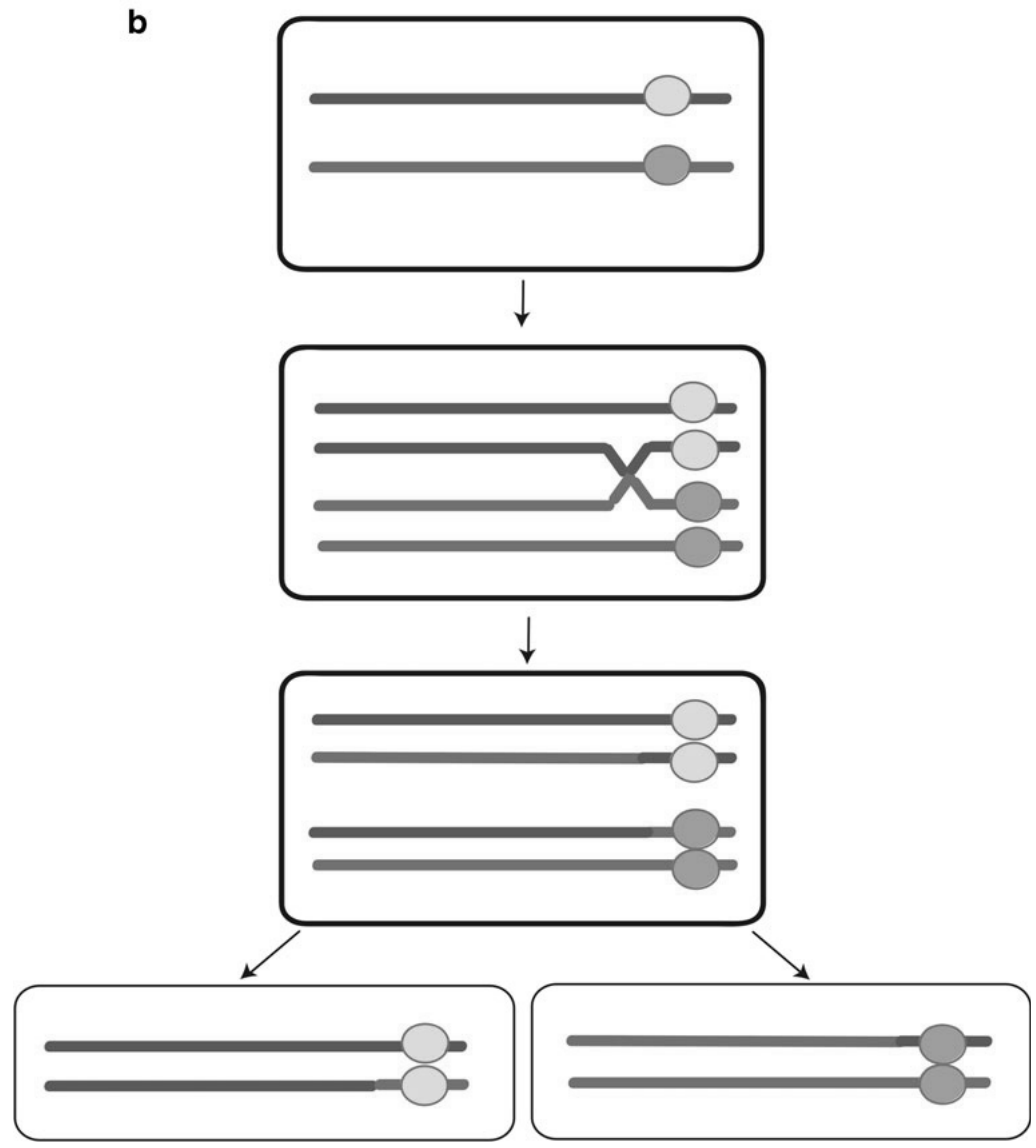

has considerable overlap with XHED. However, neural tissue can also be affected and thus, ocular defects, epilepsy and psychomotor retardation can be manifestations of IP. There is some debate as to whether these symptoms are purely caused by developmental defects or whether there is a contribution for the eosinophilic vasculitis that is part of the phenotype, possibly due to massive eotaxin release by the diseased skin
[50]. Support for the latter hypothesis is provided by the frequent occurrence in babies with IP of retinal vasculoocclusive disease. Figures of around $50 \%$ have been reported [46], excluding other ocular abnormalities that may occur such as iris colobomas. Likewise, brain abnormalities may result from vascular occlusion [21]. Interestingly, the pattern of vascular involvement may follow Blaschko lines [66]. In 


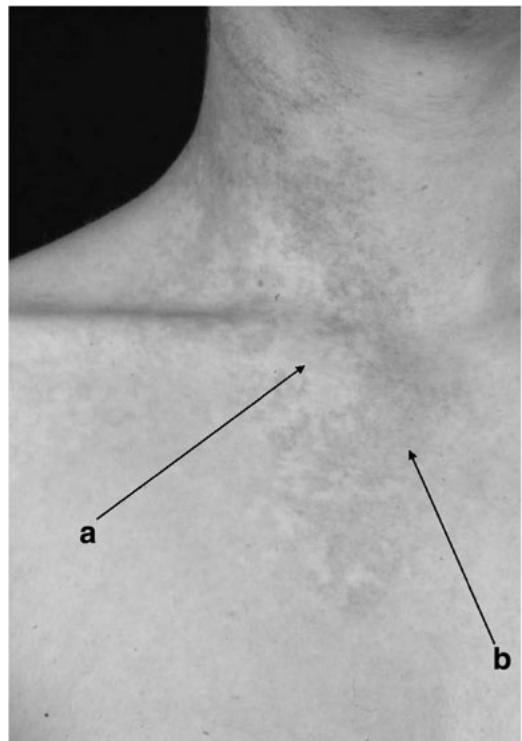

Fig. 3 Allelic twin spot. A capillary malformation (b) lying next to a so-called anemic nevus (a)

the authors' experience, which is admittedly biased, overt brain abnormalities are not common. We do always refer newly diagnosed children to an ophthalmologist. The wisdom of routine brain MRI is open to debate, although we note that eosinophil vasculitis can in principle be treated with high-dose corticosteroids, which could be an argument in favour of routine screening. Finally, males with IP can present with a severe ectodermal dysplasia-immune deficiency syndrome known as OL-EDA-ID, Osteopetrosis-LymphedemaEctodermal DysplasiA-Immune Deficiency (MIM\#300301) [18]. The osteopetrosis and immune deficiency can be understood from NFkB's functions in regulating osteoblast activity

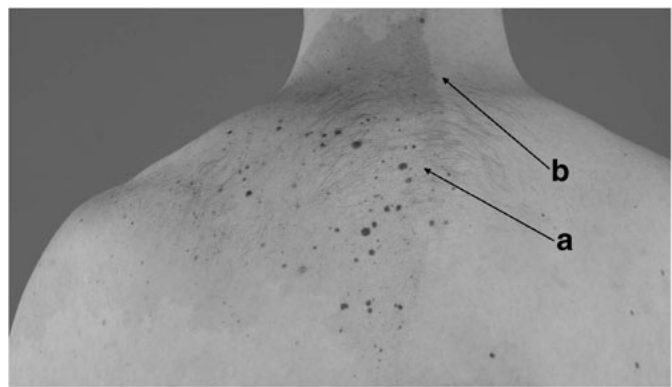

Fig. 4 Non-allelic twin spot: phakomatosis pigmentovascularis. Two neighbouring areas show different mosaic phenotypes: pigment changes (a) next to vascular patches (b)

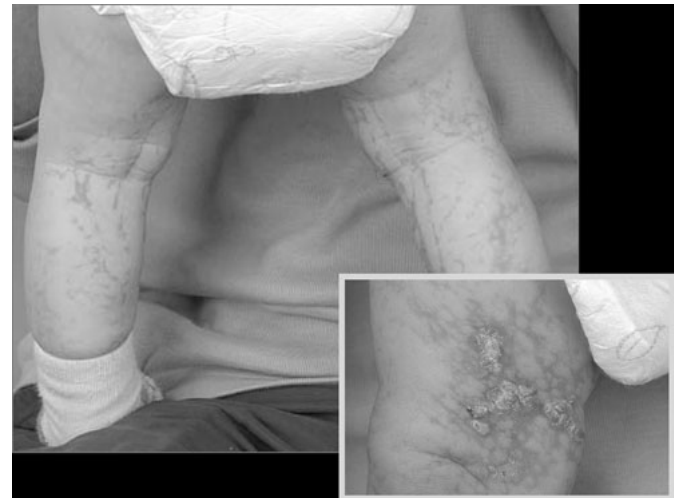

Fig. 5 Incontinentia Pigmenti. Young girl with linear hyperpigmentation following Blaschko lines on the back of her legs. In the detail, stage of the crustae is still visible

[58] and inflammatory responses, respectively. The disorder is lethal, due to overwhelming infections.

\section{Chondrodysplasia punctata}

Conradi-Hünermann-Happle syndrome, or X-linked chondrodysplasia puncata type 2 (CDPX2, MIM\#302960) results from mutations in the $E B P$ gene coding for $3 \beta$ hydroxysteroid dehydrogenase- $\partial 8, \partial 7$ isomerase, a central component of cholesterol biosynthesis that catalyzes the conversion of 8 (9)cholestenol into lathosterol [16]. Patients classically are born with erythroderma that resolves within $24 \mathrm{~h}$ [27], leaving linear hyperkeratotic brown-yellow hyperkeratoses that gradually resolve into slightly atrophic hypopigmented streaks following Blaschko lines and in which adnexal structures are absent. Presentation as a "collodion baby" is also possible, the skin being covered with a glistening membrane that resembles collodion lacquer. The cutaneous manifestations can be very mild and are often not noticed. Cholesterol being required for Hedgehog signalling, patients often have rhizomelic limb shortening, which we propose is due to Indian Hedgehog $(\mathrm{IHH})$ dysfunction. This protein is required for endochondral bone growth; congenital $\mathrm{IHH}$ deficiency results in dwarfism (acrocapitofemoral dysplasia [44]). The abnormal ossification causes punctate calcification around the epiphyses that is visible by X-ray from birth until early childhood and from which the disorder derives its name. In addition, Sonic Hedgehog dysfunction can cause segmentation defects of ribs and vertebrae leading to scoliosis, as well as linear alopecia. The latter is a common symptom. Psychomotor retardation can be part of the phenotype, but we have not seen it in our patients. Likewise, a recent larger series reports no instances of developmental delay [9]. Ocular cataracts, which of course can be sectoral 
due to mosaicism, are common. Especially in adolescents and adults, remaining skin manifestations such as linear atrophy or alopecia can be quite subtle and are easily overlooked [83].

The clinical diagnosis is usually confirmed by HPLC, which shows the presence of 8(9)-cholestenol. Males with germ line EBP mutations have been reported and there has been some controversy over whether the phenotype should be considered as a separate nosologic entity [22, 39, 42], which it probably is [2].

\section{CHILD syndrome}

Congenital Hemidysplasia with Ichthyosiform Erythroderma and Limb Defects (CHILD, OMIM \#308050) syndrome is caused by defects in distal cholesterol metabolism due to mutations in the NSDHL gene coding for the NAD $(\mathrm{P}) \mathrm{H}$ steroid dehydrogenase-like enzyme (NSDHL)[56]. It helps to catalyse the conversion of lanosterol into zymosterol. Because they are both caused by defects in cholesterol metabolism, CHILD and CDPX2 share symptoms, such as ichthyosiform erythroderma. It should be noted here that because the scaling is not generalized, CHILD and CDPX2 are no longer considered as ichthyosis [76]. The skin changes in CHILD are far more severe than in CDPX2, consisting of profound erythema, lichenification and adherent yellow hyperkeratosis [28]. Patients can also develop verruciform xanthomas, benign histiocytic proliferations that may require surgical treatment [59]. The unique feature that best distinguishes CHILD syndrome is a dramatic lateralization of the abnormalities, which can hide the actual Blaschko-linear distribution of the cutaneous lesions. In about two thirds of patients, the right side is (almost) exclusively affected, without correlation to any particular genotype [47]. The skin symptoms to a large extent disappear during life, but remain in the flexures, a phenomenon known as ptychotropism [31]. These peculiarities have long remained unexplained, but important advances have recently been made. These have also resulted in an effective treatment for the associated skin disorder. In two patients with CHILD syndrome, we found that on the disease-free side, no skin cells expressing mutant NSDHL remained [78]. The most parsimonious explanation for this phenomenon, and thence for the extreme lateralization, is that all mutant cells have died during embryogenesis. Due to the gene defect, toxic cholesterol intermediates accumulate in affected cells. In keratinocytes that produce large amounts of cholesterol, the level of toxic precursors will also be high. This is why the skin abnormalities gradually disappear during life-affected cells will die [57]. Body folds have thinner skin with lower levels of cholesterol synthesis and therefore present a less toxic milieu to mutant cells. We do not yet know why the mutant cells are deleted preferentially on the left side of the body, but we do note that left-right determination involves the selective activity of molecules such as Sonic Hedgehog (SHH) on the left [62]. SHH requires cholesterol to function, and perhaps its preferential left-sided synthesis is what triggers cell death. Treatment of the skin abnormalities was informed by these observations and now consists of topical application of a statin to prevent the toxic precursors from forming, combined with cholesterol to restore the epidermal barrier. This is a highly effective regimen that can completely clear the cutaneous abnormalities.

\section{Autosomal (lethal) mosaicism}

Polyostotic fibrous dyplasia

McCune-Albright syndrome (MIM \#174800) is often suspected, but rarely diagnosed based on the skin changes. In our experience, patients will be referred because they have café au lait-like pigmentary changes following a type 2 Blaschko pattern in a "coast of Maine" pattern, the outlines of the pigmented patches being irregular. Very often, the patient turns out rather to have pigmentary mosaicism following type 2 Blaschko lines (Fig. 1) [85]. To establish the diagnosis of McCune-Albright syndrome, endocrine or bone involvement must be present but, it being a mosaic disorder, such associated manifestations are highly variable [65]. The classically associated endocrine feature is (extremely) precocious puberty, which occurs in more than half of female patients and has also been reported in males. It is the most common presenting symptom [20]. In a large study of patients with isolated peripheral precocious puberty, activating GNAS1 mutations were detected in about one third of them [65]. It is important to realize that other endocrinopathies can also occur, again as a result of mosaicism: hyperthyroidism [68], acromegaly [48] and hyperadrenocorticism with Cushing syndrome [8].

The associated skeletal disorder is mono- or polyostotic fibrous dysplasia [12]. Medullary bone is replaced by fibrous tissue. Any bone can be affected and asymmetry is the rule. Involvement of the skull and facial bones can be striking. Pathologic fracture is the usual presentation and deformities or pseudoarthrosis ensue. Shepherd's crook deformity of the proximal femur is particularly characteristic. The bone defects can be very detrimental to quality of life because they can strongly limit mobility and are difficult to treat [49]. Vertebral fractures can cause spinal cord compression, sometimes leading to death if affecting the cervical spine (own unpublished observation).

McCune-Albright syndrome was the first disorder for which mosaicism was formally proven by demonstrating the presence of mutant alleles in affected but not in unaffected tissues [89]. GNAS is a complex locus that is imprinted and from which various transcripts are produced, each of which is 
associated with a different disorder [90]. The product affected in McCune-Albright is expressed from both alleles and codes for the $\mathrm{G}$ protein alpha unit [15]. G proteins transduce extracellular signals received by transmembrane receptors to effector proteins [60]. Inactivating mutations affecting the maternal allele cause Albright hereditary osteodystrophy with pseudopseudohypoparathyroidism, which is quite distinct from polyostotic fibrous dysplasia and can have cutaneous manifestations [55].

\section{Proteus syndrome}

This disorder (OMIM \#176920) presents one of the most iconic mosaic phenotypes and provides a vivid illustration of the lethal gene concept. Its symptoms always occur in a patchy, nevoid distribution. First recognized as a distinct entity in 1979 [11] and given its name by Wiedemann [91], it is very rare. Joseph Merrick, the famous "Elephant Man", quite probably had Proteus syndrome [86] and not neurofibromatosis type I (von Recklinghausen), a misconception that persists to the present day [61]. Typically, overgrowth affecting multiple organs and tissues appears in the first years of life and relentlessly progresses. This feature distinguishes Proteus syndrome from type 3 Klippel-Trenaunay, in which disproportionate growth ceases in puberty [75]. Vascular malformations, including lymphatic ones, are frequent [13]. The overgrowth is very disproportionate and has a tendency to affect bone, connective tissue and fat (Fig. 6). Bones can become so distorted as to become unrecognizable. Grotesque disfigurement can result. Fatty tissue can be subject to either lipoma formation or hypoplasia [34]. Connective tissue overgrowth on the soles of the feet leading to cerebriform folding of the skin is considered a hallmark symptom and should be sought when trying to establish the diagnosis [5]. The skin itself can show linear epidermal nevi-verrucous thickening following Blaschko lines. Finally, there is a recognizable facial phenotype, consisting of dolichocephaly with a long face, open mouth, low nasal bridge with anteverted nares and ptosis or antimongoloid slant of the eyes [5].

The diagnosis of Proteus syndrome can be very challenging because, as a result of its mosaic nature, symptoms can be highly variable. Criteria have been established by the NIH Proteus study group and we strongly advise to use these [5]. As mentioned above, it was recently found that Proteus is caused by activating AKT1 mutations. The resulting deregulation of mTOR signalling may be amenable to intervention with drugs such as rapamycin, which block mTOR function [24]. This is a breakthrough for patients, whose management is very challenging. Surgery is always problematic because of thrombophilia, which has recently been recognized as the most common cause of death in Proteus syndrome. The NIH Proteus group therefore recommends anti-coagulant prophylaxis for all patients [5].

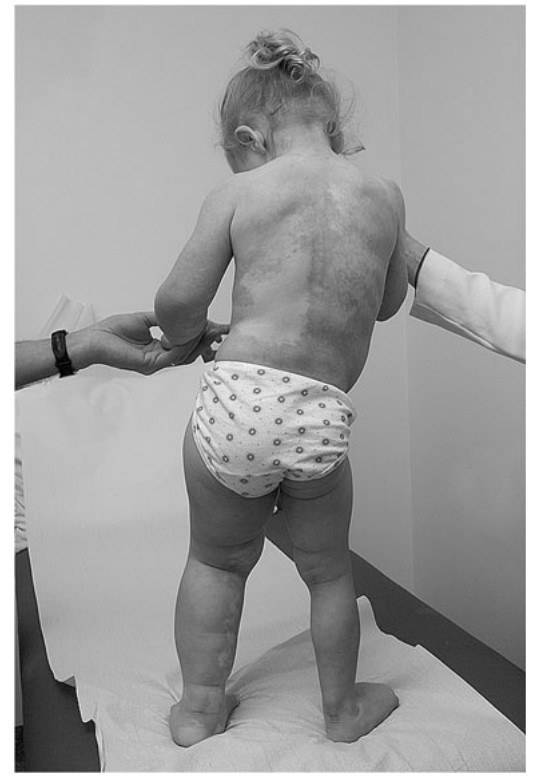

Fig. 6 Proteus syndrome. Disproportionate overgrowth of bone, connective tissue and fat causing deformation, together with vascular malformation, partly following a segmental (type2 Blaschko lines) distribution

Linear sebaceous nevus syndrome

Also known as Schimmelpenning-Feuerstein-Mims or Jadassohn syndrome, this disorder has about eight other monikers [40]. We prefer "linear sebaceous nevus syndrome", if only because eponyms can be confusing. Also, a term such as Schimmelpenning-Feuerstein-Mims syndrome refers to a specific manifestation of the mosaic, in which patients have skin abnormalities, bone defects, eye abnormalities such as choristomas, mental retardation and epilepsy, due to structural brain defects, often a hemimegalencephaly [79]. Choristomas are benign tumors arising from heterotopic proliferations of two or more tissue types, such as as lacrimal gland, bone, cartilage, adipose tissue, neural tissue or smooth muscle[81]. The cutaneous defect (figure) is a sebaceous gland nevus that initially appears as one or more verrucous brown-yellow plaques following a type 1 Blaschko distribution. In general, the nevi are ipsilateral to the other abnormalities. In childhood, the lesions can be rather subtle. They are hairless; a biopsy will usually show an increased number of hypoplastic sebaceous glands, but nothing more. The glands start to grow during puberty and then the lesions become more prominent and a biopsy more informative. Both benign and malignant skin tumours may develop in sebaceous nevi, with a recent review putting the frequency at 16 , 
respectively $8 \%$. These figures might be skewed by ascertainment bias, because they derive from specialist centres. Solitary sebaceous nevi on the scalp are very common [71] and if they are small, the risk of malignant change, underlying bone or cerebral abnormalities is in our experience very small. The authors are aware of one patient with a very small sebaceous nevus who did have underlying hemimegalencephaly and epilepsy, but he probably is the exception in almost 15 years of dealing with rare diseases that proves the rule.

In patients with extensive skin disease, osteopenia with hypophosphatemic rickets can occur, responsive to treatment with octreotide and excision of nevi [45]. Elevated plasma FGF23 levels have been detected in patients, providing a possible explanation [72]. There is also one report of a girl who developed maxillary giant cell granulomas underlying facial sebaceous nevi [51]. This might be a coincidence, but similar lesions have been reported in Noonan syndrome, which is characterized by RAS pathway hyperactivity [93]. From this observation, one might speculate that linear sebaceous nevus syndrome has a similar pathogenesis and is caused by RAS signalling defects.

\section{Chromosomal mosaicism}

Finally, numerical chromosome abnormalities can affect the skin in a mosaic pattern. The best-known example probably is Pallister-Killian syndrome, which is caused by mosaicism for tetrasomy of chromosome 12p. Skin symptoms consist of linear hyper- and hypopigmented streaks following Blaschko lines, often in a whorled type 1 pattern. This cutaneous pattern is sometimes referred to as linear and whorled nevoid hypermelanosis [17] and has also been reported in association with other mosaic chromosome defects, such as trisomy 7 and trisomy 20 [43, 87]. If only hypopigmentations are seen, the cutaneous phenotype can be referred to as hypomelanosis of Ito. The associated chromosome defects are the same, and hypomelanosis Ito is not a separate entity [19].

Almost diagnostic of chromosomal mosaicism are pigmentary changes following a phylloid, or type 3 Blaschko pattern (Fig. 7). This particular manifestation is predominantly associated with mosaic abnormalities of chromosome 13 [36], although other defects have also been seen [25] [and own unpublished observations]. It is not known why chromosome changes can result in hypopigmentation, or why this should manifest in phylloid patterns rather than in the classic type 1 Blaschko lines. Patients presenting with phylloid hypopigmentations should be thoroughly evaluated for associated abnormalities and should be presumed to harbour chromosomal defects until proven otherwise.

Confirming the diagnosis of chromosomal mosaicism, however, can be challenging. The abnormality may not be detectable in peripheral blood leucocytes. Ideally, 100 or more cultured keratinocytes are analysed so as to maximise the chances of picking up the mosaic. However, the abnormal cells tend to die in culture so that only normal cells remain. We therefore suggest that shave biopsies be analysed using SNP arrays first. These will not detect
Fig. 7 Phylloid (leaf-like) pattern of hypopigmentation in chromosomal mosaicism

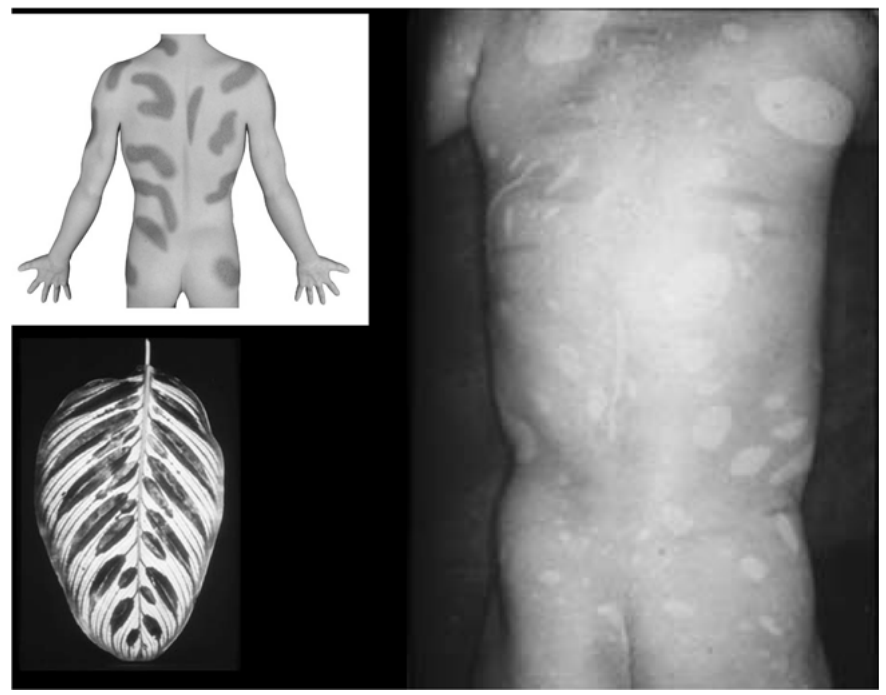


translocations and inversions, but since deletions and numerical abnormalities are more common, the majority of chromosomal abnormalities should be detected in this way.

\section{Conclusion}

In this review, we discussed cutaneous manifestations of genetic mosaicism that we consider important to paediatricians. We also outlined the mechanisms that give rise to this fascinating phenomenon. Linear skin changes should make the clinician think (twice). Not all lines are created equal, and dermatomes should not be confused with Blaschko lines. When encountering mosaics, it should be borne in mind that X-linked dominant disorders are among the most frequent genodermatoses. Of those, incontinentia pigmenti is the most common. Autosomal mosaics are also very frequent but do not often come to medical attention because their manifestations can be very limited.

Some manifestations of a number of severe mosaic disorders, such as CHILD and Proteus syndrome, can now be treated. Therefore, correct clinical and molecular diagnosis is of the utmost importance. Counselling and management should ideally take place in a multidisciplinary setting, because these issues can be complex, requiring specialist knowledge and good coordination between attending physicians.

Acknowledgments The outpatient clinic depends on the outstanding support by Ms. Y. Detisch, genetics nurse. We acknowledge Dr. Marcus-Soekarman for her enthusiastic and unwavering support and participation. MvS is partly supported by grants from the Dutch Cancer Society (KWF UM2009-4352), the Association for International Cancer Research (11-0687) and the Annadal Foundation (AU11.1068).

\section{References}

1. Aradhya S, Courtois G, Rajkovic A, Lewis RA, Levy M, Israel A, Nelson DL (2001) Atypical forms of incontinentia pigmenti in male individuals result from mutations of a cytosine tract in exon 10 of NEMO (IKK-gamma). Am J Hum Genet 68:765-771

2. Arnold AW, Bruckner-Tuderman L, Has C, Happle R (2012) Conradi-Hunermann-Happle syndrome in males versus MEND syndrome (male EBP disorder with neurological defects). Br J Dermatol 166:1309-1313

3. Baillie JK, Barnett MW, Upton KR, Gerhardt DJ, Richmond TA, De Sapio F, Brennan PM, Rizzu P, Smith S, Fell M, Talbot RT, Gustincich S, Freeman TC, Mattick JS, Hume DA, Heutink P, Carninci P, Jeddeloh JA, Faulkner GJ (2011) Somatic retrotransposition alters the genetic landscape of the human brain. Nature 479:534-537

4. Berlin AL, Paller AS, Chan LS (2002) Incontinentia pigmenti: a review and update on the molecular basis of pathophysiology. J Am Acad Dermatol 47:169-187
5. Biesecker L (2006) The challenges of Proteus syndrome: diagnosis and management. Eur J Hum Genet 14:1151-1157

6. Blaschko A (1901) Die Nervenverteilung in der Haut in ihrer Beziehung zu den Erkrankungen der Haut. Paper presented at VII Congress der Deutschen Dermatologischen Gesellschaft. Breslau, 28-30 May

7. Boente MC, Pizzi de Parra N, Larralde de Luna M, Bonet HB, Santos Munoz A, Parra V, Gramajo P, Moreno S, Asial RA (2000) Phacomatosis pigmentokeratotica: another epidermal nevus syndrome and a distinctive type of twin spotting. Eur J Dermatol 10:190-194

8. Boston BA, Mandel S, LaFranchi S, Bliziotes M (1994) Activating mutation in the stimulatory guanine nucleotide-binding protein in an infant with Cushing's syndrome and nodular adrenal hyperplasia. J Clin Endocrinol Metab 79:890-893

9. Canueto J, Giros M, Ciria S, Pi-Castan G, Artigas M, GarciaDorado J, Garcia-Patos V, Viros A, Vendrell T, Torrelo A, Hernandez-Martin A, Martin-Hernandez E, Garcia-Silva MT, Fernandez-Burriel M, Rosell J, Tejedor M, Martinez F, Valero J, Garcia JL, Sanchez-Tapia EM, Unamuno P, Gonzalez-Sarmiento R (2011) Clinical, molecular and biochemical characterization of nine spanish families with Conradi-Hunermann-Happle syndrome: New insights into CDPX2 with a comprehensive review of the literature. Br J Dermatol 166:830-838

10. Carnero A (2010) The PKB/AKT pathway in cancer. Curr Pharm Des 16:34-44

11. Cohen MM Jr, Hayden PW (1979) A newly recognized hamartomatous syndrome. Birth Defects Orig Artic Ser 15:291-296

12. Cohen MM Jr, Howell RE (1999) Etiology of fibrous dysplasia and McCune-Albright syndrome. Int J Oral Maxillofac Surg 28:366-371

13. Cohen MM Jr (2005) Proteus syndrome: an update. Am J Med Genet C: Semin Med Genet 137C:38-52

14. Cohen MM Jr (2008) Segmental hemangioma: the misuse of a term. Am J Med Genet A 146A:672-673

15. de Sanctis L, Delmastro L, Russo MC, Matarazzo P, Lala R, de Sanctis C (2006) Genetics of McCune-Albright syndrome. J Pediatr Endocrinol Metab 19(Suppl 2):577-582

16. Derry JM, Gormally E, Means GD, Zhao W, Meindl A, Kelley RI, Boyd Y, Herman GE (1999) Mutations in a delta 8-delta 7 sterol isomerase in the tattered mouse and $\mathrm{X}$-linked dominant chondrodysplasia punctata. Nat Genet 22:286-290

17. Di Lernia V (2007) Linear and whorled hypermelanosis. Pediatr Dermatol 24:205-210

18. Doffinger R, Smahi A, Bessia C, Geissmann F, Feinberg J, Durandy A, Bodemer C et al (2001) X-linked anhidrotic ectodermal dysplasia with immunodeficiency is caused by impaired NFkappaB signaling. Nat Genet 27:277-285

19. Donnai D, Read AP, McKeown C, Andrews T (1988) Hypomelanosis of Ito: a manifestation of mosaicism or chimerism. J Med Genet 25:809-818

20. Dumitrescu CE, Collins MT (2008) McCune-Albright syndrome. Orphanet J Rare Dis 3:12

21. Fiorillo L, Sinclair DB, O'Byrne ML, Krol AL (2003) Bilateral cerebrovascular accidents in incontinentia pigmenti. Pediatr Neurol 29:66-68

22. Furtado LV, Bayrak-Toydemir P, Hulinsky B, Damjanovich K, Carey JC, Rope AF (2010) A novel X-linked multiple congenital anomaly syndrome associated with an EBP mutation. Am J Med Genet A 152A:2838-2844

23. Garcia-Dorado J, de Unamuno P, Fernandez-Lopez E, Salazar Veloz J, Armijo M (1990) Incontinentia pigmenti: XXY male with a family history. Clin Genet 38:128-138

24. Georgakis GV, Younes A (2006) From Rapa Nui to rapamycin: targeting PI3K/Akt/mTOR for cancer therapy. Expert Rev Anticancer Ther 6:131-140 
25. Hansen LK, Brandrup F, Rasmussen K (2003) Pigmentary mosaicism with mosaic chromosome $5 \mathrm{p}$ tetrasomy. Br J Dermatol 149:414-416

26. Happle R (1977) Genetic significance of Blaschko's lines. Z Hautkr 52:935-944

27. Happle R (1979) X-linked dominant chondrodysplasia punctata. Review of literature and report of a case. Hum Genet 53:65-73

28. Happle R, Koch H, Lenz W (1980) The CHILD syndrome. Congenital hemidysplasia with ichthyosiform erythroderma and limb defects. Eur J Pediatr 134:27-33

29. Happle R (1985) Lyonization and the lines of Blaschko. Hum Genet 70:200-206

30. Happle R (1986) The McCune-Albright syndrome: a lethal gene surviving by mosaicism. Clin Genet 29:321-324

31. Happle R (1990) Ptychotropism as a cutaneous feature of the CHILD syndrome. J Am Acad Dermatol 23:763-766

32. Happle R, Koopman R, Mier PD (1990) Hypothesis: vascular twin naevi and somatic recombination in man. Lancet 335:376-378

33. Happle R (1991) Allelic somatic mutations may explain vascular twin nevi. Hum Genet 86:321-322

34. Happle R (1999) Elattoproteus syndrome: delineation of an inverse form of Proteus syndrome. Am J Med Genet 84:25-28

35. Happle R (1999) Loss of heterozygosity in human skin. J Am Acad Dermatol 41:143-164

36. Happle R (2000) Phylloid hypomelanosis is closely related to mosaic trisomy 13. Eur J Dermatol 10:511-512

37. Happle R (2002) Dohi memorial lecture. New aspects of cutaneous mosaicism. J Dermatol 29:681-692

38. Happle R (2002) Transposable elements and the lines of Blaschko: a new perspective. Dermatology 204:4-7

39. Happle R (2003) Hypomorphic alleles within the EBP gene cause a phenotype quite different from Conradi-Hunermann-Happle syndrome. Am J Med Genet A 122:279, author reply 280

40. Happle R (2004) Gustav Schimmelpenning and the syndrome bearing his name. Dermatology 209:84-87

41. Happle R (2006) X-chromosome inactivation: role in skin disease expression. Acta Paediatr Suppl 95:16-23

42. Happle R (2011) A novel X-linked phenotype caused by hypomorphic EBP mutations. Am J Med Genet A 155A:1770-1771, author reply 1772

43. Hartmann A, Hofmann UB, Hoehn H, Broecker EB, Hamm H (2004) Postnatal confirmation of prenatally diagnosed trisomy 20 mosaicism in a patient with linear and whorled nevoid hypermelanosis. Pediatr Dermatol 21:636-641

44. Hellemans J, Coucke PJ, Giedion A, De Paepe A, Kramer P, Beemer F, Mortier GR (2003) Homozygous mutations in IHH cause acrocapitofemoral dysplasia, an autosomal recessive disorder with cone-shaped epiphyses in hands and hips. Am J Hum Genet 72:1040-1046

45. Hoffman WH, Jueppner HW, Deyoung BR, O'Dorisio MS, Given KS (2005) Elevated fibroblast growth factor-23 in hypophosphatemic linear nevus sebaceous syndrome. Am J Med Genet A 134:233-236

46. Holmstrom G, Thoren K (2000) Ocular manifestations of incontinentia pigmenti. Acta Ophthalmol Scand 78:348-353

47. Hummel M, Cunningham D, Mullett CJ, Kelley RI, Herman GE (2003) Left-sided CHILD syndrome caused by a nonsense mutation in the NSDHL gene. Am J Med Genet A 122A:246-251

48. Ihara C, Shimatsu A, Murabe H, Kataoka K, Kondo C, Nakao K (1996) Growth hormone-secreting pituitary adenoma associated with multiple bone cysts, skin pigmentation and aortitis syndrome. J Endocrinol Investig 19:753-757

49. Ippolito E, Bray EW, Corsi A, De Maio F, Exner UG, Robey PG, Grill F, Lala R, Massobrio M, Pinggera O, Riminucci M, Snela S, Zambakidis C, Bianco P (2003) Natural history and treatment of fibrous dysplasia of bone: a multicenter clinicopathologic study promoted by the European Pediatric Orthopaedic Society. J Pediatr Orthop B 12:155-177

50. Jean-Baptiste S, O'Toole EA, Chen M, Guitart J, Paller A, Chan LS (2002) Expression of eotaxin, an eosinophil-selective chemokine, parallels eosinophil accumulation in the vesiculobullous stage of incontinentia pigmenti. Clin Exp Immunol 127:470-478

51. Kaplan I, Metzker A, Calderon S (1993) Epidermal nevus syndrome with maxillary involvement. Int J Oral Maxillofac Surg 22:298-300

52. Kargul B, Alcan T, Kabalay U, Atasu M (2001) Hypohidrotic ectodermal dysplasia: dental, clinical, genetic and dermatoglyphic findings of three cases. J Clin Pediatr Dent 26:5-12

53. Kenwrick S, Woffendin H, Jakins T, Shuttleworth SG, Mayer E, Greenhalgh L, Whittaker J, Rugolotto S, Bardaro T, Esposito T, D'Urso M, Soli F, Turco A, Smahi A, Hamel-Teillac D, Lyonnet S, Bonnefont JP, Munnich A, Aradhya S, Kashork CD, Shaffer LG, Nelson DL, Levy M, Lewis RA (2001) Survival of male patients with incontinentia pigmenti carrying a lethal mutation can be explained by somatic mosaicism or Klinefelter syndrome. Am J Hum Genet 69:1210-1217

54. Kere J, Srivastava AK, Montonen O, Zonana J, Thomas N, Ferguson B, Munoz F, Morgan D, Clarke A, Baybayan P, Chen EY, Ezer S, Saarialho-Kere U, de la Chapelle A, Schlessinger D (1996) X-linked anhidrotic (hypohidrotic) ectodermal dysplasia is caused by mutation in a novel transmembrane protein. Nat Genet 13:409-416

55. Klaassens M, Blom EW, Schrander JJ, Ris-Stalpers C, Nieuwenhuijzen Kruseman AC, van Steensel MA, Schrander-Stumpel CT (2010) Unique skin changes in a case of Albright hereditary osteodystrophy caused by a rare GNAS1 mutation. Br J Dermatol 162:690-694

56. Konig A, Happle R, Bornholdt D, Engel H, Grzeschik KH (2000) Mutations in the NSDHL gene, encoding a 3beta-hydroxysteroid dehydrogenase, cause CHILD syndrome. Am J Med Genet 90:339-346

57. Konig A, Skrzypek J, Loffler H, Oeffner F, Grzeschik KH, Happle R (2010) Donor dominance cures CHILD nevus. Dermatology 220:340-345

58. Krum SA, Chang J, Miranda-Carboni G, Wang CY (2010) Novel functions for NFkappaB: inhibition of bone formation. Nat Rev Rheumatol 6:607-611

59. Kurban M, Abbas O, Ghosn S, Kibbi AG (2010) Late evolution of giant verruciform xanthoma in the setting of CHILD syndrome. Pediatr Dermatol 27:551-553

60. Lania A, Mantovani G, Spada A (2001) G protein mutations in endocrine diseases. Eur J Endocrinol/Eur Fed Endocr Soc 145:543-559

61. Legendre CM, Charpentier-Cote C, Drouin R, Bouffard C (2011) Neurofibromatosis type 1 and the "elephant man's" disease: the confusion persists: an ethnographic study. PLoS One 6:e16409

62. Levin M, Johnson RL, Stern CD, Kuehn M, Tabin C (1995) A molecular pathway determining left-right asymmetry in chick embryogenesis. Cell 82:803-814

63. Libow LF (1993) Phakomatosis pigmentovascularis type IIIb. J Am Acad Dermatol 29:305-307

64. Lindhurst MJ, Sapp JC, Teer JK, Johnston JJ, Finn EM, Peters $\mathrm{K}$, Turner $\mathrm{J}$ et al (2011) A mosaic activating mutation in AKT1 associated with the Proteus syndrome. N Engl J Med 365:611619

65. Lumbroso S, Paris F, Sultan C (2004) Activating Gsalpha mutations: analysis of 113 patients with signs of McCune-Albright syndrome- a European Collaborative Study. J Clin Endocrinol Metab 89:2107-2113

66. Maingay-de Groof F, Lequin MH, Roofthooft DW, Oranje AP, de Coo IF, Bok LA, van der Spek PJ, Mancini GM, Govaert PP (2008) Extensive cerebral infarction in the newborn due to incontinentia pigmenti. Eur J Paediatr Neurol 12:284-289 
67. Malvehy J, Palou J, Mascaro JM (1998) Painful subungual tumour in incontinentia pigmenti. Response to treatment with etretinate. $\mathrm{Br}$ J Dermatol 138:554-555

68. Mastorakos G, Mitsiades NS, Doufas AG, Koutras DA (1997) Hyperthyroidism in McCune-Albright syndrome with a review of thyroid abnormalities sixty years after the first report. Thyroid 7:433-439

69. Migeon BR (1998) Non-random X chromosome inactivation in mammalian cells. Cytogenet Cell Genet 80:142-148

70. Milunsky JM, Maher TA, Metzenberg AB (2003) Molecular, biochemical, and phenotypic analysis of a hemizygous male with a severe atypical phenotype for X-linked dominant ConradiHunermann-Happle syndrome and a mutation in EBP. Am J Med Genet 116:249-254

71. Moody MN, Landau JM, Goldberg LH (2012) Nevus sebaceous revisited. Pediatr Dermatol 29:15-23

72. Moreira AI, Ferreira G, Santos M, Baptista A, Ferreira EO (2010) Epidermal nevus syndrome associated with hypophosphatemic rickets. Dermatol Online J 16:14

73. Mustonen T, Ilmonen M, Pummila M, Kangas AT, Laurikkala J, Jaatinen R, Pispa J, Gaide O, Schneider P, Thesleff I, Mikkola ML (2004) Ectodysplasin A1 promotes placodal cell fate during early morphogenesis of ectodermal appendages. Development 131:4907-4919

74. Oduber CE, van der Horst CM, Hennekam RC (2008) Klippel-Trenaunay syndrome: diagnostic criteria and hypothesis on etiology. Ann Plast Surg 60:217-223

75. Oduber CE, van der Horst CM, Sillevis Smitt JH, Smeulders MJ, Mendiratta V, Harper JI, van Steensel MA, Hennekam RC (2011) A proposal for classification of entities combining vascular malformations and deregulated growth. Eur J Med Genet 54:262-271

76. Oji V, Tadini G, Akiyama M, Blanchet Bardon C, Bodemer C, Bourrat E, Coudiere P et al (2010) Revised nomenclature and classification of inherited ichthyoses: results of the First Ichthyosis Consensus Conference in Soreze 2009. J Am Acad Dermatol 63:607-641

77. Pacheco TR, Levy M, Collyer JC, de Parra NP, Parra CA, Garay M, Aprea G, Moreno S, Mancini AJ, Paller AS (2006) Incontinentia pigmenti in male patients. J Am Acad Dermatol 55:251-255

78. Paller AS, van Steensel MA, Rodriguez-Martin M, Sorrell J, Heath C, Crumrine D, van Geel M, Cabrera AN, Elias PM (2011) Pathogenesis-based therapy reverses cutaneous abnormalities in an inherited disorder of distal cholesterol metabolism. J Investig Dermatol 131:2242-2248

79. Park JM, Kim DS, Kim J, Lee MG, Oh SH (2009) Epibulbar complex choristoma and hemimegalencephaly in linear sebaceous naevus syndrome. Clin Exp Dermatol 34:e686-e689
80. Siemens HW (1929) Die Melanosis corii degenerativa, eine neue Pigmentdermatose. Arch Derm Syph 382

81. Singal A, Dhaliwal U, Bhattacharya SN, Rohatgi J, Singh N (2001) Complex ocular choristomas in linear nevus sebaceus syndrome: a report of two cases. J Dermatol 28:259-264

82. Smahi A, Courtois G, Vabres P, Yamaoka S, Heuertz S, Munnich $A$, Israel A et al (2000) Genomic rearrangement in NEMO impairs NF-kappaB activation and is a cause of incontinentia pigmenti. The International Incontinentia Pigmenti (IP) Consortium. Nature 405:466-472

83. Steijlen PM, van Geel M, Vreeburg M, Marcus-Soekarman D, Spaapen LJ, Castelijns FC, Willemsen M, van Steensel MA (2007) Novel EBP gene mutations in Conradi-HunermannHapple syndrome. Br J Dermatol 157:1225-1229

84. Stern C, Tokunaga C (1971) On cell lethals in Drosophila. Proc Natl Acad Sci U S A 68:329-331

85. Taieb A, Boralevi F (2007) Hypermelanoses of the newborn and of the infant. Dermatol Clin 25:327-336, viii

86. Tibbles JA, Cohen MM Jr (1986) The Proteus syndrome: the Elephant Man diagnosed. Br Med J 293:683-685

87. Verghese S, Newlin A, Miller M, Burton BK (1999) Mosaic trisomy 7 in a patient with pigmentary abnormalities. Am J Med Genet 87:371-374

88. Vreeburg M, van Geel M, van den Heuij LG, Steijlen PM, van Steensel MA (2011) Focal dermal hypoplasia in a male patient due to mosaicism for a novel PORCN single nucleotide deletion. J Eur Acad Dermatol Venereol 25:592-595

89. Weinstein LS, Shenker A, Gejman PV, Merino MJ, Friedman E, Spiegel AM (1991) Activating mutations of the stimulatory G protein in the McCune-Albright syndrome. N Engl J Med 325:1688-1695

90. Weinstein LS, Liu J, Sakamoto A, Xie T, Chen M (2004) Minireview: GNAS: normal and abnormal functions. Endocrinology 145:5459-5464

91. Wiedemann HR, Burgio GR, Aldenhoff P, Kunze J, Kaufmann HJ, Schirg E (1983) The proteus syndrome. Partial gigantism of the hands and/or feet, nevi, hemihypertrophy, subcutaneous tumors, macrocephaly or other skull anomalies and possible accelerated growth and visceral affections. Eur J Pediatr 140:512

92. Wiley JE, Madigan M, Christie JD, Smith AW (2002) Dispermic chimerism with two abnormal cell lines, 47, XY, +21 and 47, XX, + 12. Am J Med Genet 107:64-66

93. Wolvius EB, de Lange J, Smeets EE, van der Wal KG, van den Akker HP (2006) Noonan-like/multiple giant cell lesion syndrome: report of a case and review of the literature. J Oral Maxillofac Surg 64:1289-1292 
CHAPTER 4 


\section{Macrodystrophia lipomatosa}

V.L.R.M. Verstraeten ${ }^{\mathrm{I}}$ M. Vreeburg ${ }^{2}$, M.H.G. Dremmen ${ }^{3}$, A.A.R. Stadler ${ }^{4}$, C. Sobczak ${ }^{\mathrm{I}}$, Ch.E.M. de Die', M.A.M. van Steensel ${ }^{6}$

1. Aios, afdeling Dermatologie, Maastricht Universitair Medisch Centrum, Maastricht

$$
2 .
$$

3 .

4 .

5 .

6. Dermatoloog, afdeling Dermatologie, Maastricht Universitair Medisch Centrum, Maastricht

Correspondentieadres:

Valerie L.R.M. Verstraeten

MUMC

Postbus 5800

6202 AZ Maastricht

E-mail:valerie.verstraeten@mumc.nl

\section{ZIEKTEGESCHIEDENIS}

Op het gezamenlijke genetica-dermatologiespreekuur zagen we twee niet-verwante patiënten met toegenomen omvang van enkele digiti van de handen. Bij beide patiënten werd in het verleden de diagnose proteussyndroom (\#I76920) gesteld. Het proteussyndroom is een overgroeisyndroom gekenmerkt door progressieve hyperplasie van de huid, het bindweefsel en het skelet. Ook andere weefsels en organen kunnen betrokken zijn. ${ }^{1}$ Naast gelokaliseerde overgroei is er ook een verhoogde kans op het krijgen van enige bijzondere tumoren, in het bijzonder een monomorf adenoom van de parotis en een bilateraal ovarieel cystadenoom. Onze patiën- 
ten vertoonden macrodactylie, waarbij radiologisch onderzoek aanwijzingen toonde voor een vasculaire malformatie bij de ene patiënt en een fibrolipomateus hamartoom bij de andere. De differentiële diagnose bestond uit een proteussyndroom (OMIM \#I76920), syndroom van Ollier/Maffucci (OMIM \#I66000) of een macrodystrophia lipomatosa. Het ollier/maffuccisyndroom word gekenmerkt door meerdere goedaardige intramedullaire (centraal in het bot gelegen) kraakbeentumoren. In het maffuccisyndroom komen daarbij ook vasculaire malformaties voor. Radiologisch onderzoek toonde geen enchondromen waardoor de diagnose ollier/ maffuccisyndroom kwam te vervallen. De criteria voor het proteussyndroom (tabel) zijn zeer strikt en er waren onvoldoende criteria om deze diagnose te bevestigen. ${ }^{\mathrm{I}}$ Op basis van klinisch onderzoek en radiologische bevindingen stelden wij de diagnose macrodystrophia lipomatosa. Dit is een zeldzame vorm van aangeboren botovergroei die meestal leidt tot macrodactylie en gepaard gaat met een traag progressieve overgroei van het omgevende fibroadipeus weefsel. ${ }^{2}$ Hiernavolgend zullen we eerst de beide patiënten voorstellen en daarna op de gestelde diagnose ingaan.

\section{CASUS 1}

Een man van 55 jaar presenteerde zich op onze polikliniek met een vergrote tweede en derde straal van de linkerhand en toegenomen omvang van de rechteronderarm. Deze afwijkingen manifesteerden zich op de jonge kinderleeftijd. Patiënt is de enige in zijn familie met dergelijke problematiek. In het verleden werd bij hem de diagnose proteussyndroom gesteld. Hij kwam bij ons met sinds twee jaar bestaande recidiverende pijnklachten in de rechteronderarm. Neurologisch onderzoek kon geen verklaring vinden voor deze pijnklachten. Als medicatie gebruikte hij metoprolol, losartan, chloorthalidon, diazepam en paroxetine.

Bij klinisch onderzoek zagen wij een toegenomen omvang en dwangstand van de tweede en derde vinger van de linkerhand (figuur IA, B). Aan de rechteronderarm zagen we een prominente vaattekening. Enkele lenticulaire noduli waren voelbaar in het verloop van de vaten. De omtrek van de rechteronderarm was ook iets groter in vergelijking met de linkeronderarm. Er waren geen fluctuerende zwellingen palpabel. Bij overig lichamelijk onderzoek waren er geen andere afwijkingen.

Op basis van de toegenomen omvang van de vingers en de aanwezigheid van een mogelijke vasculaire malformatie in de rechteronderarm dachten we in de eerste plaats aan het syndroom van Ollier/maffucci. Daarnaast overwogen wij een macrodystrophia lipomatosa.

Radiologisch onderzoek van de rechteronderarm toonde flebolieten en een zwelling van de subcutane weke delen die niet eenduidig te verklaren is (figuur IC). Aan de linkeronderarm konden geen afwijkingen worden vastgesteld. De linkerhand toonde duidelijk vergrote metacarpalen II en III, waarbij

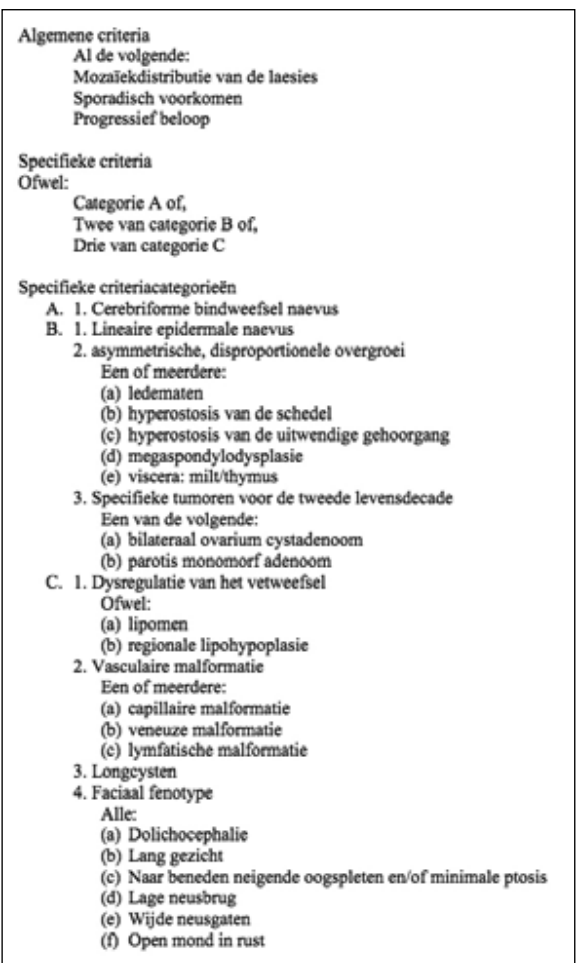

Tabel. Om de diagnose proteussyndroom te stellen, moet er sprake zijn van alle algemene criteria en meerdere specifieke criteria. Tabel gebaseerd op Biesecker. ${ }^{1}$

ook de falangen van de tweede en derde straal in omvang waren toegenomen (figuur ID). Tevens was er een standsafwijking van de midfalanx van de vierde straal en verandering van het caput van de proximale falanx. Er was sprake van cortexverbreding en botapposities zonder lucenties en met duidelijke trabeculatie. Radiologisch onderzoek van de rechterhand toonde onregelmatigheid van de cortex met verbreding van de schacht van de mid- en basisfalanx van de vierde straal (figuur IE). Deze afwijking lijkt op een exostose, echter betreft het niet het typische beeld noch de typische locatie. De radioloog concludeerde dat er geen sprake is van enchondromen en dat het radiologisch beeld goed kan passen bij een macrodystrophia lipomatosa.

De criteria voor het proteussyndroom (zie tabel) zijn strikt en de patiënt blijkt er niet aan te voldoen. Het radiologisch beeld van enchondromen is zeer typisch en werd hier niet gezien, waardoor een diagnose van het ollier/maffuccisyndroom vervalt. Aangezien het hier om een zeer gelokaliseerde, aangeboren vorm van botovergroei gaat, is zowel op klinische als radiologische grond een diagnose van macrodystrophia lipomatosa het meest waarschijnlijk.

De patiënt werd vervolgens uitvoerig geïnformeerd. De pijnklachten zijn vooralsnog onbegrepen en werden behandeld met naproxen coated $250 \mathrm{mg}$ maximum 4 per dag, in combinatie met pantoprazol 40 
mg I per dag. In de nabije toekomst zal aanvullend onderzoek plaatsvinden om de vasculaire afwijking in de rechteronderarm verder in kaart te brengen.

\section{CASUS 2}

Bij een vrouw van 47 jaar met toegenomen omvang van de eerste en tweede straal van de rechterhand en de rechterpols werd in het verleden de diagnose proteussyndroom gesteld. Deze afwijking zou kort na de geboorte zijn ontstaan. Zij werd in het verleden reeds eerder aan de getroffen hand geopereerd met het oog op een grotere functionaliteit van de getroffen vingers. Zij raadpleegde ons op het genetica-dermatologiespreekuur met de vraag naar genetisch onderzoek om de eerder gestelde diagnose van

haar familie vertoonde gelijksoortige klachten. Zij was verder goed gezond, moeder van drie gezonde kinderen en gebruikte geen medicatie.

Bij klinisch onderzoek zagen we een nodulaire beenharde vergroting van digitus I en 2 van de rechterhand, waarbij de vingers in extensiestand gefixeerd waren (figuur 2A). Volair, aan de radiale zijde van de polsbasis was een wat sponzig aanvoe-

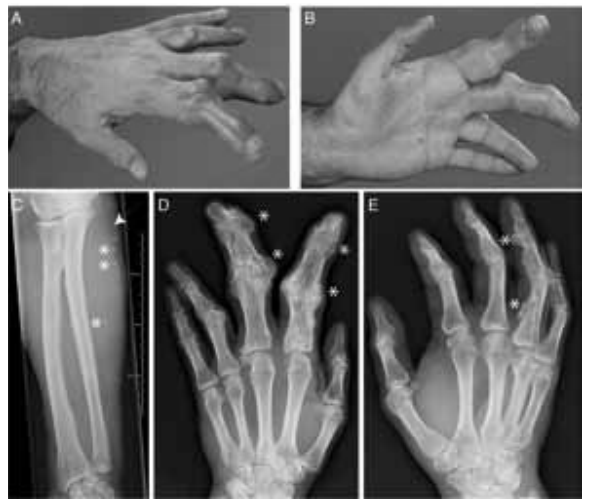

Figuur 1. (A,B) Dorsale (A) en volaire (B) zijde van de linkerhand van de man in casus 1. De tweede en derde straal van de linkerhand tonen een toegenomen omvang en beenharde noduli die met name ter hoogte van proximale interphalangeale gewrichten aanwezig zijn. Ook op het dorsum van de tweede straal en aan de radiale zijde van de derde en virede straal zien we huidkleurige beenharde noduli. (C) Röntgenopname van de rechteronderarm waarbij de radius en ulna geen afwijkingen vertonen, doch flebolieten zichtbaar zijn (*) en een zwelling van de subcutane weke delen die niet eenduidig te verklaren is (pijl). (D) De linkerhand toont hypertrofe metacarpalen II en III waarbij ook de falangen van de tweede en derde straal in omvang zijn toegenomen. Tevens is er een standsafwijking van de midfalanx van de vierde straal en verandering van het caput van de proximale falanx. Er is sprake van cortexverbreding, botapposities met duidelijke trabeculatie en gewrichtsdestructie (*). (E) De rechterhand toont op exostose gelijkende botapposities op de mid-en basisfalanx van de vierde straal (*). lende grote subcutane nodus palpabel.

Differentiaal diagnostisch werd gedacht aan het syndroom van Ollier/Maffucci of een macrodystrophia lipomatosa.

Radiologisch onderzoek van de rechterhand toonde overgroei van de distale falanx van digitus I. Er was tevens een duidelijke verbreding van de basis van metacarpaal I waarvan de contouren scherp begrensd waren, en met een normale architectuur van het medullaire bot (figuur $2 \mathrm{C}$ ). Verder zagen we verbreding van het metacarpophalangeaal (MCP) en interphalangeaal gewricht van digitus I. Daarbij was ter hoogte van het MCP-gewricht nauwelijks nog kraakbeen aanwezig met een functionele ankylose tot gevolg. De proximale falanx van digitus 2 toonde een onregelmatige scherpe subchondrale contour met iets toegenomen sclerose. Er was versmalling van het gewrichtskraakbeen in het PIP-gewricht en een beeld van ankylosering in het DIP-gewricht. Het os trapezium toonde botovergroei met hoekige contouren (figuur $2 \mathrm{C}$ ). Verder was er een wekedelenverbreding van duim en duimmuis met ter plaatse van de duimmuis een duidelijke vettige component tussen de spiervezels. Aanvullend MRI-onderzoek kon deze prominente toename van

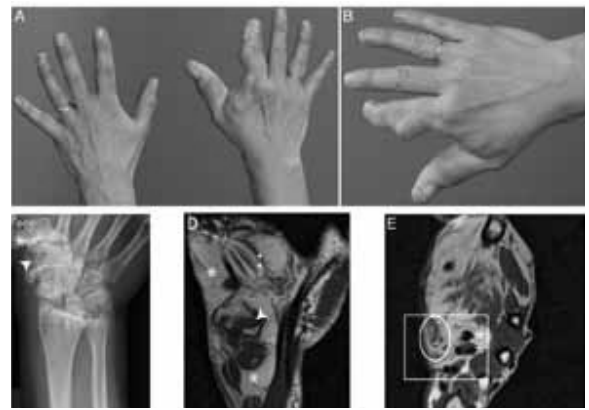

Figuur 2. (A, B) Dorsale zijde van de handen van de vrouwelijke patiënte uit casus 2 (A) met detailopname van de rechterhand in (B). Digitus 1 en 2 van de rechterhand zijn in omvang toegenomen. Met name ter hoogte van de tweede straal zien we beenharde huidskleurige noduli. Volair aan de radiaire zijde van de basis van de handpalm kunnen we een wat sponzig aanvoelende subcutane nodus palperen. (C) Er is tevens een duidelijke verbreding van de basis van metacarpaal 1 waarvan de contouren scherp begrensd zijn (*). Het os trapezium toont botovergroei met hoekige contouren (pijl). (D) MRI (coronale T1-gewogen sequentie) van de rechterpols laat een disproportionele overgroei van het vetweefsel zien (*) met infiltratie van vetweefsel in de spierbuiken van de abductor pollicis brevis (:). Daarnaast is er ook hypertrofie van het synoviaal gewrichtskapsel (pijl). (E) Op een transversale T1-gewogen sequentie van de rechterhand laat MRI een toegenomen omvang van de nervus medianus zien als gevolg van infiltratie door vetweefsel. Hierdoor zijn de vezels van de zenuw separaat van elkaar zichtbaar (ovale). Door toename van het vetweefsel aan de buigzijde van de pols worden de flexor-digitorumpezen naar ulnair verplaatst ( $*$ in rechthoek). 
subcutaan vet bevestigen (figuur 2D, E). Op de MRIopnames werd een volumevergroting van de nervus medianus gezien waarbij de vezels van de zenuw separaat van elkaar zichtbaar zijn als gevolg van infiltratie van vetweefsel (figuur 2D). Samen met het hypointens weefsel rond deze vergrote nervus medianus, duidend op perineurale fibrose, kan dit passen bij een fibrolipomateus hamartoom van de nervus medianus. De disproportionele overgroei van vetweefsel aan de buigzijde van de pols verplaatst de flexor-digitorumpezen naar ulnair (figuur 2D). Enchondromen werden niet gezien en op basis van de gelokaliseerde botovergroei en het fibrolipomateus hamartoom stelden wij de diagnose macrodystrophia lipomatosa.

\section{BESPREKING}

Macrodystrophia lipomatosa (ML) is een zeldzame gelokaliseerde overgroei van mesenchymale weefsels waaronder bot- en vetweefsel, wat leidt tot gigantisme van een of meerdere digiti, of ook wel van een geheel lidmaat. Fibroadipeus weefsel infiltreert de nabijgelegen pezen, spieren en/ of zenuwen wat kan leiden tot een fibrolipomateus hamartoom. ${ }^{3,4}$ Net zoals bij onze vrouwelijke patiënte is hierbij vaak de nervus medianus van de hand aangedaan (figuur 2E, F). Hypertrofie van het bot kan tot op exostose gelijkende afwijkingen leiden (figuur IE). ${ }^{5}$ Gewrichtspleetvernauwing en osteofietformatie met compressie van neurovasculaire structuren leidt meestal tot ankylose, gewrichtsdestructie en functionele beperkingen..$^{56}$ De trabeculaire structuur van het bot blijft intact. De aandoening kan bilateraal voorkomen doch dit blijkt zeldzaam. ML is vaak progressief en vereist soms meerdere chirurgische ingrepen omwille van esthetische en/of functionele redenen. De ziekte kan zich manifesteren op jonge kinderleeftijd zoals bij onze patiënten of slechts op volwassen leeftijd kenbaar worden. De wekedelengroei stopt meestal bij het aflopen van de groeispurt, maar progressie is ook beschreven op volwassen leeftijd.? Bij een gelokaliseerde overgroei van enkele digiti of een geheel lidmaat denken we naast macrodystrophia lipomatosa ook aan het syndroom van Ollier/ Maffucci gekenmerkt door multiple enchondromen, en een proteussyndroom. Indien er eveneens sprake is van een capillaire malformatie op het getroffen lidmaat moet ook aan een klippel-trenaunaysyndroom gedacht worden. De afwezigheid van enchondromen en een naevus flammeus, evenals de eerder trage progressie van het ziektebeeld die atypisch is voor een proteussyndroom, bracht ons tot de diagnose macrodystrophia lipomatosa.

De moleculaire basis van macrodystrophia lipomatosa is onbekend. Klinisch lijkt deze aandoening sterk op het syndroom van Ollier/Maffucci. Dit is een zeldzame, sporadisch voorkomende ziekte gekenmerkt door benigne kraakbeenvormende tumoren in de medulla van het bot. Recent werden in de enchondromen en hemangiomen somatische heterozygote puntmutaties aangetoond in IDHI en IDH2.8,9 Deze genen coderen voor isocitraat dehydrogenase, een enzym uit de citroenzuurcyclus. Mutaties in IDHı en IDH2 werden ook eerder aangetoond in gliomen, acute myeloïde leukemie en chondrosarcomen, en leiden tot de productie van 2 -hydroxyglutaraat (2HG). Deze verandert het methylatieprofiel van DNA waardoor differentiatie van cellijnspecifieke voorlopercellen wordt verhinderd. Bij het ollier/maffuccisyndroom wordt aangenomen dat $2 \mathrm{HG}$ de differentiatie van immature chondrocyten remt, met clusters van prolifererende chondrocyten of enchondromen tot gevolg. Op een dergelijke wijze zouden IDH-mutaties ook kunnen bijdragen aan de vet- en botovergroei die we zien bij macrodystrophia lipomatosa.

Anderzijds zou macrodystrophia lipomatosa moleculair ook verwant kunnen zijn aan het proteussyndroom. Ook al is er bij macrodystrophia lipomatosa geen sprake van de sterk progressieve groei van mesenchymale weefsels zoals die bij Proteus gezien wordt, toch zit er in het sporadisch en in mozaiek voorkomen van de bot- en vetweefselovergroei een gelijkenis met Proteus. Getroffen weefsels bij Proteus hebben een activerende mutatie in AKTr.Io Het AKTI-oncogen codeert voor AKTI-kinase, een enzym dat betrokken is bij processen zoals celproliferatie en apoptose. De mutatie in AKTI leidt tot activatie van $\mathrm{PI}_{3} \mathrm{~K}$-AKT-signalering in de cel, met stimulatie van mTOR (mammalian target of rapamycin) en overgroei van getroffen weefsels tot gevolg. Genetisch onderzoek van een biopt uit de nodus op de duimmuis bij onze vrouwelijke patiënte waar MRI overmaat van fibroadipeus weefsel toonde, zal hopelijk meer duidelijkheid scheppen over een mogelijke verwantschap met het proteus- of ollier/ maffuccisyndroom. Differentiatie van het ollier/ maffuccisyndroom is belangrijk daar bij deze laatste groep patiënten excisie van solitaire enchondromen de evolutie tot het maligne chondrosarcoom kan verhinderen. Mocht macrodystrophia lipomatosa genetisch verwant blijken aan het proteussyndroom zullen we bedacht zijn op AKTI-mozaïeken elders in het lichaam en screenen voor de bij Proteus typisch voorkomende tumoren. In dit laatste geval zouden ook remmers van AKTI en mTOR zoals rapamycine een therapeutische uitkomst kunnen bieden voor patiënten met macrodystrophia lipomatosa.

\section{LITERATUUR}

1. Biesecker L. The challenges of Proteus syndrome: diagnosis and management. Eur J Hum Genet 2006;14:1151-7.

2. Khan RA, Wahab S, Ahmad I, Chana RS. Macrodystrophia lipomatosa: four case reports. Ital J Pediatr 2010;36:69.

3. Cavallaro MC, Taylor JA, Gorman JD, Haghigh $P$, Resnick $D$. Imaging findings in a patient with fibrolipomatous hamartoma of the median nerve. AJR Am J Roentgenol 1993;161:837-8.

4. Silverman TA, Enzinger FM. Fibrolipomatous hamartoma of nerve. A clinicopathologic analysis of 26 cases. Am J Surg Pathol 1985;9:7-14.

5. Boren WL, Henry RE, Jr., Wintch K. MR diagnosis 
of fibrolipomatous hamartoma of nerve: association with nerve territory-oriented macrodactyly (macrodystrophia lipomatosa). Skeletal Radiol 1995;24:296-7.

6. Meyer BU, Roricht S. Fibrolipomatous hamartoma of the proximal ulnar nerve associated with macrodactyly and macrodystrophia lipomatosa as an unusual cause of cubital tunnel syndrome. J Neurol Neurosurg Psychiatry 1997;63:808-10.

7. Bailey EJ, Thompson FM, Bohne W, Dyal C. Macrodystrophia lipomatosa of the foot: a report of three cases and literature review. Foot Ankle Int 1997;18:89-93.

8. Amary MF, Damato S, Halai Det al. Ollier disease and Maffucci syndrome are caused by somatic mosaic mutations of IDH1 and IDH2. Nat Genet 2011;43:1262-5.

9. Pansuriya TC, Eijk $R$ van, Adamo Pet d', et al. Somatic mosaic IDH1 and IDH2 mutations are associated with enchondroma and spindle cell hemangioma in Ollier disease and Maffucci syndrome. Nat Genet 2011;43:1256-61.

10. Lindhurst MJ, Sapp JC, Teer JK, et al. A mosaic activating mutation in AKT1 associated with the Proteus syndrome. N Engl J Med 2011;365:611-9.

\section{SAMENVATTING}

Macrodystrophia lipomatosa is een zeldzame aandoening gekenmerkt door gelokaliseerde overgroei van de weke delen, vooral vetweefsel, en bot. Dit laatste resulteert vrijwel altijd in macrodactylie en degeneratieve gewrichtsveranderingen op latere leeftijd. De ziekte kan zich reeds bij de neonaat of eerst op volwassen leeftijd manifesteren. Patiënten bezoeken de arts omwille van het cosmetisch storende aspect en/of een functionele beperking in het betrokken gewricht. Wij zagen twee patiënten met macrodactylie waarbij eerder de diagnose proteussyndroom werd gesteld. Bij klinisch onderzoek bleken echter onvoldoende criteria aanwezig om deze diagnose te ondersteunen. Op grond van de klinisch onderzoek en radiologische bevindingen werd de diagnose macrodystrophia lipomatosa gesteld. De oorzaak van macrodystrophia is vooralsnog onbekend doch de overlap met het proteus- en ollier/maffuccisyndroom pleit voor een mozaïek door een somatische mutatie of verlies van heterozygositeit bij een kiembaanmutatie.

\section{TREFWOORDEN}

macrodactylie - bot - vetweefsel - mozaïek - AKT Proteus - Ollier/Maffucci

\section{SUMMARY}

Macrodystrophia lipomatosa is a rare disorder of localized hamartomatous overgrowth of soft tissue components, particularly adipose tissue, and bone. Macrodactyly of a few digits and degenerative joint disease are common findings. The disorder can be congenital or present later in life, sometimes only in late adulthood. Patients usually consult a physician for cosmetic reasons and/ or functional deficits in the affected joints. We present two patients with macrodactyly who were previously diagnosed with Proteus syndrome. Clinical investigation, however, revealed insufficient criteria and a diagnosis of macrodystrophia lipomatosa was made. Its cause is yet unknown, though its similarity to Proteus and Ollier/ Maffucci syndrome suggests that it is a genetic mosaic due to somatic mutation or loss of heterozygosity for a germline mutation.

\section{KEY WORDS}

macrodactyly - bone - adipose tissue - mosaic - AKT Proteus - Ollier/Maffucci 

CHAPTER 5

\section{Miscellaneous conditions}


CHAPTER 5 
If a case could not be assigned to any of the first three subgroups (dermatooncogenetic, disorders involving the X-chromosome), it was classified as miscellaneous. In the cohort of 409 patients, 236 belonged to this group. Of these 236 patients, 68 visited the outpatient clinic with questions about connective tissue disorders. 25 patients were diagnosed with a non-genetic condition, for example morphea or onychomycosis. In the remaining 143 individuals, a diagnosis was possible in 72 of them, sub-classified according to Sybert ${ }^{1}$ (Table 5.1). In 42 of these 72 patients, the diagnosis could be confirmed by molecular studies. Many of the disorders diagnosed in the miscellaneous group were only seen once in our cohort. Several diagnoses (for example Prader-Willi syndrome) or diagnostic subsets (for example, various types of ichthyosis or RASopathies) were seen more frequently. Therefore, these are highlighted in the following paragraphs.

\section{The Prader-Willi syndrome}

A cohort of 13 persons with Prader-Willi syndrome were seen. Prader-Willi syndrome (PWS) is a genetic disorder, causing mild intellectual disability, obesity, facial dysmorphism, behavioural problems and hypogonadotrophic hypogonadism. Skin abnormalities include acanthosis nigricans, hypopigmentations, lymphedema and traumatic lesions caused by skin picking ${ }^{2}$. We evaluated this group of individuals for skin abnormalities, searching for underlying cutaneous disorders that might evoke the picking behaviour.

Skin picking (86\%) and hypopigmentation (50\%) were frequently observed in these individuals. We found an unexpectedly high incidence of eczema, lymphedema and varicose veins compared to the population attending the Department of Dermatology in general (personal observation). Therefore we recommend a thorough dermatological examination at least once and stay in follow-up, even in the absence of dermatological complaints in this high risk patient population(Unpublished results).

\section{Ichthyoses}

The ichthyoses form a subset for which enrichment in the cohort was observed $\left(\mathrm{n}=9\right.$ ). The new MEDOC classification established in $2010^{3}$, classifies ichthyoses according to their clinical presentation, thereby facilitating targeted DNA analysis. In 8 of the 9 cases in the cohort, the presumptive diagnosis of a specific form of ichthyosis could be confirmed by molecular studies. This corroborates the assumption that a good clinical classification can lead to the correct molecular diagnosis. 


\section{RASopathies}

A syndrome that is well-known to the clinical geneticist is Noonan syndrome, one of the RASopathies ${ }^{4}$. Specific dermatologic abnormalities are part of RASopathies, such as lymphedema, lentigines, café au lait spots, hair abnormalities (for example, curly or sparse hair) and keratosis pilaris. ${ }^{5}$. These signs are clinical clues for the diagnosis of a RASopathy, even in young patients under the age of 1 year ${ }^{6}$. The patients in our cohort all consulted us because of lymphedema (Table 5.1).

Isolated lymphedema (not being part of a syndrome) belong to the same cluster and forms a diagnostic challenge from a genetics perspective, as not much is known about the genetic basis of non-syndromic lymphedema. Early recognition of individuals with lymphedema is important to provide treatment in an early phase, thereby improving long-term outcome.

\section{Cerebral cavernous malformations (CCM)}

Skin involvement (hyperkeratotic cutaneous capillary-venous malformations) has been reported in patients with cerebral cavernous malformations (CCM, OMIM\#116860), but is thought to be rare or not a specific feature. However, when carefully examining the skin of the two patients with CCM in our cohort, we observed these specific skin malformations in both patients. Recently we diagnosed two more families with CCM which are not part of the cohort. Hyperkeratotic cutaneous capillary-venous malformations were seen in all affected members we examined. Based on our experience, we suggest that a skin examination could be an inexpensive and easy way to assess whether a family member is likely to carry the gene mutation for CCM. 


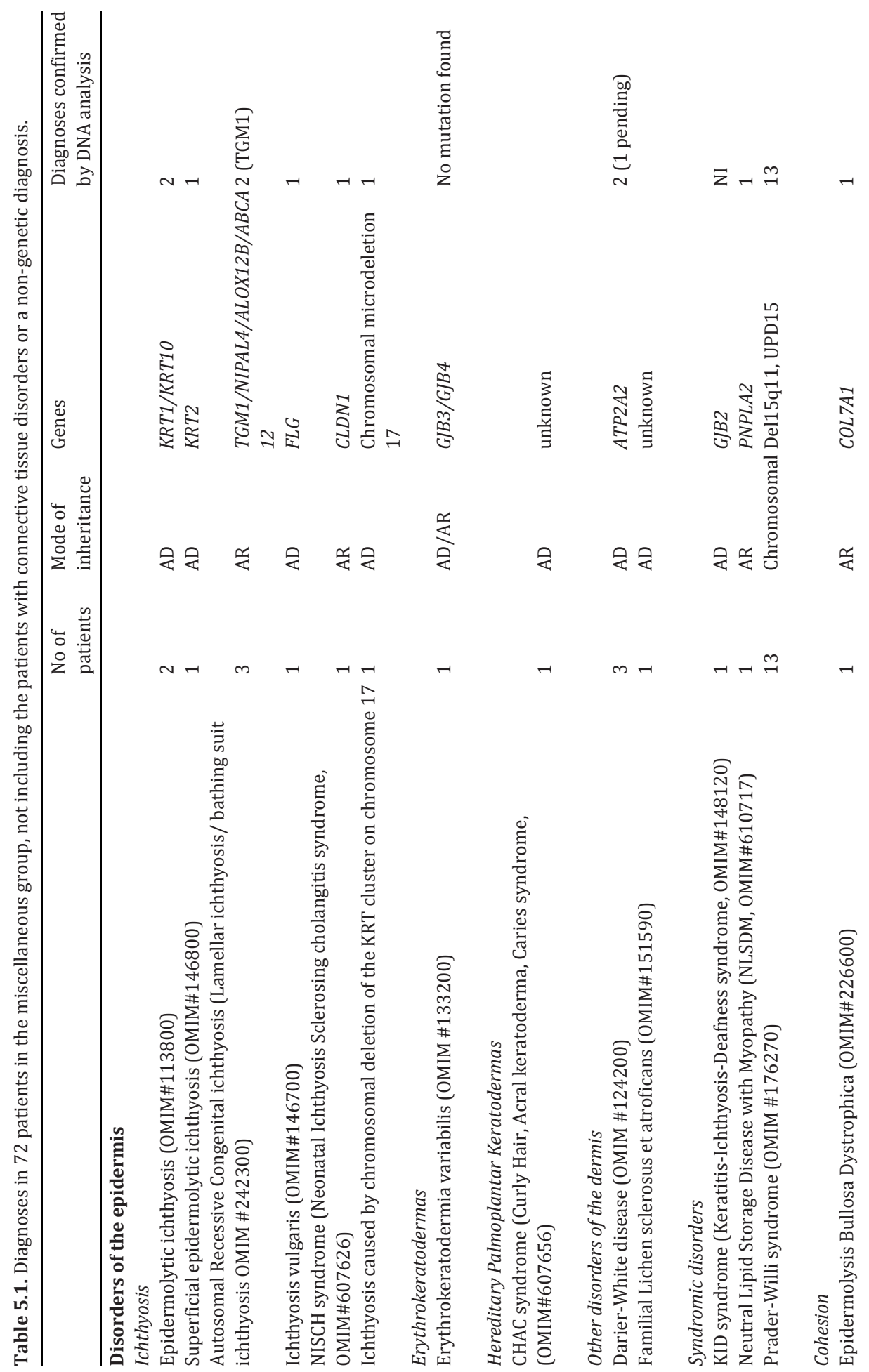




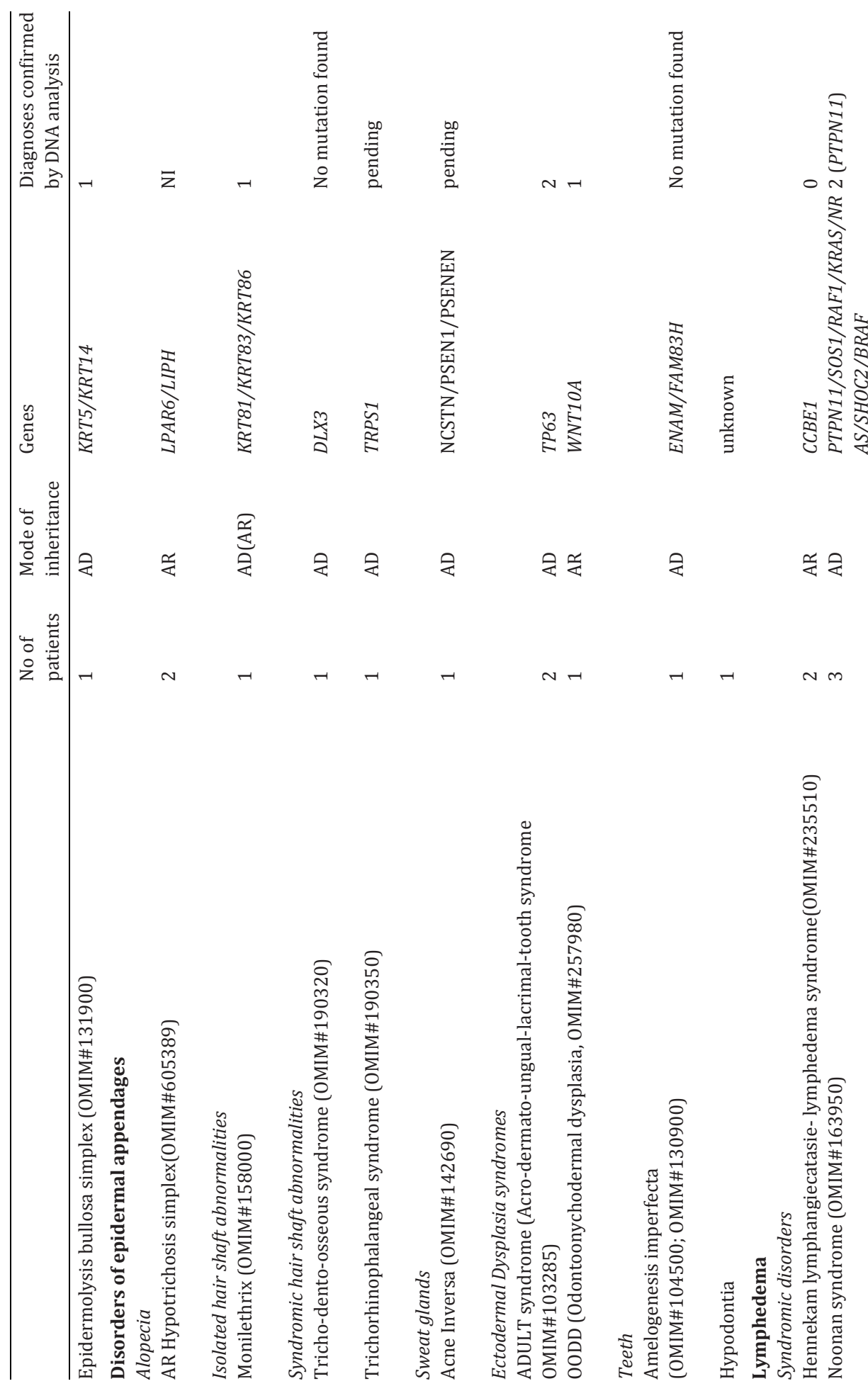




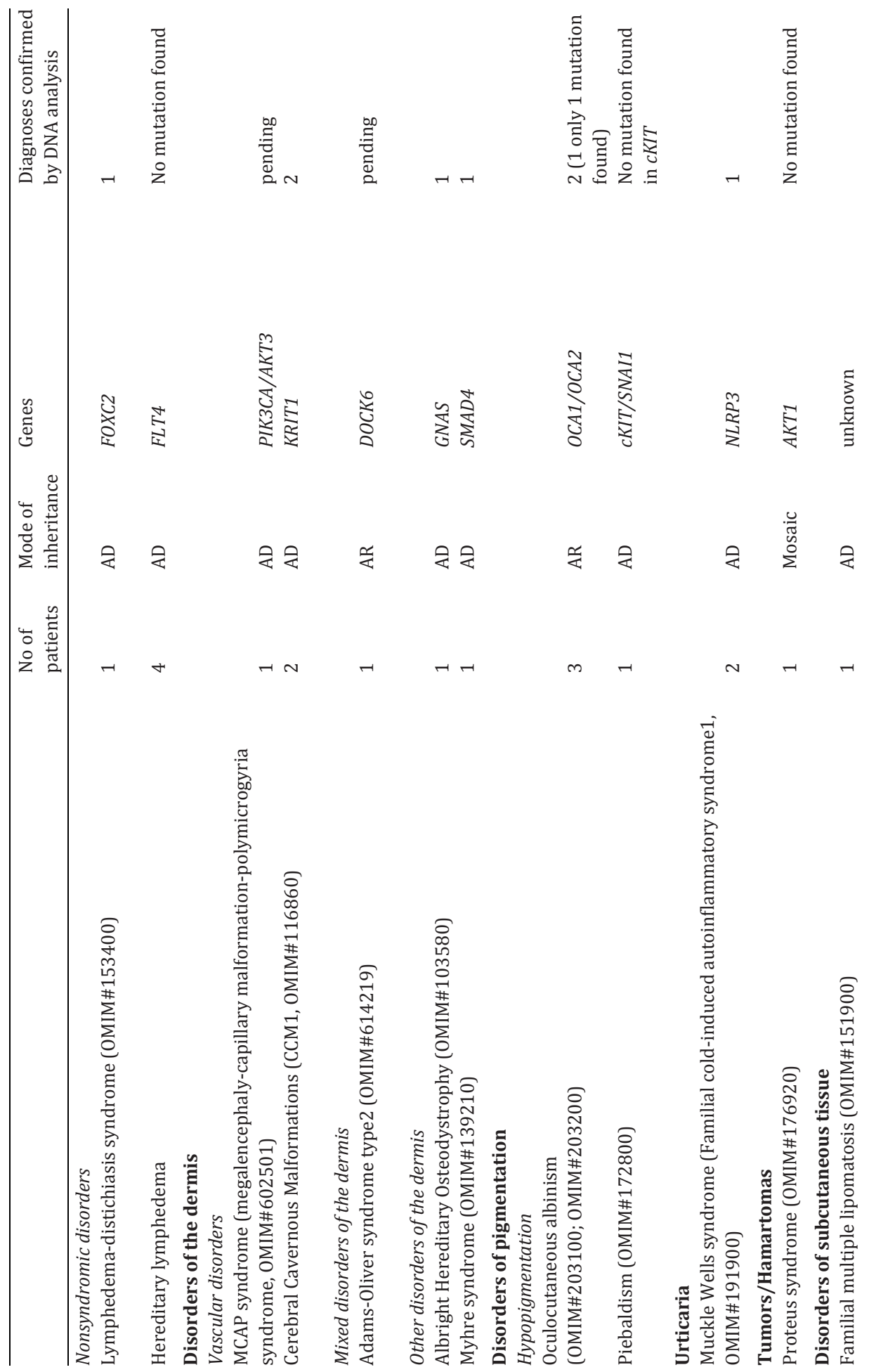


CHAPTER 5

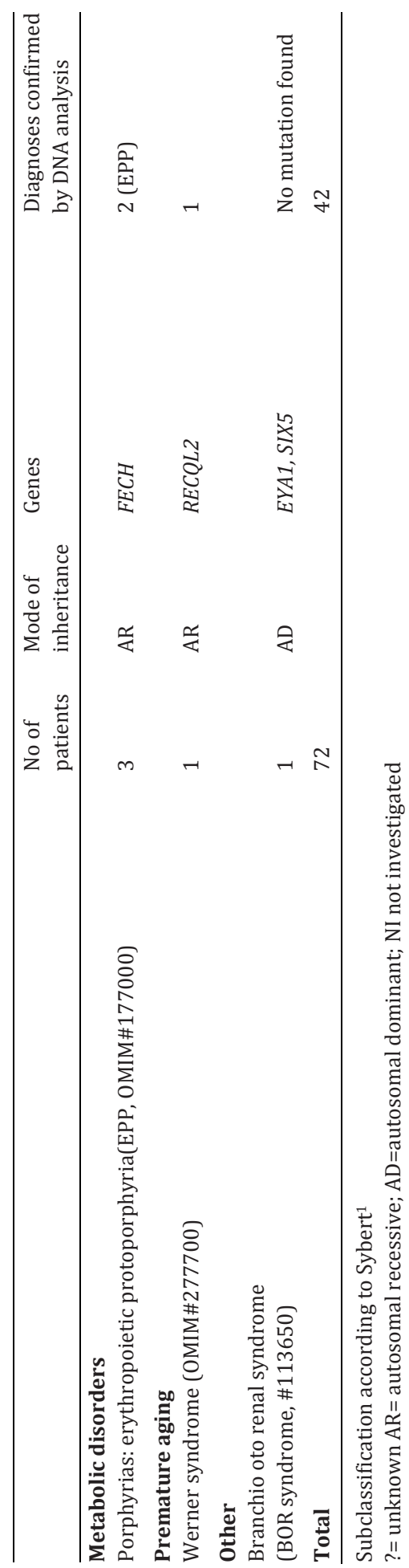


In 71 patients, we did not reach a conclusive diagnosis (table 5.2). 34 of these patients were referred to the out-patient clinic "Genodermatoses" with mental retardation, with or without multiple congenital anomalies. Referring specialists asked our opinion whether or not the skin anomalies seen in these patients could be a part of the phenotype and/or be a clue in finding the correct syndrome diagnosis. In 25 patients the skin anomalies were not likely to be a clue for the diagnosis or part of the phenotype. In 9 cases it seemed that they might be a part of the phenotype. In 4 patients, a (genetic) auto-immune disorder was.

The remaining 33 patients are without diagnosis. Most of them stay in a follow-up programme.

Table 5.2. Characteristics of patients in the miscellaneous group without a conclusive diagnosis.

\begin{tabular}{lcc}
\hline & Number of patients & Males/females \\
\hline $\begin{array}{l}\text { Mental retardation+/- multiple congenital anomalies: is the skin } \\
\text { anomaly part of the phenotype? }\end{array}$ & 34 & $20 / 14$ \\
Phenotypes suggestive for a (genetic) autoimmune disorder & 4 & $2 / 2$ \\
Unknown diagnosis & 33 & $8 / 25$ \\
Total & 71 & $30 / 41$ \\
\hline
\end{tabular}

\section{Connective tissue disorders and hypermobility}

In the cohort of 409 patients, 68 subjects were referred with a suspected hereditary connective tissue disorder such as Ehlers-Danlos syndrome (EDS). Counselees were scored for hypermobility using the Beighton scoring list and the skin was examined for known signs of EDS (hematoma, skin fragility, scarring, skin extensibility). A subgroup of the patients referred to us were females between 20 and 50 years, with a Beighton score between 4 and 7 points. The patients fulfilled the clinical criteria set for the Benign Joint Hypermobility syndrome (BJHMS ${ }^{7,8}$ ).

Pain in the musculoskeletal system and a positive family history for similar complaints as in the index case are regarded as additional clues for the diagnosis. Although pain and fatigue are part of this syndrome, and can have a major impact on activities of daily life, this condition is regarded as innocuous compared to the other subtypes of EDS. However, referral to a specialist in rehabilitation medicine in an early phase is strongly advised to prevent or postpone the development of a chronic pain syndrome. The majority of cases do not have mutations in the TNXBgene, supposedly involved in this condition ${ }^{9-11}$. Therefor, the diagnosis of this condition remains a clinical one. Whether EDS of the hypermobility type and BJHMS are different disorders on a molecular level, or different expressions of one disorder, remains unclear. Future plans include closer investigation of these patients to find its pathophysiological basis and to optimize treatment. 


\section{CHAPTER 5}

\section{References}

1. Sybert. Genetic Skin Disorders. 2nd ed. New York: Oxford University Press; 2010.

2. Schrander-Stumpel CT, Sinnema M, van den Hout L, et al. Healthcare transition in persons with intellectual disabilities: general issues, the Maastricht model, and PraderWilli syndrome. American journal of medical genetics Part C, Seminars in medical genetics 2007;145C:241-7.

3. Oji V, Tadini G, Akiyama M, et al. Revised nomenclature and classification of inherited ichthyoses: results of the First Ichthyosis Consensus Conference in Soreze 2009. J Am Acad Dermatol 2010;63:607-41.

4. Tidyman WE, Rauen KA. The RASopathies: developmental syndromes of Ras/MAPK pathway dysregulation. Curr Opin Genet Dev 2009;19:230-6.

5. Weiss G, Confino Y, Shemer A, Trau H. Cutaneous manifestations in the cardiofaciocutaneous syndrome, a variant of the classical Noonan syndrome. Report of a case and review of the literature. J Eur Acad Dermatol Venereol 2004;18:324-7.

6. Digilio MC, Lepri F, Baban A, et al. RASopathies: Clinical Diagnosis in the First Year of Life. Mol Syndromol 2011;1:282-9.

7. Remvig L, Jensen DV, Ward RC. Epidemiology of general joint hypermobility and basis for the proposed criteria for benign joint hypermobility syndrome: review of the literature. J Rheumatol 2007;34:804-9.

8. Mishra MB, Ryan P, Atkinson P, et al. Extra-articular features of benign joint hypermobility syndrome. Br J Rheumatol 1996;35:861-6.

9. Callewaert B, Malfait F, Loeys B, De Paepe A. Ehlers-Danlos syndromes and Marfan syndrome. Best Pract Res Clin Rheumatol 2008;22:165-89.

10. Schalkwijk J, Zweers MC, Steijlen PM, et al. A recessive form of the Ehlers-Danlos syndrome caused by tenascin-X deficiency. N Engl J Med 2001;345:1167-75.

11. Bristow J, Carey W, Egging D, Schalkwijk J. Tenascin-X, collagen, elastin, and the Ehlers-Danlos syndrome. Am J Med Genet C Semin Med Genet 2005;139C:24-30 


\title{
Clinical Report Skin Changes in Oculo-Dento-Digital Dysplasia Are Correlated With C-terminal Truncations of Connexin 43
}

\author{
M. Vreeburg, ${ }^{1}$ E.A. de Zwart-Storm, ${ }^{2}$ M.I. Schouten, ${ }^{1}$ R.G.L. Nellen, ${ }^{2}$ D. Marcus-Soekarman, ${ }^{1}$ \\ M. Devies, ${ }^{3}$ M. van Geel, ${ }^{2}$ and M.A.M. van Steensel ${ }^{2 *}$ \\ ${ }^{1}$ Departments of Clinical Genetics, University Hospital Maastricht, Maastricht, The Netherlands \\ ${ }^{2}$ Departments of Dermatology, University Hospital Maastricht, Maastricht, The Netherlands \\ ${ }^{3}$ Dental Practice, Elsloo, The Netherlands \\ Received 17 May 2006; Accepted 1 October 2006
}

\begin{abstract}
Oculo-dento-digital dysplasia (ODDD, OMIM no.164210) is a pleiotropic disorder caused by mutations in the GJA1 gene that codes for the gap junction protein connexin 43. While the gene is highly expressed in skin, ODDD is usually not associated with skin symptoms. We recently described a family with ODDD and palmoplantar keratoderma. Interestingly, mutation carriers had a novel dinucleotide deletion in the GJA1 gene that resulted in truncation of part of the Cterminus. We speculated, that truncation of the C-terminus may be uniquely associated with skin disease in ODDD. Here, we describe a patient with ODDD and palmar
\end{abstract}

hyperkeratosis caused by a novel dinucleotide deletion that truncates most of the connexin 43 C-terminus. Thus, our findings support the notion that such mutations are associated with the occurrence of skin symptoms in ODDD and provide the first evidence for the existence of a genotype-phenotype correlation. () 2007 Wiley-Liss, Inc.

Key words: oculo-dento-digital dysplasia; connexin 43; gap junction; keratoderma

How to cite this article: Vreeburg M, de Zwart-Storm EA, Schouten MI, Nellen RGL, Marcus-Soekarman D, Devies M, van Geel M, van Steensel MAM. 2007. Skin changes in oculo-dento-digital dysplasia are correlated with C-terminal truncations of connexin 43. Am J Med Genet Part A 143A:360-363.

\section{INTRODUCTION}

Oculo-dento-digital dysplasia (ODDD, OMIM no.164210) is caused by heterozygosity for mutations in the GJA1 gene that codes for the gap junction protein connexin 43 [Paznekas et al., 2003]. Fairly consistent features of the syndrome are facial dysmorphism, hypotelorism and hypoplasia of the alae nasi, dental abnormalities, digital anomalies (type III syndactyly), and white matter abnormalities with or without neurological manifestations [Loddenkemper et al., 2002]. A genotype-phenotype correlation has so far not been demonstrated for most mutations. However, we recently reported on a Dutch family with ODDD and skin changes, caused by a dinucleotide deletion that causes a premature termination of the connexin 43 protein resulting in absence of most of the C-terminus [van Steensel et al., 2005]. At that time, we speculated that the skin changes might be related to the unique nature of the mutation. We found that, in our patients, connexin 43 was absent from keratinocyte cell membranes. Here, we present evidence that, at least for truncating mutations, there is a genotype-phenotype correlation in ODDD. We describe a new patient with ODDD and palmar keratoderma. She has a novel dinucleotide deletion in the GJA1 gene that leads to premature truncation of the connexin 43 protein, resulting in absence of most of the C-terminus. We suggest that C-terminal deletions in GJA1 correlate with the presence of skin symptoms in ODDD.

Grant sponsor: GROW research institute; Grant sponsor: Barrier Therapeutics NV; Grant sponsor: the La Roche Posay Research Fondation; Grant sponsor: Berliner Stiftung für Dermatologie.

${ }^{*}$ Correspondence to: M.A.M. van Steensel, M.D., Ph.D., Department of Dermatology, University Hospital Maastricht, PO Box 5800, 6202 AZ Maastricht, The Netherlands. E-mail: mvst@sder.azm.nl

DOI 10.1002/ajmg.a.31558 


\section{CLINICAL REPORT}

A 23-year-old woman of Dutch descent was referred to the department of Clinical Genetics for syndrome diagnosis since she had syndactyly of both hands. At birth, she had complete cutaneous syndactyly of digits III-V of both hands (type III syndactyly), which was surgically corrected in early childhood. After surgery the patient had normal hand function, but sensation was slightly decreased. Because of a narrow nose passage, she had difficulty in breathing through her nose. She was of normal intelligence but experienced problems in social interaction for which she visited a psychologist. No neurological problems were present; therefore no brain imaging had been performed. Her dentist had noted microdontia with hypoplasia of both medial incisors in the maxilla and amelogenesis imperfecta, causing caries and decay of the permanent teeth.

Upon physical examination in our clinic, she had a midface hypoplasia with a prominent mandible, small maxilla, and a thin nose with hypoplastic alae nasi (Fig. 1). She had attached earlobes bilaterally, pale green eyes, and freckling of the facial skin. Because she reported no visual disturbances, ophthalmologic examination was not performed. Her hair was sparse and slightly curly.

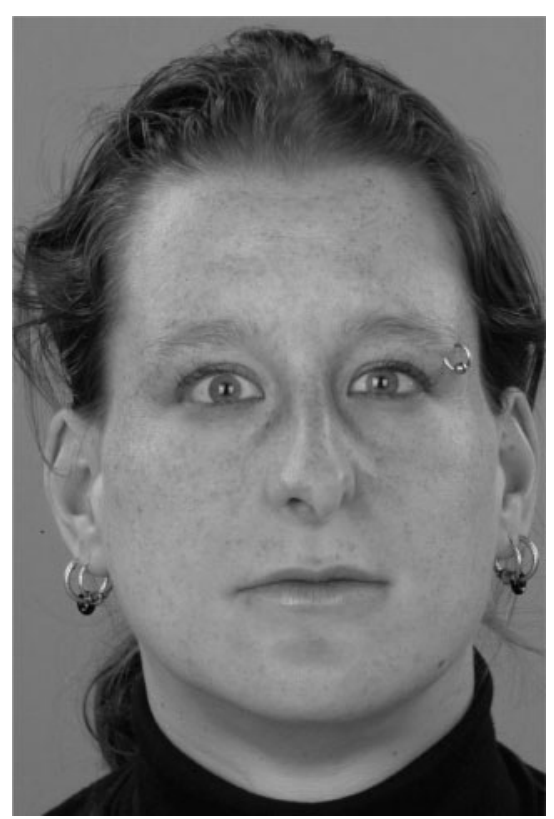

FIG. 1. Facial phenotype of the proposita. Note the hypoplastic alae nasi, hypotelorism, and thin nose.
Her hands showed the scars of previous surgery, with clinodactyly of several digits (Fig. 2A). The palms of her hands showed diffuse, nontransgredient palmar hyperkeratosis with a distinct orange hue (Fig. 2B). The plantar skin showed circumscribed hyperkeratoses but lacked the diffuse changes seen on the hands. The nails were normal. Her feet showed no syndactyly but there was bilateral shortening of digits II-V, most pronounced in digit $\mathrm{V}$ (Fig. 3). Skeletal radiographs were not available. Her parents and both her brothers did not have any form of syndactyly or dental abnormalities, nor did they show the typical facial dysmorphisms.

We made a diagnosis of ODDD and analyzed the GJA1 gene for mutations.

\section{MUTATION ANALYSIS}

Informed consent was obtained from the patient. DNA was isolated from peripheral blood leucocytes using methods described elsewhere [van Steensel et al., 2002].

A

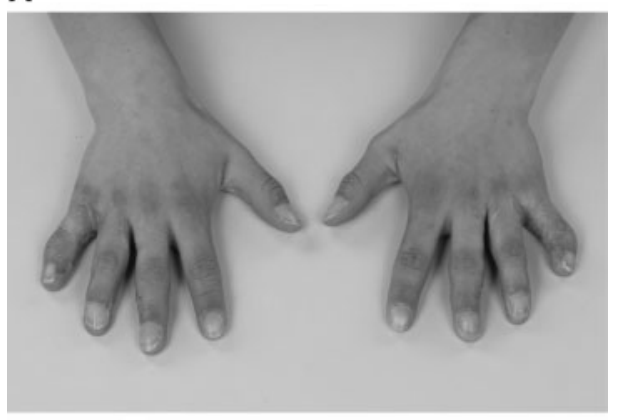

B

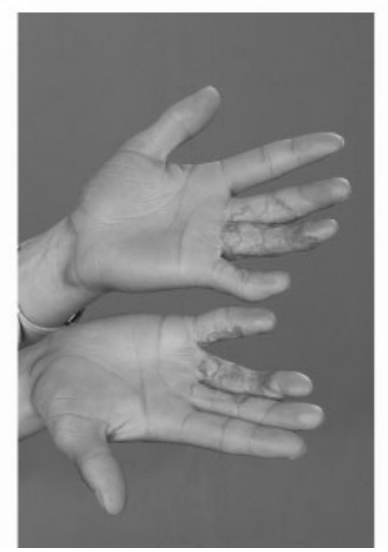

FIG. 2. A: The proposita's hands. B: A diffuse palmar hyperkeratosis with a distinctly orange hue. 


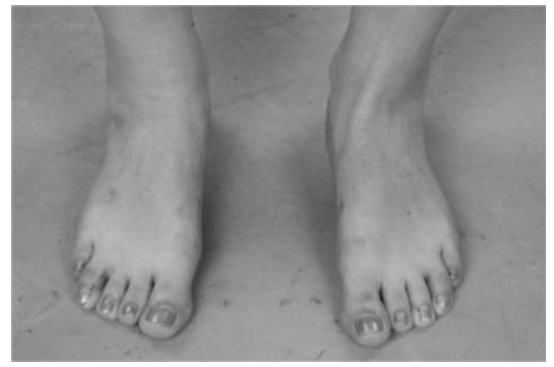

FIG. 3. Feet of the proposita with bilateral shortening of digit V.

The GJA1 gene was amplified with PCR using primers Cx43F 5'-TGGGACAGGAAGAGTTTGCAC$3^{\prime}$ and CX43R 5'-CACCTGGTGCACTTTCTACAGCAC- $3^{\prime}$. GJA1 has a pseudogene, hence the forward and reverse primers were designed to be in the GJA1 intron and in the 3' UTR, respectively. The gene was analyzed using PCR primers and the sequencing primers Cx43FS 5'-GGTGGCCTTCTTGCTGATCC-3', Cx43RS 5'-TGGGCAGGGATCTCTTTTGC-3', and CX43FS2 5'-GGTTGCCCAAACTGATGGTG-3', using the BigDyeDeoxy terminator system and an ABI 3100 capillary sequencer (Applied Biosystems, Foster City, CA).

\section{RESULTS}

We found a heterozygous dinucleotide deletion, 679_680delAT. This mutation is predicted to lead to a frameshift and a premature stop codon after six amino acid residues, Y230fsX236. We did not detect the mutation in the parents nor in 100 unrelated controls.

\section{DISCUSSION}

Here, we report on a patient with ODDD and a palmar keratoderma. We found a novel dinucleotide deletion that results in premature protein truncation. Previously, we discovered a similar mutation in other Dutch ODDD patients with prominent skin changes. Although the latter mutation deletes 30 amino acids less from the C-terminus, both result in the absence of a significant part of connexin 43's cytoplasmic tail. The new deletion we found confirms the idea that truncation leads to skin symptoms. We also noted somewhat curly hair in our patient. While this has been previously described as a symptom of ODDD caused by missense mutations [Kjaer et al., 2004], several of our patients with missense mutations do not have curly hair. Therefore, we are not sure whether hair growth patterns can be affected or not in ODDD, although the expression pattern of GJA1 suggests that they can. Our previously described patients may define a certain minimal size that the deletion must have for skin changes to occur. Both mutations result in the absence of the serines (364, 365, and 369) in the C-terminus that are phosphorylated by various kinases such as PKA and PKC [Solan and Lampe, 2005]. Absence of PKA-induced phosporylation of these serines, rather than absence of part of the protein per se, may underly the transport defect that we observed. Phosphorylation is involved in gap junction insertion into the cell membrane [Solan and Lampe, 2005]. In analogy, it may also be required for proper assembly in the endoplasmic reticulum. The finding, however, that a truncated connexin 43 in mice is transported normally as evident from membrane localization demonstrated by immunofluorescence [Kretz et al., 2004] contradicts this hypothesis. Therefore, we think that the presence of frameshifted amino acids is crucial to the transport defect. Preliminary functional data support this idea, showing that missense mutations in GJA1 do not affect transport while frameshift-truncation mutations do (unpublished data). In this regard, it is of interest to note that a recent report describes a patient with an amino terminal missense mutation who apparently also had a discrete keratoderma [Kelly et al., 2006]. It is possible that mild skin changes as described in this paper are a component of ODDD caused by missense mutations. This observation is compatible with our observations, because our patients have a pronounced keratoderma while the patient described by Kelly has mild skin changes. Thus, absence of connexin 43 from the cell membrane, as in our patients, may be associated with pronounced skin changes, whereas the presence of a mutated connexin 43 in the cell membrane might lead to mild skin changes that are often overlooked. Systematically cataloguing any skin changes in ODDD should help to settle this matter.

In conclusion, this case corroborates our notion that, for skin symptoms, a genotype-phenotype correlation exists in ODDD. Mutations that truncate the C-terminus cause a pronounced palmoplantar keratoderma, while missense mutations do not. We have found no skin symptoms in patients with missense mutations, but await confirmation of our observations by independent groups. It would also be of interest to examine whether other, perhaps more subtle, correlations for different missense mutations can be found. In particular, patients with missense mutations might be re-examined by a dermatologist to search for subtle skin alterations.

\section{ACKNOWLEDGMENTS}

We thank the patient for her kind cooperation in the study. MvS is supported by grants from the GROW research institute, Barrier Therapeutics NV, 
CHAPTER 5

American Journal of Medical Genetics Part A: DOI 10.1002/ajmg.a

A GENOTYPE-PHENOTYPE CORRELATION IN ODDD

the La Roche Posay Research Foundation and the Berliner Stiftung für Dermatologie.

\section{REFERENCES}

Kelly SC, Ratajczak P, Keller M, Purcell SM, Griffin T, Richard G. 2006. A novel GJA 1 mutation in oculo-dento-digital dysplasia with curly hair and hyperkeratosis. Eur J Dermatol 16:241-245.

Kjaer KW, Hansen L, Eiberg H, Leicht P, Opitz JM, Tommerup N. 2004. Novel Connexin 43 (GJA1) mutation causes oculo-dento-digital dysplasia with curly hair. Am J Med Genet Part A 127A:152-157.

Kretz M, Maass K, Willecke K. 2004. Expression and function of connexins in the epidermis, analyzed with transgenic mouse mutants. Eur J Cell Biol 83:647-654.

Loddenkemper T, Grote K, Evers S, Oelerich M, Stogbauer F. 2002. Neurological manifestations of the oculodentodigital dysplasia syndrome. J Neurol 249:584-595.
Paznekas WA, Boyadjiev SA, Shapiro RE, Daniels O, Wollnik B, Keegan CE, Innis JW, Dinulos MB, Christian C, Hannibal MC, Jabs EW. 2003. Connexin 43 (GJA1) mutations cause the pleiotropic phenotype of oculodentodigital dysplasia. Am J Hum Genet 72:408-418.

Solan JL, Lampe PD. 2005. Connexin phosphorylation as a regulatory event linked to gap junction channel assembly. Biochim Biophys Acta 1711:154-163.

van Steensel MA, van Geel M, Nahuys M, Smitt JH, Steijlen PM. 2002. A novel connexin 26 mutation in a patient diagnosed with keratitis- ichthyosis-deafness syndrome. J Invest Dermatol 118:724-727.

van Steensel MA, Spruijt L, van der Burgt I, Bladergroen RS, Vermeer M, Steijlen PM, van Geel M. 2005. A 2-bp deletion in the GJA1 gene is associated with oculo-dento-digital dysplasia with palmoplantar keratoderma. Am J Med Genet Part A 132A:171-174. 
Case report

\title{
Lymphedema-distichiasis syndrome: a distinct type of primary lymphedema caused by mutations in the FOXC2 gene
}

\author{
Maaike Vreeburg*, MD, Martijn V. Heitink*, MD, Robert J. Damstra, MD, Ute Moog, MD, PhD, \\ Michel van Geel, PhD, and Maurice A. M. van Steensel, MD, PhD
}

From the Departments of Clinical Genetics and Dermatology, University Hospital Maastricht, GROW Research Institute for Oncology and Developmental Biology, University of Maastricht, and Department of Dermatology, Nij Smellinghe Hospital, Drachten, the Netherlands, and Institute of Human Genetics, Heidelberg University, Germany

\section{Correspondence}

Maaike Vreeburg, MD

Department of Clinical Genetics

University Hospital Maastricht

P. Debyelaan 25; PO Box 5800

6202 AZ Maastricht

the Netherlands

E-mail: maaike.vreeburg@gen.unimaas.nl

*Both authors contributed equally to this work

\begin{abstract}
Lymphedema-distichiasis syndrome (LD, OMIM 153400) is an autosomal dominant disorder with variable expression. It is caused by mutations in the FOXC2-gene, which codes for a forkhead transcription factor involved in the development of the lymphatic and vascular system. LD is characterized by late childhood or pubertal onset lymphedema of the limbs and distichiasis (double row of eyelashes). While the latter is the most common expression of LD, venous insufficiency occurs in half of the patients. Other associations have been reported, including congenital heart disease, ptosis, cleft lip/palate and spinal extradural cysts.

Here we describe a family with classical lymphedema-distichiasis syndrome caused by a duplication in the FOXC2-gene.
\end{abstract}

\section{Introduction}

Lymphedema is a chronic swelling of the soft tissues caused by reduced drainage of lymph by lymphatic vessels. ${ }^{\mathrm{I}}$ It is a common chronic disorder with high morbidity, affecting millions of people worldwide. In most cases, lymphedema is the result of lymphatic vessel damage caused by filariasis, surgery, trauma, or infection, and is then called secondary. When arising from an intrinsic abnormality of the lymphatic system, it is referred to as primary.

Some cases of primary lymphedema are familial, usually following an autosomal dominant pattern of inheritance with reduced penetrance, variable expression, and variable age of onset. Several genes are known to be involved, including FMSlike tyrosine kinase $4\left(F L T_{4}\right)$ [coding for vascular endothelial growth factor receptor 3 (VEGFR 3 ), Nonne-Milroy disease, OMIM I 53 I00], sex-determining region $Y$ box I 8 (SOXI 8$)$ (hypotrichosis-lymphedema-telangiectasia syndrome, OMIM 607823), and forkhead box C2 (FOXC2) (lymphedema with distichiasis, OMIM I 53400 ; yellow nail syndrome, OMIM I 53300 ; lymphedema with ptosis, OMIM I 53000). Although lymphedema-distichiasis (LD) syndrome accounts for only a small fraction of the group of patients with primary lymphedema, it is a recognizable syndrome. A I $6 \mathrm{q} / \mathrm{Y}$ translocation in an individual with LD syndrome has led to the identification of the causal gene, the forkhead transcription factor $\mathrm{FOXC}_{2}$ [formerly known as the mesenchyme forkhead I (MFHI) gene], located on chromosome band I $6 \mathrm{q} 24.3 .{ }^{2} \mathrm{LD}$ syndrome is inherited as an autosomal dominant trait with variable expression. The de novo mutation rate is estimated to be about $20 \%$ and may be even higher. ${ }^{3}$

\section{Case Report}

A 36-year-old Dutch woman presented to our outpatient clinic with swelling of both legs since puberty (Fig. I). She had suffered from multiple episodes of erysipelas. At the age of I 8 years, a lymphatic-venous shunt was performed in the left leg. Two years later, reduction surgery and liposuction of both lower limbs were performed. Treatment of edema since then had consisted of manual lymphatic drainage in combination with multilayered compression bandages. After the edema had resolved, class III elastic compression stockings were prescribed. Because of complaints of corneal irritation, the patient was examined by an ophthalmologist, who diagnosed distichiasis (Fig. 2). Surgical eyelid correction was required to treat the corneal irritation. During the past few years, the patient had developed venous insufficiency of the 


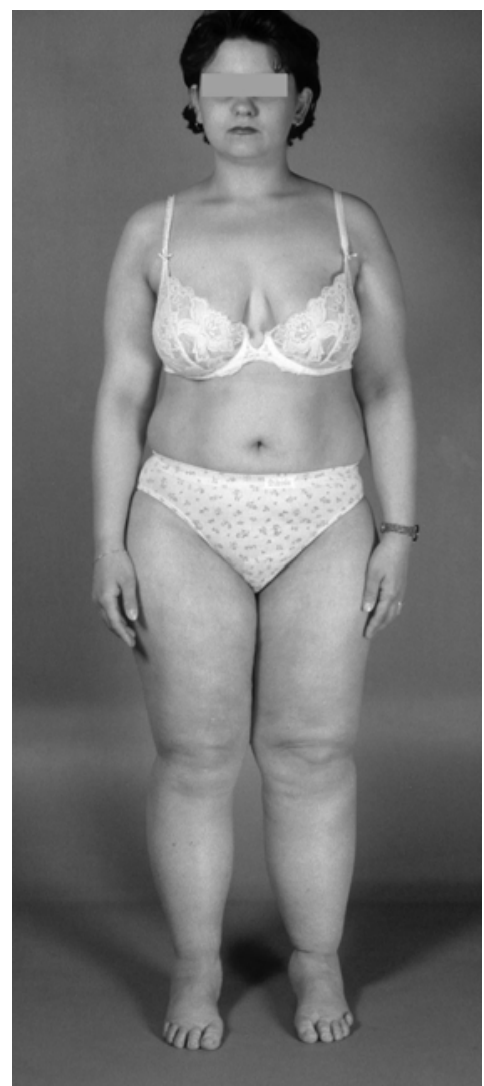

Figure 1 Overview of the proband at the age of 23 years. Notice the lymphedema of the legs and feet

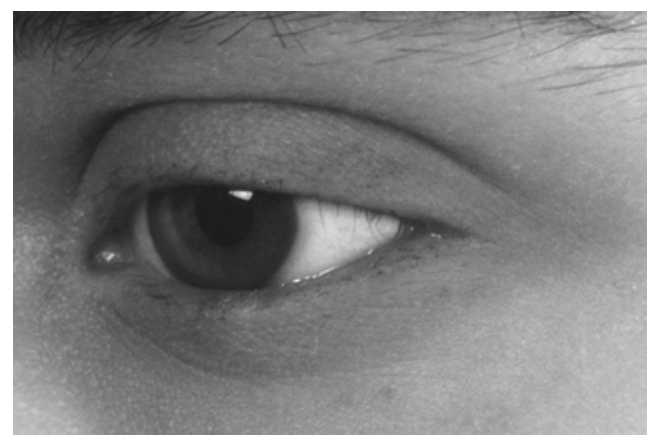

Figure 2 Detail of the left eye with distichiasis. Note the double row of eyelashes in the lateral eye corner originating from the inner margin of the eyelids legs with several episodes of thrombophlebitis, despite continuing compression therapy. She has never had deep vein thrombosis. Recent clinical examination revealed bilateral nonpitting edema of the legs, feet, and toes. Stemmer's sign (inability to pick up a fold of skin at the base of the second toe because of thickening or fibrosis of the tissues) was positive. Both lower legs showed signs of chronic venous insufficiency. The eyelids showed a double row of eyelashes, bilaterally, despite previous surgical correction (Fig. 2). No ptosis or yellow nails were present. Lymphoscintigraphic evaluation showed insufficient lymphatic drainage in both legs. Venous duplex ultrasound showed bilateral pathologic reflux in the great and lesser saphenous veins and deep venous reflux in the popliteal and femoral veins, suggesting primary venous valve failure (congenital avalvulia) in both the deep and superficial veins in the lower limbs.

The proband is the youngest of six children (Fig. 3, proband III:9). She has a daughter without signs of lymphedema or distichiasis at the age of 3 years. Three brothers, her father, and her paternal grandmother also developed lymphedema of the legs during puberty (Fig. 3, pedigree of the family). The eldest of the three affected brothers (Fig. 3, individual III:2) has experienced multiple episodes of erysipelas of the legs. His son has distichiasis, but his daughter does not. The second affected brother was diagnosed with infertility (Fig. 3, individual III:4). Sperm analysis showed azoospermia, although a testicular biopsy showed normal spermatogenesis. He suffers from lymphedema and scrotal edema in addition to a spermatocele on the left side. Phlebographic examination in the third brother (Fig. 3, individual III:6) had, in the past, showed profound superficial and deep venous insufficiency of the legs caused by dysplasia of the venous valves. Lymphoscintigraphic evaluation showed insufficient lymphatic drainage in both legs. All three affected brothers presented with the first signs of lymphedema around the age of I $2-\mathrm{I} 3$ years. The proband's father (Fig. 3, individual II:3) has also suffered from lymphedema, combined with scrotal elephantiasis, since early puberty. His mother (Fig. 3, individual I:2, the proband's grandmother) is also affected. All family members with lymphedema have distichiasis, although not all have experienced corneal irritation. The remaining two brothers are reportedly unaffected, but were not examined by us.

Mutation analysis of the forkhead box $\mathrm{C}_{2}\left(\mathrm{FOXC}_{2}\right)$ gene was performed in the proband, one of her brothers, and the son of this brother (Fig. 3, individuals III:9, III:2, and IV:I). A I9-bp duplication (c.902_920dupr9) was identified, resulting in a frameshift and a premature stop codon after 29 nonfunctional amino acids. This mutation has been reported previously as nt902_920duptggcgctgccctacgccgc (Sholto-Douglas-Vernon C, Bell R, Brice G, et al. Lymphoedema-distichiasis and FOXC2: unreported mutations, de novo mutation estimate, families without coding mutations. Hum Genet 2005; II7: 


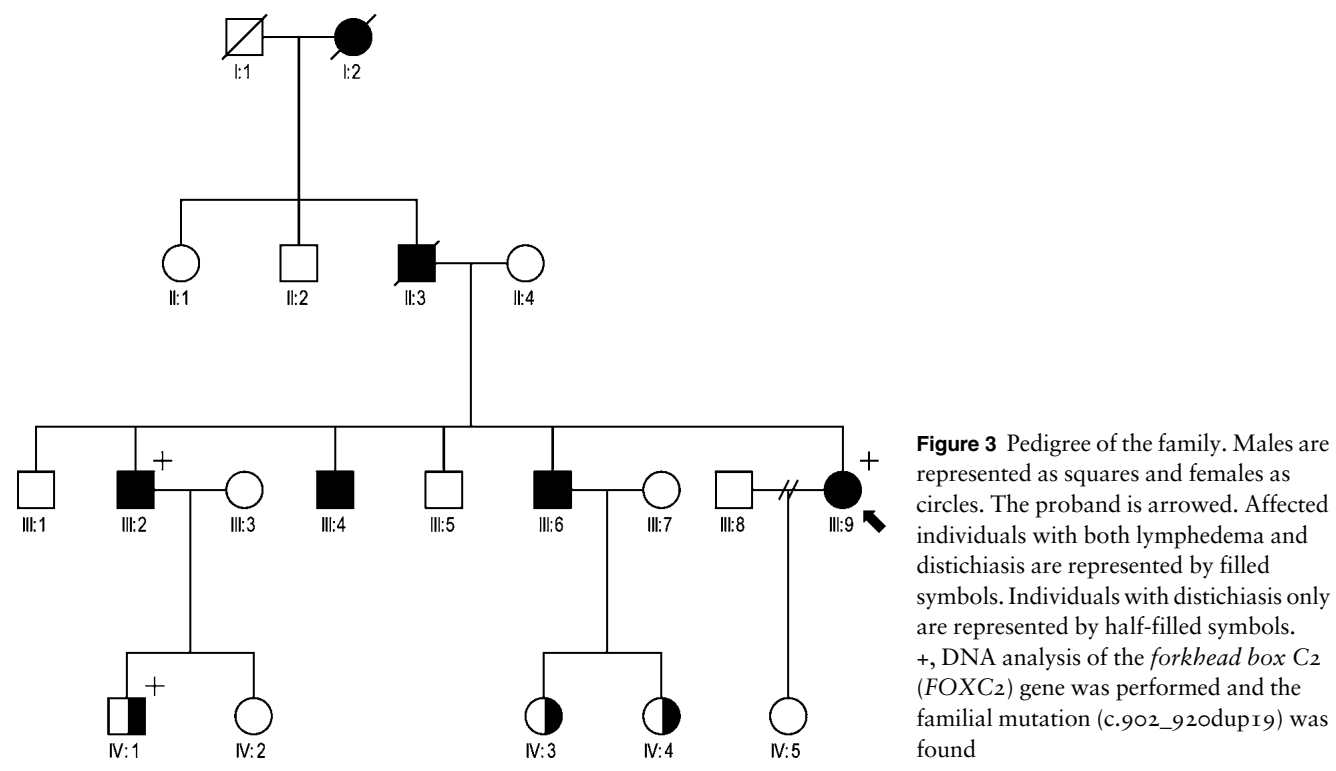

238-242). DNA analysis was offered to the other family members.

\section{Discussion}

We describe a three-generation family manifesting typical LD syndrome, including the commonly seen venous abnormalities. Although expression is highly variable, distichiasis is present in approximately $94 \%$ of patients. ${ }^{4}$ Distichiasis is defined as a congenital anomaly in which accessory eyelashes occur in the posterior border of the eyelid margins in the position of the meibomian gland orifices. The extra eyelashes may protrude into the cornea, producing severe corneal abrasions in $74 \%$ of patients, ${ }^{4}$ and may be the only symptom of a FOXC2 mutation. ${ }^{5,6}$ Lymphedema usually appears during puberty or later, but before the age of 40 years. Males are affected at an earlier age than females. The edema is usually situated in the lower limbs and is mostly bilateral and asymmetrical. The severity is variable. Venous insufficiency resulting from incompetent venous valves is common, occurring in approximately $49 \%$ of patients. ${ }^{4,7}$ A number of clinical findings can be associated in LD syndrome, including various congenital heart diseases (Fallot's tetralogy, ventricular septum defect, patent ductus arteriosus, pulmonary defects, etc.; $6.8 \%)$, ptosis $(30 \%)$, cleft lip and/or palate $(4 \%)$, and spinal extradural cysts. ${ }^{4}$ Infertility and azoospermia, as in one of the proband's brothers, has not been reported previously in LD syndrome. It could be a consequence of his scrotal lymphedema.
As mentioned above, LD syndrome is caused by mutations in the FOXC2 gene, located on chromosome band I6q24.3. The mutation found in this family (c.902_92odupig) has been reported in another family with typical LD syndrome. ${ }^{3}$ Most mutations found in LD syndrome are insertions and deletions, causing a loss of transcriptional activity, presumably by haploinsufficiency. It was thought that there was a mutational hotspot in the gene: an incomplete GCCGCCGC repeat stretching from nucleotide 893 to 930 . The mutation found in our family occurs in this area. In theory, the presence of incomplete repeats can cause deletions and duplications as a consequence of replicative slippage or homologous recombination events. It is now clear, however, that mutations of various kinds, including deletions and duplications, are found throughout the FOXC2 coding sequence. ${ }^{8}$ A phenotypegenotype correlation does not seem to be present.

The FOXC2 2 gene is composed of a single $\mathrm{I} .5 \mathrm{~kb}$ exon and codes for a forkhead transcription factor, belonging to a protein family of over 40 members (in mammals). All are transcription factors characterized by a conserved DNA-binding domain, known as a forkhead domain (FHD). ${ }^{9}$ This is a highly conserved roo-amino-acid DNA-binding pattern consisting of three major $\alpha$-helices, a smaller fourth $\alpha$-helix, and three antiparallel $\beta$-sheets. Helix three is referred to as the DNA-recognition helix. ${ }^{\text {Io }}$ Forkhead proteins play an important role in many developmental processes, including leftright asymmetry and the morphogenesis of various tissues, such as vessels and their valves. ${ }^{9}$ 
A knowledge of the function of the FOXC2 protein mostly originates from mouse studies. Lymphangiogenesis is an extremely complex process in which many proteins of different families are involved, including $\mathrm{VEGFR}_{3}$, prosperorelated homeobox I (ProxI), SOXI 8, podoplanin, lymphatic vessel endothelial hyaluronan receptor I (LYVEI), FOXCI, and $\mathrm{FOXC}_{2}$. The FOXC2 gene is highly expressed in developing and adult lymphatic vessels. ${ }^{\mathrm{II}, \mathrm{I2}}$ During embryonic development, FOXC2 appears to interact closely with the highly homologous FOXCI. The two coexist in most tissues, with the exception of lymphatic endothelial cells. Disruption of both the FOXCI and FOXC2 genes causes a severe early disturbance of vascular and lymphatic development with arteriovenous malformations, in particular of the aortic arch. ${ }^{9,13,14}$ If $F O X C_{2}$ is the only gene affected, early lymphatic angiogenesis is preserved, but the later remodelling and maturation of the lymphatic capillaries and collecting lymphatic vessels are disturbed. ${ }^{\circ}{ }^{\circ}$ Recently, the $\mathrm{FOXC}_{2}$ gene has also been shown to be involved in venous valve development, incompetent venous valves being found in almost all patients carrying a FOXC2 gene mutation. This may explain the higher incidence of venous insufficiency in patients with LD syndrome relative to that in the general population. ${ }^{\mathrm{I}}$ The mechanism by which FOXC2 mutations cause distichiasis is not yet clear.

Although LD syndrome is rare, the diagnosis should be considered in all patients presenting with primary lymphedema around puberty (i.e. the praecox variant). Distichiasis is easily missed and expert ophthalmologic examination is indicated if LD syndrome is suspected. Mutation analysis should then be performed to confirm the diagnosis.

\section{Conflicts of interest}

The authors have declared no conflicts of interest.

\section{References}

I Mortimer PS. American Cancer Society Lymphedema Workshop: the pathophysiology of lymphedema.

Cancer I998; 83(Suppl.): 2798-2802.

2 Fang J, Dagenais SL, Erickson RP, et al. Mutations in FOXC2 (MFH-I), a forkhead family transcription factor, are responsible for the hereditary lymphedema-distichiasis syndrome. Am J Hum Genet 2000; 67: 1382-I388.

3 Sholto-Douglas-Vernon C, Bell R, Brice G, et al. Lymphoedema-distichiasis and $\mathrm{FOXC}_{2}$ : unreported mutations, de novo mutation estimate, families without coding mutations. Hum Genet 2005; I I 7: 238-242.

4 Brice G, Mansour S, Bell R, et al. Analysis of the phenotypic abnormalities in lymphoedema-distichiasis syndrome in 74 patients with FOXC2 mutations or linkage to $16 \mathrm{q} 24$. J Med Genet 2002; 39: 478-483.

5 Brooks BP, Dagenais SL, Nelson CC, et al. Mutation of the FOXC2 gene in familial distichiasis. J Am Assoc Pediatr Ophthalmol Strabismus 2003; 7: 354-357.

6 Patil BB, Bell R, Brice G, et al. Distichiasis without lymphedema? Eye 2004; I 8: I 270-I 272.

7 Mellor RH, Brice G, Stanton AW, et al. Mutations in FOXC2 are strongly associated with primary valve failure in veins of the lower limb. Circulation 2007; II 5: I9I2I 920 .

8 Bell R, Brice G, Child AH et al. Analysis of lymphoedemadistichiasis families for $\mathrm{FOXC}_{2}$ mutations reveals small insertions and deletions throughout the gene. Hum Genet 200I; I08: 546-55I.

9 Mäkinen T, Norrmén C, Petrova TV. Molecular mechanisms of lymphatic vascular development. Cell Mol Life Sci 2007; 64: I9I 5-I929.

Io Berry FB, Tamimi Y, Carle MV, et al. The establishment of a predictive mutational model of the forkhead domain through the analysis of $F O X C_{2}$ missense mutations identified in patients with hereditary lymphedema with distichiasis. Hum Mol Genet 2005; 14: 2619-2627.

I I Petrova TV, Karpanen T, Norrmén C, et al. Defective valves and abnormal mural cell recruitment underlie lymphatic vascular failure in lymphedema distichiasis. Nat Med 2004; I0: 974-98I.

I 2 Dagenais SL, Hartsough RL, Erickson RP, et al. Foxc2 is expressed in developing lymphatic vessels and other tissues associated with lymphedema-distichiasis syndrome. Gene Express Patterns 2004; 4: 6I I-6I9.

I3 Kriederman BM, Myloyde TL, Witte MH, et al. FOXC2 haploinsufficient mice are a model for human autosomal dominant lymphedema-distichiasis syndrome. Hum $\mathrm{Mol}$ Genet 2003; I2: II 79-II 85 .

I4 Seo S, Fujita H, Nakano A, et al. The forkhead transcription factors, FoxcI and Foxc2, are required for arterial specification and lymphatic sprouting during vascular development. Dev Biol 2006; 294: 458-470. 


\title{
Clinical Report Myhre Syndrome in a Female With Previously Undescribed Symptoms: Further Delineation of the Phenotype
}

\author{
M.A.M. van Steensel, ${ }^{1 *}$ M. Vreeburg, ${ }^{2}$ P.M. Steijlen, ${ }^{1}$ and C. de Die-Smulders ${ }^{2}$ \\ ${ }^{1}$ Department of Dermatology, University Hospital Maastricht, Maastricht, The Netherlands \\ ${ }^{2}$ Department of Clinical Genetics, University Hospital Maastricht, Maastricht, The Netherlands
}

\begin{abstract}
Myhre syndrome is a rare connective tissue disease characterized by nonprogressive stiffness of the large joints, short stature with a peculiar build, and a distinctive facial phenotype. Developmental delay is common. Three female patients have so far been described. Here, we report on a 16-year-old female with Myhre syndrome. She has vertebral defects, hypertrophic scar formation, and a stiff skin in addition to the features that have previously been reported in association with Myhre syndrome. ๑ 2005 Wiley-Liss, Inc.
\end{abstract}

KEY WORDS: Myhre syndrome; skin; vertebral; hypertrophic scar

\section{INTRODUCTION}

Myhre syndrome (OMIM 139210) is a rare disorder characterized by short stature with a seemingly muscular build, generalized nonprogressive stiffness of joints, and a distinctive face with prognathism [Myhre et al., 1981]. Deafness can also be part of the phenotype. Developmental delay is common, with autism reported in one patient [Titomanlio et al., 2001] One case was reported with thickening of the dermis with anomalous subcutaneous tissue [Titomanlio et al., 2001]. There is considerable phenotypic overlap with acromicric dysplasia, Moore-Federman syndrome, Weill-Marchesani syndrome, and geleophysic dysplasia and there has been some discussion concerning the distinctness of these disorders [Winter et al., 1989; Figuera, 1996; Hennekam et al., 1996; Burglen et al., 2003]. Nevertheless, Myhre syndrome is generally accepted as a distinct clinical entity since features present in acromicric dysplasia, Weill-Marchesani syndrome, and geleophysic dysplasia, notably structural eye abnormalities and cardiac valve thickening, are lacking. Most patients reported so far were males, prompting speculation about a possibly X-linked recessive inheritance. Recently, two female patients were reported [Davalos et al., 2003; Lopez-Cardona et al., 2004]. Here, we describe a 16 -year-old Dutch female patient with Myhre syndrome who presented with additional

Grant sponsor: Barrier Therapeutics NV; Grant sponsor: GROW Research Institute; Grant sponsor: International Pachyonychia Congenita Foundation.

*Correspondence to: M.A.M. van Steensel, M.D., Ph.D., Department of Dermatology, University Hospital Maastricht, P.O. Box 5800, $6202 \mathrm{AZ}$ Maastricht, The Netherlands.

E-mail: mvst@sder.azm.nl

Received 18 April 2005; Accepted 21 August 2005

DOI 10.1002/ajmg.a.30988 symptoms of striking stiffness of the skin, hypertrophic scar formation, and vertebral fusion defects. These abnormalities have not been previously described in Myhre syndrome.

\section{CLINICAL REPORT}

The patient, a 16-year-old Dutch female, was born to non-consanguineous Dutch parents. A younger brother, age 15-year-old, was healthy. The family history was unremarkable. The patient was born at term after an uneventful pregnancy. Apgar scores at 5 and 10 min were 6 and 8 , respectively. At birth, she was proportionally small for gestational age with a birth weight of $2,310 \mathrm{~g}(<3$ rd centile) and a birth length of $47 \mathrm{~cm}$ ( $<3$ rd centile). Elbows and knees showed flexion contractures at birth. Length has since been below the 3rd centile for the Dutch population. A year after birth, the mother noted a "stiff face" and progressive stiffness in the back (Fig. 1 shows the phenotype around that age). Mobility in the large joints was also said to be increasingly limited, with the possible exception of knees and elbows. Multiple episodes of otitis media have left the patient with a bilateral conductive hearing loss. A pharyngoplasty was performed at age 6 for nasal speech. She also had a pericarditis at that age. Apparently it resolved spontaneously. Psychomotor delay was apparent at an early age. The patient currently attends a school for children with learning difficulties; her IQ has been tested between 75 and 85 .

\section{Physical Examination}

We first saw the patient when she was 16 years old. Length was $136 \mathrm{~cm}$ ( $-5 \mathrm{SD})$, weight $53 \mathrm{~kg}(>+2 \mathrm{SD}$ for length), and OFC 53.5 cm (-1SD). Upon examination, we observed a typical facial phenotype with prognathism, midface retraction with a flat nasal bridge, and downward pointing nose (Fig. 2). Both external ears had simple, cup-shaped helices (Fig. 2, inset). Opening of the mouth was limited and the neck was broad. Joint movement was limited with flexion contractures of elbows, hips, and knees and limited supination in the elbows. Both hands showed brachydactyly (hand length $14 \mathrm{~cm},<<3 \mathrm{rd}$ centile) with bilateral clinodactyly of the fifth finger. Limited extension of both ankles necessitated the patient to compensate by exorotation of the hips and increased hip flexion (Fig. 3). There was a general impression of a muscular build with centripetal obesity.

The skin had a peculiar, somewhat stiff feel, comparable to that of scleroderma and similar to what can be observed in lysosomal storage diseases. Movement of the skin over the subcutaneous movement was limited. Over the right buttock, lateral to the natal cleft, we noted a hypertrophic scar that had reportedly resulted from the removal of a benign nevoid lesion some years previously. Interestingly, the scars resulting from the biopsies taken at this first visit were evidently hypertrophic when the patient was seen again a year later. An extensive follicular hyperkeratosis was present on both thighs. Hair growth was normal as were the nails and teeth. Additional investigations were performed. 

van Steensel et al.

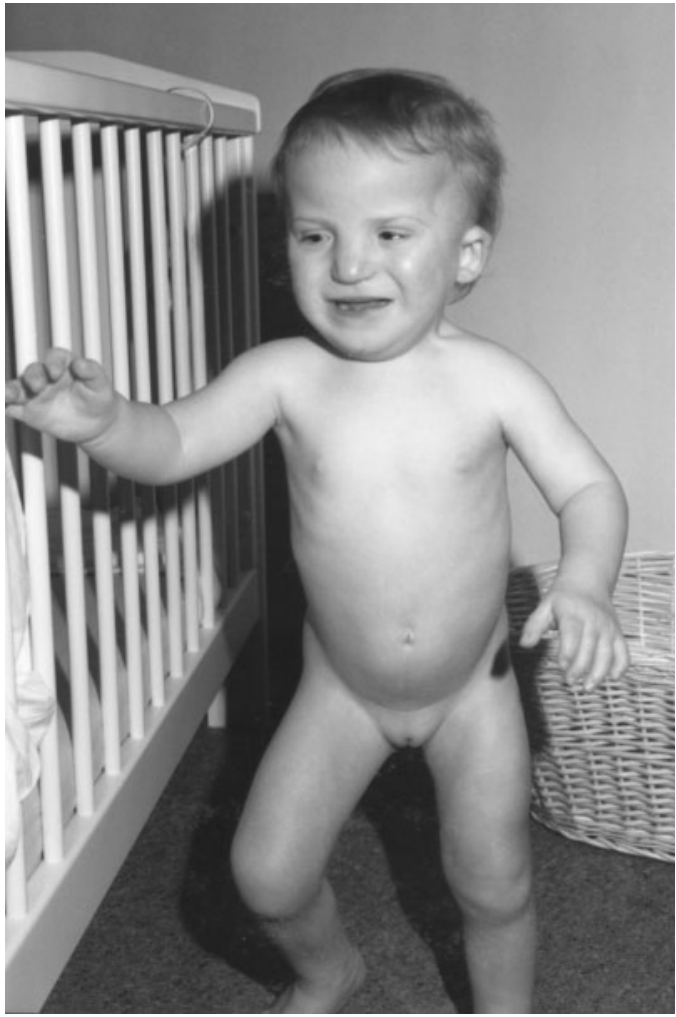

Fig. 1. The phenotype of the patient around 1 year of age. Note the limited mobility of the face and the broad nasal bridge with down-turned tip.

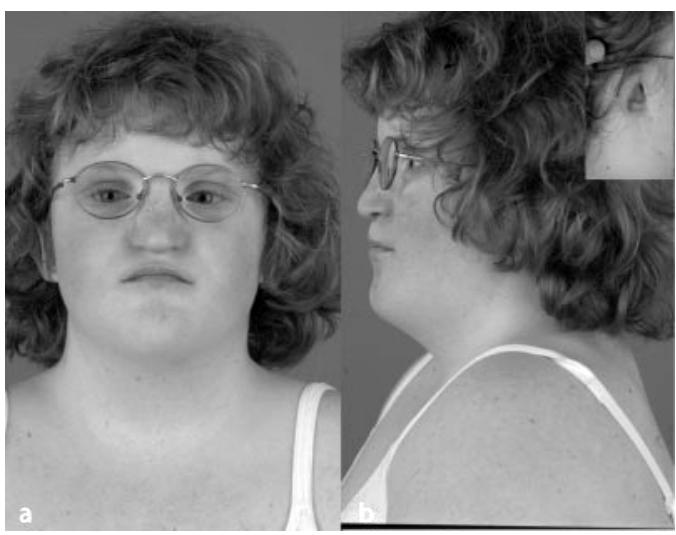

Fig. 2. The patient's phenotype at 16 years of age. Note the peculiar face with flat midface (in b), broad nose with downturned nasal tip. The corners of the mouth are downturned. The neck is short. The inset shows the malformation of the external ear.

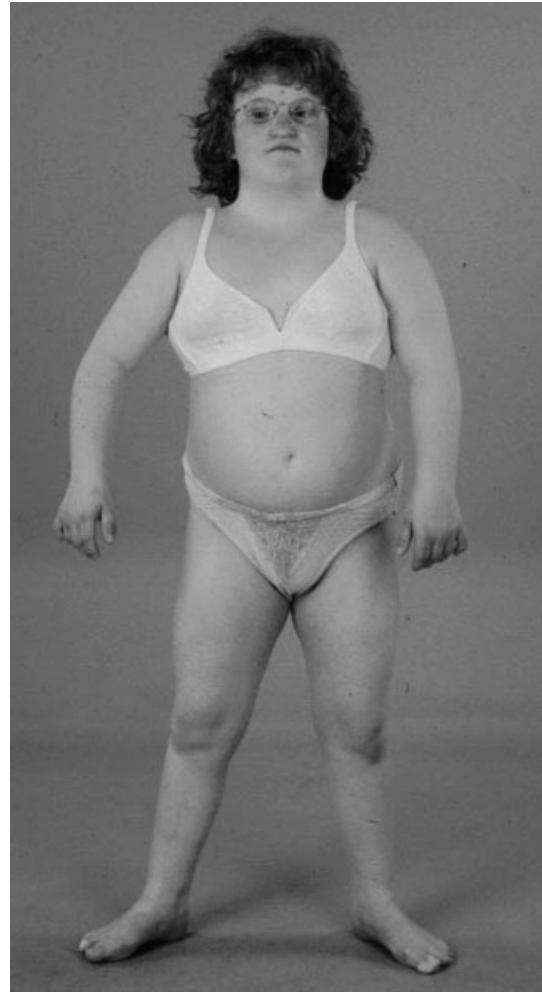

Fig. 3. The patient's phenotype. Short stature with a prominent abdomen. Both elbows are fixed in flexion with limited supination. A brachydactyly can also be noted. The patient compensates for the limited mobility of the ankles by exorotation of the hips.

\section{Abdominal Ultrasound}

Liver size and density were normal. A single spleen of normal size was observed. Other abnormalities were not evident either.

\section{Echocardiography}

There was no evidence of thickening of valves or presence of septal defects. The aorta and pulmonic artery had a normal width.

\section{Laboratory Examination}

The karyotype was 46,XX. Extensive metabolic examination, performed elsewhere, did not reveal any abnormalities. In particular, no indication of a storage disease or congenital disorder of glycosylation was found. After having obtained informed consent from the patient's mother and assent from the patient herself, two 3-mm skin punch biopsies were taken. Fibroblasts were isolated from one and cultured using standard laboratory technique. No inclusion bodies were seen in the cells; cell growth and proliferation were apparently normal.

\section{Histopathology}

The skin biopsy specimen was examined by light microscopy. In light microscopy, a normal epidermis and dermis were 
observed. Collagen and elastic fibrils had a normal width and distribution. No accumulation of PAS- or Alcian Blue-positive material was seen. Congo Red staining showed no evidence of lysosomal inclusions.

\section{Skeletal Radiography}

Several abnormalities were observed upon X-ray examination of the skull, axial skeleton, and extremities. The skull bones were thickened, most prominently the base of the skull in the sphenoid area (Fig. 4a). Fusion of vertebrae $\mathrm{C} 2-3$ and partial fusions of T3-5, 6/7, and 8/9 was noted (Fig. 4b,c), as was fusion of ribs 10 and 11 on the right dorsal side. There was a dorsal closure defect of L5. All vertebrae had irregular endplates. All tubular bones were shortened but no specific abnormalities were noted. The epiphyses were small but had a normal shape.

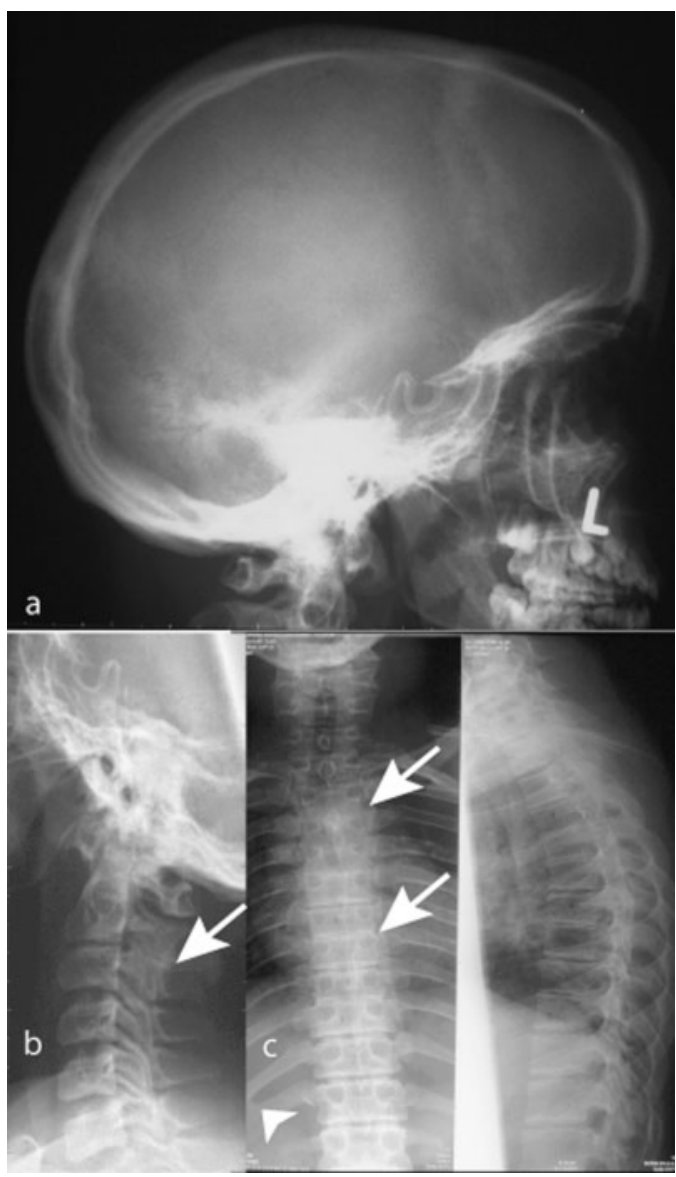

Fig. 4. a: Radiograph of the skull. There is prominent thickening of the calvaria and of the base of the skull. $\mathbf{b}$ : Radiograph of the cervical vertebral column showing fusion of C2-3 (arrow). c: Radiograph of the thoracic column showing fusion of C2-3 (arrow). c: Radiograph of the thoracic
vertebral column. Several vertebrae show irregular endplates. Partial fusion of T3-5 and T8/9 can be seen (arrows). The pedicles are large. Ribs 10 and 11 are partially fused on the right dorsal side (arrowhead).
Based on the abnormalities that we found we made a diagnosis of Myhre syndrome. The possibility of WeillMarchesani syndrome or geleophysic dysplasia was raised. These diagnoses were rejected based on the absence of specific lens and heart abnormalities or hepatomegaly. The facial phenotype was also inconsistent with either diagnosis.

\section{DISCUSSION}

In 1981, Myhre et al. described two patients with a new growth retardation syndrome, today referred to as Myhre syndrome (MIM 139210). Features of the syndrome were mental retardation, short stature with a muscular build, facial dysmorphism, hearing loss and joint limitations. Today, 14 patients with Myhre syndrome have been described in the literature, 11 males and 3 females. The syndrome seems to be characterized mainly by short stature with a "muscular" build, generalized nonprogressive stiffness of joints, and a distinctive face with prognathism. Developmental delay is common, autism and difficult social relationships have been described [Titomanlio et al., 2001; Burglen et al., 2003]. A thick skin was observed in a number of patients [Titomanlio et al., 2001; Burglen et al., 2003]. Titomanlio et al. [2001] saw a thickening of the dermis with anomalous subcutaneous tissue at skin histology. Thickened calvarium, hypoplastic iliac wings, broad ribs, and flattened vertebrae with large pedicles were found frequently at radiological examination of patients with Myhre syndrome. The pattern of inheritance is still unclear. X-linked recessive inheritance was proposed because of the major prevalence in male patients as well as reduced clinical expressivity in reported female patients. As paternal age was increased in some families, de novo autosomal dominant mutation was also suggested.

Here, we report on a female suffering from Myhre syndrome (OMIM 139210). The diagnosis was made after we first considered geleophysic dysplasia because a search of the OMIM database using the terms "stiff skin short stature" returned 12 entries of which Weill-Marchesani, Moore-Federman syndrome, and geleophysic dysplasia seemed to best fit the phenotype presented by our patient. The identity of MooreFederman syndrome is uncertain and it may in fact be identical to acromicric dysplasia [Hennekam et al., 1996]. The latter disorder is characterized among other symptoms by severe eye abnormalities. The facial dysmorphism is less pronounced. The same applies to Weill-Marchesani syndrome. Hence, these diagnoses were rejected. As echographic examination of liver and heart showed no abnormalities in our patient, geleophysic dysplasia was deemed unlikely. A further search of the literature then turned up Myhre syndrome as the likely diagnosis. The seemingly muscular build and the facial dysmorphism with retraction of the midface and prognathism that are seen in our patient (Figs. 1 and 2) are quite similar to what is shown in previous reports. The limitation of movements in large joints is also consistent with the diagnosis of Myhre syndrome.

The peculiar thickness of the skin as previously reported by Titomanlio et al. [2001] and Burglen et al. [2003] is likely to be a common finding in Myhre syndrome, considering the apparent uniformity of the rest of the phenotype. Limitation of joint mobility has to our knowledge not been previously described, but this may be due to an ascertainment bias. It would be of interest to ask the parents of the presently known patients about it. Hypertrophic scar formation is a new finding and might, with the thickness of the skin, be consistent with a storage disorder as underlying abnormality. One report mentions abnormal organization of the dermis and subcutaneous fat, with apparent accumulation of disorganized collagen bundles [Titomanlio et al., 2001]. We were not able to confirm these findings in our patient. Instead, fully normal organization was found. Inclusions that might indicate lysosomal 


\section{CHAPTER 5}

American Journal of Medical Genetics: DOI 10.1002/ajmg.a

van Steensel et al.

accumulations were not seen. In I-cell disease, the skin is stiff without obvious histological abnormalities, although evidence of lysosomal accumulation is usually present (own observation). It is conceivable that a storage defect will become obvious upon prolonged culture of keratinocytes or fibroblasts but we have so far not observed this in cultured fibroblasts. The absence of other storage disease phenomena, with the possible exception of the hypertrophic scar and the stiff skin, also argues against a storage defect being the cause of Myhre syndrome. The lack of skin elasticity may be due to defects in collagen or elastic fibrils (or in associated molecules) that do not lead to microscopically visible structural abnormalities but do result in abnormal mechanical behavior. Disturbed organization and metabolism of collagen might also explain the presence of a hypertrophic scar [Paddock et al., 2003].

Finally, vertebral anomalies as seen in our patient have to our knowledge not yet been reported in Myhre syndrome. A mild platyspondyly with irregular endplates was seen in one previously described patient. Large pedicles seem to be a common skeletal anomaly. While unspecific in themselves and occurring sometimes as isolated autosomal dominant or recessive traits, vertebral fusion defects may be part of the syndrome. Future clinical reports should clarify the matter.

\section{ACKNOWLEDGMENTS}

MvS's research is supported by Barrier Therapeutics NV, the GROW research institute (University of Maastricht) and the International Pachyonychia Congenita Foundation.

\section{REFERENCES}

Burglen L, Heron D, Moerman A, Dieux-Coeslier A, Bourguignon JP, Bachy A, Carel JC, Cormier-Daire V, Manouvrier S, Verloes A. 2003. Myhre syndrome: New reports, review, and differential diagnosis. J Med Genet 40:546-551.

Davalos NO, Garcia-Ortiz JE, Garcia-Cruz D, Feria-Velasco A, SanchezCorona J. 2003. Myhre syndrome: First female case. Clin Dysmorphol 12:119-121.

Figuera LE. 1996. Geleophysic dysplasia vs. Myhre syndrome. Am J Med Genet 65:361-362.

Hennekam RC, van Bever Y, Oorthuys JW. 1996. Acromicric dysplasia and geleophysic dysplasia: Similarities and differences. Eur J Pediatr 155: 311-314.

Lopez-Cardona MG, Garcia-Cruz D, Garcia-Ortiz JE, Davalos NO, Feria-Velasco A, Rodriguez-Rojas LX, Garcia-Cruz MO, FigueraVillanueva LE, Stephens A, Larios-Arceo F, Sanchez-Corona J. 2004. Second female case of Myhre syndrome. Clin Dysmorphol 13: 91-94.

Myhre SA, Ruvalcaba RH, Graham CB. 1981. A new growth deficiency syndrome. Clin Genet 20:1-5.

Paddock HN, Schultz GS, Baker HV, Varela JC, Beierle EA, Moldawer LL, Mozingo DW. 2003. Analysis of gene expression patterns in human postburn hypertrophic scars. J Burn Care Rehabil 24:371-377.

Titomanlio L, Marzano MG, Rossi E, D’Armiento M, De Brasi D, Vega GR, Andreucci MV, Orsini AV, Santoro L, Sebastio G. 2001. Case of Myhre syndrome with autism and peculiar skin histological findings. Am J Med Genet 103:163-165.

Winter RM, Patton MA, Challener J, Mueller RF, Baraitser M. 1989. MooreFederman syndrome and acromicric dysplasia: Are they the same entity? J Med Genet 26:320-325. 
CHAPTER 6

General discussion 
CHAPTER 6 
We initiated an interdisciplinary team with a dermatologist and a clinical geneticist as partners, because we hypothesized that synergy might contribute to increasing the number of diagnoses identified in persons with a genodermatological disorder. Clarifying a diagnosis adds significantly to the structure of care and follow- up for patients and their family members in the genetic clinic. Parents experience more anxiety, cope less effectively and do not adapt as well, when they feel as if they have less control over their child's condition $(1,2)$. A delay in diagnosis may contribute to the feeling of isolation of having a rare condition (3). Reported data indicates that pooling skills and experience improves the quality of care for the individual patient, raises awareness by health care professionals in general, and is an educational resource and a source of support for other professionals $(1,4)(5-9)$.

We are aware of national as well as international initiatives of dermatologists and clinical geneticists working together in a multidisciplinary outpatient clinic (unreported data and(10)). There are however few reports in the medical literature on diagnostic multidisciplinary outpatient clinics. And the ones that do exist often involve single disease entities. Furthermore, most reports in the literature concern less than 250 subjects, whereas our cohort is much larger, with 409 subjects.

When searching Pubmed for "multidisciplinary teams" and "genetic", reports are found on such teams for schisis (7), disorders of sexual development (8), neurofibromatosis type 1 (3), multiple endocrine neoplasia type 1(MEN1)(11), retinoblastoma(12), familial breast cancer/HBO (13) (14) and intellectual disability(15). As far as we know, systematic efforts in multidisciplinary genodermatological counselling have not been reported in the medical literature.

In this retrospective, descriptive study data of an interdisciplinary approach to patients with genodermatoses are presented. In the interdisciplinary outpatient clinic "Genodermatoses" we saw 409 patients during an 8-year time period (20042012). Their characteristics are described in the previous chapters of this thesis (Chapters 1 to 5).

Selection bias is an issue in this cohort, since our team is regarded as a tertiary referral centre in the Netherlands. There has however already been interest and expertise on several conditions in which the skin plays a major role in the past, both in the department of clinical genetics and in the department of dermatology (for example: neurofibromatosis type 1, Prader-Willi syndrome, disorders of keratinization, Birt-Hogg-Dubé syndrome).

First, there is a surplus of females in the cohort (246 females> 163 males; Chapter 1 , Table 1). There are several possible explanations:

To begin with, women might be more likely to seek medical attention (16). In clinical genetics as well as in dermatological practice, daily routine involves more female than male counselees (personal observation) (17). Dermatological disorders 
are often visible and not compatible with general cosmetic ideals. In present-day society, cosmetic issues still are more a woman's burden than a man's concern. Secondly, a reasonable number of X-linked disorders are lethal in males. More females than males were therefore present in this subgroup of the cohort. The most frequent diagnosis was Incontinentia Pigmenti (IP) (Chapter 1, Table 1.1; Chapter 3 ). While autosomal conditions are expressed independently of gender, females with dominant X-linked conditions have a higher survival rate due to rescue by skewed X-inactivation. Many of the X-linked genodermatoses are recognizable by specific skin patterns, and since this organ is easily accessible to the human eye, contrary to internal organs, this might also have been one of the factors involved in overrepresentation in our cohort. Finally, a subset of patients belonging to the diagnostic subgroup "miscellaneous" consisted mainly of females (Chapter 5, connective tissue disorders).

Secondly, because of our separate research projects on Birt-Hogg-Dubé syndrome (BHD), a relatively large group of individuals with BHD was present in this cohort (Chapter 2).

Finally, from the MUMC expertise centre role for individuals with Prader-Willi syndrome (PWS) we performed a project concerning skin features in this syndrome. 13 individuals with PWS attended the interdisciplinary team and were assigned to the miscellaneous group.

\section{Aim 1: Improving patient care}

Stratifying the cohort into 4 main subgroups (Chapter 2: dermato-oncogenetic, Chapter 3: disorders involving the X-chromosome, Chapter 4: mosaicism, Chapter 5: miscellaneous) simplified the diagnostic process and approach to treatment and follow-up in our experience.

Data on the diagnosis and outcome were recorded for each patient in the cohort. Figure 6.1 summarizes the main observations, which are also described in chapter 1 (Table 1.1). 


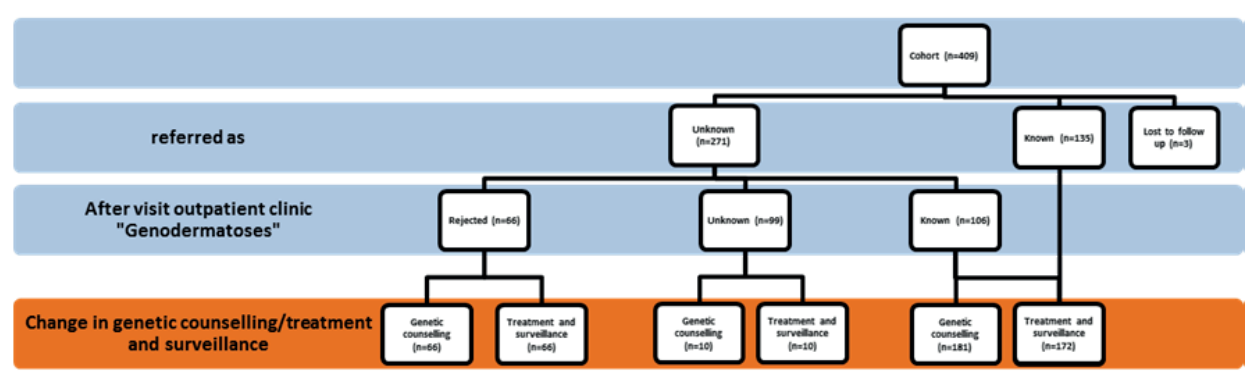

Figure 6.1. In blue: diagnostic yield.

In orange: outcome on genetic counselling and treatment/surveillance.

Aim 1a Increasing the number of diagnoses: the diagnostic yield

The total percentage of diagnoses in the cohort was 59\% (241 of the 409 patients; Chapter 1, Table 1.1, Chapter 6, figure 6.1). New diagnoses were identified by the interdisciplinary team in $26 \%$ of the cases (106/409). The contribution of new diagnoses made by our team differed depending on the diagnostic subgroup, with the highest relative yield in the mosaic and X-linked conditions (Table 6.1). While the percentage of new diagnoses in the miscellaneous group is lower with $24 \%$, this is a numerically important subset in the cohort $(n=57)$.

Our total yield of $59 \%$ exceeds that of earlier reports on diagnostic yield in cohorts of patients with intellectual disability (ID). The diagnostic yield in these cohorts varied from 30 to $47.8 \%$ in several studies on the etiology of ID using a diagnostic approach comparable to the one we used in our cohort $(6,18-20)$.

Table 6.1. Diagnosis by referring clinician vs. diagnosis by the team per diagnostic subgroup.

\begin{tabular}{|c|c|c|c|}
\hline & $\begin{array}{l}\text { Known diagnosis at } \\
\text { referral : } \\
\text { Number of patients( } \% \\
\text { total in the subgroup) }\end{array}$ & $\begin{array}{l}\text { Number of diagnoses made by } \\
\text { the interdisciplinary team : } \\
\text { Number of patients ( } \% \text { total of } \\
\text { the subgroup) }\end{array}$ & $\begin{array}{l}\text { Number of } \\
\text { patients in } \\
\text { subgroup }\end{array}$ \\
\hline $\begin{array}{l}\text { Dermato-oncogenetic } \\
\text { group }\end{array}$ & $43(39 \%)$ & $17(15,4 \%)$ & 110 \\
\hline $\begin{array}{l}\text { Disorders involving the } \mathrm{X} \\
\text { chromosome }\end{array}$ & $16(53 \%)$ & $14(47 \%)$ & 30 \\
\hline Mosaisicm & $9(30 \%)$ & $18(60 \%)$ & 30 \\
\hline Miscellaneous & $67(28 \%)$ & $57(24 \%)$ & 236 \\
\hline Total & $135(33 \%)$ & $106(26 \%)$ & 406 \\
\hline
\end{tabular}

In the past decades the development of molecular techniques has moved the focus on medical care and genetic research from the clinical setting to the laboratory (21). Reports on the diagnostic yield, that can be accomplished by using techniques such as next generation sequencing and whole exome sequencing, are becoming available. Willemsen and Kleefstra reported a yield of 59,8\% in a cohort of individ- 
uals with an intellectual disability (ID) incorporating the abovementioned techniques into diagnostic practice (22). This observation indicates that genomewide techniques might be a powerful tool in increasing the yield in diagnoses in general, especially of "unknown" cases. In the cohort attended to by the interdisciplinary team "Genodermatosis", an overall diagnostic yield similar to the one observed by Willemsen, was found, but without applying genome-wide techniques. We therefore expect our diagnostic yield to increase when we start to use similar techniques in the future. However, exome sequencing is still a time consuming and costly procedure at the moment. Prospective studies on cost/benefit ratio are required before implementing the newer techniques in routine clinical care and more specifically: in the care by the outpatient clinic "Genodermatoses".

\section{Aim 1b. Contributing to (preventive) management and genetic counselling of individual patients and their families}

A diagnosis may change the genetic counselling and/or follow-up of a patient. In $60,1 \%(248 / 409)$ of the cases the visit resulted in a change in therapy or follow-up care (Chapter 1, Table 1.1; Chapter 6, Figure 6.1). Additional genetic counselling was provided in $62 \%$ of the cases (Chapter 1 , Table 1.1; Chapter 6, Figure 6.1). The contribution of these changes differed in the various diagnostic subgroups.

\section{Dermato-oncogenetic subgroup}

Rejecting a diagnosis might be equally important as identifying one, as observed in the dermato-oncogenetic group, where a rejection of a diagnosis resulted in adaptation of the surveillance protocol in many cases (83/110: 75\% change in treatment or surveillance observed, Chapter 1 , Table 1.1).

Many dermato-oncogenetic conditions have autosomal dominant traits with a significantly increased risk of developing cancer, such as Lynch syndrome (also including Muir Torre syndrome: chapter 2) and Birt-Hogg-Dubé syndrome. When dealing with an as yet unknown diagnosis, the emphasis should be on diagnosing a condition. This diagnosis dictates the surveillance program for the index patient, but also has consequences for (asymptomatic) family members. Presymptomatic individuals at risk of a familial oncogenetic condition, based on a known mutation within that family, require a different approach in counselling according to wellestablished guidelines $(23,24)$. In case the counselee does not carry the familial mutation, the risk for developing cancer becomes equal to the population risk of developing a particular tumour. Follow-up is not required in this situation.

However, asymptomatic individuals might choose not to be tested (yet) based on various considerations.

The finding that confirming or rejecting a diagnosis occurs frequently in this group is corroborated by reports by other groups involved in counselling of patients for hereditary cancer syndromes(12) (11). A multidisciplinary team may reduce diagnostic delay, provide more accurate risk prediction to patients and their 
family members, and facilitate the identification of individuals at risk. This may decrease overutilization of clinical screening tests (12) (3). Identifying non-carriers reduced anxiety in individual cases and made screening programmes redundant. This is analogous to observations by others $(3,12)(11)$

\section{Mosaic/X-linked group}

Most diagnoses of mosaicism were based on clinical features alone (Chapter 4, $\mathrm{n}=18 / 30: 60 \%$ ). A molecular confirmation in such cases can be highly challenging and is not always necessary for counselling. Autosomal mosaicism is a post-zygotic event. Most autosomal gene mutations appearing as mosaics are lethal if occurring in the germline (Lethal Gene Theory, Chapter 4 (25)). In rare cases, such a mutation can give rise to a different phenotype in its mosaic versus its germline form. For example: a mutation of the HRAS gene can cause a sebaceous nevus when in a mosaic form (26), while the same mutation causes Costello syndrome when present in all cells of the human body (germline)(27). Of many of the mosaic conditions in genodermatology, no germline form is known as yet. Diagnosing a mosaic condition at a clinical level in a patient is often linked to a recurrence risk of a few percent in further offspring of the parents. Moreover, index patients were often young, and future counselling at childbearing age was offered (Chapter 3, table 1).

\section{Miscellaneous group}

In over $60 \%$ of the patients, a change in treatment/follow-up and/or the provision of genetic counselling was observed (Chapter 1, Table 1.1). Apart from counselling patients with a known diagnosis, we were able to provide treatment options and/or genetic counselling in some of the patients without such a diagnosis (Figure 6.1, Chapter 6, n=10).

A subgroup of patients in the miscellaneous group, for whom a change in follow-up was frequently observed, presented with questions about connective tissue disorders. These patients asked if a hereditary connective tissue disorder could explain their complaints (Chapter 5, page 7). In this group, skin abnormalities can be the major clue towards the diagnosis of a known connective tissue disorder. Examples of skin abnormalities specific to a connective tissue disorder are for instance peau d'orange in pseudoxanthoma elasticum (28) or cigarette-paper scars in EhlersDanlos syndrome type 1 or 2 (29).

A large subset of patients presented with hypermobility, a relatively frequent feature in the general population, usually asked whether or not they had EhlersDanlos syndrome. They often asked for advice since they had developed a chronic pain syndrome. Based on our experience, we recommend physicians to use the simplified scoring list of Beighton before referral to a team for tertiary care (30). We consider referral to a specialist in rehabilitation medicine more appropriate for the patients with Beighton scores under 6 (31). This particular patient group forms 
a challenge in designing an appropriate prevention programme before therapy resistant pain develops and is subject to further research.

\section{Therapeutic options now and in the future}

Due to rapid expansion of general knowledge on the molecular basis of specific (genetic) disorders, more therapeutic options have become available in the last decades. Genetic disorders are no longer by definition untreatable. Different strategies for treatment are applied to specific groups of disorders. For example, enzyme replacement is now available in disorders caused by enzyme dysfunction, like lysosomal storage diseases (32). Agents acting on specific steps of general pathways such as the mTOR pathway (kinase inhibitors like for example rapamycin or everolimus (Afinitor $($ )) can be used to treat symptoms of disorders like Tuberous Sclerosis Complex(33-35). Kinase inhibitors are mainly used in situations in which pathway overactivity (activating mutations) is present.

In multiple rare disorders, including several genodermatoses, treatments are being developed based on relevant molecular pathways involved in the origin of the particular condition. Examples of pathogenesis-based therapy are for instance the treatment of CHILD (Congenital Hemidysplasia with Ichthyosiform Erythroderma and Limb Defects) syndrome with a topical lotion containing lovastatin and cholesterol, which completely resolves the skin features (36). Another study by Leachman et al was proof of principle that gene-therapy using siRNA could treat callus formation in Pachyonychia Congenita (37). Many of these treatments are based on genotype, stressing the importance of molecular diagnostics in individual cases.

In the future, pathogenesis-based treatment of genetic disorders might become part of a personalized treatment programme in addition to the conventional therapeutic options. Carefully, we are taking the first steps in this field in our cohort:

In one of the patients with Macrodystrophia lipomatosa we reported on in Chapter 4, a mosaic activating PIK3CA gene mutation is causing the disorder. PIK3CA is part of the mTOR pathway, which can be inhibited with agents like rapamycin and everolimus. This patient will soon start taking a low dose of one of these agents (everolimus), in the hope of slowing down the overgrowth of her right hand.

Aim 1c clustering of single rare disorders into subgroups and providing clinical clues for referring physicians

Clustering cases into subgroups helped us in the diagnosis of complex cases The reviews on X-linked disorders (Chapter 3, (38),) and mosaicism (Chapter 4(39)) may facilitate diagnosis for other clinicians. Clinical features can lead directly to a specific diagnosis: in a boy with X-linked recessive ichthyosis (XLRI) with an intellectual disability and/or multiple congenital anomalies, one should consider a contiguous gene syndrome of the X-chromosome (Chapter 3, (40)). In a phylloid 
mosaic pattern (type 3 patterns, Chapter 4, (39)) a chromosomal cause is likely (for example mosaicism of trisomy 13).

Over the years we have gained experience that has translated into the clinical clues that were described in the preceding paragraph. Hopefully, these clues will enable clinicians to recognize and diagnose genodermatoses more easily. The most important clues as reported by us so far are summarised below:

- If a (female) patient has a mosaic pattern of skin lesions following the lines of Blaschko, an X-linked disorder should be considered. A precise and accurate description of the skin lesions by an experienced dermatologist is of vital importance for diagnosing the correct disorder.

- Skin abnormalities in a newborn, such as erythroderma and vesicles or lymphedema, should be documented precisely, by photography when possible. Special attention should be paid to distribution according to the lines of Blaschko. Referral to, or consultation of, a dermatologist is warranted.

- If a congenital disease such as Conradi-Hünermann-Happle syndrome or focal dermal hypoplasia is considered in the differential diagnosis, skeletal imaging should take place to find additional clues for the diagnosis.

- If an indication of male lethality is present in the pedigree, an X-linked dominant condition should be considered.

- Although DNA analysis is the method of choice nowadays to diagnose many Xlinked conditions, (molecular) karyotyping is still warranted in males with features 'outside the spectrum' (developmental delay, dysmorphic features and/or congenital anomalies) or in females with an X-linked condition that usually is not expressed in this gender.

\section{Aim 2: Outcome in education}

We tried to share our experience on interdisciplinary teamwork and genodermatology with other professionals in health care. Every outpatient clinic was attended by residents from either the department of dermatology or the department of clinical genetics. Colleagues from departments of dermatology and clinical genetics from medical centres throughout the Netherlands also regularly visited the outpatient clinic. We provided training on different aspects of genodermatological disorders for groups of paediatricians, dermatologists, clinical geneticists and their residents, both locally as well as nationally. All medical students of the University of Maastricht attended lectures on genodermatology from 2004 onwards (approximately 250 students/year). Medical students in their master phase were offered the opportunity to participate in research projects and clinical internships.

Our team is part of the Dutch Taskforce on Pediatric Dermatology, section for genodermatology. 
With these initiatives we provided and still provide education on genodermatoses in different forums of medical practitioners.

\section{Aim 3 Improving knowledge on genodermatoses}

Aim 3a/3b. Sharing our experience-based findings in peer-reviewed journals and reporting new features

Apart from the peer-reviewed publications in this thesis, other publications were also based on data derived from this cohort. Several abstracts resulting in posters and oral presentations were submitted to national and international meetings. New features were reported in several disorders including Myhre syndrome (Chapter 5)(41) and oculo-dento-digital dysplasia (Chapter5)(42). The observations we made regarding squamous cell carcinoma as part of the phenotype of Muir-Torre syndrome (Chapter 2) could influence the identification of families with MTS and the surveillance programs that might be appropriate for these patients.

\section{Aim 3c. Identifying research questions for future research projects}

There were two groups of patients that initiated further research projects.

Birt-Hogg-Dubé syndrome

The Birt-Hogg-Dubé syndrome (BHD OMIM \#135150,) is probably an underdiagnosed condition since various families were identified via our cohort whereas before the start of the multidisciplinary team only few families were known of (personal observation). Birt-Hogg-Dubé syndrome (BHD) is an autosomal dominantly inherited disorder characterized by the development of benign hair follicle tumors with characteristic histological appearance called fibrofolliculomas, an increased risk for pulmonary cysts resulting in spontaneous pneumothorax and an increased risk for malignant renal tumors(43-45). The disease is caused by mutations in the BHD gene that encodes folliculin (FLCN) (46). Most mutations reported so far putatively truncate the protein and are considered to be oncogenic by causing haploinsufficiency(47). FLCN is involved in many different processes including ciliogenesis, HIF1 $\alpha$ / mTOR signaling and WNT signaling, but its exact role is still unclear(4852). In our clinic, a person with BHD is offered a screening protocol following (inter)national guidelines for the kidneys consisting of a renal MRI examination every 1 to 2 years starting from the age of 20 years. It is recommended to perform a CT scan the first time, so as to have a base line examination. The function of folliculin, working towards treatment of the disease and developing further surveillance protocols for individuals with BHD are research goals for our group (53), which is imbedded in the European BHD consortium (www.europeanbhdconsortium.eu). 


\section{Hypermobility}

As mentioned in earlier paragraphs and chapter 5, we encountered a group of patients with questions regarding connective tissue disorders. Especially the patients with hypermobility, who developed features of chronic pain syndrome, gained our interest. Such patients had often been in the diagnostic tract for years, occupying inappropriately chosen health care services while their quality of life deteriorated significantly. This study group was enlarged and data on clinical features, family history and molecular studies have been collected. Currently, these data are being analysed for further research. Future studies will focus towards genetic factors in pain perception because many of the patients in this group develop features of chronic pain syndrome. Furthermore, the medical approach in this group will be subject of future research.

\section{Outcome of the aims of this thesis in summary}

Aim number 1, to improve patient care was achieved: We increased the number of diagnoses in this cohort by $26 \%$. This almost doubled the number of diagnoses, known at the moment of referral. New techniques for genome-wide analysis might increase the diagnostic yield in the future. We positively contributed to genetic counselling and/or management options in over $60 \%$ of the cases. Treatment options for the future are explored. The interdisciplinary team seems to contribute to patient care in this cohort, but an exact cost/benefit ratio estimation and evaluation of patient satisfaction is required to quantify this correctly. For such evaluation other study-designs are needed, and it was therefore not part of this thesis $(54,55)$. We are planning to incorporate cost/benefit ratio estimation and evaluation of patient satisfaction in future studies.

We hope that the principle of clustering patients into subgroups as described in this thesis, and the clinical clues provided in the various chapters might facilitate other clinicians in recognizing and diagnosing a patient with a genodermatosis. Regarding aim 2: we provided and are still providing education to other health care professionals.

We successfully identified new patients groups for future research projects as well as added new features to known genodermatoses to the literature and have made observations that influence patient care. In this way we achieved aim 3 of this project. 


\section{References}

1. Young CA. Building a care and research team. J Neurol Sci. 1998 Oct;160 Suppl 1:S137-40. PubMed PMID: 9851664. Epub 1998/12/16. eng.

2. Lipinski SE, Lipinski MJ, Biesecker LG, Biesecker BB. Uncertainty and perceived personal control among parents of children with rare chromosome conditions: the role of genetic counseling. Am J Med Genet C Semin Med Genet. 2006 Nov 15;142C(4):232-40. PubMed PMID: 17068805. Epub 2006/10/28. eng.

3. Cnossen MH, Smit FJ, de Goede-Bolder A, Frets PG, Duivenvoorden HJ, Niermeijer MF. Diagnostic delay in neurofibromatosis type 1. European journal of pediatrics. 1997 Jun;156(6):482-7. PubMed PMID: 9208248.

4. Cnossen MH, de Goede-Bolder A, van den Broek KM, Waasdorp CM, Oranje AP, Stroink H, et al. A prospective 10 year follow up study of patients with neurofibromatosis type 1 . Archives of disease in childhood. 1998 May;78(5):408-12. PubMed PMID: 9659085. Pubmed Central PMCID: 1717584.

5. van Karnebeek CD, Jansweijer MC, Leenders AG, Offringa M, Hennekam RC. Diagnostic investigations in individuals with mental retardation: a systematic literature review of their usefulness. Eur J Hum Genet. 2005 Jan;13(1):6-25. PubMed PMID: 15523501. Epub 2004/11/04. eng.

6. van Karnebeek CD, Scheper FY, Abeling NG, Alders M, Barth PG, Hoovers JM, et al. Etiology of mental retardation in children referred to a tertiary care center: a prospective study. Am J Ment Retard. 2005 Jul;110(4):253-67. PubMed PMID: 15941363. Epub 2005/06/09. eng.

7. Fontes MI, Almeida LN, de Oliveira Reis Junior G, Filho JI, Dos Santos KM, Dos Anjos FS, et al. Local strategies to address health needs of individuals with orofacial clefts in alagoas, Brazil. The Cleft palate-craniofacial journal : official publication of the American Cleft Palate-Craniofacial Association. 2013 Jul;50(4):424-31. PubMed PMID: 22236341.

8. Parisi MA, Ramsdell LA, Burns MW, Carr MC, Grady RE, Gunther DF, et al. A Gender Assessment Team: experience with 250 patients over a period of 25 years. Genetics in medicine : official journal of the American College of Medical Genetics. 2007 Jun;9(6):348-57. PubMed PMID: 17575501.

9. Zadeh N, Getzug T, Grody WW. Diagnosis and management of familial Mediterranean fever: integrating medical genetics in a dedicated interdisciplinary clinic. Genetics in medicine : official journal of the American College of Medical Genetics. 2011 Mar;13(3):263-9. PubMed PMID: 21317656.

10. Duipmans JC, Jonkman MF. Interdisciplinary management of epidermolysis bullosa in the public setting: the Netherlands as a model of care. Dermatologic clinics. 2010 Apr;28(2):383-6, xiii. PubMed PMID: 20447507.

11. White HD, Blair J, Pinkney J, Cuthbertson DJ, Day R, Weber A, et al. Improvement in the care of multiple endocrine neoplasia type 1 through a regional multidisciplinary clinic. QJM : monthly journal of the Association of Physicians. 2010 May;103(5):337-45. PubMed PMID: 20231234.

12. Dhar SU, Chintagumpala M, Noll C, Chevez-Barrios P, Paysse EA, Plon SE. Outcomes of integrating genetics in management of patients with retinoblastoma. Archives of ophthalmology. 2011 Nov;129(11):1428-34. PubMed PMID: 22084214.

13. Brain K, Gray J, Norman P, France E, Anglim C, Barton G, et al. Randomized trial of a specialist genetic assessment service for familial breast cancer. Journal of the National Cancer Institute. 2000 Aug 16;92(16):1345-51. PubMed PMID: 10944557.

14. Firth C, Jacobs C, Evison M, Pichert G, Izatt L, Hunter MS. Novel one-stop multidisciplinary follow-up clinic for BRCA1/2 carriers: patient satisfaction and decision making. Psycho-oncology. 2011 Dec;20(12):1301-8. PubMed PMID: 22114045.

15. Bhatt C, Misra Z, Goyel N. Detection of inherited metabolic diseases in children with mental handicap. Indian journal of clinical biochemistry : IJCB. 2008 Jan;23(1):10-6. PubMed PMID: 23105712. Pubmed Central PMCID: 3453658.

16. Schappert SM. Ambulatory care visits of physician offices, hospital outpatient departments, and emergency departments: United States, 1995. Vital and health statistics Series 13, Data from the National Health Survey. 1997 Jun(129):1-38. PubMed PMID: 9198408. 
17. Benton EC, Kerr OA, Fisher A, Fraser SJ, McCormack SK, Tidman MJ. The changing face of dermatological practice: 25 years' experience. The British journal of dermatology. 2008 Aug;159(2):413-8. PubMed PMID: 18565175.

18. Van Buggenhout GJ, van Ravenswaaij-Arts C, Mieloo H, Syrrou M, Hamel B, Brunner H, et al. Dysmorphology and mental retardation: molecular cytogenetic studies in dysmorphic mentally retarded patients. Annales de genetique. 2001 Apr-Jun;44(2):89-92. PubMed PMID: 11522247.

19. Stevenson RE, Procopio-Allen AM, Schroer RJ, Collins JS. Genetic syndromes among individuals with mental retardation. Am J Med Genet A. 2003 Nov 15;123A(1):29-32. PubMed PMID: 14556243.

20. Rauch A, Hoyer J, Guth S, Zweier C, Kraus C, Becker C, et al. Diagnostic yield of various genetic approaches in patients with unexplained developmental delay or mental retardation. Am J Med Genet A. 2006 Oct 1;140(19):2063-74. PubMed PMID: 16917849.

21. Hou L, Zhao H. A review of post-GWAS prioritization approaches. Frontiers in genetics. 2013;4:280. PubMed PMID: 24367376. Pubmed Central PMCID: 3856625.

22. Willemsen M, Kleefstra T. Making headway with genetic diagnostics of intellectual disabilities. Clinical genetics. 2013 Jul 29. PubMed PMID: 23895455.

23. Richtlijn Erfelijke darmkanker. Vereniging Klinische Genetica en Kwaliteitsinstituut voor de Gezondheidszorg CBO. Website: http://www.oncoline.nl (2008).

24. Richtlijn Mammacarcinoom. Vereniging van Integrale Kankercentra (VIKC). Kwaliteitsinstituut voor de Gezondheidszorg CBO. Website: http://www.oncoline.nl (2008).

25. Happle R. The McCune-Albright syndrome: a lethal gene surviving by mosaicism. Clinical genetics. 1986 Apr;29(4):321-4. PubMed PMID: 3720010.

26. Hafner C, Toll A, Real FX. HRAS mutation mosaicism causing urothelial cancer and epidermal nevus. The New England journal of medicine. 2011 Nov 17;365(20):1940-2. PubMed PMID: 22087699.

27. Aoki Y, Niihori T, Kawame H, Kurosawa K, Ohashi H, Tanaka Y, et al. Germline mutations in HRAS proto-oncogene cause Costello syndrome. Nature genetics. 2005 Oct;37(10):1038-40. PubMed PMID: 16170316.

28. Plomp AS, Toonstra J, Bergen AA, van Dijk MR, de Jong PT. Proposal for updating the pseudoxanthoma elasticum classification system and a review of the clinical findings. Am J Med Genet A. 2010 Apr;152A(4):1049-58. PubMed PMID: 20358627.

29. Malfait F, Wenstrup RJ, De Paepe A. Clinical and genetic aspects of Ehlers-Danlos syndrome, classic type. Genetics in medicine : official journal of the American College of Medical Genetics. 2010 Oct;12(10):597-605. PubMed PMID: 20847697.

30. Remvig L, Jensen DV, Ward RC. Epidemiology of general joint hypermobility and basis for the proposed criteria for benign joint hypermobility syndrome: review of the literature. J Rheumatol. 2007 Apr;34(4):804-9. PubMed PMID: 17407233. Epub 2007/04/05. eng.

31. Vreeburg MdV-H, J. Schouten, M. Weiss, J. Pals, G. Maugeri,A. Robben,S. Detisch, Y.van Eijsden, M. Verbunt, J. Klaassens, M. van Douveren, D. van Steensel,MAM. Marcus-Soekarman, D. The benign joint hypermobility syndrome: guidelines for diagnosis and management. First international symposium on EDS; Ghent, Belgium2012.

32. Ohashi T. Enzyme replacement therapy for lysosomal storage diseases. Pediatric endocrinology reviews : PER. 2012 Oct;10 Suppl 1:26-34. PubMed PMID: 23330243.

33. Lebwohl D, Anak O, Sahmoud T, Klimovsky J, Elmroth I, Haas T, et al. Development of everolimus, a novel oral mTOR inhibitor, across a spectrum of diseases. Annals of the New York Academy of Sciences. 2013 Jul;1291:14-32. PubMed PMID: 23659703.

34. Turner SG, Peters KB, Vredenburgh JJ, Desjardins A, Friedman HS, Reardon DA. Everolimus tablets for patients with subependymal giant cell astrocytoma. Expert opinion on pharmacotherapy. 2011 Oct;12(14):2265-9. PubMed PMID: 21806479. Pubmed Central PMCID: 3389821.

35. Curatolo P, Moavero R. mTOR Inhibitors in Tuberous Sclerosis Complex. Current neuropharmacology. 2012 Dec;10(4):404-15. PubMed PMID: 23730262. Pubmed Central PMCID: 3520048.

36. Paller AS, van Steensel MA, Rodriguez-Martin M, Sorrell J, Heath C, Crumrine D, et al. Pathogenesisbased therapy reverses cutaneous abnormalities in an inherited disorder of distal cholesterol metabolism. The Journal of investigative dermatology. 2011 Nov;131(11):2242-8. PubMed PMID: 21753784. Pubmed Central PMCID: 3193573. 
37. Leachman SA, Hickerson RP, Schwartz ME, Bullough EE, Hutcherson SL, Boucher KM, et al. First-inhuman mutation-targeted siRNA phase Ib trial of an inherited skin disorder. Molecular therapy : the journal of the American Society of Gene Therapy. 2010 Feb;18(2):442-6. PubMed PMID: 19935778. Pubmed Central PMCID: 2839285.

38. Vreeburg M, Sallevelt SC, Stegmann AP, van Geel M, Detisch YJ, Schrander-Stumpel CT, et al. Cutaneous clues for diagnosing X-chromosomal disorders. Clinical genetics. 2014 Apr;85(4):328-35. PubMed PMID: 23578112.

39. Vreeburg M, van Steensel MA. Genodermatoses caused by genetic mosaicism. European journal of pediatrics. 2012 Dec;171(12):1725-35. PubMed PMID: 23114847.

40. van Steensel MA, Vreeburg M, Engelen J, Ghesquiere S, Stegmann AP, Herbergs J, et al. Contiguous gene syndrome due to a maternally inherited $8.41 \mathrm{Mb}$ distal deletion of chromosome band Xp22.3 in a boy with short stature, ichthyosis, epilepsy, mental retardation, cerebral cortical heterotopias and Dandy-Walker malformation. Am J Med Genet A. 2008 Nov 15;146A(22):2944-9. PubMed PMID: 18925676.

41. van Steensel MA, Vreeburg M, Steijlen PM, de Die-Smulders C. Myhre syndrome in a female with previously undescribed symptoms: further delineation of the phenotype. Am J Med Genet A. 2005 Dec 1;139A(2):127-30. PubMed PMID: 16278892.

42. Vreeburg M, de Zwart-Storm EA, Schouten MI, Nellen RG, Marcus-Soekarman D, Devies M, et al. Skin changes in oculo-dento-digital dysplasia are correlated with C-terminal truncations of connexin 43. Am J Med Genet A. 2007 Feb 15;143(4):360-3. PubMed PMID: 17256797.

43. Birt AR, Hogg GR, Dube WJ. Hereditary multiple fibrofolliculomas with trichodiscomas and acrochordons. Arch Dermatol. 1977 Dec;113(12):1674-7. PubMed PMID: 596896. Epub 1977/12/01. eng.

44. Zbar B, Alvord WG, Glenn G, Turner M, Pavlovich CP, Schmidt L, et al. Risk of renal and colonic neoplasms and spontaneous pneumothorax in the Birt-Hogg-Dube syndrome. Cancer Epidemiol Biomarkers Prev. 2002 Apr;11(4):393-400. PubMed PMID: 11927500. Epub 2002/04/03. eng.

45. Toro JR, Glenn G, Duray P, Darling T, Weirich G, Zbar B, et al. Birt-Hogg-Dube syndrome: a novel marker of kidney neoplasia. Arch Dermatol. 1999 Oct;135(10):1195-202. PubMed PMID: 10522666. Epub 1999/10/16. eng.

46. Nickerson ML, Warren MB, Toro JR, Matrosova V, Glenn G, Turner ML, et al. Mutations in a novel gene lead to kidney tumors, lung wall defects, and benign tumors of the hair follicle in patients with the Birt-Hogg-Dube syndrome. Cancer Cell. 2002 Aug;2(2):157-64. PubMed PMID: 12204536. Epub 2002/09/03. eng.

47. Hudon V, Sabourin S, Dydensborg AB, Kottis V, Ghazi A, Paquet M, et al. Renal tumour suppressor function of the Birt-Hogg-Dube syndrome gene product folliculin. Journal of medical genetics. 2010 Mar;47(3):182-9. PubMed PMID: 19843504.

48. Luijten MN, Basten SG, Claessens T, Vernooij M, Scott CL, Janssen R, et al. Birt-Hogg-Dube syndrome is a novel ciliopathy. Human molecular genetics. 2013 Nov 1;22(21):4383-97. PubMed PMID: 23784378. Pubmed Central PMCID: 3792695.

49. Reiman A, Lu X, Seabra L, Boora U, Nahorski MS, Wei W, et al. Gene expression and protein array studies of folliculin-regulated pathways. Anticancer research. 2012 Nov;32(11):4663-70. PubMed PMID: 23155228.

50. Baba M, Furihata M, Hong SB, Tessarollo L, Haines DC, Southon E, et al. Kidney-targeted Birt-HoggDube gene inactivation in a mouse model: Erk1/2 and Akt-mTOR activation, cell hyperproliferation, and polycystic kidneys. Journal of the National Cancer Institute. 2008 Jan 16;100(2):140-54. PubMed PMID: 18182616. Pubmed Central PMCID: 2704336.

51. Preston RS, Philp A, Claessens T, Gijezen L, Dydensborg AB, Dunlop EA, et al. Absence of the BirtHogg-Dube gene product is associated with increased hypoxia-inducible factor transcriptional activity and a loss of metabolic flexibility. Oncogene. 2011 Mar 10;30(10):1159-73. PubMed PMID: 21057536. Pubmed Central PMCID: 3787473.

52. Hartman TR, Nicolas E, Klein-Szanto A, Al-Saleem T, Cash TP, Simon MC, et al. The role of the BirtHogg-Dube protein in mTOR activation and renal tumorigenesis. Oncogene. 2009 Apr 2;28(13):1594-604. PubMed PMID: 19234517. Pubmed Central PMCID: 2664853. 
53. Menko FH, van Steensel MA, Giraud S, Friis-Hansen L, Richard S, Ungari S, et al. Birt-Hogg-Dube syndrome: diagnosis and management. The lancet oncology. 2009 Dec;10(12):1199-206. PubMed PMID: 19959076.

54. van Montfoort AP, Fiddelers AA, Janssen JM, Derhaag JG, Dirksen CD, Dunselman GA, et al. In unselected patients, elective single embryo transfer prevents all multiples, but results in significantly lower pregnancy rates compared with double embryo transfer: a randomized controlled trial. Human reproduction. 2006 Feb;21(2):338-43. PubMed PMID: 16253973.

55. Veldhorst-Janssen NM, Fiddelers AA, Zandstra H, Kessels AG, Zandstra H, Marcus MA, et al. Patient satisfaction with intranasal fentanyl for breakthrough pain. Journal of palliative medicine. 2012 Jun;15(6):631-2. PubMed PMID: 22656053. 

CHAPTER 7

Conclusions and future plans 
CHAPTER 7 


\section{Conclusions}

In an effort to maximize the diagnostic yield, joint consultation by the two disciplines of Clinical Genetics and Dermatology took place in combination with the support of a molecular laboratory providing DNA-testing, while using techniques not yet implemented in routine-diagnostics. In this set-up we achieved an additional diagnostic yield of $26 \%$ (up to $38,7 \%$ in unknown cases/cases pro diagnosi).

Newly developed technology provides extensive possibilities for diagnosing and studying human diseases at the molecular level. Review of more recent research indicates that clinical phenotyping remains an important part of genomics at the present. Input from the clinical side as well as from the laboratory side into the diagnostic process remains significant. The genome-wide data have to be interpreted in light of the clinical phenotype of the patient.

In this thesis, the diagnostic process was simplified by stratifying cases into a few diagnostic subgroups. Although many individual diagnoses are rare, clustering into a few subgroups (dermato-oncogenetic, mosaicism, disorders involving the $\mathrm{X}$ chromosome, miscellaneous) facilitates the diagnostic process and enables supplying of structured care, even in the absence of a definitive diagnosis. Careful documentation of findings remains important for follow-up and an eventual diagnosis, especially in unsolved cases. Moreover, grouping patients by cardinal features facilitates the recognition of specific disease-entities thereby enabling the professional to improve his/her professional qualities. Subgrouping the disorders of similar aetiology narrows down the choices in applying newly developed techniques of analysis, either in a diagnostic or research setting.

Based on the experience of the team, clinical tools were designed for referring clinicians to facilitate diagnosis and management in their own patient population. Correct categorization of skin abnormalities, pattern recognition of the skin (according to Blaschko's lines?) and the family pedigree (is there an autosomal dominant, recessive or X-linked trait?) are powerful tools to find a diagnosis in the group of patients attending the outpatient clinic "Genodermatoses". The special position of X-linked conditions and mosaicism in genodermatosis in general and the diagnostic process in particular, are reflected in the associated chapters of this thesis (Chapter 3 and 4). Reviews on recognizing and diagnosing these groups were written and published to help colleagues along $(1,2)$.

We experienced the interdisciplinary approach as a highly rewarding form of teamwork, expanding (personal) knowledge on genetic, dermatologic and genodermatologic disorders for both the dermatologist and the clinical geneticist. Our combined expertise allows us to function as a diagnostic clinic at tertiary care level. It also enables us to provide disease management in addition to family counselling. The expert knowledge on rare genodermatological disorders can inform state of the art research projects, aimed at understanding more of the pathophysiology of these 
disorders and developing new management approaches. We were able to share our experience and knowledge with other health care professionals, thereby furthering the knowledge on genodermatoses.

\section{Future plans}

In the following years we hope to further expand our interdisciplinary team and form a Centre of Excellence on Genodermatology. In a Centre of Excellence, the trias academica are secured: to be a true Centre of Excellence the team should excel in patient care, provide education and have ongoing research projects. Our Centre of Excellence will enable us to support more patients and improve on

- Diagnostic yield. We aim to increase our diagnostic yield to $50 \%$ in unknown cases visiting the outpatient clinic "Genodermatoses". Introducing new genomewide techniques, as well as structuring the outpatient clinic further in terms of patient groups can achieve this.

- Clinical care for patients with genodermatoses.

- Further research for the group of patients with hypermobility and Birt-HoggDubé syndrome. The expert knowledge on rare genodermatological disorders will stimulate the designing of research projects, aimed at understanding more of the pathophysiology of these disorders and developing new management approaches.

- Ongoing education of other health care professionals.

- (Targeted) treatment of symptoms of genodermatoses, providing a customized therapy guided by the molecular defects that cause the disorder. In future, we expect that more genetic genodermatological disorders will become treatable. Thus, discussing treatment options with the patient, as well as treatment itself will become a larger part of the work in the outpatient clinic "Genodermatoses".

- Future studies regarding cost/benefit ratio and patient satisfaction are required in the future to estimate the feasibility of implementing this team as a permanent partner in the structure of the Maastricht University Medical Centre. This interdisciplinary clinic with a diagnostic approach could be the perfect test case to examine whether working in a multidisciplinary setting is rewarding for both patients and healthcare providers. Studies on cost/benefit ratio should not only be aimed at the present but should also focus on the future development of an appropriate health insurance reimbursement for this kind of interdisciplinary team work. 


\section{References}

1. Vreeburg M, van Steensel MA. Genodermatoses caused by genetic mosaicism. European journal of pediatrics. 2012 Dec;171(12):1725-35. PubMed PMID: 23114847.

2. Vreeburg M, Sallevelt SC, Stegmann AP, van Geel M, Detisch YJ, Schrander-Stumpel CT, et al. Cutaneous clues for diagnosing X-chromosomal disorders. Clinical genetics. 2014 Apr;85(4):328-35. PubMed PMID: 23578112. 

CHAPTER 8

\section{Valorisation}


CHAPTER 8 


\section{Why study rare diseases like genodermatoses?}

Monogenetic disorders are rare conditions compared to other diseases such as diabetes or cancer, which are more common conditions with a multifactorial background. Most monogenetic disorders are defined as rare, using the definition by the European Union as affecting fewer than 50 people per 100,000 population or by the Food and Drug Administration as affecting fewer than 200,000 people in the United States. The frequency of monogenetic genodermatoses, which are genetic conditions with major skin involvement, ranges from 1 in 3000 for neurofibromatosis type I (OMIM \#162200), which is one of the more common autosomal dominant disorders, to 1 in 100.000 or even less. All diseases defined as rare together, affect $7 \%$ of the population (1). Four out of five are genetic in origin or have a genetic component (1). Approximately half of these disorders are diagnosed during childhood, affecting the patients and their families for decades. From this point of view the group of rare diseases are a significant burden not only for individual patients (and their families) but also for society in general.

\section{What's to gain by researching these rare disorders for patients, healthcare professionals and the (scientific) society}

\section{Patients and their families}

Clarifying a diagnosis adds significantly to the structure of care and follow- up for patients and their family members in the genetic clinic. Parents experience more anxiety, cope less effectively and do not adapt as well, when they feel as if they have less control over their child's condition(2). A delay in diagnosis may contribute to the feeling of isolation of having a rare condition (3). Reported data indicates that pooling skills and experience improves the quality of care for the individual patient, raises awareness by health care professionals in general, and is an educational resource and a source of support for other professionals $(4,5)(6-10)$. Recognizing the correct diagnosis is important as it allows us to offer personalized medicine in individual cases and improve health care for a particular patient. Provision of health care from physicians with a lack of experience of relatively rare conditions results in difficulties with the diagnosis of said conditions.

Advances in molecular genetics and the problems in interpreting these data in the care for individual patients

Because of the development of new techniques in molecular genetics, such as micro-arrays and whole exome or whole genome sequencing (next generation sequencing, NGS), the yield of molecular diagnoses is increasing. Introducing whole 
exome sequencing leads to an additional diagnostic yield of approximately $10-25 \%$ in patients with intellectual disability in whom extensive investigations had not revealed a diagnosis so far(11). These techniques provide the clinician with a wealth of molecular data, often establishing a genotype before phenotyping has been performed. Modern molecular techniques enable scientists to study even the more common, multifactorial diseases for their genetic components.

The problems that are encountered interpreting data from such Genomic Wide Association Studies (GWAS) studies, which often involve several thousands of cases and controls, show that careful phenotyping still remains one of the pillars of medical care and research(12). Stratifying such large study populations into sub-groups defined by a set of clinical parameters might improve the yield of significant associations with certain genetic variants(12) (13). Thus, in-depth phenotyping seems to be important in improving the interpretation of molecular GWAS data. The same principle applies to phenotyping in diagnostic whole exome sequencing in individual patients. The knowledge we gathered on phenotypes of genodermatoses will help to interpretate new molecular findings in research correctly.

Health care professionals, patient organizations and health care economics

Coordinated actions of professionals from different backgrounds working in a multidisciplinary setting are supposed to offer a complimentary range of skills, resulting in more efficient healthcare, which benefits both patients and care provid$\operatorname{ers}(10,14-16)$.

A multidisciplinary approach in healthcare is now recognised as important by healthcare professionals, patient organisations and health care economics. The general assumption is that a multidisciplinary approach could improve patient care and possibly have a positive cost-benefit ratio. The interdisciplinary team seems to contribute to patient care in this cohort, but an exact cost/benefit ratio estimation and evaluation of patient satisfaction is required to quantify this correctly. For such evaluation other study-designs are needed, and it was therefore not part of this thesis $(17,18)$.

\section{How did the outpatient clinic " Genodermatoses" contribute in improving health care for patients?}

The outpatient clinic "Genodermatoses" was set up as a model for improving (health)care for patients with diagnostic questions in the combined fields of dermatology and clinical genetics. We increased the number of diagnoses in this cohort by $26 \%$. This almost doubled the number of diagnoses, known at the moment of referral. In $60,1 \%(248 / 409)$ of the cases the visit resulted in a change in therapy or follow-up care (Chapter 1, Table 1.1; Chapter 6, Figure 6.1). Additional genetic coun- 
selling was provided in $62 \%$ of the cases (Chapter 1, Table 1.1; Chapter 6, Figure 6.1). These results indicate a more tailored approach for these specific individuals and their family, avoiding unnecessary diagnostic testing and unnecessary surveillance protocols.

Due to rapid expansion of general knowledge on the molecular basis of specific (genetic) disorders, more therapeutic options have become available in the last decades. Genetic disorders are no longer by definition untreatable. In multiple rare disorders, including several genodermatoses, treatments are being developed based on relevant molecular pathways involved in the origin of the particular condition. Examples of pathogenesis-based therapy are for instance the treatment of CHILD (Congenital Hemidysplasia with Ichthyosiform Erythroderma and Limb Defects) syndrome with a topical lotion containing lovastatin and cholesterol, which completely resolves the skin features (19). Another study by Leachman et al was proof of principle that gene-therapy using siRNA could treat callus formation in Pachyonychia Congenita (20). Many of these treatments are based on genotype, stressing the importance of molecular diagnostics in individual cases. In the future, pathogenesis-based treatment of genetic disorders might become part of a personalized treatment program in addition to the conventional therapeutic options.

\section{How did the outpatient clinic " Genodermatosis" contributed to education of health care providers?}

We hope that the principle of clustering patients into subgroups as described in this thesis, and the clinical clues provided in the various chapters might facilitate other clinicians in recognizing and diagnosing a patient with a genodermatosis. Clustering cases into subgroups helped us in the diagnosis of complex cases. The reviews on Xlinked disorders (Chapter 3, (21),) and mosaicism (Chapter 4(22)) may facilitate diagnosis for other clinicians. Apart from the peer-reviewed publications in this thesis, other publications were also based on data derived from this cohort. Several abstracts resulting in posters and oral presentations were submitted to national and international meetings. We successfully identified new patients groups for future research projects as well as added new features to known genodermatoses in the literature, and we have made observations that influenced the patient care we provided.

The combined consultation creates opportunities for education of students, residents and colleagues regarding phenotyping and dysmorphology, as well as background and rationale for performing DNA-analysis. We tried to share our experience on interdisciplinary teamwork and genodermatology with other professionals in health care. Every outpatient clinic was attended by residents from either the 
department of dermatology or the department of clinical genetics. Colleagues from departments of dermatology and clinical genetics from medical centres throughout the Netherlands also regularly visited the outpatient clinic. We provided training on different aspects of genodermatological disorders for groups of paediatricians, dermatologists, clinical geneticists and their residents, both locally as well as nationally. All medical students of the University of Maastricht attended lectures on genodermatology from 2004 onwards (approximately 250 students/year). Medical students in their master phase were offered the opportunity to participate in research projects and clinical internships.

Our team is part of the Dutch Taskforce on Pediatric Dermatology, section for genodermatology.

With these initiatives we offered and still provide education on genodermatoses in different forums of medical practitioners.

\section{Future plans ( Chapter 7 Conclusions and future plans)}

In the following years we hope to further expand our interdisciplinary team and form a Centre of Excellence on Genodermatology. In a Centre of Excellence, the trias academica are secured: to be a true Centre of Excellence the team should excel in patient care, provide education and have ongoing research projects. Our Centre of Excellence will enable us to support more patients and improve on

- Diagnostic yield. We aim to increase our diagnostic yield to 50\% in unknown cases visiting the outpatient clinic "Genodermatoses". Introducing new genomewide techniques, as well as structuring the outpatient clinic further in terms of patient groups might enable us to do so.

- Clinical care for patients with genodermatoses.

- Further research for specific groups of patients. The expert knowledge on rare genodermatological disorders will stimulate the designing of research projects, aimed at understanding more of the pathophysiology of these disorders and developing new management approaches.

- Ongoing education of other health care professionals.

- (Targeted) treatment of symptoms of genodermatoses, providing a customized therapy guided by the molecular defects that cause the disorder. In future, we expect that more genetic genodermatological disorders will become treatable. Thus, discussing treatment options with the patient, as well as treatment itself will become a larger part of the work in the outpatient clinic "Genodermatoses".

- Future studies regarding cost/benefit ratio and patient satisfaction are required in the future to estimate the feasibility of implementing this team as a permanent partner in the structure of the Maastricht University Medical Centre. This interdisciplinary clinic with a diagnostic approach could be the perfect test case to examine whether working in a multidisciplinary setting is rewarding for both 
patients and healthcare providers. Studies on cost/benefit ratio should not only be aimed at the present but should also focus on the future development of an appropriate health insurance reimbursement for this kind of interdisciplinary team work. 


\section{References}

1. In: Field MJ, Boat TF, editors. Rare Diseases and Orphan Products: Accelerating Research and Development. The National Academies Collection: Reports funded by National Institutes of Health. Washington (DC) 2010.

2. Lipinski SE, Lipinski MJ, Biesecker LG, Biesecker BB. Uncertainty and perceived personal control among parents of children with rare chromosome conditions: the role of genetic counseling. Am J Med Genet C Semin Med Genet. 2006 Nov 15;142C(4):232-40. PubMed PMID: 17068805. Epub 2006/10/28. eng.

3. Cnossen MH, Smit FJ, de Goede-Bolder A, Frets PG, Duivenvoorden HJ, Niermeijer MF. Diagnostic delay in neurofibromatosis type 1. European journal of pediatrics. 1997 Jun;156(6):482-7. PubMed PMID: 9208248.

4. Young CA. Building a care and research team. J Neurol Sci. 1998 Oct;160 Suppl 1:S137-40. PubMed PMID: 9851664. Epub 1998/12/16. eng.

5. Cnossen MH, de Goede-Bolder A, van den Broek KM, Waasdorp CM, Oranje AP, Stroink H, et al. A prospective 10 year follow up study of patients with neurofibromatosis type 1 . Archives of disease in childhood. 1998 May;78(5):408-12. PubMed PMID: 9659085. Pubmed Central PMCID: 1717584.

6. van Karnebeek CD, Jansweijer MC, Leenders AG, Offringa M, Hennekam RC. Diagnostic investigations in individuals with mental retardation: a systematic literature review of their usefulness. Eur J Hum Genet. 2005 Jan;13(1):6-25. PubMed PMID: 15523501. Epub 2004/11/04. eng.

7. van Karnebeek CD, Scheper FY, Abeling NG, Alders M, Barth PG, Hoovers JM, et al. Etiology of mental retardation in children referred to a tertiary care center: a prospective study. Am J Ment Retard. 2005 Jul;110(4):253-67. PubMed PMID: 15941363. Epub 2005/06/09. eng.

8. Fontes MI, Almeida LN, de Oliveira Reis Junior G, Filho JI, Dos Santos KM, Dos Anjos FS, et al. Local strategies to address health needs of individuals with orofacial clefts in alagoas, Brazil. The Cleft palate-craniofacial journal : official publication of the American Cleft Palate-Craniofacial Association. 2013 Jul;50(4):424-31. PubMed PMID: 22236341.

9. Parisi MA, Ramsdell LA, Burns MW, Carr MC, Grady RE, Gunther DF, et al. A Gender Assessment Team: experience with 250 patients over a period of 25 years. Genetics in medicine : official journal of the American College of Medical Genetics. 2007 Jun;9(6):348-57. PubMed PMID: 17575501.

10. Zadeh N, Getzug T, Grody WW. Diagnosis and management of familial Mediterranean fever: integrating medical genetics in a dedicated interdisciplinary clinic. Genetics in medicine : official journal of the American College of Medical Genetics. 2011 Mar;13(3):263-9. PubMed PMID: 21317656.

11. Willemsen M, Kleefstra T. Making headway with genetic diagnostics of intellectual disabilities. Clinical genetics. 2013 Jul 29. PubMed PMID: 23895455.

12. Boycott KM, Vanstone MR, Bulman DE, MacKenzie AE. Rare-disease genetics in the era of nextgeneration sequencing: discovery to translation. Nature reviews Genetics. 2013 Oct;14(10):681-91. PubMed PMID: 23999272.

13. Lin DY, Zeng D, Tang ZZ. Quantitative trait analysis in sequencing studies under trait-dependent sampling. Proceedings of the National Academy of Sciences of the United States of America. $2013 \mathrm{Jul}$ 23;110(30):12247-52. PubMed PMID: 23847208. Pubmed Central PMCID: 3725118.

14. Tirosh E, Jaffe M. Global developmental delay and mental retardation--a pediatric perspective. Developmental disabilities research reviews. 2011 Nov;17(2):85-92. PubMed PMID: 23362028.

15. Pruthi S, Boughey JC, Brandt KR, Degnim AC, Dy GK, Goetz MP, et al. A multidisciplinary approach to the management of breast cancer, part 2: therapeutic considerations. Mayo Clinic proceedings. 2007 Sep;82(9):1131-40. PubMed PMID: 17803883.

16. Khandelwal KD, van Bokhoven H, Roscioli T, Carels CE, Zhou H. Genomic approaches for studying craniofacial disorders. American journal of medical genetics Part C, Seminars in medical genetics. 2013 Nov;163(4):218-31. PubMed PMID: 24142857.

17. van Montfoort AP, Fiddelers AA, Janssen JM, Derhaag JG, Dirksen CD, Dunselman GA, et al. In unselected patients, elective single embryo transfer prevents all multiples, but results in significantly lower pregnancy rates compared with double embryo transfer: a randomized controlled trial. Human reproduction. 2006 Feb;21(2):338-43. PubMed PMID: 16253973. 
18. Veldhorst-Janssen NM, Fiddelers AA, Zandstra H, Kessels AG, Zandstra H, Marcus MA, et al. Patient satisfaction with intranasal fentanyl for breakthrough pain. Journal of palliative medicine. 2012 Jun;15(6):631-2. PubMed PMID: 22656053.

19. Paller AS, van Steensel MA, Rodriguez-Martin M, Sorrell J, Heath C, Crumrine D, et al. Pathogenesisbased therapy reverses cutaneous abnormalities in an inherited disorder of distal cholesterol metabolism. The Journal of investigative dermatology. 2011 Nov;131(11):2242-8. PubMed PMID: 21753784. Pubmed Central PMCID: 3193573.

20. Leachman SA, Hickerson RP, Schwartz ME, Bullough EE, Hutcherson SL, Boucher KM, et al. First-inhuman mutation-targeted siRNA phase Ib trial of an inherited skin disorder. Molecular therapy : the journal of the American Society of Gene Therapy. 2010 Feb;18(2):442-6. PubMed PMID: 19935778. Pubmed Central PMCID: 2839285.

21. Vreeburg M, Sallevelt SC, Stegmann AP, van Geel M, Detisch YJ, Schrander-Stumpel CT, et al. Cutaneous clues for diagnosing X-chromosomal disorders. Clinical genetics. 2014 Apr;85(4):328-35. PubMed PMID: 23578112.

22. Vreeburg M, van Steensel MA. Genodermatoses caused by genetic mosaicism. European journal of pediatrics. 2012 Dec;171(12):1725-35. PubMed PMID: 23114847. 



\section{Samenvatting}

In deze thesis worden de resultaten van een interdisciplinaire polikliniek genodermatosen besproken, zowel op gebied van directe patiëntenzorg als op research nivo. Genodermatosen zijn erfelijke aandoeningen waarin de huid, nagels, haren en/of tanden betrokken zijn.

In hoofdstuk 1 werd een introductie gegeven over de opzet van de samenwerking en is de patiëntengroep besproken. In een 8-jarige periode 2004-2012 werden 409 patiënten gezien op een interdisciplinair spreekuur van de dermatoloog en de klinisch geneticus. De patiëntengroep kon uitgesplitst worden naar aandoeningen in 4 subgroepen: dermato-oncogenetische aandoeningen, aandoeningen waarbij het Xchromosoom betrokken is, mozaïcisme en een algemene groep inclusief de bindweefselaandoeningen en hypermobiliteit (miscellaneous). Deze subgroepen zijn de basis voor deze dissertatie. In elk hoofdstuk hebben we informatie verstrekt, op basis van onze ervaringen, over patroonherkenning en hebben we geprobeerd klinische aanwijzingen, die kunnen helpen bij het stellen van een diagnose, te determineren. Daarnaast beschreven we verschillende nieuwe phenotypische kenmerken van reeds bekende genodermatosen.

In hoofdstuk 2 werden de inspanningen rondom de patiëntengroep met dermatooncogenetische vragen bekeken. Naast inventarisatie en het delen van de klinische ervaring opgedaan bij het counselen van de patiënten staan nieuwe bevindingen bij Muir Torre syndroom beschreven, die gevolgen hebben voor de therapeutische aanpak naar personen met deze aandoening. Er is aandacht geschonken aan een dermato-oncogenetisch syndroom genaamd Cowden syndroom, waarbij de huid een belangrijke rol speelt.

In hoofdstuk 3 zijn verschillende vormen van X-gebonden huidaandoeningen belicht. Het hoofdstuk begint met een review over onze ervaring in het cohort met aandoeningen waarbij het X-chromosoom betrokken is. We hebben geprobeerd aan te tonen zien dat het correct herkennen van huidafwijkingen, het herkennen van patronen op/in de huid (zoals de lijnen van Blaschko) en het herkennen van patronen in de stamboom (is er een autosomaal dominante, recessieve of x-gebonden overerving?), krachtige instrumenten zijn bij het stellen van een X-gebonden diagnose. Een aantal X-gebonden aandoeningen worden apart belicht, namelijk Conra- 
di-Hünermann-Happle syndroom, een contiguous gene syndrome op basis van een deletie op het X-chromosoom en focale dermale hypoplasie.

Hoofdstuk 4 gaat over een veel voorkomend en vaak gemist onderdeel van de genodermatosen: aandoeningen die voorkomen in mozaïcisme. In een review zijn de basismechanismes van mozaïcisme en de huidige ideeën rondom ontstaansmechanisme, alsook een aantal voorbeelden en therapeutische opties binnen de kindergeneeskunde besproken. Daarnaast wordt een autosomaal dominant mozaïcisme, macrodystrophia lipomatosa, als voorbeeld getoond.

In hoofdstuk 5 worden enkele voorbeelden naar voren gebracht uit de groep van zeldzame syndromen. Het hoofdstuk toont de kracht van multidisciplinair samenwerking tussen de dermatoloog en de klinisch geneticus in het stellen van (zeldzame) diagnoses in de syndroomdiagnostiek. Een subgroep binnen deze groep waren de mensen met een bindweefselaandoeningen en hypermobiliteit.

In de discussie in hoofdstuk 6 wordt de meerwaarde van multidisciplinair samenwerken belicht, zowel vanuit de participerende partijen als vanuit het perspectief van de patiënt. Ook wordt de meerwaarde van deze samenwerking voor de wetenschap bekeken. De doelen, die gesteld waren in hoofdstuk 1, worden geëvalueerd.

In hoofdstuk 7 staan de conclusies van dit werk en worden plannen voor de toekomst besproken. Er wordt geconcludeerd dat deze samenwerking vanuit verschillende perspectieven waardevol lijkt, zowel voor de patiënt (hoog aantal diagnoses), als voor de betrokken professionals. Voor een substantieel deel van de patiënten veranderde, door het bezoek aan de polikliniek Genodermatosen, de behandeling of het screeningsadvies. Het stimuleerde het wetenschappelijk onderzoek en heeft het mogelijk gemaakt om de kennis en kunde over deze zeldzame groep aandoeningen te delen met collega's in het veld. We hopen zo de zorg voor patiënten met een genodermatose te verbeteren. Toekomstplannen, zoals bijvoorbeeld kosten-baten analyse en wetenschappelijke onderzoeksprojecten worden besproken. 


\section{Summary}

In this thesis, the results on patient care and in research projects of an interdisciplinary outpatient clinic "Genodermatoses" are presented. Genodermatoses are hereditairy conditions which involve the skin, nails, hair and/or teeth.

In chapter 1 an introduction is given on the aims of the study and the patient cohort that was studied. During an 8 year period (March 2004- March 2012) 409 patients visited the outpatient clinic "Genodermatoses" . Although a wide variety of disorders was observed, four diagnostic subgroups, each with its own characteristics, emerged in due course: dermato-oncogenetic conditions, disorders involving the $\mathrm{X}$ chromosome, mosaicism and miscellaneous conditions, including rare syndromes and the connective tissue disorders. These sub-groups form the basis for this thesis. In each chapter we provide information on our experience-based efforts in pattern recognition and determining clinical clues as diagnostic aids. We also describe several new phenotypic features in known genodermatoses.

In chapter 2, information is provided on the patients which visited the outpatient clinic "Genodermatoses" with questions regarding dermato-oncogenetic conditions. Experiences derived from counselling these patients are shared. New features of Muir Torre syndrome are added, which warrant adaption of the surveillance protocol for families with this condition. Another dermato-oncogenetic syndrome, the Cowden syndrome, is discussed as an example of a condition in which skin features are important clues towards a diagnosis.

In chapter 3 the group of the X-linked disorders are discussed. The chapter starts with a review based on our experience in X-chromosomal disorders in the cohort. We attempted to provide clinical clues for clinicians to recognise X-linked genodermatological disorders. We tried to show that categorizing skin abnormalities correctly and cutaneous pattern recognition (according to Blaschko's lines) and pattern recognition in the pedigree (is there a autosomal dominant, recessive or Xlinked trait?) are powerful tools in making a diagnosis. A couple of X-linked conditions are descibed, namely Conradi-Hünermann-Happle syndrome, a contiguous gene syndrome caused by a deletion of the X-chromosome and focal dermal hypoplasia. 
Chapter 4 concerns a relatively frequent but often missed diagnosis in the genodermatology: the mosaic genodermatoses. The review in this chapter describes the basic mechanisms of mozaicism, the current hypotheses on pathofysiology and therapeutic options of some of the more frequent mosaic conditions in pediatric medicine. The paper on macrodystrophia lipomatosa is an example of a mosaicism of a autosomal dominant mutation.

Chapter 5 contains examples of rare genodermatological syndromes. The chapter shows how powerful the multidisciplinary approach can be in diagnosing rare conditions. A subgroup that emerged from this miscellaneous group are patients with connective tissue disorders and/or hypermobility.

In the general discussion (chapter 6) the value of working together in an interdisplinary outpatient clinic "Genodermatoses" is discussed, both from the viewpoint of the participants and from the patients and their families. The value of this collaboration is also discussed from a scientific point of view. The aims set in the beginning of the study (chapter 1 ) are evaluated.

Chapter 7 contains the conclusions that are derived from our studies. Working together in an interdisciplinary outpatient clinic " Genodermatoses" seems to be highly rewarding for the professionals participating in the team. A high diagnostic yield was accomplished. In a substantial part of the cases, the visit resulted in a change of treatment or surveillance protocols. It stimulated new research projects and increased our knowledge on genodermatoses. The team has tried share this knowledge by educating other healthcare providers, thus improving the care for individuals with rare genodermatological conditions. Future plans, like cost-benifit studies and research projects on specific patient groups are discussed. 


\section{Dankwoord}

Een thesis schrijven over samenwerken doe je niet in het eentje. Er zijn heel veel mensen, direct en indirect, betrokken geweest bij dit werk. Ik dank iedereen die mij gesteund heeft, op welke manier dan ook. Maar een paar mensen zou ik toch graag hier expliciet noemen, wetende dat de kans bestaat dat ik daarbij waarschijnlijk toch belangrijke mensen zal vergeten. Daarvoor bij voorbaat mijn excuses...

Allereerst: alle patiënten en families die we in de loop van de jaren hebben mogen ontmoeten. Zonder hen was dit proefschrift er niet gekomen, voor hen is dit proefschrift geschreven.

Mijn promotieteam:

Connie, mijn eerste promotor. Onder jouw begeleiding ben ik van keuzestudent naar klinisch geneticus i.o. naar klinisch geneticus en nu ook naar promovenda gegroeid. Ik bewonder je vermogen om, ook als het moeilijk is, de moed erin te houden en te zorgen dat er weer lichtpuntjes zijn, al lijkt het nog zo duister. Er zijn veel mensen die zeggen dat je ze altijd mag bellen. Maar bij jou weet ik, dat het ook echt te allen tijde mag!

Maurice, de tweede promotor. In de loop van de jaren zijn we op de polikliniek zo op elkaar ingespeeld geraakt dat we elkaars zinnen afmaken. Ik ken maar weinig mensen die van zoveel markten thuis zijn, dat het bijna intimiderend kan zijn. Dat maakte onze gesprekken, onder andere in de Twingo op de terugweg na de polikliniek in Veldhoven, zeer divers. Ik zal de directe samenwerking zeker missen als je naar Dundee vertrekt. Maar ik ben ervan overtuigd dat ook dat een aantal prachtige mogelijkheden voor samenwerking in de toekomst gaat bieden.

En mijn co-promotor

Dominique, dit werk is net zoveel van jou als van mij. Ik ben ontzettend blij dat je me destijds hebt voorgesteld om mee te gaan draaien in de nieuwe samenwerking die je ging opzetten: een stel dermatologen met interesse in de genodermatologie kwam van Nijmegen naar Maastricht en zocht de samenwerking met de genetica. Ik heb mijn eerste stappen in de genetica onder jouw supervisie genomen, we zijn jaren kamergenoten geweest en hebben elkaar goed leren kennen. Je enthousiasme, vindingrijkheid, doorzettingsvermogen en lef bewonder ik zeer. Ik hoop in de toe- 
komst zeker de banden tussen Maastricht en Qatar te kunnen verstevigen en uitbouwen!

De leden van de leescommissie, prof. dr. Zimmermann, prof. dr. Koopmans, prof. dr. Knoers, prof. dr. Jonkman en prof. dr. Hennekam, wil ik hartelijk danken voor het kritisch beoordelen van mijn manuscript.

De leden van de leescommissie van het eerste uur, prof. dr. Steijlen en prof. dr. Happle, ben ik zeer erkentelijk voor hun inspanningen rondom mijn manuscript en hun steun.

Meyke Schouten en Marieke van Onna, ik ben blij jullie aan mijn zijde te hebben als paranimfen bij deze promotie!

Marieke, we hebben al eens eerder voor de aula gestaan samen, maar toen stond jij voorop. $\mathrm{Nu}$ is het mijn beurt. We hebben al heel veel samen gezien van de wereld, lief en leed gedeeld en vooral ook vreselijk veel gelachten. Ik hoop dat daar in de toekomst alleen nog maar meer ervaringen bij zullen komen!

Meyke, we kunnen samenwerken, samen lachen, samen huilen en samen boos zijn. Even leek het feit dat samenwerken er niet meer in zat, roet in het eten te gooien. Echter, onze vriendschap bleek solide genoeg te zijn om, toen het directe samenwerken weg viel, toch close te blijven ondanks de afstand Nijmegen-Maastricht. Er is geen beter congresmaatje als jij en er zijn niet veel mensen die mij zo goed kennen. En nu ziet het er naar uit dat het samenwerken, door de nauwe banden van Nijmegen en Maastricht, er ook weer in zit.

Het team Genodermatosen in Maastricht:

Michel van Geel, tijdens mijn opleiding heb ik onder jouw leiding in het laboratorium Experimentele Dermatologie zelf eens echt lab-werk mogen doen. In dat laboratorium heerste de sfeer: Ja, tenzij.... Oftewel: heb je een plan, zullen we proberen je te helpen. Deze positieve benadering van samenwerking heb ik altijd ervaren als stimulerend. Ik ben erg blij dat we nu ook binnen de afdeling klinische genetica collega's zijn!

Yvonne Detisch: we hebben soms nog steeds een beetje moeite om je goed voor te stellen aan patiënten: case manager, ceremonie meester, "degene die ons in het gareel houdt", degene die voor de koekjes bij de koffie zorgt.... het dekt allemaal de lading niet echt. Je bent veel meer voor de polikliniek genodermatologie dan dat. En voor mij in de loop van de tijd niet alleen een prettige collega, maar ook een goede vriendin en steun en toeverlaat geworden.

Mijn collega's van de polikliniek klinische genetica: jullie zijn het team waar ik me in thuis voel. Iedereen is een schakeltje in het grote geheel, met allemaal vreselijk veel hart voor de (patiënten) zaak. Daar mogen we trots op zijn! 
Alle collega's van de afdeling klinische genetica van de laboratoria en de " unit algemeen". Ik ben blij dat we elkaar zo makkelijk kunnen vinden.

Alle collega's van andere vakgroepen in het MUMC waarmee ik multidisciplinaire spreekuren draai: voor mij is de meerwaarde van het werken met jullie groot en zit er nog veel toekomstmuziek in!

Alle collega's van de klinische genetica Nijmegen: daar ligt een volgende uitdaging in samenwerken, die vast heel wat stof gaat doen opwaaien!

Merel Klaassens, je bent niet alleen mijn partner in crime voor de patiëntenzorg en in het onderwijs, maar ook in de loop van de tijd een waardevolle vriendin geworden buiten het MUMC.

Lieve vrienden en vriendinnen, heel dichtbij of juist ver weg, tegengekomen in verschillende fases van mijn leven. Ik hoop dat ik nu wat ruimte krijg om jullie de aandacht te geven die jullie allemaal verdienen!

Utrecht: mijn afkomst en nog steeds veilige basis.

Marij en Kees, ik had me geen betere ouders kunnen wensen. Dit was me zonder jullie nooit gelukt! Onze Sinterklaasavond moet dit jaar wijken voor dit promotiefeestje, maar dat maken we goed met Sinter-kerst en nieuw!

Arjan, mijn broertje (want dat -tje kom je nooit meer vanaf ook al steek je meer dan een kop boven mij uit). Als het moeilijk was in dit promotie traject en het voelde als een verplichting, heb ik nog vaak moeten denken aan jouw verzuchting: " jij MAG tenminste promoveren, die kans krijgen geschiedenisstudenten meestal niet". Jij hebt veel meer moeite moeten doen om je opleiding tot een carrière om te buigen. Voor mij was het veel simpeler: als je geneeskunde studeert, wordt je dokter. Ik bewonder de manier waarop je de keuzes in je leven maakt en altijd trouw blijft aan jezelf.

Loes, zo vanzelfsprekend dat je er altijd op belangrijke momenten bij bent. Maar daarom zeker niet minder waardevol voor mij!

Alle familieleden die altijd heel lief bleven informeren of het werk al vorderde. Aan wie het soms zo moeilijk uit te leggen was, wat ik nu precies aan het doen was en waarom het maar zo langzaam ging. Ik hoop dat dit boekje jullie eindelijk een beetje duidelijkheid geeft over die vragen.

En als laatste mijn mannen van de Meidoorn 76:

Freek heeft heel wat troostende werkzaamheden moeten verrichten de afgelopen jaren: er is bijna niets zo stress reducerend als een spinnende kat aaien.

Mijn lieve Peter, onze laatste jaar was turbulent: 2 verhuizingen, huizen verkopen, huizen kopen, een master afronden voor jou en een promotie afronden voor mij. $\mathrm{Nu}$ komt er hopelijk wat rust en tijd voor ons om al onze plannen te gaan uitvoeren! 
En dan is het nu tijd om de rest van de winter in mijn vrije uren op de bank voor de open haard boeken te lezen. Dat klinkt mij nu enorm fijn en rustig in de oren. Maar hoe lang ik dat volhoudt.......we zullen wel zien:- 


\section{Curriculum vitae}

Maaike Vreeburg werd geboren op 5 juni 1976 te Utrecht. Na het behalen van het eindexamen VWO aan het St Bonifatius college te Utrecht, startte ze in 1994 met de studie Geneeskunde aan de Universiteit Maastricht. In februari 2001 werd het artsexamen behaald. Ze werkte gedurende een periode van anderhalf jaar als assistent geneeskunde niet in opleiding (AGNIO) Kindergeneeskunde in de Isala klinieken te Zwolle en een half jaar als AGNIO Beschouwende vakken in het ziekenhuis De Tjongerschans te Heerenveen. In september 2003 keerde zij terug naar Maastricht om te werken als AGNIO klinische genetica in het MUMC. In augustus 2004 werd gestart met de opleiding Klinische genetica (opleider: C.T.R.M. Stumpel) . Deze opleiding werd 1 augustus 2008 voltooid. Sindsdien werkt zij als klinisch geneticus op de afdeling klinische genetica MUMC.

Zij was vanaf de start van het multidisciplinair team Genodermatosis betrokken bij het team en draaide, aanvankelijk onder supervisie van Dr. D. MarcusSoekarman, mee in de polikliniek Genodermatologie. De resultaten die voortvloeiden uit deze samenwerking in de periode 2004-2012 zijn verzameld in dit proefschrift.

Ze woont met Peter van Geel en kat Freek in Maastricht. 



\section{List of publications}

Klaassens M, Morrogh D, Rosser EM, Jaffer F, Vreeburg M, Bok LA, Segboer T, van Belzen M, Quinlivan RM, Kumar A, Hurst JA, Scott RH. Malan syndrome: Sotos-like overgrowth with de novo NFIX sequence variants and deletions in six new patients and a review of the literature. European journal of human genetics. 2014;Aug:ePub.

Vreeburg M, Sallevelt SC, Stegmann AP, van Geel M, Detisch YJ, Schrander-Stumpel CT, van Steensel MA, Marcus-Soekarman D. Cutaneous clues for diagnosing Xchromosomal disorders. Clinical genetics. 2014;85(4):328-35.

Luijten MN, Basten SG, Claessens T, Vernooij M, Scott CL, Janssen R, Easton JA, Kamps MA, Vreeburg M, Broers JL, van Geel M, Menko FH, Harbottle RP, Nookala RK, Tee AR, Land SC, Giles RH, Coull BJ, van Steensel MAM. Birt-Hogg-Dube syndrome is a novel ciliopathy. Human molecular genetics. 2013;22(21):4383-97.

Vreeburg M, van Steensel MAM. Genodermatoses caused by genetic mosaicism. European journal of pediatrics. 2012;171(12):1725-35.

Bukkems SF, Ijspeert WJ, Vreeburg M, van Rhijn LW, Schrander JJ, van Steensel MA. [Conradi-Hunermann-Happle syndrome]. Nederlands tijdschrift voor geneeskunde. 2012;156(10):A4105.

Vreeburg M, van Geel M, van den Heuij LG, Steijlen PM, van Steensel MA. Focal dermal hypoplasia in a male patient due to mosaicism for a novel PORCN single nucleotide deletion. Journal of the European Academy of Dermatology and Venereology. 2011;25(5):592-5.

Paulussen AD, Stegmann AP, Blok MJ, Tserpelis D, Posma-Velter C, Detisch Y, Smeets EE, Wagemans A, Schrander JJ, van den Boogaard MJ, van der Smagt J, van Haeringen A, Stolte-Dijkstra I, Kerstjens-Frederikse WS, Mancini GM, Wessels MW, Hennekam RC, Vreeburg M, Geraedts J, de Ravel T, Fryns JP, Smeets HJ, Devriendt K, Schrander-Stumpel CT. MLL2 mutation spectrum in 45 patients with Kabuki syndrome. Human mutation. 2011;32(2):E2018-25. 
Claessens T, Weppler SA, van Geel M, Creytens D, Vreeburg M, Wouters B, van Steensel MA. Neuroendocrine carcinoma in a patient with Birt-Hogg-Dube syndrome. Nature reviews Urology. 2010;7(10):583-7.

van der Velden JJ, Vreeburg M, Smeets EE, Schrander-Stumpel CT, van Steensel MA. Skin abnormalities in individuals with macrocephaly: Cowden disease from a dermatologist's point of view. International journal of dermatology. 2008;47 Suppl 1:45-8.

Vreeburg M, Heitink MV, Damstra RJ, Moog U, van Geel M, van Steensel MA. Lymphedema-distichiasis syndrome: a distinct type of primary lymphedema caused by mutations in the FOXC2 gene. International journal of dermatology. 2008;47 Suppl 1:52-5.

van Steensel MA, Badeloe S, Winnepenninckx V, Vreeburg M, Steijlen PM, van Geel M. Granulomatous rosacea and Crohn's disease in a patient homozygous for the Crohn-associated NOD2/CARD15 polymorphism R702W. Experimental dermatology. 2008;17(12):1057-8.

van Steensel MA, Vreeburg M, Engelen J, Ghesquiere S, Stegmann AP, Herbergs J, van Lent J, Smeets B, Vles JH. Contiguous gene syndrome due to a maternally inherited $8.41 \mathrm{Mb}$ distal deletion of chromosome band Xp22.3 in a boy with short stature, ichthyosis, epilepsy, mental retardation, cerebral cortical heterotopias and Dandy-Walker malformation. American journal of medical genetics Part A. 2008;146A(22):2944-9.

Steijlen PM, van Geel M, Vreeburg M, Marcus-Soekarman D, Spaapen LJ, Castelijns FC, Willemsen M, van Steensel MA. Novel EBP gene mutations in ConradiHunermann-Happle syndrome. The British journal of dermatology. 2007;157(6):1225-9.

Vreeburg M, de Zwart-Storm EA, Schouten MI, Nellen RG, Marcus-Soekarman D, Devies M, van Geel M, van Steensel MA. Skin changes in oculo-dento-digital dysplasia are correlated with C-terminal truncations of connexin 43. American journal of medical genetics Part A. 2007;143(4):360-3.

van Steensel MA, Vreeburg M, Peels C, van Ravenswaaij-Arts CM, Bijlsma E, Schrander-Stumpel CT, van Geel M. Recurring HRAS mutation G12S in Dutch patients with Costello syndrome. Experimental dermatology. 2006;15(9):731-4.

van Steensel MA, Vreeburg M, Steijlen PM, de Die-Smulders C. Myhre syndrome in a female with previously undescribed symptoms: further delineation of the phenotype. American journal of medical genetics Part A. 2005;139A(2):127-30. 


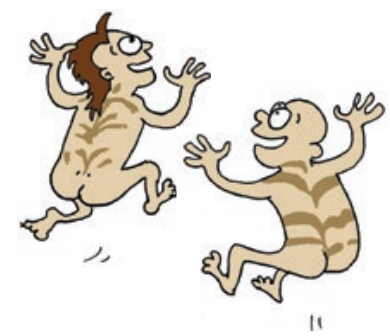

